\title{
Tecnologías emergentes para la captura y visualización de imagen 3D
}

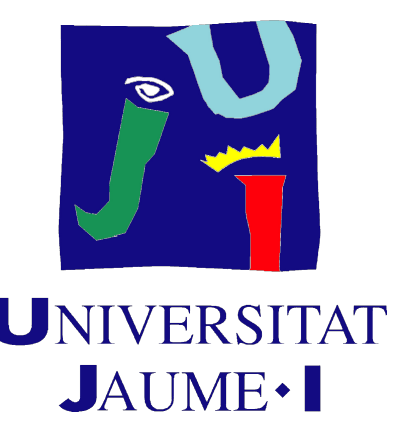

\section{TESIS DOCTORAL}

\author{
Eva Salvador Balaguer \\ Institute of New Imaging Technologies \\ Universidad Jaume I \\ Directores: \\ Dr. Filiberto Pla Bañón \\ Dr. José Martínez Sotoca \\ Dr. Enrique Tajahuerce Romera \\ 2017
}





\title{
Tecnologías emergentes para la captura y visualización de imagen $3 \mathrm{D}$
}

\author{
Tesis doctoral \\ Universitat Jaume I
}

Castellón

Institute of New Imaging Technologies

Universidad Jaume I

Directores:

Dr. Filiberto Pla Bañón

Dr. José Martínez Sotoca

Dr. Enrique Tajahuerce Romera

2017 
Copyright (c) Eva Salvador Balaguer 


\section{A mi madre}





\title{
Agradecimientos
}

\author{
Decir gracias es decir poco
}

Joaquín Sabina

Nunca olvidaré la llamada que recibí un 28 de Agosto de 2010, cuando volvía a Castellón después de las fiestas de La Jana. Hacía un mes que había acabado la carrera y el verano llegaba también a su fin. Con una mezcla de alegría y tristeza se acababa esa larga etapa de mi vida de estudio, o eso es lo que yo creía. Sonó el móvil, un número desconocido más largo que estos agradecimientos, y con apenas cobertura recibí la gran noticia que cambió mi destino: el 1 de Septiembre empezaría mi contrato en el laboratorio de investigación del departamento de lenguajes y sistemas informáticos en la UJI. Y así empezó mi aventura, la que os debo a todos vosotros.

En primer lugar, gracias Filiberto por esa llamada y por hacerme sentir como en casa durante todos estos años. De ti he aprendido a ser humilde, organizada y a viñetear mis ideas. Gracias también a Jose por estar siempre disponible para resolver mis dudas a pesar de tu apretada agenda. Gracias por ser tan directo y claro, nunca olvidaremos tu frase: sólo un cambio, quita mi nombre. Y como no, gracias Enrique por tus consejos, tu ayuda y por contagiarme tu espíritu trabajador. De ti he aprendido a ser más concisa y curiosa. Gracias a los tres por compartir vuestro conocimiento e ideas conmigo, ha sido un placer aprender de vosotros, y como ya sabéis, esta tesis es en gran parte vuestra.

De mi etapa en visión me quedo con todo y con todos. Gracias Isabel por ser una profesora excelente, Pedro, por tus clases de percepción visual y por el libro de transformadas wavelet, $\mathrm{M}^{\mathrm{a}}$ Ángeles, porque contigo aprendí lo que era una línea epipolar, Salva, por organizar esas magníficas escuelas de verano, Javier y Pedro, por ayudarme tanto en el capítulo 3 de esta tesis, Ramón, por despertar mi interés por aprender salsa, David, por ser un técnico brillante y Nacho, por compartir conmigo toda tu sabiduría, tanto a nivel profesional como a nivel personal. Además, me falta dar un agrade- 
cimiento especial a la comunidad latina. Vuestro cariño, alegría y forma de tomaros la vida me han enseñado mucho más de lo que os imagináis. Gracias a Mónica y Ianisse, fue muy chévere conocerlas y compartir además del trabajo, bailes, gimnasios, bodas y cenas. Mi casa siempre estará abierta para vosotras tal y como las vuestras lo han estado para mí. Gracias también a Dámaris y Fernando por presentarme vuestro precioso país. Estoy tremendamente agradecida de que nos mostrarais todas las caras de Cuba. Gracias también a Jorge, Raúl, Henry, Manoli, Guillermo, Alejandro, Josep y Carlos, que aunque no hemos coincidido tanto, sí que hemos compartido mucho.

$\mathrm{Y}$ de esta misma etapa tengo que agradecer enormemente a los que transforman lo serio en divertido, lo formal en informal y las penas en glorias. Ese equipazo de laboratorio que, en lo que al cachondeo se refiere, eran expertos, y trabajadores más aún. Gracias Rubén, por enseñarme a simplificar las cosas, a reírme de la vida y a "preocuparme despreocupadamente" ( $i n o$ problemo, no problemo, hasta que problemo!). Gracias Adolfo por tu sentido del humor, tu disposición siempre y como no, por el chuletón en casa Enrique! ¿Para cuándo la próxima comida? Gracias también Tomás por todo y más. Ya ves que de ti he aprendido a hacer rimas tontas, a ver fácil lo difícil, a hacer dos cosas a la vez (bailar y trabajar) y en defininitva, a ser feliz. Finalmente, una mención especial para Javier Ortells Lorenzo (jortells), compañero de viaje en carrera, máster, doctorado y juergas. Gracias por tu cariño, tus consejos, tus numerosas rimas, por acogerme en tu colla (no sé por qué la manía de llamarlo peña) y en general por considerarme una más entre los tuyos. Moltes gràcies reis.

De mi etapa en el GROC tampoco cambio nada. Gracias Lluís y Gladys, recuerdo como fuistéis los primeros en hacerme sentir como en casa. A ti Gladys y a Omel, gracias también por nuestras numerosas salidas montañeras. A Vicente, no tengo nada que agradecerle, porque es malo con ganas. Aun así, la experiencia boreal no estuvo del todo mal y los cafés en el círculo tampoco. Así que gracias por tu conspicua compañía y tus sabios consejos. Gracias a Pere, hombre trabajador y festero donde los haya. Gracias por aparecer cuando nada funciona y solucionarnos los problemas a más de uno. Gracias también a Merche (cinéfila empedernida) no sólo por hacerme de taxista sino también por enriquecer las conversaciones en nuestros almuerzos. Gracias a Pedro y al vicerrector, Jesús, porque vuestra pasión por la investigación y la ciencia es contagiosa. Pedro, te prometo que un día te enseñaré los olivos, y Jesús, en el próximo congreso te dejo elegir hotel a ti.

A los jóvenes del GROC también les debo mucho. Gracias Omar y Humberto, platicar con vosotros es un placer. A ti Omar, gracias por iniciarnos 
en la tarea de la divulgación científica. Gracias a Rocío, porque aunque coincidimos poco tiempo fue lo suficiente para mantener el contacto e incluso para viajar juntas. Gracias a Jorge, que aunque no nos vemos ni en Balsicas ni en Castellón, podemos escuchar tu voz siempre que queramos: Hello, I am Jorge, from the GOC Student Chapter of Castellón.... Gracias Yessenia, por tu apoyo y tus palabras bonitas. De ti me quedo con tu valentía y espíritu de superación, estoy segura de que llegarás donde te propongas, incluso a nado en la alberca. Gracias a Eduardo, el chileno amante de la sobrasada que aprendió perfecto español conmigo, ¿tu cachái? Y un especial agradecimiento a Miguel, porque rodeada de tanto físico loco, hace falta un ingeniero cuerdo que ponga orden. Aunque cuerdo del todo no estás, tu gato y tu buen humor siempre son buenos para calmar los ánimos. Gracias también a Ángel, el murciano que no lo parece, acho. De ti no sólo he aprendido de series, sino también de fotografía, astronomía, drones y en general, de estar a la última. Gracias a Carlos que, aunque no se come las cucarachas, nos invita a su casa con piscina. Y hablando de piscina... que placer de vacaciones en Elche. Gracias Esther, por la costra, tu energía positiva y por el ambientador aviar. Pero sobretodo, gracias por ser, más que una compañera de despacho, una buena amiga. Al igual que Fernando, un buen amigo que, conociendo su pasión por la lectura, va a ser el único capaz de leerse estos agradecimientos hasta el final. Contigo he compartido conversaciones interminables sobre ciencia, sociedad, tecnología, cultura y deportes. Tantos temas que dan para un buen periódico, el Proletarios Times, un regalo que junto con la máquina arcade, quedarán para el recuerdo. ¡Que bien lo pasemos!

Pero no sólo quiero acordarme de los amigos del trabajo y me gustaría también agradecer a los que me dan energía para empezar cada lunes con las pilas cargadas. Gracias a Cris por las cervezas dentro y fuera de España (el labio), a Raquel por sus visitas inesperadas con selfies y abrazos recargantes, a las Modernas de Pueblo: Miriam, Marta y Lorena por nuestros viajes y comilonas (sin gluten), a la chupipandi por las cenas multitudinarias, al grupo de El Cole por nuestras cenas menos multitudinarias, también als bocassins, por acogerme como una más y a las forasteres a la Jana por nuestras risas con llanto incluido ios he dicho que odio el sorbete de limón y más aún a Camela? En especial quiero agradecer a Margaret, Rocio y Ali, porque el amor que me transmitís junto con vuestros hijos, no tiene precio.

I per al final em deixo lo millor, eixa família que no he triat, perquè si ho haguera fet, no haguera encertat tant. Gràcies Tere per les classes d'història, geografia, llengua i literatura. Ramon i jo mai oblidarem els afluents del Duero, ni el viatge a Madrid, les tardes de cine o els dinars de reis. Gràcies prim 
per voler-me com una germana, al igual que pixu, que sempre m'ha fet sentir tant protegida. Gràcies també als nous integrants de la família, Gabriel, Carla, David i Christine, per traure el millor dels meus. Però sobretot, gràcies a la única germana que tinc, Mònica. Gràcies per ser la millor germana, millor amiga i millor persona. Gràcies també per ser durant molt temps la meva segona mare, i ara la primera, i per donar-me bons consells sempre que els he necessitat. Com no, gràcies al papi perquè les teves filles sempre han sigut la teva prioritat $\mathrm{i}$ en tot el teu treball i esforç has aconseguit donar-nos una bona formació acadèmica. Però sobre tot, gràcies per ensenyar-me a ser una bona persona, a valorar i apreciar el que tinc i afrontar cada repte en coratge i valentia. I gràcies a la mami o millor, la super mami, que en el seu: suerte y al toro, sempre aconseguia que donés el millor de mi, fins que m'ha fet arribar on estic. Segur que allà on estiga estarà molt orgullosa, com ho estic jo de tindre-vos a tots vatros al costat. També, gràcies a tu, amor, perquè eres la persona que mes confia en mi, perquè traus la meva millor versió i perquè, en el teu temps de descans, no has dubtat en ajudar-me en alguna que altra figura. I gràcies als teus (ara també meus) per considerar-me com una germana més, una filla més o una cosina més. Finalment, gràcies per portar a Nala, que ha despertat el meu amor perruno, però sobre tot, gràcies per voler-me com soc. Téstimo David.

Y para que no queden tan cortos mis agradecimientos deciros que mi personalidad, mi aprendizaje y mi forma de ser se han ido construyendo a través de las experiencias vividas con todos vosotros. Algunas dramáticas, otras excepcionales, pero todas las experiencias me han conducido a intentar mejorar cada día. Así que aquellos de los que ahora me alejo, ojalá nuestros caminos se vuelvan a cruzar algún día. 


\section{Resumen}

En el mundo en el que vivimos se reconocen tres dimensiones espaciales. Por ello, desde los orígenes de los tiempos los humanos han tratado de representar esta tercera dimensión. Más allá de la industria del cine, la imagen tridimensional ha supuesto una revolución en multitud de disciplinas. Sin embargo, los sistemas actuales disponibles presentan numerosas limitaciones que impiden un uso más extendido. Además, todavía no se han explorado ni explotado todas las ventajas y aplicaciones de la imagen 3D.

En la presente tesis se hace un recorrido por parte de la tecnología 3D disponible estudiando ventajas, limitaciones y aplicaciones. De las diferentes alternativas para la captura y visualización de imagen 3D, se exploran los dispositivos autoestereoscópicos multivista, la imagen integral, la imagen con información de rango y la fotometría estéreo. Además, se utiliza una técnica similar a la luz estructurada para obtener imágenes bidimensionales o incluso imágenes tridimensionales con detectores sin resolución espacial. Los estudios realizados en esta tesis nos permiten decantarnos por una u otra tecnología dependiendo de la aplicación. El objetivo no es pues proponer una única alternativa de tecnología para imagen tridimensional, sino ofrecer una visión general de las distintas técnicas disponibles y plantear soluciones a algunas de las limitaciones principales. 



\section{Índice}

\begin{tabular}{|l|l}
\hline Agradecimientos & VII
\end{tabular}

Resumen XI

1. Introducción 1

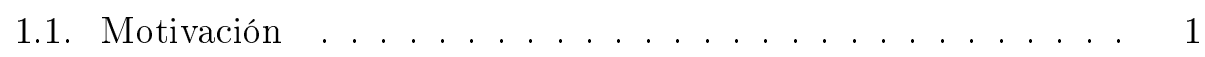

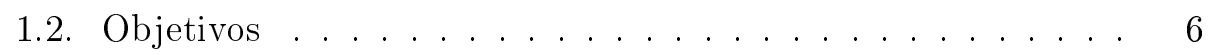

1.3. Estructura de la tesis . . . . . . . . . . . . . 8

1.4. Aportaciones . . . . . . . . . . . . . . . . 9

1.4.1. Capítulo 2. . . . . . . . . . . . . . 9

1.4.2. Capítulo $3 \ldots \ldots \ldots \ldots$

1.4.3. Capítulo 4. . . . . . . . . . . . . . . . 10

2. Imagen 3D para visualización pasiva 11

2.1. Dispositivos autoestereoscópicos multivista. . . . . . . . . 12

2.2. Vistas sintéticas . . . . . . . . . . . . . . . 13

2.2.1. Adquisición de imágenes y calibración de las cámaras. 15

2.2.2. Rectificación de múltiples vistas . . . . . . . . . . . . 19

2.2.3. Generación de mapas de disparidad. . . . . . . . . . 21

2.2.4. Algoritmo de View Synthesis . . . . . . . . . . . . 23

2.3. Resultados experimentales . . . . . . . . . . . . 24

\begin{tabular}{|l|}
\hline 3. Imagen 3D para reconocimiento de gestos \\
\hline
\end{tabular}

3.1. Introducción . . . . . . . . . . . . . 28

3.2. Imagen integral . . . . . . . . . . . . . . . . . . . . 29

3.3. Imágenes con información de rango . . . . . . . . . . . . 31

3.4. Reconocimiento de acciones . . . . . . . . . . . . . 32

3.4.1. Detección de descriptores en los vídeos. . . . . . . . . 33

3.4.2. Cuantización de los descriptores en palabras . . . . . . 35 
3.4.3. Generación de bolsas de palabras para cada vídeo. . . 35

3.4.4. Clasificación de vídeos a partir de las bolsas de palabras 36

3.5. Resultados experimentales . . . . . . . . . . . 38

3.5.1. Imagen integral vs imagen monocular . . . . . . . . 41

3.5.2. Imagen integral vs monocular vs sensor Kinect . . . . 43

\begin{tabular}{|ll|}
\hline 4. Imagen 3D con cámaras de un solo píxel & 51
\end{tabular}

4.1. Introducción . . . . . . . . . . . . . . . 52

4.2. Teoría básica . . . . . . . . . . . . . . 56

4.3. Desarrollo experimental de una cámara single-pixel . . . . . . 60

4.3.1. Proyección con tecnología DMD. . . . . . . . . . . 60

4.3.2. Proyección con una matriz de LEDs . . . . . . . . . 62

4.3.3. Sistema de detección . . . . . . . . . . . . 63

4.4. Muestreo adaptativo . . . . . . . . . . . . . . 63

4.4.1. Introducción a la transformada wavelet. . . . . . . . . 64

4.4.2. Descripción del algoritmo . . . . . . . . . . . 66

4.4.3. Resultados experimentales . . . . . . . . . . . . . . 70

4.5. Soluciones económicas para imagen en color . . . . . . . . . 72

4.5.1. Resultados experimentales . . . . . . . . . . . . . . 72

4.6. Imagen 3D con sensores de un sólo píxel . . . . . . . . . 76

4.6.1. Estereoscopía . . . . . . . . . . . . . . . . 76

4.6.2. Fotometría estéreo . . . . . . . . . . . . . 79

\begin{tabular}{ll}
\hline 5. & Conclusiones y trabajo futuro \\
\hline
\end{tabular}

5.1. Aportaciones . . . . . . . . . . . . . 84

5.2. Trabajo futuro $\ldots \ldots \ldots \ldots \ldots$ 


\section{Índice de figuras}

1.1. Clasificación de técnicas disponibles para conseguir imagen 3D. 3

1.2. Esquema de la tesis donde se destacan las técnicas de imagen 3D utilizadas en cada capítulo. . . . . . . . . . . . . 7

2.1. Pantalla con hoja lenticular de dos vistas. . . . . . . . . . 13

2.2. Hoja lenticular inclinada. . . . . . . . . . . . . . . . 14

2.3. Descripción del algoritmo de síntesis de imágenes. . . . . . . . 15

2.4. Relación geométrica que nos permite conocer la profundidad de un punto de la escena capturado por un par de cámaras. . 17

2.5. Geometría epipolar . . . . . . . . . . . . . . . 17

2.6. Patrón de calibración utilizado. . . . . . . . . . . . . 18

2.7. Rectificación de un par estéreo. . . . . . . . . . . . . 20

2.8. Rectificación de múltiples cámaras [1]. . . . . . . . . . . . 20

2.9. Imagen entrelazada aceptada por el dispositivo autoestereoscópico utilizado. . . . . . . . . . . . . . . . 25

2.10. Descripción de la obtención de las 8 vistas de entrada necesarias para un dispositivo autoestereoscópico utilizando el algoritmo en 4 pasos descrito. A partir de 5 imágenes de la escena se sintetizan las vistas restantes. . . . . . . . . . 25

2.11. Vistas sintéticas obtenidas para dos cámaras vituales distintas. La primera columna muestra las imágenes reales capturadas por una cámara en la posición correspondiente. En la segunda columna se muestran las imágenes obtenidas con el algoritmo de vistas sintéticas propuesto. La última columna muestra la diferencia entre las dos imágenes anteriores. . . . . 26 
3.1. Principio de captura y reproducción de imagen integral. La información de profundidad se traduce en un desplazamiento entre las diferentes vistas de la escena, conocidas como imágenes elementales. . . . . . . . . . . . 30

3.2. Adquisición y reconstrucción de imagen integral con apertura sintética. (a) Una matriz de cámaras adquiere imágenes de la escena con distintas perspectivas. (b) A partir de la superposición de las imágenes capturadas se reconstruye la escena 3D.

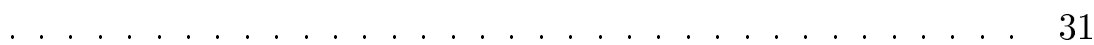

3.3. Esquema del procedimiento de reconocimiento utilizando el enfoque tradicional de Bag of visual Words (BoW). . . . . . . 33

3.4. Infinitos hiperplanos dividen los dos grupos. $H_{2}$ los separa, pero sólo con un margen pequeño, sin embargo, $H_{1}$ los separa con el margen máximo. . . . . . . . . . . . . . . . . . 37

3.5. Sensores utilizados para crear dos bases de datos. La primera base de datos incluye vídeos de un grupo de usuarios realizando acciones frente a los sensores de la figura $|3.5 \mathrm{a}|$ La segunda base de datos está formada por un conjunto de vídeos de un grupo distinto de usuarios que realizan las mismas acciones frente a los sensores de la figura $|3.5 \mathrm{~b}| \ldots \ldots . . \ldots 39$

3.6. Esquema de obtención de imágenes enfocadas a distintas profundidades para un gesto de un usuario. . . . . . . . . . . . 40

3.7. Información de profundidad capturada con el sensor de profundidad de la cámara Kinect. La profundidad viene expresada en $\mathrm{mm}$. . . . . . . . . . . . . . . . . . 41

3.8. Resultados de reconocimiento de gestos para imagen 2D monocular e imagen integral 3D para tres descriptores (HOF, HOG, HOG+HOF). . . . . . . . . . . . . . . 47

3.9. Resultados de reconocimiento de gestos para el mejor descriptor en cada caso (imagen integral y monocular). . . . . . . . . 48

3.10. Reconocimiento de gestos en imagen integral con y sin oclusión para tres descriptores distintos (HOG, HOF y HOG $+\mathrm{HOF}) .48$

3.11. Resultados de clasificación para los vídeos de Kinect con el conjunto de todos los STIPs detectados (RGB) y con los STIPs filtrados según la profundidad de los mismos $(\mathrm{RGB}+\mathrm{DBF})$, para vocabularios pequeños y grandes. . . . . . . . . . . . 49 
4.10. Imagen original, transformada de wavelet de nivel 1 y nivel 3 respectivamente. Los píxeles claros de la transformada de wavelet representan los bordes de la escena. . . . . . . . . . 65

4.11. Algoritmo ACI. Objeto: Imagen de 256x256 píxeles de las células de Fasciola hepatica capturada con un microscopio comercial. Etapa 1: Imagen a baja resolución (64x64 y su transformada de wavelet de nivel 1. Se descarta el cuarto cuadrante ya que no tiene información relevante. Etapa 2: Cuadrantes de la imagen original y de nuevo sus transformadas de wavelet de nivel 1. En esta etapa se descartan 6 cuadrantes sin información de bordes. Etapa 3: Cuadrantes no descartados del nivel anterior con sus transformadas de wavelet de nivel 1. Utilizando las transformadas de wavelet de cada una de las etapas el algoritmo construye la transformada de wavelet de nivel 3 del objeto original. A partir de la transformada inversa de wavelet se obtiene la reconstrucción de la escena original. En este ejemplo la imagen se reconstruye utilizando un $62 \%$ de las $256^{2}$ medidas establecidas por el criterio de Nyquist. . . 67

4.12. Imagen de 4MP de la Fasciola hepatica (izquierda) y su reconstrucción utilizando el algoritmo ACI (derecha). La reconstrucción ACI se ha adquirido con aproximadamente un $25 \%$ de las $2048^{2}$ medidas establecidas por la relación de Nyquist. $\quad 68$

4.13. Comparación de calidad y tiempo de adquisición para los algoritmos ACI y CS. . . . . . . . . . . . . . . . 69

4.14. Comparación de calidad de imágenes entre ACI y CS para regiones de interés (ROI). . . . . . . . . . . . . . 70

4.15. Resultados experimentales. Las imágenes de la izquierda se han obtenido con una cámara digital convencional de alta resolución, mientras que a la derecha se muestran las imágenes obtenidas con la técnica de single-pixel. En la fila superior se reconstruye una figura de LEGO a una resolución de $256 \times 256$. En la fila inferior se muestra la reconstrucción de un test de USAF1951 a una resolución de $512 \times 512$. El único post procesado hecho a las imágenes ha sido un balance de blancos. . 71

4.16. Señal eléctrica generada por el fotodiodo al enviar un par de patrones de Hadamard a la escena. . . . . . . . . . . . . . 73

4.17. (a) Esquema experimental de cámara single-pixel. (b) Imagen en color con resolución $256 \times 256$ obtenida con dicho montaje. 74 
4.18. Esquema de cámara single-pixel utilizando una matriz de LEDs y una FPGA. La matriz de LEDs codifica los patrones almacenados en la FPGA y un sistema óptico los proyecta sobre el objeto. Un fotodiodo recoge las intensidades reflejadas por cada patrón. . . . . . . . . . . . . . . 74

4.19. Montaje experimental de una cámara single-pixel utilizando una matriz de LEDs y una FPGA. . . . . . . . . . . . . . 75

4.20. Imágenes obtenidas utilizando el montaje experimental de la \begin{tabular}{|l|l|l|l}
\hline figura & 4.18 & (a) Frame de un vídeo capturado a 5 fps. (b) Ima-
\end{tabular} gen en color obtenida al enviar una secuencia de patrones en rojo, verde y azul. Para una mejor visualización se ha realizado una interpolación bicúbica y se ha aumentado el brillo. . . . . 76

4.21. Montaje experimental para conseguir imagen single-pixel con dos fotodiodos. La imagen obtenida con cada fotodiodo se corresponde con la que se obtendría al colocar una fuente de luz puntual en la posición del fotodiodo. . . . . . . . . . . . 77

4.22. Resultados obtenidos con el montaje experimental de la figura 4.21. (a) Imagen capturada con una cámara CCD. (b) Imagen obtenida con los coeficientes obtenidos con el fotodiodo de la izquierda. (c) Imagen obtenida con los coeficientes obtenidos con el fotodiodo de la derecha. . . . . . . . . . . . 78

4.23. Montaje experimental para reconstruir un par estereoscópico de imágenes en color utilizando un fotodiodo. Un par de patrones de Hadamard con colores cromáticamente opuestos se superponen en un plano 3D de la escena. La señal capturada $\begin{array}{ll}\text { por el fotodiodo permite reconstruir directamente el anaglifo. } & 78\end{array}$

4.24. Imágenes recuperadas utilizando el montaje experimental de la figura 4.23 , Para una mejor visualización a la imagen del anaglifo se le ha aumentado el brillo y reducido el ruido. . . . 79

4.25. Imágenes obtenidas utilizando el montaje experimental de la figura 4.18 desplazando el fotodiodo de la izquierda a la derecha del objeto . . . . . . . . . . . . . . 80

4.26. Imagen 3D del objeto utilizando la técnica de fotometría estéreo con las imágenes de la figura 4.25 . . . . . . . . . . 81 



\section{Índice de Tablas}

3.1. Reconstrucción en profundidad con imagen integral. . . . . . 40

3.2. Conjunto de gestos tras el seccionado conseguido con imagen

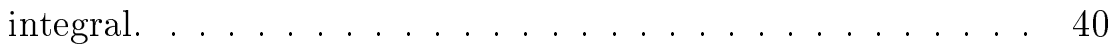

3.3. Conjunto de gestos capturados por la cámara RGB del sensor Kinect. . . . . . . . . . . . . . . . . 41

3.4. Resultados de reconocimiento (\%) para las dos modalidades de vídeo y los tres descriptores utilizados. Los promedios y las desviaciones estandard se muestran redondeados a un decimal. 42

3.5. Resoluciones espaciales utilizadas en las tres modalidades de

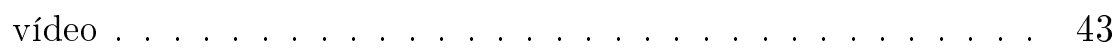

3.6. Imágenes de un gesto con oclusión para las tres modalidades de vídeo utilizadas. . . . . . . . . . . . . . . . . . . 44 



\title{
Capítulo 1
}

\section{Introducción}

\author{
La ciencia de hoy es \\ la tecnología del mañana.
}

Edward Teller

\subsection{Motivación}

La expresión vale más una imagen que mil palabras cobra sentido al descubrir que procesamos las imágenes 600 veces más rápido que los textos; que más de un $70 \%$ de la información que recibimos del mundo que nos rodea se realiza a través de la vista; o que recordamos el $80 \%$ de lo que vemos frente al $20 \%$ de lo que leemos. Es mucha la información que recibimos a partir de una imagen, pero mucha más la que podríamos percibir añadiendo dimensionalidad a la misma. Por eso, ya desde nuestros orígenes los humanos hemos tratado de representar nuestro entorno con el máximo número de dimensiones, para así conseguir ser más fieles a la realidad. Por ejemplo, en las pinturas rupestres levantinas que se pueden encontrar en el arco mediterráneo de la península ibérica, los chamanes del paleolítico narraron los conflictos bélicos o las cacerías a través de figuras humanas y animales que por sus posturas, intentan representar escenas que sugieren un gran dinamismo. Además, algunos expertos señalan que en algunas de estas pinturas, se adivina el uso de una perspectiva muy rudimentaria, utilizando cierta línea de fuga, para conseguir así sensación de profundidad. Como sabemos, el dinamismo lo conseguimos en la actualidad a través de los vídeos pero todavía no se ha afianzado una única tecnología para la captura y visualización de imágenes en tres dimensiones (3D). 
La industria cinematográfica fue la primera en explorar la tecnología 3D, con la primera proyección de un largometraje en 3D en 1922. La película, The Power of Love, no tuvo ningún éxito, pero sirvió para despertar el interés por la cinematografía en $3 \mathrm{D}$, que tras periodos de decadencia, se volvió a popularizar en 2010, con el estreno de la película Avatar. Pero aunque los inicios de la imagen 3D se encuentran en la industria cinematográfica, hoy en día el 3D va mucho más allá de las películas, aumentando su utilidad y popularidad en numerosos campos. Desde el ocio a la medicina, pasando por la arquitectura, la tecnología 3D está cada vez más presente en nuestras vidas. Impresoras, ecografías, tomografía computerizada, entornos interactivos, televisores... cientos son los ejemplos que muestran el creciente interés por ser capaces de capturar y representar la información en tres dimensiones. Por eso, las últimas décadas han venido marcadas por la investigación, desarrollo y comercialización de la tecnología 3D.

Pero cuando hablamos de imagen 3D, ¿a qué nos referimos? Una imagen 2D se puede definir mediante una función real bidimensional $f(x, y)$. Generalmente estas imágenes se imprimen en algún medio o se muestran en una pantalla y cada pixel o punto representa el valor de $f$ en ese punto $(x, y)$. Una imagen 3D será aquella que incorpore en su representación la información de profundidad de los objetos. En este caso, la representación de la función $f(x, y, z)$ en un dispositivo no resulta tan directa. Sin embargo, al igual que sucede con las imágenes bidimensionales, el proceso de formación de una imagen 3D se divide en dos etapas. La primera consiste en capturar la escena, y la segunda en representar la información capturada en algún medio o dispositivo. Dependiendo de los sensores utilizados para la captura y la forma de representar la información tridimensional se puede realizar una clasificación como la mostrada en la figura 1.1 .

Hasta el momento, las cámaras y sensores más utilizados son capaces de capturar únicamente imágenes $2 \mathrm{D}$, perdiendo así la información de profundidad de las escenas. Idealmente, para poder capturar las tres dimensiones de la escena habría que utilizar un sensor tridimensional. El problema en la captura de imagen 3D reside en la dificultad de encontrar la estrategia adecuada para obtener información tridimensional, utilizando detectores bidimensionales. Por ello, se hace necesario estudiar diversas estrategias que permitan aumentar la dimensionalidad en la captura de forma práctica. 


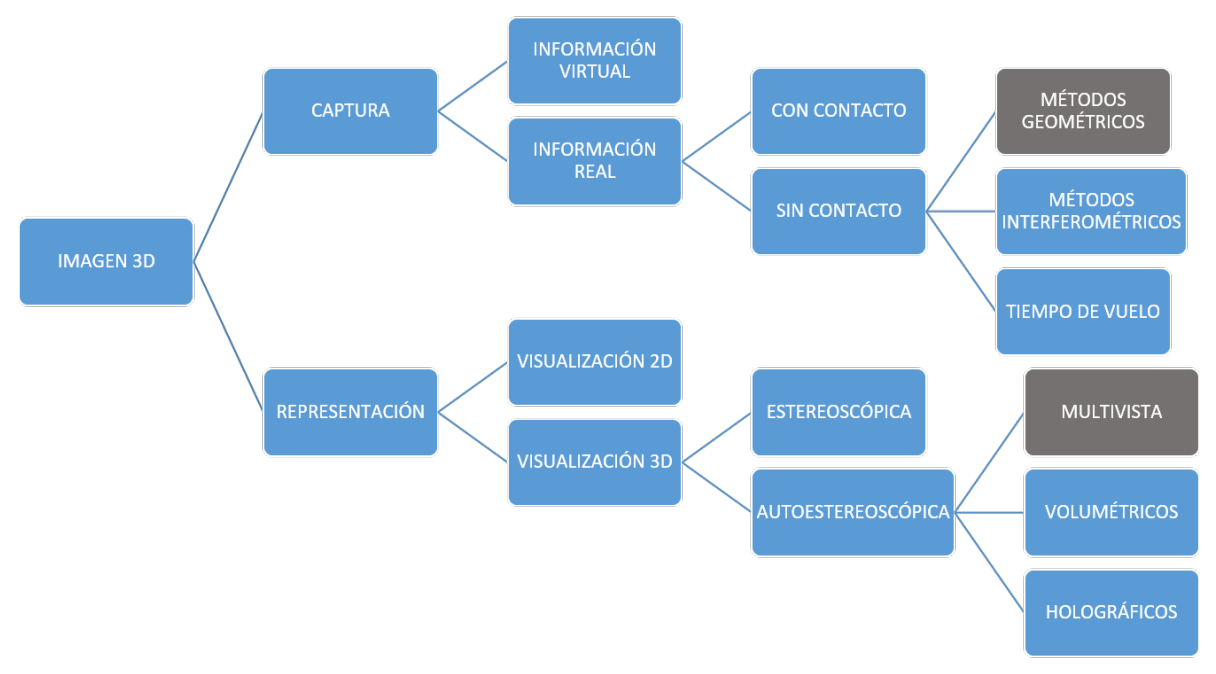

Figura 1.1: Clasificación de técnicas disponibles para conseguir imagen 3D.

Existen múltiples métodos para capturar información de profundidad de las escenas, muchas de las cuales ya se utilizaban en los años 70 [2]. La adquisición 3D de los objetos se puede dividir en dos categorías, tecnologías con o sin contacto contacto [3]. La tecnología con contacto determina la información 3D a través del contacto físico mientras que las otras no necesitan interactuar mecánicamente con el objeto. Estas últimas se suelen dividir a su vez en métodos geométricos, interferométricos y tiempo de vuelo (Time Of Flight, TOF). En primer lugar, los métodos geométricos explotan la relación geométrica entre los objetos de la escena y el sistema de formación de imagen. Las técnicas basadas en interferometría, explotan la naturaleza ondulatoria de la luz y, por lo tanto, calculan las distancias a partir de fenómenos interferenciales. Los métodos de TOF calculan la profundidad midiendo el tiempo que tarda una señal luminosa en recorrer la distancia entre el objeto y un detector de luz. Como los más utilizados en soluciones económicas y de media distancia son los métodos geométricos, estos son los que se estudian en esta tesis. En particular, algunas técnicas geométricas de imagen 3D, obtienen información de profundidad a partir de varias imágenes bidimensionales de una misma escena. Analizar cómo mejorar la estrategia para obtener información más precisa con un número limitado de vistas, así como proponer aplicaciones de esta metodología será clave para su expansión. 
Otro método geométrico utilizado para la reconstrucción de la superficie 3D de un objeto es el empleo de luz estructurada, que se basa en la proyección de un patrón de iluminación conocido. De la deformación de dicho patrón al incidir sobre los objetos de la escena, es posible inferir las posiciones 3D de determinados puntos de las superficies de dichos objetos. Una estrategia similar a la luz estructurada se ha utilizado en el ámbito de la imagen bidimensional, para conseguir imágenes $2 \mathrm{D}$, a partir de sensores sin resolución espacial. Se trata de las denominadas cámaras de un sólo píxel que han adquirido cierta relevancia en la última década, y podrían convertirse en una alternativa real a los sensores tradicionales. En este tipo de cámaras, la segunda dimensión se resuelve, de nuevo, a partir de la proyección de un conjunto de patrones conocidos, pero en este caso, no se estudia la deformación de dichos patrones, sino que se mide, con un detector sin resolución espacial, la luz reflejada por cada patrón. Este proceso nos permite obtener imágenes bidimensionales utilizando sensores sin resolución espacial, o incluso, como veremos en esta tesis, nos permite obtener imágenes tridimensionales a partir de sensores sin resolución espacial.

El principal problema de las cámaras con un sólo píxel es que requieren la proyección secuencial de un conjunto de funciones, lo que limita la velocidad del proceso de adquisición de la imagen. Además, este tiempo aumenta al incrementar la resolución. Es por ello que, aunque la idea básica de cámara de un solo píxel la propuso el profesor Marcel Golay en 1949 [4], no fue hasta el año 2006 cuando comenzaron a popularizarse con el uso de los moduladores espaciales de luz y la aparición de la primera cámara de un solo píxel que utilizaba la técnica de muestreo compresivo (Compressive Sensing, CS) [5]. La técnica de CS permite reconstruir una imagen utilizando un número de medidas menor que el número total de píxeles de la imagen, y por tanto, permite reducir el tiempo de adquisición. Aun así, la reducción del tiempo de proyección sigue siendo un reto en la generación de vídeos de alta resolución en tiempo real. Por ello, están surgiendo numerosas alternativas para superar esta limitación, una de las cuales se propone en esta tesis.

Por otro lado, una vez se ha capturado la información tridimensional, se han de buscar soluciones para la visualización 3D. En la disciplina de la informática gráfica y los gráficos por ordenador se suele hacer una reconstrucción tridimensional de la escena para que el usuario, de forma interactiva, elija la perspectiva de visualización. Otra opción consiste en representar la profundidad en escala de grises, donde los valores de los píxeles se corres- 
ponden con la profundidad de dicho punto de la escena. A esta técnica se la conoce como imagen con información de rango (range imaging). En ambos casos, aunque se habla de imagen 3D, porque el ordenador tiene almacenada la información de profundidad de la escena, la visualización sigue siendo bidimensional. Para que el usuario pueda experimentar la sensación de profundidad, tienen que llegarle dos imágenes distintas de la escena a sus ojos. La tecnología más extendida de visualización tridimensional tiene sus bases en la visión estereoscópica, cuyos primeros trabajos surgieron en 1838 [6]. Este principio imita el funcionamiento del sistema visual humano, un sistema binocular con dos sensores que debido a su separación obtienen dos perspectivas distintas de una misma escena. Estas dos imágenes ligeramente distintas llegan a nuestro cerebro que las fusiona, consiguiendo así formar la sensación 3D. En estereoscopía, el par de imágenes se hacen llegar a los ojos del usuario a través de unas gafas de conmutación o polarizadas. Sin embargo, dado los inconvenientes de esta técnica, han aparecido más recientemente los dispositivos autoestereoscópicos, que muestran una imagen tridimensional a múltiples espectadores sin la necesidad de utilizar cristales o gafas [7].

Los dispositivos autoestereoscópicos se pueden clasificar en tres categorías [8]. (1) dispositivos 3D multivista, (2) dispositivos 3D volumétricos y (3) dispositivos de holografía digital. Desde un punto de vista teórico, los dispositivos holográficos son los que presentan una mejor experiencia de visualización 3D. Sin embargo, existen numerosas limitaciones que restringen su aplicación, como por ejemplo la necesidad del uso de iluminación coherente. Por otro lado, los dispositivos 3D volumétricos son capaces de representar la información 3D de un objeto físicamente dentro de un espacio cerrado, sin embargo, el principal inconveniente reside en la incapacidad de reconstruir escenas con objetos opacos o con oclusiones. Por ello, en esta tesis sólo se estudian los dispositivos de visualización autoestereoscópica multivista.

De entre la tecnología existente, los dispositivos 3D multivista y en particular las pantallas que utilizan hojas lenticulares cilíndricas, han sido ampliamente utilizadas [9, 10]. Una de las limitaciones principales de este tipo de pantallas es que sólo proporcionan paralaje horizontal. Esto no es en realidad una limitación si está pensada para una visualización pasiva, pero si se quiere lograr paralaje en ambas direcciones, la técnica de imagen integral utiliza lentes esféricas en lugar de cilíndricas [11, 12]. Existen además una gran variedad de dispositivos con distintas prestaciones. Sin embargo, dada la necesidad de capturar, grabar y visualizar grandes cantidades de 
datos, en muchos estudios se afirma que la generación de contenido para la visualización 3D es un reto del futuro [13]. De hecho, incluso existen congresos dedicados únicamente a la generación de contenido para pantallas 3D.

Para visualizar una imagen 3D utilizando esta tecnología, no es necesario conocer la profundidad en cada punto de la imagen, sino que basta con realizar tantas capturas bidimensionales como vistas tenga el dispositivo de visualización. De este modo, aunque en este caso no se conoce la tercera dimensión, también se consideran imágenes 3D. Por lo tanto, la definición de imagen 3D no es tan directa como la de imagen 2D y para cada aplicación, será necesario estudiar qué tecnología de captura y visualización es la más apropiada. Por ejemplo, en el caso de querer conocer con precisión el tamaño de los objetos de una escena, por ejemplo, para el diagnóstico clínico, la imagen 3D más apropiada será aquella que se haya capturado con técnicas activas. Sin embargo, si el objetivo consiste en ofrecer una experiencia de visualización 3D a múltiples usuarios, lo más apropiado será utilizar técnicas pasivas para la captura. Estas últimas presentan además la ventaja de ser económicas ya que no necesitan un hardware específico y se suelen utilizar los sensores tradicionales de imagen bidimensional para la captura. Por ello, en esta tesis se explotan las técnicas de captura de información 3D con modelos geométricos y la visualización multivista.

\subsection{Objetivos}

En la figura 1.2 se muestra una clasificación de los métodos de captura y visualización de imagen 3D utilizados a lo largo de esta tesis. Como se puede observar, la tesis se centra en estudiar y explotar las técnicas de captura de información 3D a partir de métodos geométricos. La estrategia más apropiada para capturar imagen 3D se determina a partir de la aplicación. En esta tesis se demuestra, por ejemplo, cómo la imagen integral presenta ventajas sobre otras estrategias de imagen $3 \mathrm{D}$ para la aplicación particular de reconocimiento de gestos. Además, también se propone un algoritmo para la obtención de vistas virtuales para minimizar el número de capturas necesarias de una escena. Finalmente, es objeto de esta tesis ampliar el abanico de posibilidades de la imagen 3D utilizando para ello el nuevo modelo de imagen surgido a partir de las cámaras de un solo píxel.

Los objetivos concretos de esta tesis son los siguientes:

- Proponer un modelo de calibración y rectificación de múltiples cámaras. 


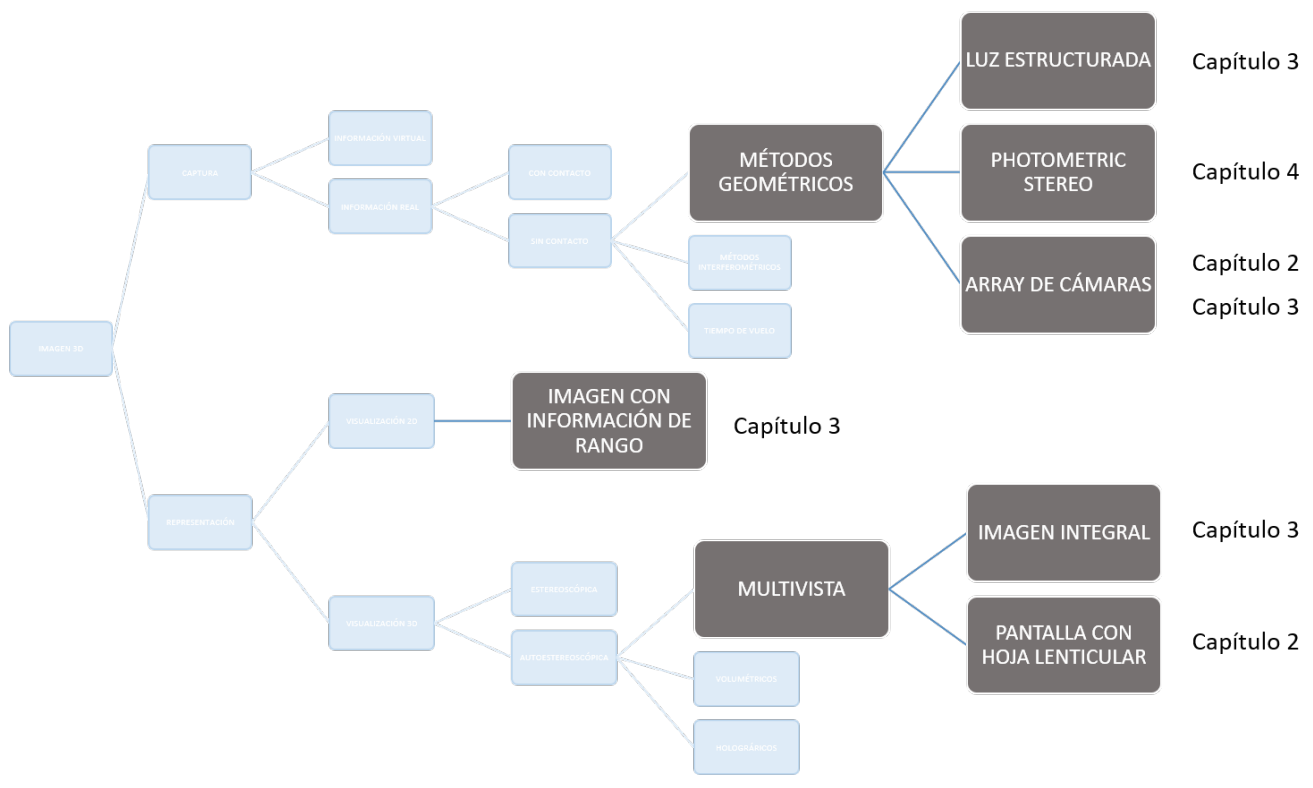

Figura 1.2: Esquema de la tesis donde se destacan las técnicas de imagen 3D utilizadas en cada capítulo.

- Plantear un algoritmo de gereración de vistas virtuales para ser capaces de, a partir de un número limitado de vistas, generar contenido para la visualización $3 \mathrm{D}$ en dispositivos multivista.

- Explorar las ventajas de la imagen integral en aplicaciones de reconocimiento de acciones. Comparar los resultados de clasificación con los resultados obtenidos con imagen $2 \mathrm{D}$.

- Comparar los resultados de clasificación en la tarea de reconocimiento de gestos parcialmente ocultos para tres modalidades distintas de imagen: imagen integral, imagen con información de rango e imagen 2D.

- Diseñar un algoritmo que permita reducir el tiempo de captura de una imagen en los modelos de cámaras de un solo píxel.

- Exponer soluciones económicas para formación de imagen 2D a partir de cámaras de un solo píxel.

- Proponer soluciones para obtener imágenes 3D utilizando las cámaras de un solo píxel. 


\subsection{Estructura de la tesis}

La tesis está dividida en cinco capítulos. Tras el capítulo de introducción, se describen las contribuciones principales de esta tesis.

En primer lugar, en el capítulo 2 se estudian los dispositivos actuales que permiten una visualización 3D pasiva a múltiples usuarios sin utilizar ningún dispositivo adicional. De las opciones disponibles, se elige aquella que se considera más adecuada y se propone un método de generación de contenido apropiado para este tipo de dispositivos. En concreto, aunque existen múltiples posibilidades para visualización 3D, dado que se trata de presentar contenido 3D a usuarios prácticamente estáticos, como pueden ser espectadores de cine o usuarios sentados en el sofá de sus casas, se eligen las pantallas autoestereoscópicas de hojas lenticulares. Como una de las dificultades de esta tecnología consiste en la creación de contenido, se explora la posibilidad de generar vistas sintéticas para disminuir el número de capturas necesarias para estos dispositivos.

A continuación, en el capítulo 3 se estudian los beneficios y aplicaciones de la imagen 3D, comparando la información que ofrecen vídeos $2 \mathrm{D}$ frente a la que ofrecen vídeos capturados utilizando la técnica de imagen integral. En particular, se analiza cómo estos sensores tridimensionales capturan información clave para obtener mejores resultados de clasificación en la tarea de reconocimiento de acciones o gestos. Además, se estudia cómo esta ventaja se hace más efectiva en entornos con oclusión. Por último, se comparan los resultados de clasificación de esta técnica con otro tipo de sensores tridimensionales, como es el sensor RGB $+\mathrm{D}$ del dispositivo comercial Kinect.

En el capítulo 4 se exploran las posibilidades que ofrecen las nuevas cámaras de un sólo pixel así como los principales inconvenientes de esta tecnología. Para subsanar algunos de estos inconvenientes se propone un método que permite reducir el tiempo de adquisición de imágenes. En este capítulo también se describen dos soluciones económicas para la construcción de cámaras single-pixel. Además, se propone un montaje que permite una visualización estereoscópica de un escenario 3D utilizando este nuevo modelo de cámara, así como la obtención de profundidad de una escena utilizando la técnica de fotometría estéreo.

Finalmente, en el capítulo 5 se presentan las conclusiones de esta tesis junto con las nuevas líneas de investigación y trabajo futuro. 


\subsection{Aportaciones}

Esta tesis se basa en las siguientes publicaciones de revistas y congresos realizadas en los últimos años y que se incluyen al final del documento.

\subsubsection{Capítulo 2}

- Display-based light field model for auto-stereo image visualization. E. Salvador, C. González, J. Martínez and F. Pla. The 11th International Meeting on Information Display October 11-15, 2011 Kintex, Seoul, Korea

- Síntesis de vistas para la generación de campos de luz en visualización autoestereoscópica.

E. Salvador, J. Martínez, F. Pla. XXXIV Reunión bienal de la Real Sociedad Española de Física y $23^{\circ}$ Encuentro Ibérico de Enseñanza de la Física. Valencia, (España) Real Sociedad Española de Física, 2013. ISBN: 978-84-616-5607-3

- View Synthesis for Real Scene Visualisation on Autostereoscopic Displays.

E. Salvador, J. Martínez, F. Pla. 6th Iberian Conference on Pattern Recognition and Image Analysis, IbPRIA 2013. Funchal, Madeira, (Portugal) Springer LNCS VOL7887, Pp. 839-846, 2013. ISSN: 0302-9743

\subsubsection{Capítulo 3}

- Human gesture recognition using three-dimensional integral imaging. V. J. Traver, P. Latorre, E. Salvador, F. Pla y B. Javidi. Journal of the Optical Society of America A, Vol. 31, October, 2014, pp. 2312-2320. ISSN: $1084-7529$

- Integral imaging acquisition and processing for human gesture recognition.

F. Pla, P. Latorre, E. Salvador, B. Javidi. Porceedings of International Society for Optics and Photonics ( Conference Three-Dimensional Imaging, Visualization, and Display 2015-SPIE 2015). Baltimore, Maryland, United States, Proceedings of SPIE, Vol. 9495, Seccion 5, 2015. ISSN: 0277-786X 
- Three-dimensional Integral Imaging for Gesture Recognition under Occlusions.

V. J. Traver, P. Latorre, E. Salvador, F. Pla, B. Javidi. IEEE Signal Processing Letters, Vol. 24, No. 2, February 2017, pp. 171-175. ISSN: 1070-9908

\subsubsection{Capítulo 4}

- Fast high resolution single-pixel imaging.

F. Soldevila, E. Salvador, P. Clemente, E. Tajahuerce, and J. Lancis. Reunión Nacional de Óptica. RNO 2015.

- High-resolution adaptive imaging with a single photodiode.

F. Soldevila, E. Salvador, P. Clemente, E. Tajahuerce, and J. Lancis. Nature - Scientific Reports. Vol 5, pp. 1-9, 2015. ISSN: 2045-2322

- Full-Color Stereoscopic Imaging With a Single-Pixel Photodetector.

E. Salvador, P. Clemente, E. Tajahuerce, F. Pla, and J. Lancis, Journal of Display Technology. Vol 12, pp. 417-422, 2016. ISSN: 1551-319X

- Stereoscopic color imaging by compressive sensing with a single-pixel photodetector.

E. Salvador, P. Clemente, M. Fernández, E. Tajahuerce and J. Lancis. 23rd Congress of the International Commission for Optics Santiago de Compostela (Spain) 26-29 August 2014, ISBN: 978-84-697-1027-2

- Full-color stereoscopic single-pixel camera based on DMD technology. E. Salvador ; P. Clemente ; E. Tajahuerce ; F. Pla ; J. Lancis. Proc. SPIE 10117, Emerging Digital Micromirror Device Based Systems and Applications IX, 101170M, February 20, 2017. 


\title{
Capítulo 2
}

\section{Imagen 3D para visualización pasiva}

\author{
Poner en duda que el cine en relieve \\ sea el cine de mañana es tan ingenuo \\ como dudar del mañana en general.
}

Sergéi Eisenstein, 1947

\section{RESUMEN:}

La imagen 3D tiene sus orígenes en la industria cinematográfica. Sin embargo, la tecnología de visualización presente en nuestros cines no dista tanto de la propuesta hace más de 90 años, presentando numerosos inconvenientes, como por ejemplo, la necesidad de utilizar lentes especiales. Tras la aparición de los dispositivos autoestereoscópicos multivista, que pueden ser muy apropiados en este contexto, son muchos los estudios que centran sus esfuerzos en aliviar los inconvenientes de esta tecnología para permitir así su proliferación. En este capítulo se describen brevemente los dispositivos actuales multivista que permiten una visualización pasiva 3D a múltiples usuarios sin necesidad de utilizar gafas. Dado que uno de los mayores inconvenientes de esta tecnología consiste en la creación de contenido, se propone un algoritmo de generación de vistas sintéticas. Con este algoritmo se consigue la creación de vistas intermedias que permiten mover una cámara virtual a lo largo de una serie de cámaras. En particular, se propone un algoritmo capaz de generar imágenes de un escenario real complejo, preparadas para pasarse como entrada a un dispositivo autoestereoscópico de hojas lenticulares. 


\subsection{Dispositivos autoestereoscópicos multivista}

La visualización 3D está cada vez más presente en nuestras vidas, sin embargo, la tecnología más popular requiere el uso de gafas u otros dispositivos que resultan molestos a los usuarios finales. Por ello se espera que el próximo avance tecnológico para la visualización 3D se haga entorno a dispositivos que permitan generar sensación 3D de forma directa, como son los dispositivos autoestereoscópicos [14]. Por definición, todos los dispositivos 3D que no requieren aparatos especiales para su visualización, se pueden clasificar como pantallas autoestereoscópicas. Sin embargo, en general el término está reservado para pantallas que proporcionan sólo estereopsis basada en el envío de imágenes tomadas desde distintos puntos de vista.

Existen en la actualidad multitud de dispositivos multivista que permiten visualización 3D a múltiples usuarios. Al igual que sucede con los dispositivos estereoscópicos, éstos también se basan en el funcionamiento de la visión humana para lograr la sensación 3D. A diferencia de los dispositivos estereoscópicos que únicamente proporcionan dos vistas para lograr visión estéreo, la mayoría de dispositivos autoestereoscópicos ofreden un mayor número de perspectivas consiguiendo así paralaje horizontal y vertical. Este paralaje permite que dependiendo del punto de vista del observador, la posición aparente del objeto varíe, es decir, permite que un observador visualice distintas perspectivas de un objeto 3D.

Para generar el contenido de entrada de los dispositivos autoestereoscópicos es necesario capturar la escena utilizando tantas cámaras o lentes como vistas tenga el dispositivo. Por lo tanto, cuantas más vistas tenga el dispositivo de visualización, mayor será la dificultad de generar contenidos para el mismo. En este capítulo se descartan los dispositivos que proporcionan paralaje completo y se centra el estudio en aquellos que permiten paralaje horizontal ya que este es el más común en una visualización pasiva, como la que realiza un usuario en una sala de cine. Los dispositivos multivista que proporcionan paralaje horizontal más comunes son los dispositivos con barreras de paralaje y los dispositivos con hojas lenticulares [15], siendo este último el dispositivo utilizado en nuestros experimentos.

En las pantallas con hojas lenticulares se utilizan lentes cilíndricas moldeadas en un sustrato plástico para dirigir la luz de un píxel en un determinado ángulo. El conjunto de lentes se coloca delante del dispositivo y con 
ello se consigue que la pantalla emita varias vistas en ángulos distintos. De este modo, un observador colocado a la distancia óptima y dentro del ángulo de visión de la pantalla recibirá dos vistas distintas de una misma escena. En la figura 2.1 se ilustra el funcionamiento básico de una pantalla con hoja lenticular de dos vistas.

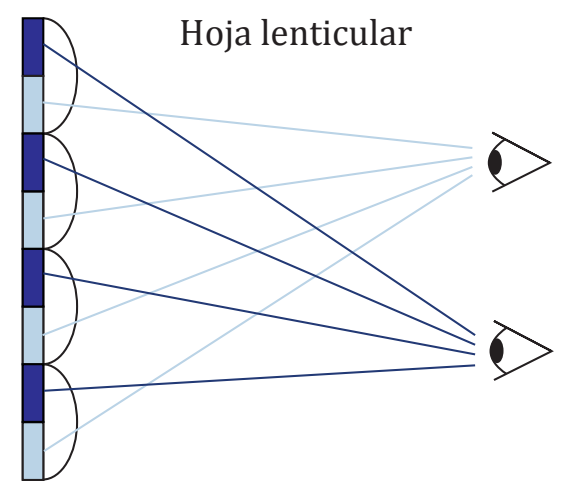

Figura 2.1: Pantalla con hoja lenticular de dos vistas.

En estos dispositivos la alineación del conjunto de lentes es vital, ya que al aumentar el número de vistas se reduce la resolución. Para subsanar el problema de la reducción de la resolución, se propone utilizar una hoja lenticular inclinada un cierto ángulo [16], tal y como se muestra en la figura 2.2 Esta mejora ayuda a obtener una transición más suave entre las vistas, así como a eliminar el efecto Moiré, que consiste en la visualización de unas bandas oscuras surgidas por la separación entre los píxeles. Más información sobre el diseño de hojas lenticulares y avances en este tipo de tecnología se puede encontrar en [17].

El principal inconveniente de estos dispositivos reside en la generación de contenidos, ya que conseguir alinear un conjunto de cámaras y obtener las vistas necesarias para el dispositivo no es una tarea fácil. Por ello, a continuación se propone un algoritmo de vistas sintéticas que permita utilizar un menor número de cámaras y lograr la misma visualización 3D.

\subsection{Vistas sintéticas}

Los algoritmos de vistas sintéticas (view synthesis) permiten obtener una imagen de una escena desde un nuevo punto de vista utilizando la infor- 


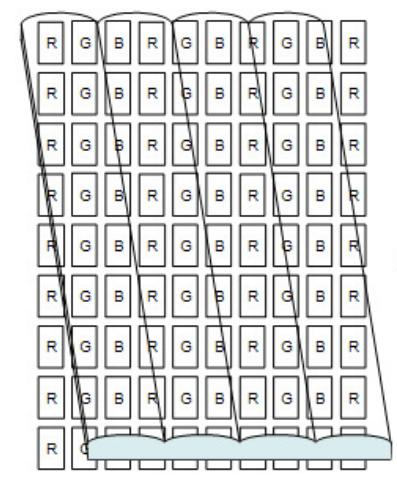

Figura 2.2: Hoja lenticular inclinada.

mación recogida por el resto de cámaras. Algunas estrategias requieren la reconstrucción de la estructura completa de la escena para producir nuevas vistas sintéticas [18]. Otras propuestas usan Depth Image Based Rendering (DIBR) para sintetizar múltiples imágenes [19, 20]. En este caso, la calidad de las vistas sintéticas depende enormemente de la exactitud de los mapas de profundidad.

Nuestra propuesta se inspira en el algoritmo de view morphing propuesto por Seitz y Dyer [21. En ese caso, el proceso de síntesis de imagen se divide en tres etapas. En primer lugar se realiza un prewarp (rectificado) de la imagen de entrada antes del proceso de morphing (fusión o deformado). Finalmente se transforma la imagen deformada en un proceso denominado postwarp para obtener la nueva perspectiva deseada.

En nuestro caso, a diferencia del algoritmo propuesto por Seitz, no se lleva a cabo la última etapa. En su lugar, se recupera la relative affine structure [22], modelo propuesto en 1994 para facilitar la reconstrucción 3D a partir de varias vistas, y se utiliza para sintetizar una nueva vista de la escena a lo largo de una serie de cámaras.

Como sucede en el algoritmo de Seitz, en nuestro método es necesario calibrar las cámaras para conocer así las matrices de proyección de las mismas. A continuación, se han de rectificar las imágenes para asegurar que las vistas sintéticas entre un par de cámaras no presentan rotaciones, es decir, para asegurar que los ejes ópticos de las cámaras sean paralelos. Posteriormente se ha de realizar una correspondencia entre los píxeles de las cámaras para poder finalmente aplicar el algoritmo de síntesis de imágenes. Este proceso 
se ilustra en la figura 2.3 y se describe en las siguientes secciones.

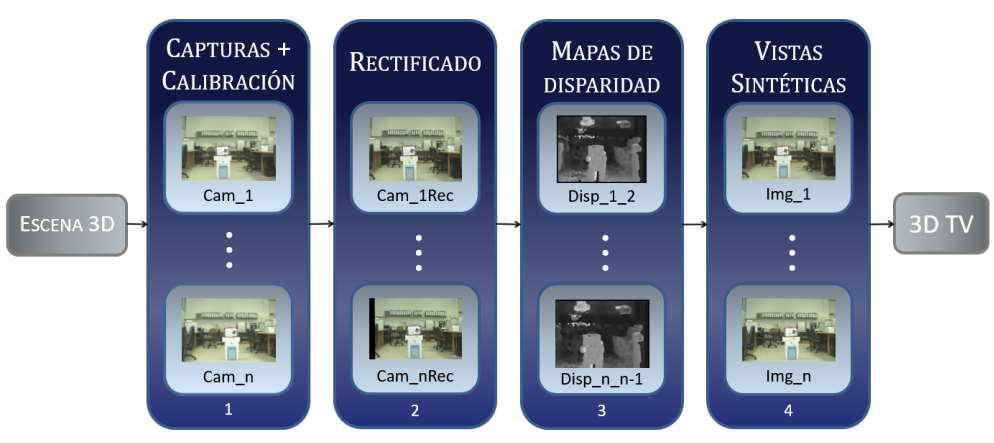

Figura 2.3: Descripción del algoritmo de síntesis de imágenes.

\subsubsection{Adquisición de imágenes y calibración de las cámaras}

\subsubsection{Teoría básica}

Para poder relacionar las coordenadas 3D de una escena con los puntos 2D del plano imagen, es necesario calibrar la cámara con la que se ha tomado la imagen. El proceso de calibración permite obtener los parámetros que establecen una relación métrica entre una escena tridimensional y la imagen bidimensional capturada por una cámara. Estos parámetros de modelización aproximan la conducta de un sensor físico en un modelo geométrico conocido como modelo pinhole [23]. Según este modelo, en una cámara se distinguen entre parámetros extrínsecos y parámetros intrínsecos. A estos parámetros, expresados de forma matricial, se les conoce como matriz de proyección. A partir de esta matriz es posible transformar cualquier punto 3D de la escena en su correspondiente punto $2 \mathrm{D}$ en la imagen, pero no al revés. Los parámetros extrínsecos son aquellos que relacionan la posición relativa entre un objeto de la escena y la propia cámara. Dichos parámetros se expresan de forma matricial, a partir de las matrices de rotación y traslación de la cámara. La matriz de rotación $R$ es una matriz $3 \times 3$ que determina los ángulos de rotación sobre cada uno de los ejes:

$$
R=\left(\begin{array}{lll}
r_{11} & r_{12} & r_{13} \\
r_{21} & r_{22} & r_{23} \\
r_{31} & r_{32} & r_{33}
\end{array}\right)
$$


El vector de traslación, $T$, indica la distancia entre el centro óptico de la cámara y el origen de coordenadas mundo:

$$
T=\left(\begin{array}{c}
t_{x} \\
t_{y} \\
t_{z}
\end{array}\right)
$$

Los parámetros intrínsecos, $K$, se definen a partir de una matriz $3 \times 3$ y dan información sobre la geometría interna de la cámara, es decir, relacionan el sistema de coordenadas de la cámara con el sistema de coordenadas de la imagen. Esta matriz se define como:

$$
K=\left(\begin{array}{ccc}
\alpha & 0 & u_{0} \\
0 & \beta & v_{0} \\
0 & 0 & 1
\end{array}\right)
$$

Los parámetros $\alpha$ y $\beta$ dan información sobre la dimensión de los píxeles, es decir, nos dan la relación píxel $/ \mathrm{cm}$. En particular $\alpha=f k_{u}$ y $\beta=f k_{v}$, donde $f$ es la focal de la lente y $k_{u}, k_{v}$ son factores de escala en ambos ejes. Finalmente, $u_{0}$ y $v_{0}$ definen la posición del centro de proyección. Los parámetros de distorsión radial producidos por las lentes también se incluyen en la matriz de parámetros intrínsecos, pero para simplificar el problema no los consideramos.

A partir de estos parámetros, la matriz de proyección de la cámara que permite expresar las coordenadas mundo $(x, y, z)$, en coordenadas del plano imagen $(u, v)$, se define de forma matricial utilizando coordenadas homogéneas como:

$$
\left(\begin{array}{c}
s u \\
s v \\
s
\end{array}\right)=\left(\begin{array}{cccc}
\alpha & 0 & u_{0} & 0 \\
0 & \beta & v_{0} & 0 \\
0 & 0 & 1 & 0
\end{array}\right) \cdot\left(\begin{array}{cccc}
r_{11} & r_{12} & r_{13} & t_{x} \\
r_{21} & r_{22} & r_{23} & t_{y} \\
r_{31} & r_{32} & r_{33} & t_{z} \\
0 & 0 & 0 & 1
\end{array}\right) \cdot\left(\begin{array}{c}
x \\
y \\
z \\
1
\end{array}\right),
$$

donde $s$ es un factor de escala. Sin embargo, si conocemos las coordenadas de un punto $P_{L}$ del plano imagen, no podemos saber de qué punto 3D se trata. En la figura 2.4 se muestra como, a partir de la matriz de proyección de la cámara de la izquierda cuyo centro óptico es $O_{L}$, el punto de la imagen $\left(P_{L}\right)$ se corresponde con cualquiera de los puntos $\left(P, P_{1}, P_{2}, P_{3}\right)$ de la escena. Esta indeterminación en la profundidad puede resolverse por triangulación si conocemos el punto correspondiente en la imagen capturada por una segunda cámara. 


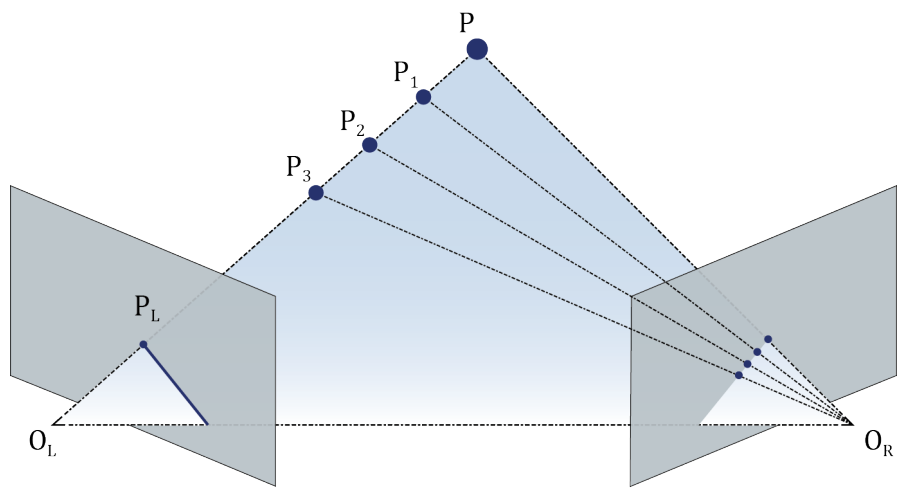

Figura 2.4: Relación geométrica que nos permite conocer la profundidad de un punto de la escena capturado por un par de cámaras.

Por lo tanto, para obtener información 3D a partir de imágenes 2D, es necesario establecer una correspondencia entre los píxeles de las imágenes obtenidas por varias cámaras. El problema de la correspondencia se resuelve a través de la geometría epipolar, que es la geometría de la visión estéreo. La figura 2.5 representa la geometría epipolar a partir de dos cámaras estenopeicas (pinhole) que miran al punto 3D de la escena $P=(x, y, z)$. Siendo de nuevo $O_{L}$ y $O_{R}$ los centros ópticos de las cámaras, las rectas que unen estos centros con el punto $P$, intersectan en los planos imagen en los puntos $P_{L}$ y $P_{R}$. Además, se denomina línea base (baseline) a la recta que conecta los centros ópticos de las dos cámaras. Estas tres rectas forman un plano, denominado plano epipolar, que intersecta con los dos planos imagen en las conocidas líneas epipolares. Esta definición nos permite encontrar con más facilidad la correspondencia entre píxeles de ambas imágenes, ya que la proyección del punto $P$ se encuentra sobre las líneas epipolares de las dos imágenes.

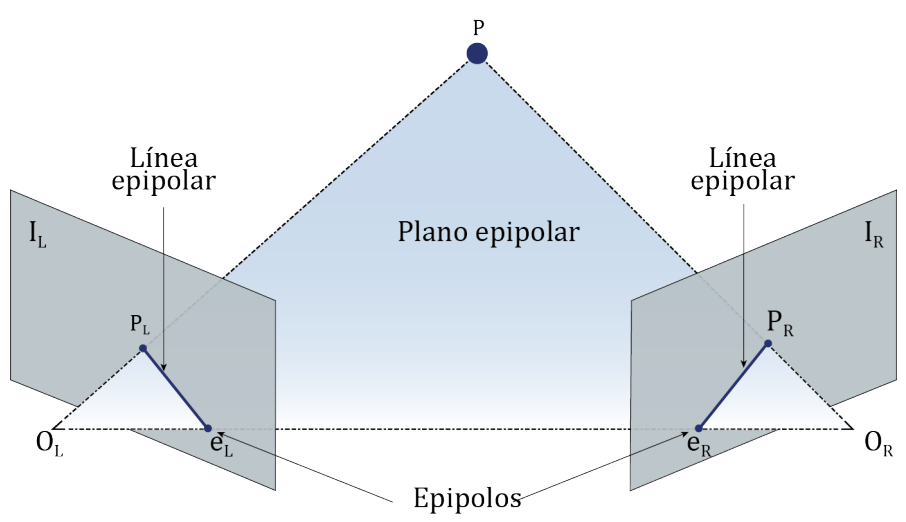

Figura 2.5: Geometría epipolar 


\subsubsection{Calibración experimental}

En nuestro experimento, con el fin de obtener las matrices de proyección de las cámaras, se ha utilizado el algoritmo de calibración propuesto por Zhang [24]. Este método de calibración se basa en la colocación de un patrón conocido en la escena con distintas orientaciones para obtener los parámetros de las cámaras. La principal ventaja de este algoritmo de calibración con respecto al resto de métodos es que resulta muy fácil de implementar y se obtienen valores fiables que tienen en cuenta la distorsión radial de las lentes. Por ello, se ha elegido este algoritmo y se ha adaptado para la calibración de múltiples cámaras.

En el experimento realizado se utiliza un conjunto de ocho cámaras colocadas en un eje horizontal, y en el ángulo de visión coincidente de todas ellas se sitúa un damero como patrón de calibración (Fig. 2.6). A continuación, se realiza una captura sincronizada de todas las cámaras y se utiliza un algoritmo de reconocimiento de puntos característicos para detectar las esquinas del damero. Tanto el número de cuadros como el tamaño de los mismos son elegidos por el usuario y serán parámetros de entrada en el algoritmo de calibración. En particular, el patrón utilizado tiene 54 casillas de las que se utilizan las 28 casillas centrales, por lo que se ofrecen 40 esquinas como puntos de referencia. Para que el algoritmo funcione correctamente, se necesitan al menos cuatro imágenes por cámara con el patrón en distintas orientaciones. De este modo, con al menos cuatro capturas sincronizadas de las 8 cámaras, se estiman los parámetros intrínsecos y extrínsecos de todas las cámaras mediante relaciones algebraicas.

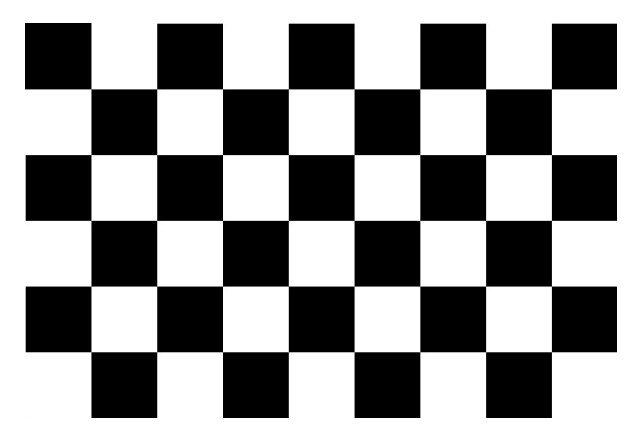

Figura 2.6: Patrón de calibración utilizado.

Como se ha visto, los parámetros extrínsecos se definen a través de la matriz de rotación, $R$ y de traslación , $T$, y los parámetros intrínsecos a través de la matriz $K$. Utilizando estos parámetros, obtenidos mediante la calibración de Zhang, la matriz de proyección de una cámara $n$ se define como:

$$
P_{n}=\left[K_{n} *\left[R_{n} \mid T_{n}\right]\right] .
$$

Esta matriz de proyección obtenida en la calibración será necesaria en el proceso de rectificación de las cámaras. 


\subsubsection{Rectificación de múltiples vistas}

El proceso de rectificación consiste en trasformar las imágenes originales para alinear sus líneas epipolares, es decir, conseguir alinear los ejes ópticos de forma que los planos imagen sean paralelos entre sí. Aunque las cámaras se dispongan horizontalmente, siempre existen pequeños desajustes en las posiciones y orientaciones de las mismas. Por este motivo, las imágenes capturadas originalmente por una serie de cámaras deben transformarse para conseguir así una distribución ideal donde no exista ningún desajuste.

Las técnicas de rectificado estéreo han sido estudiadas durante mucho tiempo en el campo de la visión por ordenador [25, 26. En la figura 2.7 se representa la rectificación de un par de cámaras utilizando la definición de homografía. Una homografía se define a partir de una matriz $3 \times 3$ denominada matriz homográfica, $H$. Esta matriz define la transformación perspectiva entre dos planos distintos. Si estos dos planos son las imágenes $I_{1}^{\prime}$ y $I_{1}$, entonces la homografía proyectiva entre estos dos planos se define como:

$$
\left(\begin{array}{c}
u^{\prime} \\
v^{\prime} \\
1
\end{array}\right)=\left(\begin{array}{lll}
h_{11} & h_{12} & h_{13} \\
h_{21} & h_{22} & h_{23} \\
h_{31} & h_{32} & h_{33}
\end{array}\right)\left(\begin{array}{c}
u \\
v \\
1
\end{array}\right) .
$$

La rectificación consiste en obtener las dos matrices de rectificación $H_{1}$ y $H_{2}$ que permiten transformar los puntos de las imágenes originales $I_{1}$ e $I_{2}$ en las imágenes rectificadas $I_{1}^{\prime}$ e $I_{2}^{\prime}$.

$$
\begin{aligned}
& I_{1} * H_{1}=I_{1}^{\prime} ; \\
& I_{2} * H_{2}=I_{2}^{\prime} .
\end{aligned}
$$

El resultado de la rectificación estéreo son un par de imágenes que satisfacen las condiciones de una configuración de cámaras ideal. En esta configuración ideal las dos cámaras tienen los mismos parámetros intrínsecos, la misma orientación y la misma posición, pero distinto desplazamiento horizontal. Como consecuencia, las dos imágenes resultantes tendrán las líneas epipolares alineadas.

Para aumentar el realismo de la imagen 3D, cada vez se utilizan un número mayor de cámaras. Por lo tanto, se ha hecho necesario desarrollar algoritmos de rectificación para múltiples cámaras [27-30]. Nuestro algoritmo se basa en el método descrito en [1] para la rectificación de múltiples cámaras en disposición paralela. Este método consiste en transformar las imágenes originales capturadas desde una serie de cámaras, para obtener las imágenes que se capturarían en una disposición ideal. Por lo tanto, una vez obtenidos los parámetros con la calibración de Zhang, faltará definir estos mismos parámetros en una disposición ideal. 


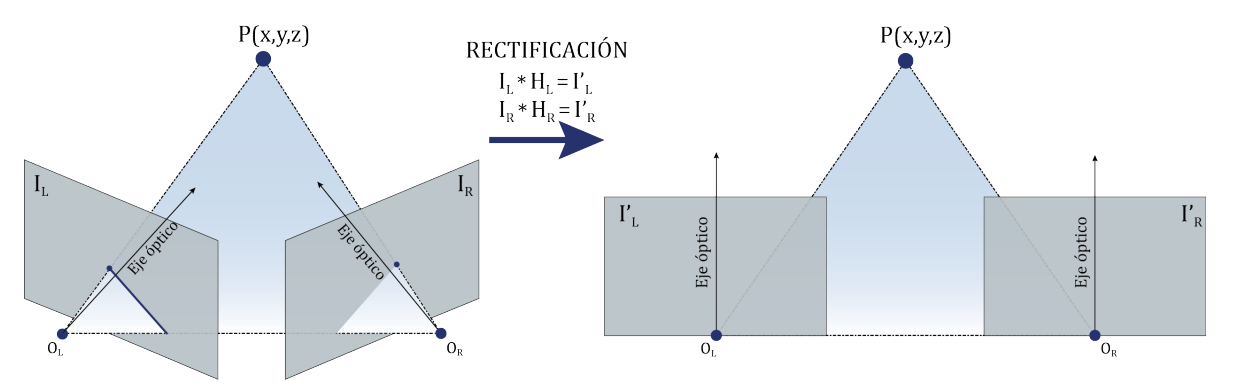

Figura 2.7: Rectificación de un par estéreo.

En una configuración ideal, todas las cámaras están colocadas sobre una línea en el espacio, equidistantes entre sí y con la misma orientación. En la figura 2.8 se muestra un ejemplo del proceso de rectificación de múltiples cámaras. La matriz de rectificación se calcula como la homografía proyectiva entre los parámetros de la disposición ideal y los parámetros obtenidos en la calibración. En particular, para cada cámara se obtiene la homografía entre el plano imagen original y el ideal, del siguiente modo:

$$
H_{n}=P_{\text {ideal }, n} \cdot P_{n}^{+},
$$

donde $P_{\text {ideal }, n}$ es la matriz de proyección para la cámara ideal $n$ ' y $P_{n}^{+}$es la pseudo inversa de la matriz de proyección de la cámara $n$.

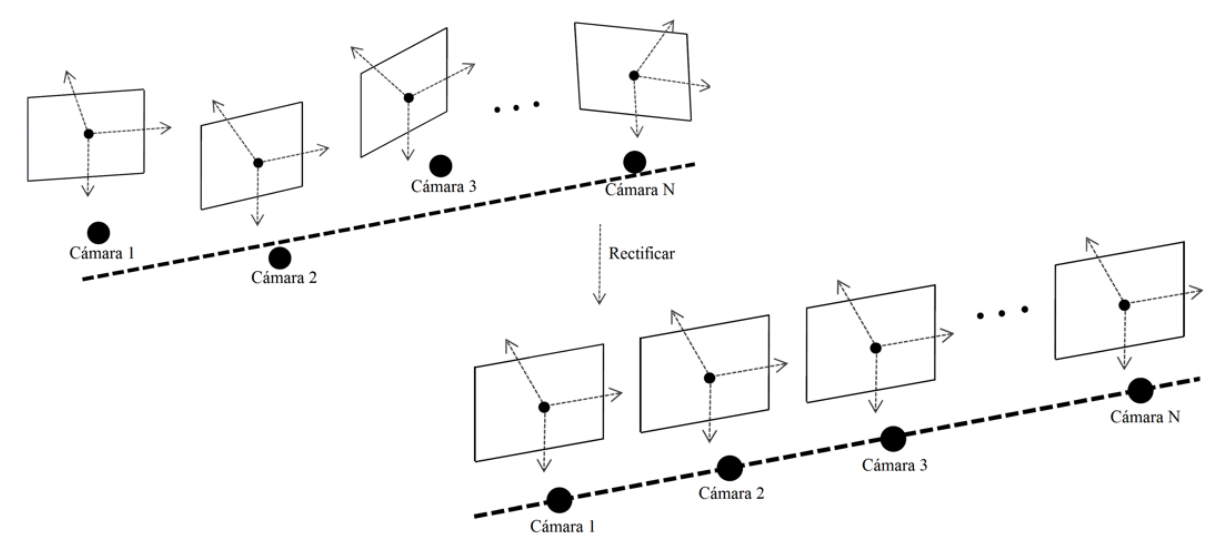

Figura 2.8: Rectificación de múltiples cámaras [1].

La matriz $P_{n}$ se obtiene a partir del proceso de calibración descrito en el apartado anterior, mientras que $P_{i d e a l, n}$ se obtiene del siguiente modo. En primer lugar se ha de definir la matriz de rotación ideal, $R_{\text {ideal }}$, que describe la disposición de las cámaras, para considerarlo como el eje básico. En nuestro algoritmo, definimos $R_{\text {ideal }}$ como la matriz identidad, ya que así se describe una disposición rígida de las cámaras en las que sus ejes coinciden con las direcciones del sistema de coordenadas 
mundo. Esta matriz es común para todas las cámaras. A continuación, a partir de los centros ópticos de las cámaras, se definen sus vectores de traslación. La matriz de traslación ideal de la cámara $n$ se define como:

$$
T_{i d e a l, n}=R_{\text {ideal }} C_{\text {ideal }, n},
$$

donde $C_{\text {ideal }, n}$ es la posición del centro óptico de la cámara $n$. Dado que $R_{\text {ideal }}$ la hemos definido como la matriz identidad, entonces $T_{\text {ideal }, n}=C_{\text {ideal }, n}$.

Considerando que todas las cámaras están dispuestas sobre una línea en el espacio y que únicamente existe un desplazamiento horizontal entre cámaras adyacentes, definimos las posiciones de sus centros ópticos. Colocando el sistema de coordenadas mundo sobre una de las cámaras, para esa cámara de referencia el vector de traslación ideal será $T_{\text {ideal }, r}=(0,0,0)^{t}$. En el resto, $T_{\text {ideal }, n}=\left(d_{n}, 0,0\right)^{t}$, donde $d_{n}$ es la distancia entre la cámara $n$ y la de referencia, $r$. Finalmente, se definen unos parámetros intrínsecos comunes a todas ellas $K_{\text {ideal }}$ como:

$$
\left(\begin{array}{ccc}
\alpha \_i d e a l & 0 & u_{0} \_i d e a l \\
0 & \beta \_i d e a l & v_{0}{ }_{i d e a l} \\
0 & 0 & 1
\end{array}\right),
$$

donde no se tiene en cuenta el ángulo de inclinación en el eje de la imagen. Además, si las dimensiones de la imagen capturadas pos las cámaras son $h \times w$, entonces $u_{0} \_i d e a l=h / 2$ y $v_{0} \_i d e a l=w / 2$, es decir, los puntos principales están situados en el centro de la imagen. Finalmente, los parámetros $\alpha_{-} i d e a l$ y $\beta \_i d e a l$ se definen a partir de la distancia focal de las cámaras. De este modo se define la matriz de proyección ideal para cada una de las cámaras de una configuración horizontal como:

$$
P_{\text {ideal }, n}=\left[K_{\text {ideal }} \cdot\left[R_{\text {ideal }} \mid T_{\text {ideal }, n}\right]\right] .
$$

Si el número de cámaras utilizadas y la disposición de las mismas coincide con las vistas de entrada necesarias para un dispositivo autoestereoscópico multivista, entonces las imágenes rectificadas $\left(I_{1}, \ldots, I_{n}\right)$ se pueden utilizar directamente como entrada al dispositivo. Si por lo contrario, el número de imágenes obtenidas es menor que el número de vistas del dispositivo autoestereoscópico, entonces es necesario un proceso de síntesis de imágenes para generar aquellas que no han sido adquiridas directamente.

\subsubsection{Generación de mapas de disparidad}

Dado que el algoritmo de vistas sintéticas, que describiremos en la próxima sección, necesita como entrada un conjunto de mapas de disparidad, el primer paso consiste en obtener dichos mapas. Un mapa de disparidad representa la distancia entre un par de píxeles correspondientes de dos imágenes estéreo. Por lo tanto, a partir de un par de imágenes estereoscópicas se puede producir un mapa de disparidad denso. Estos mapas deberían ser suaves y detallados, es decir, las superficies 
continuas deberían producir una región de valores de disparidad suaves, mientras que los objetos pequeños deberían ser detectados como regiones distinguibles. Sin embargo, no es común que los algoritmos estero satisfagan estas dos condiciones simultáneamente.

Zitnick y Kanade [31] propusieron un algoritmo que intenta resolver este problema, y es el algoritmo que utilizamos para generar los mapas de disparidad. Se trata de un algoritmo clásico que recibe como entrada el valor máximo y el valor mínimo de disparidad. El mapa de disparidad tiene como dimensiones el número de filas, $r$, el número de columnas, $c$ y disparidad, $d$. Dado que el par de imágenes han sido previamente rectificadas, cada elemento $(r, c, d)$ del espacio de disparidad se proyecta al píxel $(r, c)$ de la imagen de la izquierda y al píxel $(r, c+d)$ de la imagen de la derecha.

Para obtener un mapa detallado y suave a la vez, se utiliza una función iterativa que refina en cada paso la correspondencia entre píxeles de ambas imágenes a partir de dos suposiciones propuestas por Marr y Poggio [32, 33]: unicidad y continuidad. Es decir, se supone que cada píxel del mapa de disparidad tiene un valor único y además, excepto en los bordes, hay una continuidad en los valores de disparidad. Denotamos como $L_{n}(r, c, d)$ al valor de correspondencia del elemento $(r, c, d)$ en la iteración $n$. El valor inicial $L_{0}(r, c, d)$ debe ser obtenido a partir de las imágenes $I_{1}$ e $I_{2}$ utilizando:

$$
L_{0}(r, c, d)=\delta\left(I_{1}, I_{2}, r, c, d\right),
$$

donde $\delta$ es una función de similitud como las diferencias cuadradas o la correlación normalizada sobre ventanas centradas en $(r, c)$ y $(r, c+d)$. A continuación, teniendo en cuenta la asunción de continuidad, elementos cercanos en la imagen deberían tener valores consistentes, por lo que este algoritmo propone hacer promedios iterativos de estos valores para incrementar la consistencia. La región cercana, $\Phi$, a considerar, la definen a partir de un valor de anchura, altura y disparidad fijo. Además, dependiendo de la distancia, se define como $S_{n}(r, c, d)$ la cantidad de contribución local para $(r, c, d)$ :

$$
S_{n}(r, c, d)=\sum_{\left(r^{\prime}, c^{\prime}, d^{\prime}\right) \in \Phi} L_{n}\left(r+r^{\prime}, c+c^{\prime}, d+d^{\prime}\right) .
$$

Por último, la asunción de unicidad implica que sólo puede existir una correspondencia por píxel. Este algoritmo propone una función de inhibición que asigna un peso a los píxeles con más de un valor de correspondencia. Sea $\Psi(r, c, d)$ el conjunto de elementos que se superponen sobre el elemento $(r, c, d)$. Definimos $R_{n}(r, c, d)$ como la cantidad de inhibición que $S_{n}(r, c, d)$ recibe de los elementos en $\Psi(r, c, d)$. Esta función de inhibición la definen como:

$$
R_{n}(r, c, d)=\left(\frac{S_{n}(r, c, d)}{\sum_{\left(r^{\prime \prime}, c^{\prime \prime}, d^{\prime \prime}\right) \in \Psi(r, c, d)} S_{n}\left(r^{\prime \prime}, c^{\prime \prime}, d^{\prime \prime}\right)}\right)^{\alpha} .
$$


Todas las restricciones anteriores se definen para encontrar el valor de disparidad entre dos píxeles correspondientes como:

$$
L_{n+1}(r, c, d)=L_{0}(r, c, d) *\left(\frac{S_{n}(r, c, d)}{\sum_{\left(r^{\prime \prime}, c^{\prime \prime}, d^{\prime \prime}\right) \in \Psi(r, c, d)} S_{n}\left(r^{\prime \prime}, c^{\prime \prime}, d^{\prime \prime}\right)}\right)^{\alpha} .
$$

Una vez se ha asignado un valor de disparidad en cada píxel de la imagen se estudian las oclusiones. En esta propuesta identifican las oclusiones examinando la magnitud del valor de correspondencia junto con la restricción de unicidad (el valor de la función de inhibición). Dado que en áreas con oclusión no existe una correspondencia, todos los valores de correspondencia de píxeles con oclusión deberían ser pequeños. Además, la función de inhibición habrá afectado a todos los píxeles consecutivos hasta encontrar la correspondencia correcta. Es por ello que se puede determinar si un píxel está ocluido buscando el elemento con mayor valor de coincidencia a lo largo de una línea. Si el valor máximo encontrado está por encima de un umbral, el píxel se clasifica como ocluido.

\subsubsection{Algoritmo de View Synthesis}

Una vez obtenidos los mapas de disparidad, para generar un nuevo punto de vista de la escena utilizamos un algoritmo de síntesis similar al descrito en 34 y 35]. La idea principal consiste en obtener el plano homográfico $H_{12}$ que relaciona dos puntos conjugados $p_{1}$ y $p_{2}$ :

$$
p_{2}=H_{12} p_{1}+e_{21}
$$

Esta ecuación sólo funciona para puntos $3 \mathrm{D}, P$, que pertenecen a un plano particular de la escena. Si $P$ no pertenece a dicho plano existe un desplazamiento residual denominado paralaje y esta distancia es proporcional a la relative affine structure de $P$ [36]. Para cada par de imágenes consecutivas $\left(I_{1} ; I_{2}\right)$ el algoritmo de síntesis es el siguiente:

- Utilizando los valores de disparidad, obtener un conjunto de pares conjugados

$$
\left(m_{1}^{k} ; m_{2}^{k}\right) k=1, \ldots, m
$$

- A partir de las matrices de proyección de las vistas rectificadas recuperar el epipolo $e_{21}$ y la homografía $H_{12}$

$$
H_{12}=P_{2} * P_{1}^{-1} \text {. }
$$

- Para cada par conjugado calcular la relative affine structure como:

$$
\gamma^{k}=\frac{\left(m_{2}^{k} \times e_{21}\right)^{T} \cdot\left(H_{12} m_{1}^{k} \times m_{2}\right)}{\left\|m_{2}^{k} \times e_{21}\right\|^{2}} .
$$


- Especificar un nuevo epipolo $e_{31}$ y una nueva homografía $H_{13}$ y para cada par conjugado, calcular la nueva posición del pixel como:

$$
m_{3}^{k}=H_{13} m_{1}^{k}+e_{31} \gamma^{k} .
$$

El epipolo, $e_{31}$ y la homografía, $H_{13}$, se pueden obtener a partir de la matriz de proyección ideal de una nueva vista con un desplazamiento horizontal determinado. Por lo tanto, con el algoritmo anterior se pueden obtener las posiciones de cualquier número de vistas intermedias.

Una vez calculadas las posiciones de los píxeles en la vista interpolada, falta definir su color. Asumimos que se denomina $\lambda=0 . ., 1$, a la relación entra la distancia entre la vista virtual y el punto de vista de una de las imágenes originales, con la distancia entre las dos imágenes originales. La contribución de color se determina por la distancia del plano virtual a cada una de las imágenes originales. De este modo, si el color del pixel $m_{1}^{k}$ es $a$, y el color del píxel $m_{2}^{k}$ es $b$, el color en la imagen virtual se calcula como:

$$
C=(1-\lambda) * a+\lambda * b
$$

\subsection{Resultados experimentales}

Todos los experimentos se han realizado con el fin de visualizar un escenario real en el dispositivo XYZ 3D diseñado por la empresa Zero Creative. Se trata de una pantalla autoestereoscópica multivista con hojas lenticulares con una resolución de $1920 \times 1080$ píxeles y ocho vistas. Por ello, se ha utilizado un conjunto de 8 cámaras STINGRAY F-080B/C IEEE-1394b alineadas horizontalmente enfrente de la escena a capturar. La sincronización en la captura de las cámaras se ha realizado a través del bus 1394 y la resolución de las imágenes obtenidas es de $1024 \times 768$.

En el primer experimento realizado se han rectificado las imágenes obtenidas por las ocho cámaras y se han visualizado directamente en la pantalla autoestereoscópica consiguiendo una buena percepción 3D de la escena. Para generar la imagen entrelazada aceptada por el dispositivo autoestereoscópico, esta se construye de acuerdo a la distribución subpíxel de la pantalla utilizada. La vista entrelazada generada se muestra en la figura 2.9 .

La contribución principal se muestra en el segundo experimento, en el que algunas de las ocho vistas se han obtenido a partir de un algoritmo de construcción de vistas sintéticas. En particular se han sintetizado tres vistas intermedias utilizando el algoritmo en cuatro pasos descrito en los apartados anteriores. Como se muestra en la figura 2.10, las vistas 2, 4 y 6 son vistas obtenidas mediante el algoritmo de vistas sintéticas mientras que el resto son imágenes rectificadas de las capturas originales. 


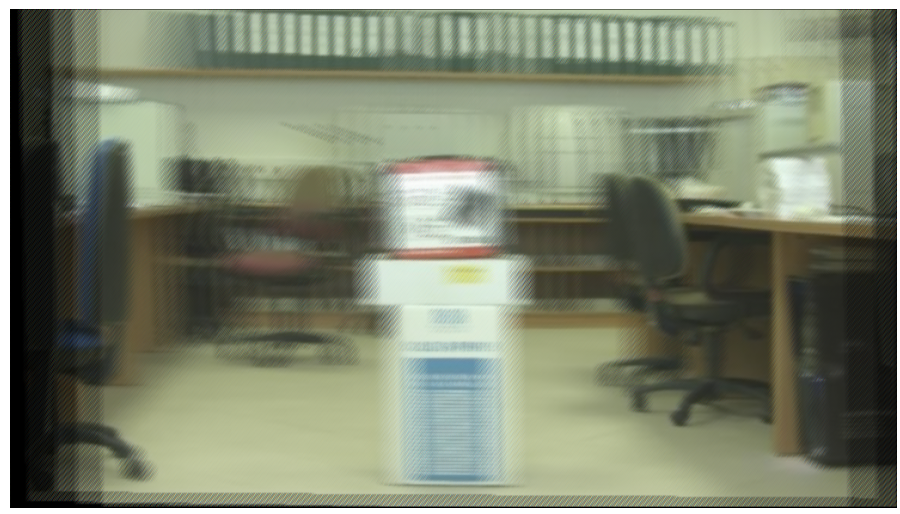

Figura 2.9: Imagen entrelazada aceptada por el dispositivo autoestereoscópico utilizado.

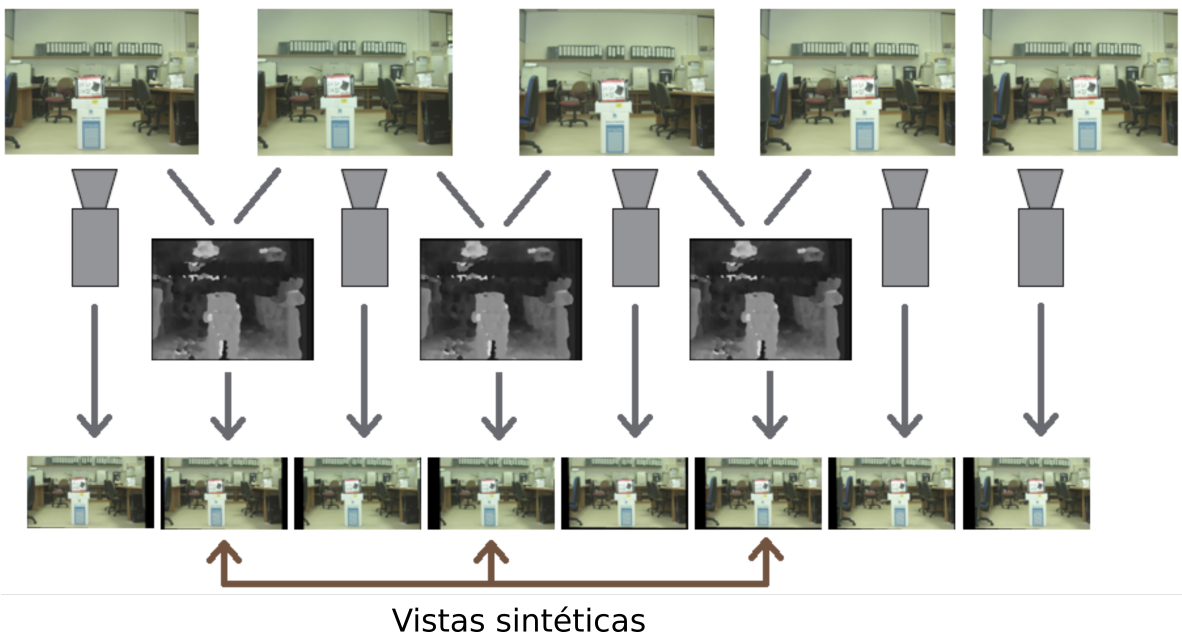

Figura 2.10: Descripción de la obtención de las 8 vistas de entrada necesarias para un dispositivo autoestereoscópico utilizando el algoritmo en 4 pasos descrito. A partir de 5 imágenes de la escena se sintetizan las vistas restantes.

Las vistas sintéticas obtenidas deberían coincidir con las de una cámara colocada en esa posición. Como en el apartado anterior se ha realizado la captura de las ocho cámaras, podemos comparar las imágenes obtenidas con nuestro algoritmo con las imágenes reales capturadas. En la figura 2.11 se muestra a la izquierda la vista real capturada y en el centro la vista sintética obtenida con nuestro método. La diferencia entre ambas imágenes se muestra en la última columna de la derecha. Esta imagen se ha obtenido utilizando el algoritmo estéreo propuesto por Lewis en [37. El color azul representa que no hay diferencia de color entre las dos imágenes mientras que el color rojo refleja que si la hay. Dado que las mayores diferencias aparecen en las zonas homogéneas de la escena, estos errores no se perciben fácil- 
mente por el usuario final y por lo tanto se obtiene una buena percepción 3D. El motivo de aparición de diferencias en estas zonas reside en que la correspondencia entre píxeles en zonas homogéneas suele ser complicada. Esto se debe a que la diferencia de intensidad en regiones cercanas de zonas homogéneas es muy pequeña. Sin embargo, para obtener mejores resultados, los mapas de disparidad se deberían mejorar utilizando por ejemplo técnicas de suavizado que reduzcan las inconsistencias encontradas.
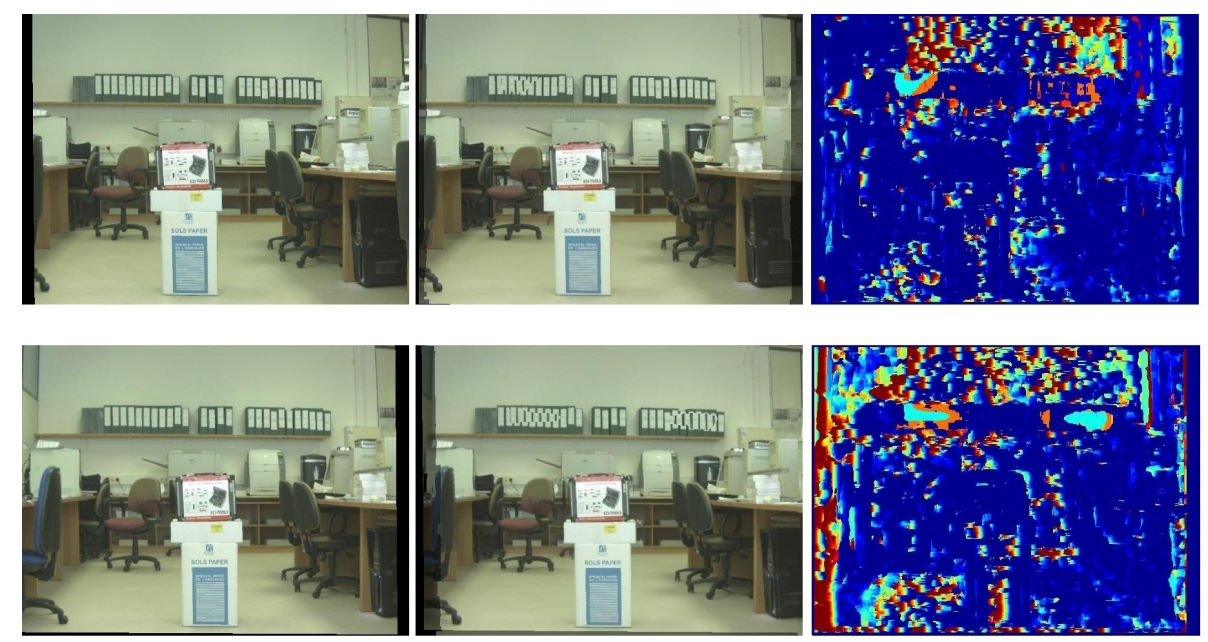

Figura 2.11: Vistas sintéticas obtenidas para dos cámaras vituales distintas. La primera columna muestra las imágenes reales capturadas por una cámara en la posición correspondiente. En la segunda columna se muestran las imágenes obtenidas con el algoritmo de vistas sintéticas propuesto. La última columna muestra la diferencia entre las dos imágenes anteriores. 


\section{Capítulo 3}

\section{Imagen 3D para reconocimiento de gestos}

The true mystery of the world is the visible, not the invisible.

Oscar Wilde, 1890

\section{Resumen:}

Existen multitud de tecnologías para la captura y la visualización de imágenes 3D. En este capítulo se estudian las posibilidades de imagen $3 \mathrm{D}$ con paralaje completo. En particular, se explora el potencial de utilizar imagen integral (Integral Imaging, II) para reconocimiento de gestos humanos en secuencias de vídeos grabados en escenas $3 \mathrm{D}$. Como estudio preliminar se utiliza una matriz de cámaras y un algoritmo apropiado de reconstrucción 3D de la escena. Dado que esta tecnología presenta ventajas frente a los sistemas monoculares, se exploran las posibilidades de esta misma disposición de cámaras en reconocimiento de acciones en entornos con oclusión. Estos resultados se comparan además con el comportamiento de sistemas que proporcionan información de rango como son las conocidas cámaras Kinect, que no solo tienen sensores que proporcionan imagen RGB sino que a dichas imágenes se les asocia un valor de profundidad (D). Los resultados de la comparación demuestran que la imagen integral para reconocimiento de acciones con oclusión, presenta mejores resultados que los sitemas monoculares o los datos RGB-D que proporciona la cámara Kinect. 


\subsection{Introducción}

Durante la última década, debido al amplio rango de aplicaciones, el reconocimiento de acciones y gestos ha sido uno de los campos más estudiados en visión por ordenador y aprendizaje automático [38-42]. Por otro lado, y como se ha comentado a lo largo de la tesis, la imagen $3 \mathrm{D}$ se ha utilizado en numerosas áreas y su investigación se encuentra en continua expansión. Una de las ventajas de la imagen $3 \mathrm{D}$ frente a las técnicas de imagen 2D tradicionales es su capacidad de capturar información estructural de los diferentes objetos que se encuentran en la escena. Esta ventaja permite, por ejemplo, segmentar más fácilmente partes de la escena basándose en la profundidad de las mismas, lo que permitirá eliminar ambigüedades en el reconocimiento de acciones.

Así pues, el objetivo de este estudio consiste en analizar las ventajas que ofrece un vídeo $3 \mathrm{D}$ frente a un vídeo $2 \mathrm{D}$ en la tarea de reconocimiento de acciones. Sin embargo, tal y como se ha comentado, existen multitud de soluciones a la hora de capturar y representar una imagen 3D. De toda la tecnología disponible, se propone la imagen integral como mejor solución para esta aplicación y se comparan los resultados con la tecnología que ha sido utilizada hasta el momento para este fin, la imagen con información de rango (range imaging).

Esta tecnología se ha popularizado recientemente tras la comercialización del sensor Microsoft Kinect, con el que es posible obtener información de profundidad en tiempo real de forma muy económica. Este sensor proporciona una imagen RGB con información de profundidad, D, lo que se conoce como RGB-D. En el área de reconocimiento de acciones y en la detección de partes del cuerpo, el número de estudios realizados utilizando la técnica de range imaging va en aumento 43. Sin embargo, aunque estos sistemas proporcionan información de profundidad que puede ayudar a eliminar algunas ambigüedades, no ofrecen la posibilidad de proporcionar imágenes con paralaje. El paralaje será clave en el reconocimiento de acciones o gestos parcialmente ocultos, ya que gracias al mismo será posible recuperar información de algunos objetos ocultos de la escena.

Por otro lado, la imagen integral resulta muy conveniente en esta aplicación por varios motivos. En primer lugar, se trata de un sistema que trabaja con luz incoherente o con luz ambiente, lo cual es necesario para muchas aplicaciones de reconocimiento de acciones. Además, la imagen integral, a diferencia de la imagen multivista descrita en el capítulo anterior, presenta tanto paralaje vertical como horizontal. Esta información es clave en aplicaciones de reconocimiento en la que las acciones pueden presentar oclusión en los dos ejes. Finalmente, la imagen integral ha demostrado ser una herramienta potente en varias tareas de reconstrucción o reconocimiento de objetos en condiciones de baja iluminación [44], en medios turbios 45 , o en presencia de oclusiones 46. 48. 
Así pues, el objetivo de este capítulo no es sólo demostrar que el vídeo 3D mejora los resultados de clasificación de gestos frente al vídeo $2 \mathrm{D}$, sino que además, de entre la tecnología de formación de imagen 3D, la imagen integral es más apropiada en esta aplicación. Con el fin de mostrar las ventajas de la imagen integral, la tarea de reconocimiento se realiza sobre tres tipos distintos de vídeos o secuencias de imágenes: vídeos 2D, vídeos obtenidos con la técnica de imagen integral y vídeos RGB-D capturados con la Kinect. En el primer apartado de experimentos se estudian las propiedades de reconocimiento de gestos usando imagen integral frente a imagen monocular. En el segundo apartado, se añade además oclusión y se compara el comportamiento con los vídeos RGB-D. Para ello, en los vídeos 3D, tanto de imagen integral como RGB-D, la tarea de reconocimiento se realiza sólo en la región de interés cercana al gesto a reconocer teniendo en cuenta la profundidad de la escena.

\subsection{Imagen integral}

La imagen integral (denominada en sus orígenes como fotografía integral) es un método autoestereoscópico de imagen 3D propuesto originalmente por G. Lippman en 1908 [49]. Los orígenes históricos de la imagen integral pueden vincularse a la aparición de la estereoscopía, ya que esta técnica se basa de nuevo en la captura y reproducción de imágenes con perspectivas ligeramente distintas. Así pues, se trata de un sistema pasivo de captura de imágenes 2D (referidas como imágenes elementales) a través de un conjunto de lentes. Cada una de estas lentes proporciona una imagen 2D de la escena 3D desde el punto de vista de la lente, en función de su posición y focal.

Para la captura de las imágenes elementales, Coffey propuso en 1935 utilizar lo que a día de hoy se conoce como matriz de microlentes [50. La primera cámara de imagen integral para la comercialización la propuso Gruetzner en 1953 [51, pero no fue hasta los años 80 cuando resurgió el interés por la imagen integral [52 54 ]. Más tarde, en 1991, Adelson y Bergen definieron el concepto de función plenóptica. Esta función describe formalmente toda la información visible a través de cualquier punto de vista y en cualquier dirección de visualización. En 1992, Adelson y Wang utilizaron esta definición para proponer la primera cámara plenóptica, que no es más que una cámara de imagen integral como la propuesta por Coffey, pero descrita a partir de la función plenóptica. En 1996 la función plenóptica descrita por Adelson fue rebautizada por Levoy con el nombre de campo de luz (light field) [55] y por Gortler como Lumigraph [56]. Además, en lugar de una matriz de microlentes, Levoy y Gortler propusieron utilizar una cámara que se desplaza a múltiples posiciones para capturar distintas perspectivas de la escena. En esta tesis se propone un sistema de captura con varias cámaras para conseguir más paralaje que con una cámara de imagen integral con matriz de microlentes. 
Una vez se diseña un sistema de captura, la información se puede utilizar para reconstruir un modelo 3D o para reproducirla en algún dispositivo de visualización. En primer lugar, se pueden utilizar pantallas con microlentes de forma que un observador sólo sea capaz de ver, según la posición de sus ojos, el área perteneciente a la escena que vería desde dicha posición. Estas son las pantallas autoestereoscópicas multivista de las que se ha hablado en el capítulo anterior, pero en esta ocasión, con lentes esféricas que proporcionan tanto paralaje horizontal como vertical. La figura 3.1 ilustra el principio de imagen integral tanto para el proceso de adquisición como de reproducción.

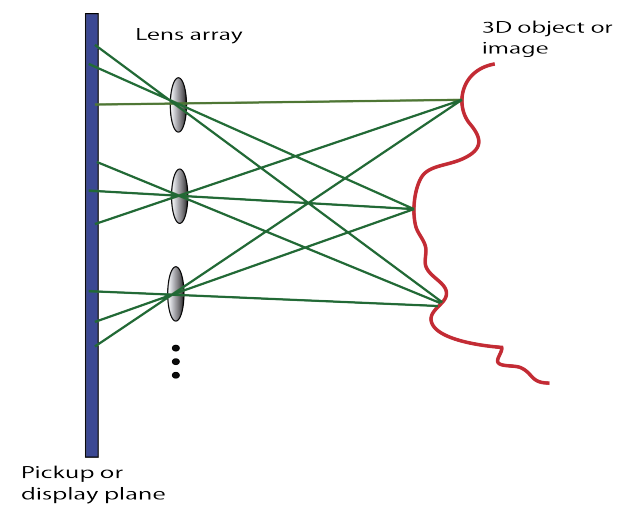

Figura 3.1: Principio de captura y reproducción de imagen integral. La información de profundidad se traduce en un desplazamiento entre las diferentes vistas de la escena, conocidas como imágenes elementales.

En segundo lugar, a partir de las imágenes elementales se pueden utilizar varios algoritmos de reconstrucción de la escena 3D que obtienen información de profundidad a partir del desplazamiento de la escena en cada imagen. Una solución consiste en simular la retroproyección de cada una de las imágenes elementales de forma computacional. En particular, se utiliza una matriz virtual de pinholes para hacer un mapeado inverso de las imágenes elementales al espacio objeto (Fig. 3.2). De este modo, diferentes superposiciones de las imágenes elementales, proporcionan la reconstrucción de objetos a distintas profundidades de la escena 3D de la siguiente forma:

$$
\begin{gathered}
I(x, y, z)=\frac{1}{O(x, y)} \cdot \sum_{k=0}^{K-1} \sum_{l=0}^{L-1} E_{k l}\left(x^{\prime}, y^{\prime}\right), \\
x^{\prime}=x-k \frac{N_{x} \cdot p}{s_{x} \cdot M}, \quad y^{\prime}=y-l \frac{N_{y} \cdot p}{s_{y} \cdot M},
\end{gathered}
$$

donde $I(x, y, z)$ representa la intensidad de la imagen $3 \mathrm{D}$ reconstruida a profundidad $z$ en la posición $x, y ; O(x, y)$ es la matriz que representa el número de imágenes elementales que contribuyen a cada posición $x, y$, es decir, es la matriz que indica el número de cámaras que se solapan; $E_{k l}$ representa la intensidad de la imagen 


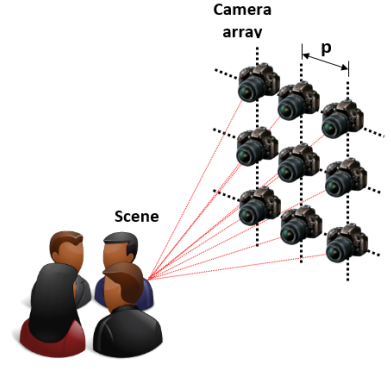

(a) Captura

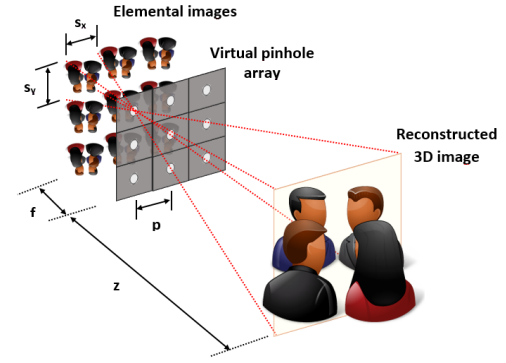

(b) Reconstrucción

Figura 3.2: Adquisición y reconstrucción de imagen integral con apertura sintética. (a) Una matriz de cámaras adquiere imágenes de la escena con distintas perspectivas. (b) A partir de la superposición de las imágenes capturadas se reconstruye la escena $3 \mathrm{D}$.

elemental adquirida por la cámara $k, l$ del array; $p$ es la distancia en milímetros entre centros ópticos de dos cámaras contiguas; $N_{x} \times N_{y}$ es el tamaño en píxeles de las imágenes elementales; $M=\frac{z}{f}$ es el factor de aumento y $s_{x} \times s_{y}$ es el tamaño físico del sensor de la cámara.

Existen otras alternativas para representar una imagen 3D a partir de imágenes elementales. Sin embargo, en esta aplicación de reconocimiento de acciones, el objetivo principal consiste en utilizar la información de profundidad para obtener mejores resultados en la clasificación, al utilizar únicamente la información proveniente de la profundidad a la que se encuentra la acción. Esto se consigue tras la segmentación en profundidad. El proceso de segmentación sonsiste en dividir la escena en planos a distintas profundidades. Por ello, la representación propuesta es más adecuada, ya que de esta forma, sólo utilizamos las reconstrucciones de las imágenes integrales a la profundidad en la que se encuentra el gesto en foco.

\subsection{Imágenes con información de rango}

Gracias a su bajo coste y fácil manejo, el sensor RGB-D Kinect es uno de los sensores más utilizados en la actualidad para la obtención de información 3D. Este sistema, lanzado por la compañía Microsoft en 2011, utiliza una cámara RGB y un sensor de profundidad para obtener una imagen en color de la escena con información de profundidad para cada píxel (RGB-D). El sensor de profundidad está formado por dos componentes, un emisor y un receptor de luz infrarroja, que mediante la técnica de luz estructurada obtiene información 3D de la escena.

Existen multitud de técnicas de luz estructurada. Todas consisten en proyectar un patrón de luz conocido y ver cómo este se deforma, para inferir la información 3D de los objetos de la escena. En el caso del sensor de profundidad de Kinect 
[57, 58, se utiliza la proyección de un patrón conocido de puntos aleatorios (un patrón de speckle). En la unidad de control del sistema se incluye un conjunto de imágenes del patrón proyectado a distintas profundidades. Comparando las imágenes de referencia con la imagen del patrón sobre la escena a analizar, se pueden inferir las profundidades de los objetos en la escena. Aunque existen dos versiones distintas del dispositivo Kinect, todos los experimentos realizados en este capítulo se han hecho con el sensor Kinect v1.

Como en el caso de imagen integral sólo se utiliza la reconstrucción en profundidad en la que el gesto aparece enfocado, tenemos que proponer una solución similar para el sensor RGB-D en el que se descarten los objetos de la escena que no se encuentren a la profundidad en la que está el gesto. Por ello, los puntos de interés detectados en las imágenes RGB capturadas por la cámara Kinect se filtran de forma que sólo permanecen aquellos puntos de interés que se mantienen dentro de las regiones con profundidades similares a la profundidad en la que se encuentra el gesto.

\subsection{Reconocimiento de acciones}

Como ya se ha comentado, el reconocimiento de acciones y gestos ha sido un tema muy estudiado en los últimos años. Un tema de investigación implícito en el anterior es el análisis e interpretación de vídeos, ya que para poder reconocer una acción es necesario localizar dicho gesto en un conjunto de frames.

En este caso, el procedimiento para el reconocimiento de acciones utilizado sigue un enfoque tradicional de Bag of visual Words (BoW) 59 con las siguientes fases:

- (1) Detección de descriptores en los vídeos.

- (2) Cuantización de los descriptores en palabras.

- (3) Generación de bolsas de palabras para cada vídeo.

- (4) Clasificación de vídeos a partir de las bolsas de palabras.

En la figura 3.3 se muestran gráficamente estas cuatro etapas. En el primer paso se utiliza un detector de puntos característicos. En el caso de una imagen, estos puntos característicos suelen ser bordes, mientras que en un vídeo, no sólo se tendrá en cuenta el color, sino también el movimiento. Estos puntos de interés detectados serán los descriptores característicos de cada una de las imágenes o vídeos. A continuación, el algoritmo agrupa los descriptores en un número determinado de clusters (grupos). En la figura 3.3 los descriptores se han agrupado en cinco clusters distintos. El centro de cada cluster representa una característica o palabra. Del mismo modo que un humano utiliza distintas palabras para describir un objeto o vídeo, en este caso cada vídeo o imagen de entrada se describe a partir de un conjunto de palabras. Así pues, el tercer paso del algoritmo consiste en generar una bolsa de palabras para cada vídeo. Estas bolsas de palabras no son más que histogramas en los que el eje horizontal representa las diferentes palabras o clusters y el eje vertical 
el número de veces que se repite cada palabra. De este modo, cada uno de los vídeos de entrada se describe a partir de un histograma de palabras. Finalmente, el último paso consiste en clasificar los vídeos a partir de las bolsas de palabras. Para ello, se asigna manualmente una etiqueta a cada vídeo o imagen. En la figura 3.3 se asignan las etiquetas barco, taza y gorro. Seguidamente, a partir de una nueva imagen o vídeo, el algoritmo predice a cuál de estos tres grupos pertenece. Finalmente, a partir del número de aciertos o fallos en la predicción, se determina un porcentaje de acierto en la clasificación.

A continuación pasan a describirse formalmente cada una de estas etapas según el algoritmo utilizado en cada caso.

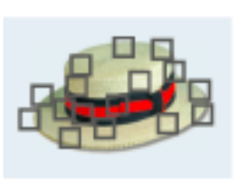

(1)

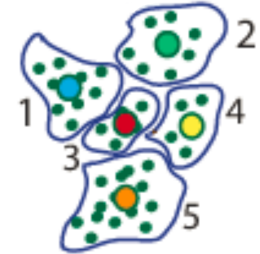

(2)

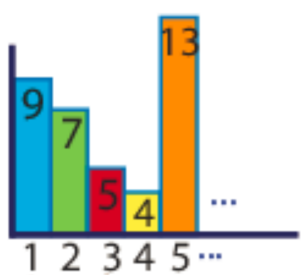

(3)

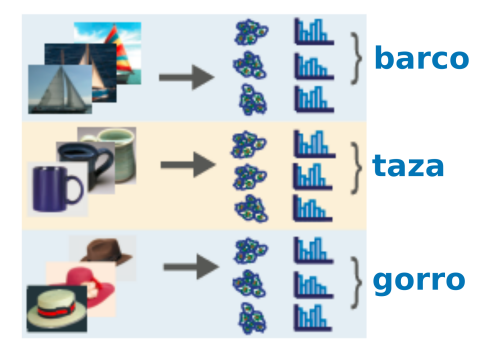

(3)

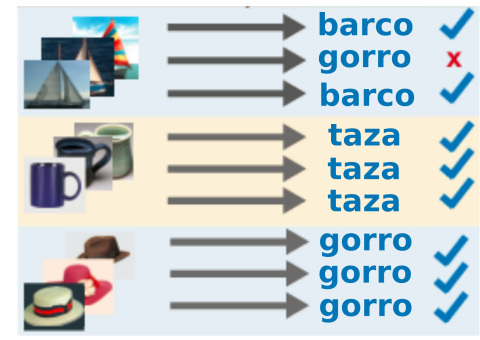

(4)

Figura 3.3: Esquema del procedimiento de reconocimiento utilizando el enfoque tradicional de Bag of visual Words (BoW).

\subsubsection{Detección de descriptores en los vídeos}

En primer lugar, a partir de los videos capturados se han de detectar los descriptores a través de los denominados puntos de interés espacio-temporales (SpatioTemporal Interest Points, STIPs). Para ello se sigue la idea descrita en [60] utilizando el código de Ivan Laptev disponible en 61. La idea principal del algoritmo es considerar los vídeos como volúmenes $3 \mathrm{D}(x, y, t)$. Los puntos pertenecientes a este volumen se caracterizan localmente utilizando un histograma de gradientes (Histogram Of Gradients, HOG) y/o un histograma de flujo óptico (Histogram Of Flow, HOF) dentro de una región del volumen 3D. En el domino espacial, se consideran puntos de interés aquellos que presentan una variación de intensidades significativa, mientras que en el dominio temporal, serán aquellas regiones que presentan un 
patrón de movimiento aparente.

Este descriptor funciona para vídeos 2D que no tienen en cuenta la profundidad de sus objetos. Como ya se ha adelantado, en este estudio se van a comparar los resultados de clasificación de vídeos $2 \mathrm{D}$, vídeos de imagen integral y vídeos RGBD. Para la detección de descriptores en el caso de vídeos de imagen integral y RGB-D, se fija la dimensión $z$ a la profundidad en la que el gesto se encuentra en foco, y se detectan los STIPS teniendo en cuenta esta restricción. La elección de la dimensión $z$ se realiza manualmente para cada uno de los usuarios y se considera la misma profundidad tanto para los vídeos sin oclusión como con oclusión. Así pues, a partir de los vídeos segmentados con profundidades cercanas al gesto, el volumen $3 \mathrm{D}(\mathrm{x}, \mathrm{y}, \mathrm{t})$ correspondiente a la secuencia de imágenes $f: \mathbb{R}^{3} \rightarrow \mathbb{R}$, se convoluciona con un filtro Gaussiano anisotrópico, tal y como se describe en [60]:

$$
\begin{gathered}
L\left(\cdot ; \sigma_{l}^{2}, \tau_{l}^{2}\right)=g\left(\cdot ; \sigma_{l}^{2}, \tau_{l}^{2}\right) * f(\cdot), \\
g\left(x, y, t ; \sigma_{l}^{2}, \tau_{l}^{2}\right)=\frac{1}{\sqrt{(2 \pi)^{3} \sigma_{l}^{4} \tau_{l}^{2}}} \cdot e^{-\frac{x^{2}+y^{2}}{2 \sigma_{l}^{2}}-\frac{t^{2}}{2 \tau_{l}^{2}}},
\end{gathered}
$$

donde $x, y, t$ se refieren a las dos dimensiones espaciales y la dimensión temporal y $\sigma_{l}^{2}, \tau_{l}^{2}$ son las varianzas en la escala espacial y temporal respectivamente. En el dominio espacial, la idea consiste en encontrar puntos con cambios significativos en ambas direcciones. Además, el uso de un parámetro de escala temporal es esencial, ya que los eventos temporales y espaciales son en general independientes. Para una determinada escala de observación $\sigma_{l}^{2}$, estos puntos de interés se pueden encontrar utilizando un tensor estructural (structure tensor), que se define a partir de una matriz $3 \times 3$ compuesta por derivadas parciales espaciales y temporales de primer orden, promediada utilizando una función de ponderación Gausiana $g\left(\cdot ; \sigma_{i}^{2}, \tau_{i}^{2}\right)$ con varianza $\sigma_{i}^{2}$ :

$$
\mu=g\left(\cdot ; \sigma_{i}^{2}, \tau_{i}^{2}\right) *\left(\begin{array}{ccc}
L_{x}^{2} & L_{x} L_{y} & L_{x} L_{t} \\
L_{x} L_{y} & L_{y}^{2} & L_{y} L_{t} \\
L_{x} L_{t} & L_{y} L_{t} & L_{t}^{2}
\end{array}\right)
$$

con $\sigma_{i}^{2}=s \sigma_{l}^{2}$ y $\tau_{i}^{2}=s \tau_{l}^{2}$ para una $s$ dada. Además, las derivadas parciales se definen como:

$$
\begin{aligned}
& L_{x}\left(\cdot ; \sigma_{l}^{2} ; \tau_{l}^{2}\right)=\partial_{x}(g * f), \\
& L_{y}\left(\cdot ; \sigma_{l}^{2} ; \tau_{l}^{2}\right)=\partial_{y}(g * f), \\
& L_{t}\left(\cdot ; \sigma_{l}^{2} ; \tau_{l}^{2}\right)=\partial_{t}(g * f),
\end{aligned}
$$

Finalmente, de las distintas aproximaciones para encontrar regiones de interés, en este método se utiliza una función inspirada en el detector de esquinas de Harris 62. Para ello, se define la función $H$ como:

$$
H=\operatorname{det}(\mu)-k \operatorname{trace}{ }^{3}(\mu) .
$$


El máximo local de $H$ identifica los puntos de interés espacio-temporales de $f$, por ejemplo, aquellos que presentan grandes variaciones tanto en el domino espacial como en el dominio temporal. A este algoritmo se le conoce como detector de Harris 3D. A continuación le sigue un proceso de multi-escalado con escalas $\left\{\sigma_{l}=2^{\frac{l+1}{2}}: l \in\{1,2, \cdots, 6\}\right\}$ y $\left\{\tau_{l}=2^{l}: l \in\{1,2\}\right\}$. Esto permite detectar puntos de interés a diferentes resoluciones.

\subsubsection{Cuantización de los descriptores en palabras}

Los descriptores resultantes se han de cuantizar en palabras, en nuestro caso a través de un método de clustering sin supervisión utilizando el algoritmo k-means 63] disponible en la librería VLFeat 64. El objetivo consiste pues en asignar los puntos de interés a un número determinado de clusters (grupos) de forma que cada uno de los puntos pertenece al grupo cuyo centroide es más cercano. De este modo, dados $n$ puntos $\left\{\boldsymbol{x}_{i}\right\}_{i=1}^{n}$, el objetivo del algoritmo $k$-means es encontrar la agrupación de esos puntos en $K$ grupos $\left\{C_{j}\right\}_{j=1}^{K}$ de forma que se minimice la suma de las distancias de cada punto a la media de su grupo $\left(\boldsymbol{\mu}_{i}\right)$. Por lo tanto, se trata de minimizar:

$$
\sum_{j=1}^{K} \sum_{\boldsymbol{x}_{i} \in C_{j}}\left\|\boldsymbol{x}_{i}-\boldsymbol{\mu}_{j}\right\|^{2} .
$$

Dado que el problema de optimización es muy complejo, $k$-means utiliza una estrategia para actualizar iterativamente el centro de los clusters, asignándole a cada punto su cluster más cercano repetidamente hasta que converge.

En el problema de clasificación de un conjunto de datos existen muestras de entrenamiento y de test. En nuestro caso, los STIPs de los vídeos del subconjunto de entrenamiento son los que se utilizan para encontrar los clusters. Una vez definidos el número total de clusters del conjunto, a cada STIP, tanto del subconjunto de entrenamiento como el de test, se le asigna un cluster. Finalmente, cada cluster representa una palabra, con lo que finaliza el proceso de cuantización de los descriptores en palabras.

Sin embargo, dado que los resultados del algoritmo de $k$-means son dependientes de la inicialización, se ejecuta el algoritmo cinco veces con los mismos datos, con el fin de utilizar el resultado de clustering con el que se obtenga una energía mínima (mínimo valor de la Eq. 3.4.5.

\subsubsection{Generación de bolsas de palabras para cada vídeo}

Una vez se le ha asignado una palabra a cada punto de interés hay que calcular la bolsa de palabras (Bag of Words, BoW) de cada vídeo, es decir, cuántas veces aparece cada cluster en dicho vídeo. Para ello, siguiendo el enfoque tradicional de 
BoW, cada vídeo se representa utilizando un histograma de palabras [59]. Este histograma está compuesto por $K$ valores distintos, siendo $K$ el número de clusters asignados en el procedimiento anterior. Formalmente, si $\left\{\boldsymbol{x}_{i}\right\}_{i=1}^{n}$ son los descriptores de $n$ STIPs detectados en un vídeo, y $\left\{\boldsymbol{\mu}_{j}\right\}_{j=1}^{K}$ los centros de los $K$ clusters encontrados tras aplicar el algoritmo de $k$-means a los vídeos de entrenamiento, entonces el histograma $\left\{\boldsymbol{h}_{j}\right\}_{j=1}^{K}$ de dicho vídeo se obtiene siguiendo la siguiente fórmula:

$$
\boldsymbol{h}_{j}=\sum_{i=1}^{n}\left[c\left(\boldsymbol{x}_{i}\right)=j\right], \quad j \in\{1,2, \ldots, K\}
$$

siendo [·] la notación de los corchete Iverson para la función de delta de Kronecker. Esta notación de Iverson indica un número que es 1 si la condición entre corchetes se cumple, y 0 en caso contrario. Además, $\boldsymbol{h}_{j}$ es la $j$-ésima barra del histograma $\boldsymbol{h}$, y $c(\boldsymbol{x})$ se corresponde con el cluster más cercano al punto $\boldsymbol{x}$ :

$$
c(\boldsymbol{x})=\arg \operatorname{mín}_{i \in\{1, \ldots, K\}}\left\|\boldsymbol{x}-\boldsymbol{\mu}_{i}\right\|^{2} .
$$

De este modo, se asigna un histograma a cada vídeo que se conoce como bolsa de palabras y que representa a dicho vídeo. A partir de la información de las palabras que hay para cada cluster, se podrá realizar una clasificación de los vídeos.

\subsubsection{Clasificación de vídeos a partir de las bolsas de pala- bras}

Para la validación del proceso de clasificación de gestos a partir de las bolsas de palabras se utiliza el protocolo leave-one-subject-out, dado que se trata de una elección muy común cuando el número de muestras es limitado [65, 66]. Este protocolo consiste en reconocer los gestos de un usuario tras entrenar al algoritmo con los gestos del resto de usuarios. De este modo, dados $S$ usuarios, las bolsas de palabras de todos los vídeos de un usuario permanecen como conjunto de test, mientras que el resto de vídeos de los $S-1$ usuarios restantes sirven como entrenamiento. Este proceso se repite $S$ veces, una por cada usuario. De este modo se obtiene la precisión en la clasificación para cada uno de los usuarios.

El algoritmo de clasificación utilizado es el Support Vector Machine (SVM) 67]. Estos algoritmos son ampliamente utilizados por sus habilidad de generalización gracias a la formulación max-margin. Esta formulación busca un hiperplano con la mayor distancia (margen) al punto más cercano al mismo. En la figura 3.4 se observa como, aunque tanto $H_{1}$ como $H_{2}$ separan las dos clases, sólo el hiperplano $H_{1}$ lo hace con el margen máximo, por lo que será la mejor solución según el algoritmo SVM. Formalmente, dado un conjunto de entrenamiento $\left\{\left(\boldsymbol{x}_{i}, y_{i}\right): \boldsymbol{x}_{i} \in \mathbb{R}^{d}, y_{i} \in\right.$ $\{-1,1\}\}_{i=1}^{n}$ con puntos $\boldsymbol{x}_{i}$ y sus correspondientes etiquetas de clase $y_{i}$, el algoritmo SVM tiene como objetivo resolver: 


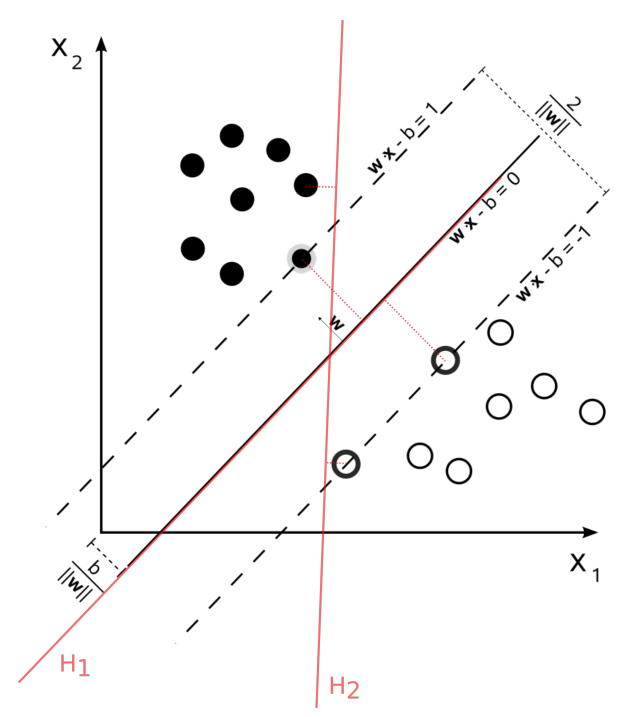

Figura 3.4: Infinitos hiperplanos dividen los dos grupos. $H_{2}$ los separa, pero sólo con un margen pequeño, sin embargo, $H_{1}$ los separa con el margen máximo.

$$
\arg \min _{\boldsymbol{w}, \boldsymbol{\xi}, b} \quad \frac{1}{2}\|\boldsymbol{w}\|^{2}+C \sum_{i=1}^{n} \xi_{i}
$$

sujeto a

$$
y_{i}\left(\boldsymbol{w} \cdot \boldsymbol{x}_{i}-b\right) \geq 1-\xi_{i}, \quad \xi_{i} \geq 0
$$

donde $(\boldsymbol{w}, b)$ son los parámetros que se aprenden a partir de los datos de entrada. $\frac{1}{\|\boldsymbol{w}\|}$ determina el margen alrededor del límite de decisión que ha de ser maximizado, $\boldsymbol{\xi}=\left\{\xi_{i}\right\}_{i=1}^{n}$ son las llamadas variables de holgura (slack) que representan los errores en la clasificación, y $C$ es un parámetro de regularización que permite una solución equilibrada con un gran margen (buena generalización) pero sin embargo con pocas clasificaciones erróneas (buen ajuste a los datos de entrenamiento). Así pues, este parámetro $C$ controla la compensación entre errores de entrenamiento y los márgenes. La clase predicha, $\hat{y}$, para una nueva entrada $\boldsymbol{x}, \hat{y}(\boldsymbol{x})$, se encuentra a través de los parámetros aprendidos $(\boldsymbol{w}, b)$ con la función de decisión $\hat{y}(\boldsymbol{x})=\operatorname{sign}\left(\boldsymbol{w}^{T} \boldsymbol{x}+b\right)$.

Este algoritmo de clasificación se puede extender para un mayor número de clases. En particular en los experimentos realizados se utiliza el método SVM lineal multi-clase disponible en [68. El parámetro de regularización $C$ en la ecuación 3.4 .8 se elige a través de la validación del valor en un rango entre $10^{-4}$ y $10^{4}$ con el que se obtiene una mayor precisión. En cada ronda de validación, cuando se entrena con $S-1$ usuarios, $S-2$ usuarios se utilizan para entrenamiento y el resto para test. 
Dada la naturaleza aleatoria del algoritmo $k$-means, tanto la cuantización de los descriptores como el aprendizaje y predicción se repite en 10 ocasiones. Los datos que se muestran son, por tanto, el promedio en la clasificación obtenida en las 10 repeticiones.

\subsection{Resultados experimentales}

Como se ha señalado, el objetivo ha sido en una primera fase explorar el reconocimiento de acciones en imagen integral y, posteriormente, demostrar sus beneficios frente a otras alternativas de adquisición de vídeos. Para ello, se ha aplicado el esquema de bolsa de palabras tanto para los vídeos de imagen integral como para los vídeos RGB-D y vídeos "monoculares" provenientes de una sola cámara y sin información de profundidad de la escena.

Con el fin de explorar las capacidades de utilizar imagen integral en el reconocimiento de gestos se realizan dos experimentos. En el primer experimento se crea una base de datos de los vídeos grabados a un grupo de usuarios que se coloca frente a un array de 9 cámaras como el que se muestra en la figura 3.5a. En el segundo experimento, los gestos de los usuarios se graban también con el sensor de la cámara Kinect, siguiendo la disposición de los sensores que muestra la figura $3.5 \mathrm{~b}$. En ambos experimentos se obtienen vídeos de usuarios distintos realizando tres gestos diferentes. Cada uno de estos gestos se repite además dos veces por cada usuario. Para realizar los gestos, los usuarios se colocan a una distancia aproximada de $2.5 \mathrm{~m}$ de las cámaras, con el brazo derecho extendido. Con la mano del brazo extendido se realizan tres gestos a los que denominamos abrir, izquierda y negación. El primer gesto consiste en abrir y cerrar la mano con la palma apuntando al suelo; el segundo, en abrir y cerrar la mano con la palma apuntando a la izquierda y perpendicular al suelo y por último, la tercera acción se corresponde con el gesto de negación realizado con el dedo índice. Las grabaciones se realizan en un laboratorio en el que, aparte del movimiento del gesto del usuario, no existe ningún otro movimiento. Además, los gestos de un usuario son capturados al mismo tiempo utilizando el array de 9 cámaras y el sensor Kinect. Algunos vídeos de ejemplo de los tres tipos de gestos anteriores, así como información detallada de la base de datos se ha publicado en la siguiente dirección web: http://www.vision.uji.es/II-hand-gestures/

Para la adquisición de los vídeos de imagen integral se utiliza un array de $3 \times 3$ cámaras Stingray F080B/C. La sincronización de las 9 cámaras, al igual que en el capítulo anterior, se ha realizado a través del bus 1394, y en este caso, la velocidad de captura de los vídeos ha sido de 15 frames por segundo. Como en el caso anterior, la resolución de las cámaras utilizadas es de $1024 \times 768$ píxeles. Además, para eliminar errores generados por los pequeños desajustes en la colocación de las cámaras, se ha utilizado el algoritmo de rectificación de múltiples cámaras desarrollado en el capítulo anterior (Sección 2.2.2). Sin embargo, en el caso anterior las cámaras 


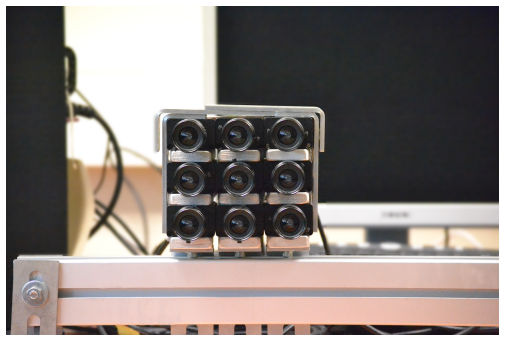

(a) Sensores utilizados en el primer experimento.

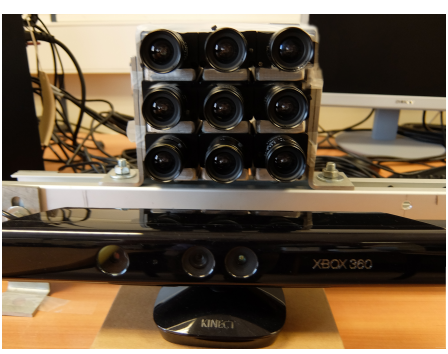

(b) Sensores utilizados en el segundo experimento.

Figura 3.5: Sensores utilizados para crear dos bases de datos. La primera base de datos incluye vídeos de un grupo de usuarios realizando acciones frente a los sensores de la figura $3.5 \mathrm{a}$ La segunda base de datos está formada por un conjunto de vídeos de un grupo distinto de usuarios que realizan las mismas acciones frente a los sensores de la figura $3.5 \mathrm{~b}$

estaban dispuestas en un array horizontal, mientras que ahora la disposición es en forma matricial. De este modo, el único parámetro que varía respecto al capítulo anterior es la matriz de traslación de la ecuación 2.2.10. En este caso, la matriz $T_{\text {ideal }}$ para cada una de las $n$ cámaras, sigue una distribución $3 \times 3$ con la misma separación horizontal y vertical entre cámaras.

Tras el proceso de rectificación, las imágenes capturadas con el array de 9 cámaras son las que se muestran al centro de la figura 3.6. Una vez rectificadas, se sigue el algoritmo de reconstrucción de imagen integral descrito anteriormente (Sección 3.2). A partir de las 9 imágenes elementales se crea un volumen 3D con el que es posible reconstruir en foco únicamente los objetos que se encuentran a una determinada profundidad. Esto se consigue utilizando la fórmula 3.2.1. con la que se puede reconstruir una imagen distinta por cada plano en profundidad. En cada una de estas imágenes únicamente aparece en foco el plano que se encuentra a la profundidad seleccionada, mientras que el resto de la imagen aparece desenfocada.

Para una mejor visualización, las imágenes de la derecha de la figura 3.6 se muestran de nuevo en la tabla 3.1. Se trata de las 3 imágenes correspondientes a la reconstrucción de la imagen integral de un mismo gesto en tres planos distintos. Como muestra la figura 3.6. las tres imágenes se han obtenido de un mismo array de 9 imágenes elementales, es decir, se corresponden con la misma acción de un mismo usuario. En cada uno de los tres planos, sólo una parte de la escena está en foco mientras que el resto aparece desenfocado. En la primera imagen de la tabla ?? el fondo aparece enfocado, en la segunta imagen la cara del usuario, mientras que en la tercera se enfoca la mano del mismo. Esto muestra la capacidad de segmentado que presenta la imagen integral y que puede ser útil a la hora de reconocer un gesto ya que las partes enfocadas de la imagen aportan más información. Por último, 


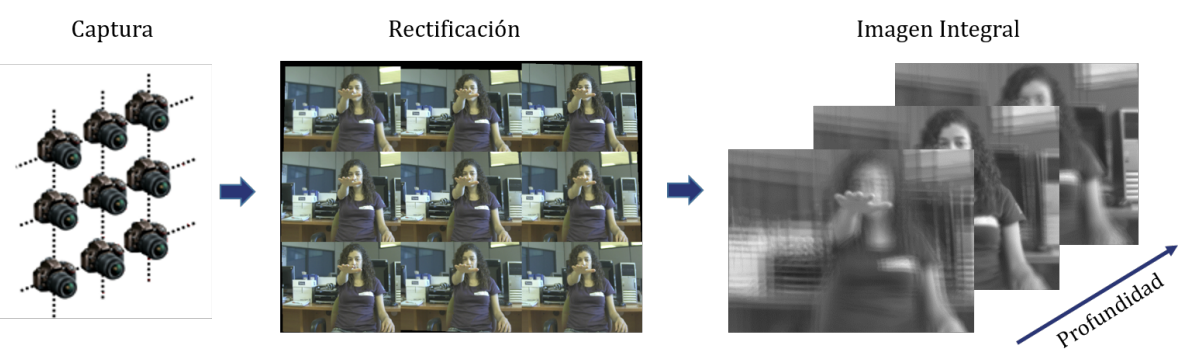

Figura 3.6: Esquema de obtención de imágenes enfocadas a distintas profundidades para un gesto de un usuario.

en la tabla 3.2 se muestra un ejemplo de escena de imagen integral en el que sólo se encuentra enfocada la mano de otro usuario para los tres gestos distintos que realiza. Estos son los vídeos que se utilizan en imagen integral para la tarea de reconocimiento de gestos.

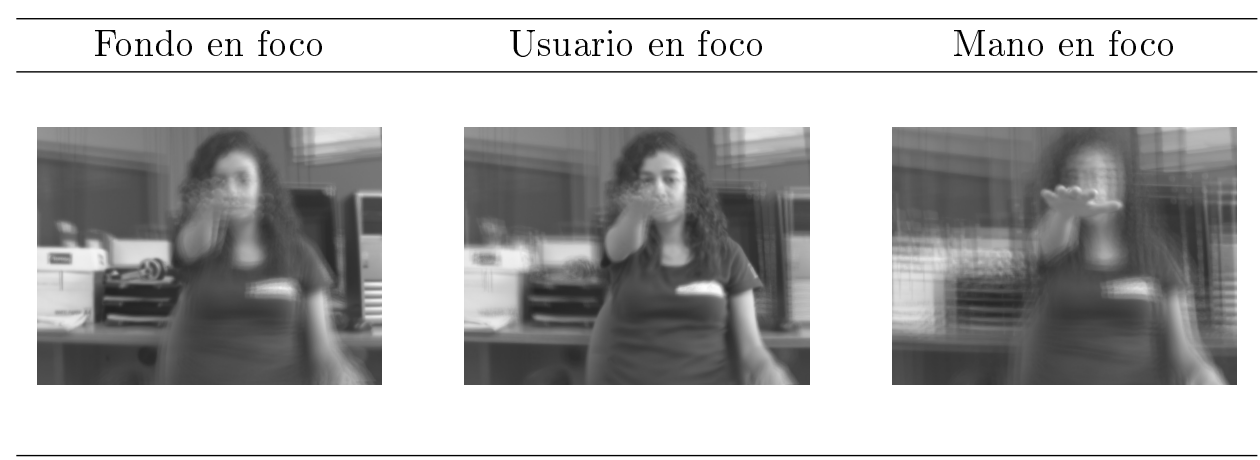

Tabla 3.1: Reconstrucción en profundidad con imagen integral.

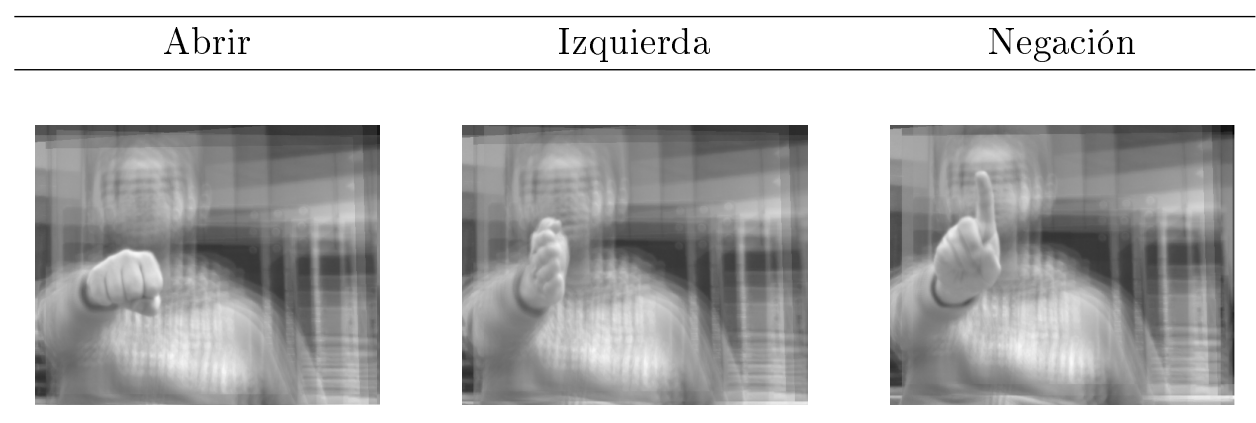

Tabla 3.2: Conjunto de gestos tras el seccionado conseguido con imagen integral. 
Para obtener los vídeos de la cámara Kinect se ha utilizado el software disponible en [69]. A partir de la secuencia de imágenes que proporciona el software anterior se obtienen dos tipos de vídeos, vídeos RGB (tabla 3.3) y vídeos en escala de grises con información de profundidad (Fig. 3.7).

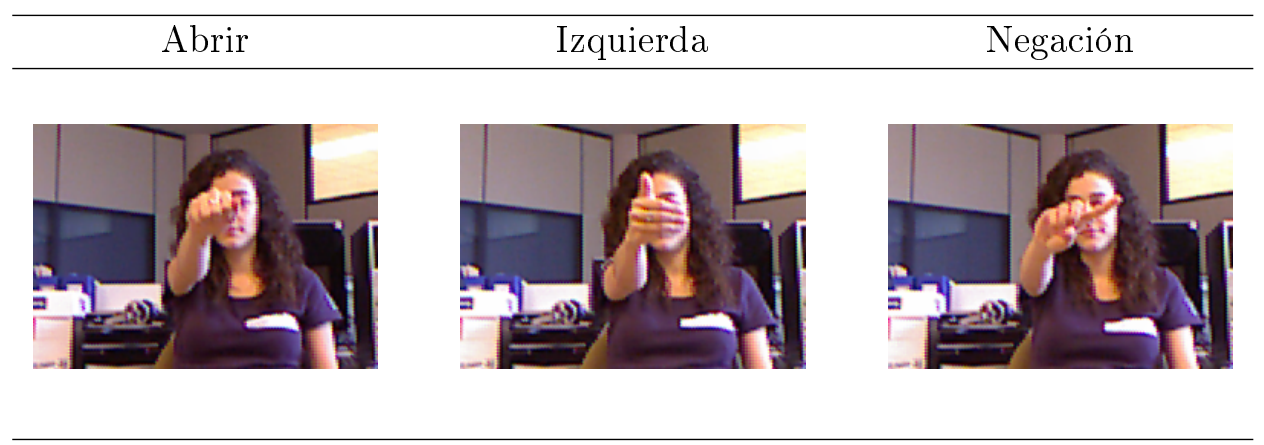

Tabla 3.3: Conjunto de gestos capturados por la cámara RGB del sensor Kinect.

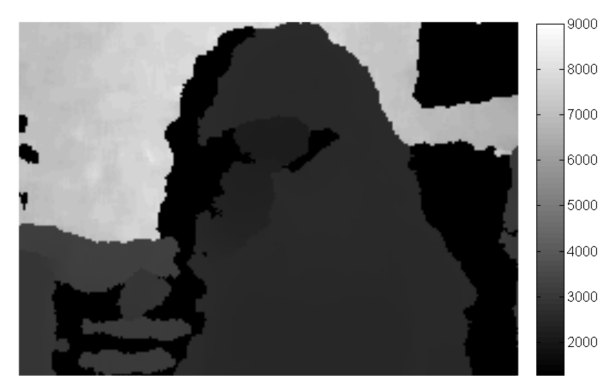

Figura 3.7: Información de profundidad capturada con el sensor de profundidad de la cámara Kinect. La profundidad viene expresada en mm.

En las siguientes secciones se estudian, en primer lugar, las ventajas de reconocimiento de gestos de imagen integral frente a los resultados de reconocimiento utilizando únicamente la cámara central. A continuación, se amplía el estudio con nuevos usuarios cuyos gestos se obtienen no sólo con la técnica de imagen integral y una sola cámara, sino también con el sensor de Kinect RGB-D. Además, se estudian los resultados de clasificación de las tres modalidades con gestos en presencia de oclusión.

\subsubsection{Imagen integral vs imagen monocular}

Para comparar los resultados de reconocimiento de gestos de imagen integral, frente a los obtenidos con una sola cámara se capturan los vídeos de los gestos descritos en la sección anterior para 10 usuarios distintos. Como se ha comentado en el apartado anterior, se utiliza un array de 9 cámaras (Fig. 3.5a) para formar la imagen integral con seccionado donde sólo el gesto aparece en foco y se utiliza 


\begin{tabular}{lccccc}
\hline \multicolumn{6}{c}{ Monocular } \\
\hline \multirow{6}{*}{ Descriptor $\nabla$} & 10 & 25 & 50 & 100 & 200 \\
\cline { 2 - 6 } & $70.1(4.2)$ & $81.5(5.1)$ & $88.7(3.4)$ & $90.9(3.5)$ & $92.6(2.0)$ \\
HOF & $66.4(5.0)$ & $75.2(4.1)$ & $76.8(5.4)$ & $76.3(3.7)$ & $78.0(4.4)$ \\
HOG + HOF & $64.0(5.2)$ & $78.7(6.8)$ & $84.7(3.1)$ & $86.2(2.8)$ & $89.1(3.1)$ \\
\hline \multicolumn{5}{c}{ Imagen integral } \\
\hline \multicolumn{6}{c}{ Número de palabras (K) } \\
Descriptor $\nabla$ \\
\cline { 2 - 6 } & 10 & 25 & 50 & 100 & 200 \\
\hline HOF & $48.0(4.0)$ & $66.2(5.0)$ & $73.3(4.1)$ & $78.8(3.7)$ & $82.3(4.2)$ \\
HOG & $74.7(4.6)$ & $84.3(4.1)$ & $84.2(3.5)$ & $84.5(4.9)$ & $85.1(3.8)$ \\
\hline
\end{tabular}

Tabla 3.4: Resultados de reconocimiento (\%) para las dos modalidades de vídeo y los tres descriptores utilizados. Los promedios y las desviaciones estandard se muestran redondeados a un decimal.

la cámara central en la situación monocular para realizar la comparación de resultados. Los STIPs se detectan en ambas modalidades utilizando 0 como umbral del detector de Harris3D, por lo tanto, no se descarta ningún STIP. El número de palabras varía en el rango $K \in\{10,25,50,100,200\}$. Finalmente, se consideran tres posibles descriptores (HOG, HOF y HOG $+\mathrm{HOF}$ ), dado que se pueden obtener resultados diferentes según se apliquen a las dos modalidades propuestas.

Los resultados de clasificación (Fig. 3.8) muestran que el reconocimiento de gestos con una sola cámara presenta mejores resultados que imagen integral cuando se utiliza el descriptor HOF. Sin embargo, con imagen integral se obtienen mejores resultados utilizando tanto el descriptor HOG como la combinación de HOF + HOG. Como se verá en la siguiente sección, esto no sucede con otra base de datos distinta, con la que los resultados de imagen integral superan siempre a los de la imagen monocular. Esto se puede deber a que en la segunda base de datos, se les dio más libertad a los usuarios a la hora de realizar los gestos, y por tanto se trata de un conjunto de acciones grabadas en condiciones menos ideales que en la primera base de datos. Así pues, en condiciones más controladas, el seccionado conseguido con imagen integral no mejora los resultados de clasificación para el descriptor HOF. Sin embargo, para el resto de casos, con imagen integral el reconocimiento de gestos es más preciso. Además, en términos absolutos, cuando se compara el mejor descriptor en cada caso (por ejemplo, HOF para monocular y HOF $+\mathrm{HOG}$ para imagen integral) se puede ver que la imagen integral supera la imagen $2 \mathrm{D}$ monocular (Fig. 3.9). En la tabla 3.4 también se muestran los resultados numéricos obtenidos para esta primera base de datos y los tres descriptores utilizados. 


\begin{tabular}{lcc}
\hline Sensor & Resolución Reducida & Resolución original \\
\hline Kinect & $224 \times 160$ & $640 \times 480$ \\
Monocular & $290 \times 218$ & $1024 \times 768$ \\
Imagen integral & $305 \times 230$ & $1075 \times 810$ \\
\hline
\end{tabular}

Tabla 3.5: Resoluciones espaciales utilizadas en las tres modalidades de vídeo

\subsubsection{Imagen integral vs monocular vs sensor Kinect}

El segundo conjunto de experimentos se realiza sobre una base de datos ligeramente distinta a la anterior. Aunque el conjunto de gestos y repeticiones son los mismos, como ya se ha adelantado en el apartado anterior, en este caso se les da más libertad a los usuarios a la hora de realizar las acciones. A diferencia de las grabaciones anteriores, no se le especifica al usuario la altura o posición del brazo ni la forma exacta de realizar los gestos. En este caso se graban las acciones de 11 usuarios utilizando, además del array de 9 cámaras, el sensor de la cámara Kinect (Fig. 3.5b). De nuevo, los vídeos del array de 9 cámaras se sincronizan a través del bus 1394 y los vídeos de la Kinect no se sincronizan frame a frame con la captura de imagen integral, pero sí que se capturan simultáneamente con los vídeos de las 9 cámaras. El resultado son un conjunto de 132 vídeos para cada una de las 3 modalidades que se corresponden con las 3 acciones $\times 11$ usuarios $\times 2$ repeticiones $\times 2$ escenarios. Estos dos escenarios son, en este caso, los gestos realizados sin oclusión y cuando una planta ocluye parcialmente la mano de los usuarios. En esta nueva base de datos no se reutilizan los vídeos anteriores ya que en este caso los resultados se graban también con la cámara Kinect y con oclusión, versiones no disponibles en la base de datos anterior.

Las imágenes del sensor de Kinect tienen un campo de visión más grande pero menor resolución $(640 \times 480)$ mientras que las imágenes de las cámaras del array tienen menor campo de visión pero mayor resolución $(1024 \times 768)$. Con el fin de realizar una comparación equitativa, se han redimensionado y cortado las imágenes para conseguir resoluciones efectivas comparables en la región de interés, es decir, en la parte superior del cuerpo de los usuarios. En la tabla 3.5 se muestran las resoluciones de las imágenes utilizadas para cada uno de los tres sensores. En la figura 3.6 se muestra una acción en oclusión de un usuario para las tres modalidades de vídeo capturadas. Como se puede observar, existe una oclusión significativa del gesto que se suaviza para la modalidad de imagen integral, gracias a la capacidad de seccionado. Al enfocar correctamente en el plano del gesto por medio del proceso de reconstrucción de apertura sintética descrito previamente, parte de la oclusión desaparece, al no encontrarse las hojas en el mismo plano que el gesto.

Para la comparación de resultados en el reconocimiento de gestos, se utilizan, como en el apartado anterior, tres descriptores distintos: el histograma de gradien- 


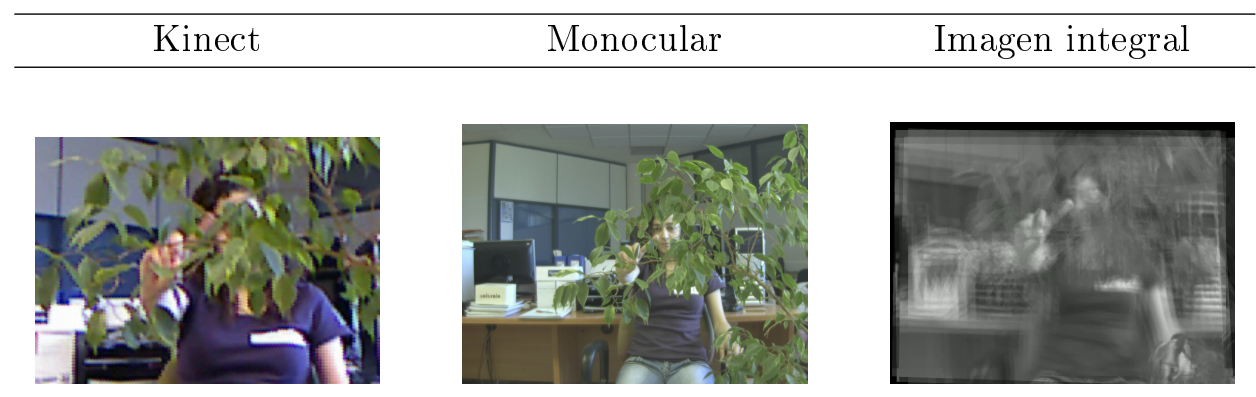

Tabla 3.6: Imágenes de un gesto con oclusión para las tres modalidades de vídeo utilizadas.

tes (HOG), histograma de flujo óptico (HOF) y su concatenación (HOG $+\mathrm{HOF}$ ). En este caso, como se ha adelantado en el apartado anterior, los resultados de clasificación para los tres descriptores son muy similares. En la figura 3.10 se muestra cómo los resultados de clasificación para la modalidad de imagen integral con y sin oclusión, no difiere al utilizar los distintos descriptores. Para una mejor visualización de los resultados, dado que en este caso se comparan entornos con y sin oclusión y con tres modalidades distintas, se muestran únicamente los resultados de la concatenación de descriptores $\mathrm{HOG}+\mathrm{HOF}$.

Para los vídeos con oclusión, se tiene que elegir un criterio a la hora de elegir los STIPs utilizados para construir la bolsa de palabras y entrenar el clasificador. La opción más razonable consiste en realizar el entrenamiento únicamente con los STIPs encontrados en entornos sin oclusión, e incluir en el conjunto de test los STIPs de los vídeos con oclusión. En la práctica, normalmente se utilizan gestos ideales para el entrenamiento, mientras que en el conjunto de test estos gestos pueden aparecer impredeciblemente con oclusión. O dicho de otro modo, el hecho de utilizar los STIPs de los vídeos con oclusión en el entrenamiento se traduciría en un conocimiento a priori del tipo de oclusión que ocurriría en un contexto determinado, lo que no suele ser habitual en situaciones prácticas.

\subsubsection{Efectos del filtrado de STIPs basado en la profundidad con Kinect.}

Para estudiar la efectividad del sistema propuesto del filtraje de STIPs basado en la profundidad con el sensor de Kinect, comparamos los resultados obtenidos al realizar la clasificación utilizando todo el conjunto de STIPs detectados en las imágenes RGB de Kinect con el conjunto de STIPs reducido, resultante de eliminar aquellos STIPs que no se encuentran a la profundidad del gesto realizado por el usuario. Como se muestra en la figura 3.11, la clasificación de gestos en los vídeos de Kinect es efectiva para vocabularios grandes, tanto utilizando todos los STIPs como al utilizar el conjunto de STIPs reducido tras el filtrado por profundidad. 
Además, para grandes vocabularios $(K>1000)$ la clasificación funciona mejor tras el filtrado basado en profundidad, que al utilizar el conjunto original de todos los STIPs. En estas gráficas se observa, además, cómo el filtrado basado en profundidad reduce el número de STIPs, por lo que no se tienen suficientes puntos para utilizar $K>5000$ clusters.

\subsubsection{Comparación de resultados de las tres modalidades.}

Al comparar los resultados de las tres modalidades (Fig. 3.12) con y sin oclusión, se pueden hacer las siguientes observaciones:

- Oclusión: Cumpliendo las previsiones, todas las modalidades son muy sensibles a la oclusión, con caídas de alrededor de 20 puntos en los resultados de clasificación. Además, en comparación con los resultados de clasificación en entornos sin oclusión, se necesitan vocabularios más grandes para poder conseguir resultados aceptables.

- Imagen Integral vs Monocular: Al igual que sucede en la sección anterior, los resultados de clasificación son mejores utilizando imagen integral que imagen monocular. Además, esta diferencia se acentúa al clasificar gestos en entornos con oclusión, y la diferencia es mayor cuanto mayor es el tamaño del vocabulario.

- Imagen Integral vs RGB-D: En entornos sin oclusión la técnica de imagen integral es más eficaz que RGB-D para vocabularios pequeños pero al aplicar el filtrado basado en profundidad (DBF) los resultados de Kinect superan a la imagen integral. Resulta además interesante destacar cómo la técnica de imagen integral consigue buenas clasificaciones incluso con los vocabularios más pequeños, lo que sugiere que las palabras en este conjunto de datos son más expresivas. Esto se traduce en la posibilidad de reconocer los gestos realizando cálculos más eficientes y con menores requisitos de memoria que con RGB-D. Sin embargo, cuando la tarea de reconocimiento se realiza sobre gestos parcialmente ocultos, se observa cómo la imagen integral supera los resultados de RGB-D para cualquier tamaño de vocabulario. Tal y como se había predicho, el filtrado en profundidad proporcionado por la cámara Kinect no aporta gran ventaja en entornos con oclusión, ya que los datos son capturados desde un único punto de vista, por lo que la oclusión sigue presente. En cambio, en imagen integral, las distancias entre las cámaras del array permiten realizar un seccionado en el plano del gesto, que elimina parte de la oclusión, obteniendo por tanto descriptores más ricos.

- RGB-D vs Monocular: Tal y como se ha estudiado en el apartado anterior, con el filtrado en profundidad de Kinect, en los resultados de clasificación para vocabularios pequeños la precisión es baja. Es por ello que RGB-D con un 
pequeño número de palabras obtiene peores resultados que imagen monocular tanto con oclusión como sin ella. Sin embargo, cuando no existe oclusión, RGB-D supera a la imagen monocular para el resto de tamaños. Por otro lado, en entornos con oclusión ambas modalidades obtienen resultados similares, siendo la imagen monocular la que obtiene mejores resultados. Esto se puede deber a que el filtrado en profundidad en entornos con oclusión, puede estar filtrando tanto STIPs ruidosos que nada tienen que ver con el gesto, como STIPs que son necesarios para una buena clasificación. Eso refuerza de nuevo el supuesto de que la imagen 3D RGB-D proporcionada por Kinect no ofrece información adicional a la imagen monocular en entornos con oclusión, ya que las imágenes son tomadas desde un único punto de vista.

Así pues, aunque en el caso de imagen integral no se utiliza explícitamente una estrategia para manejar la oclusión, la técnica por sí sola proporciona datos que, por su capacidad de enfoque en un plano, eliminan parcialmente la oclusión. Sin embargo, esto no ocurre con imagen monocular o RGB-D ya que los datos son obtenidos desde un único punto de vista, con lo que la oclusión sigue presente y los resultados de clasificación son siempre peores. Además, mientras que con Kinect se necesitan vocabularios grandes para obtener buenos resultados, en el caso de imagen integral basta con 10 palabras para obtener unos resultados razonables y estables. 


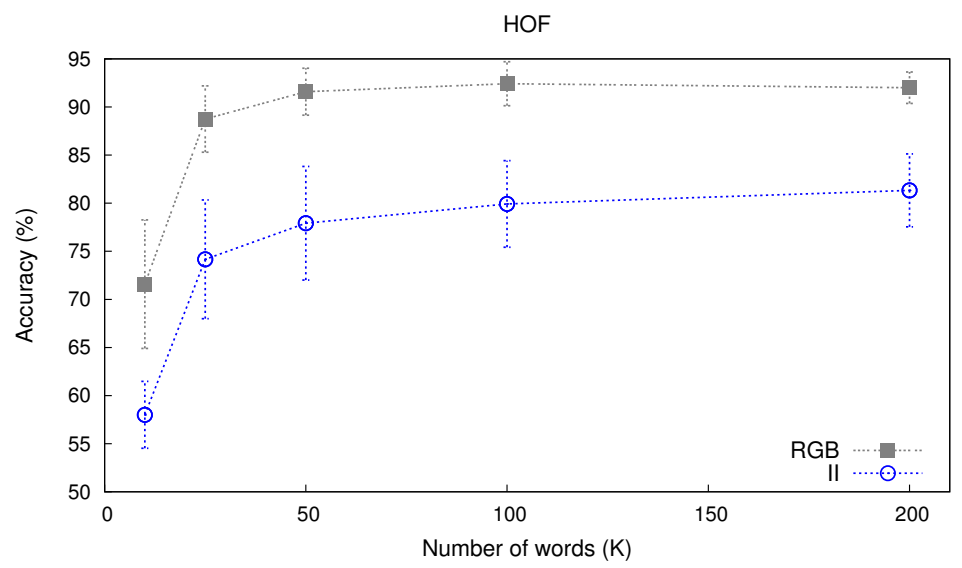

(a) HOF

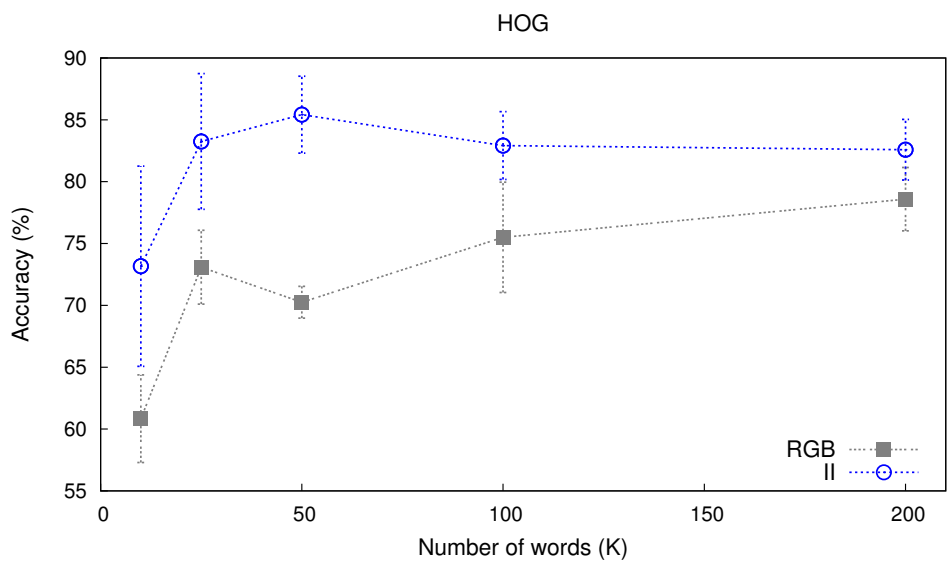

(b) HOG

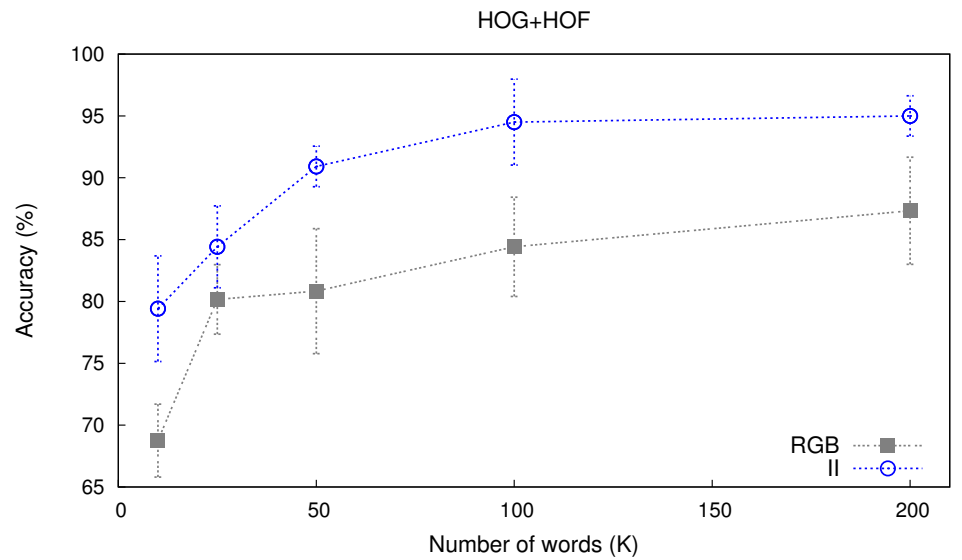

(c) $\mathrm{HOF}+\mathrm{HOG}$

Figura 3.8: Resultados de reconocimiento de gestos para imagen 2D monocular e imagen integral 3D para tres descriptores (HOF, HOG, HOG $+\mathrm{HOF}$ ). 


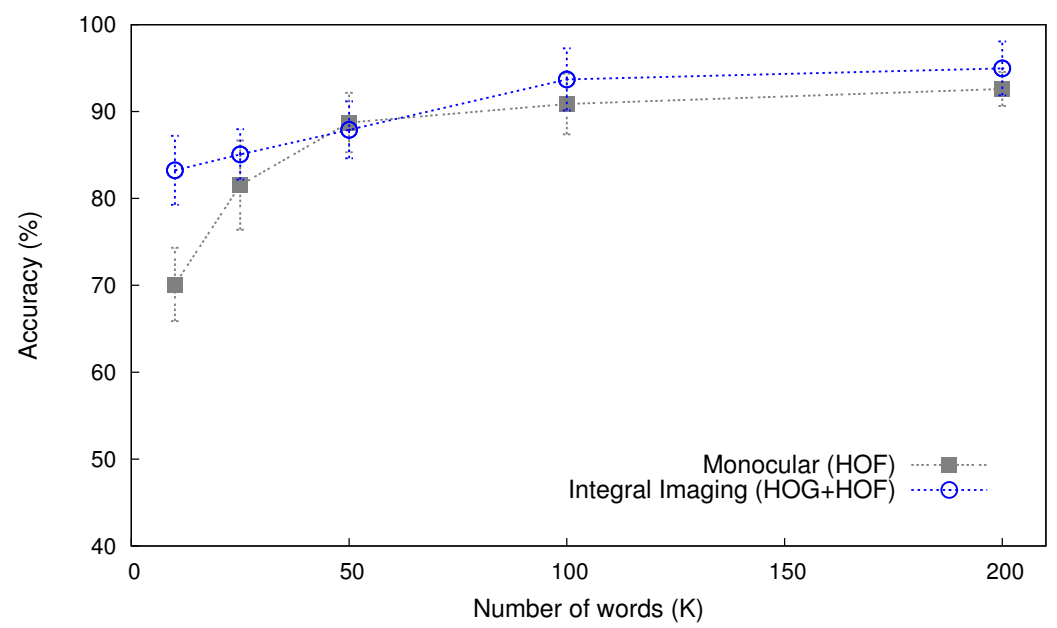

Figura 3.9: Resultados de reconocimiento de gestos para el mejor descriptor en cada caso (imagen integral y monocular).

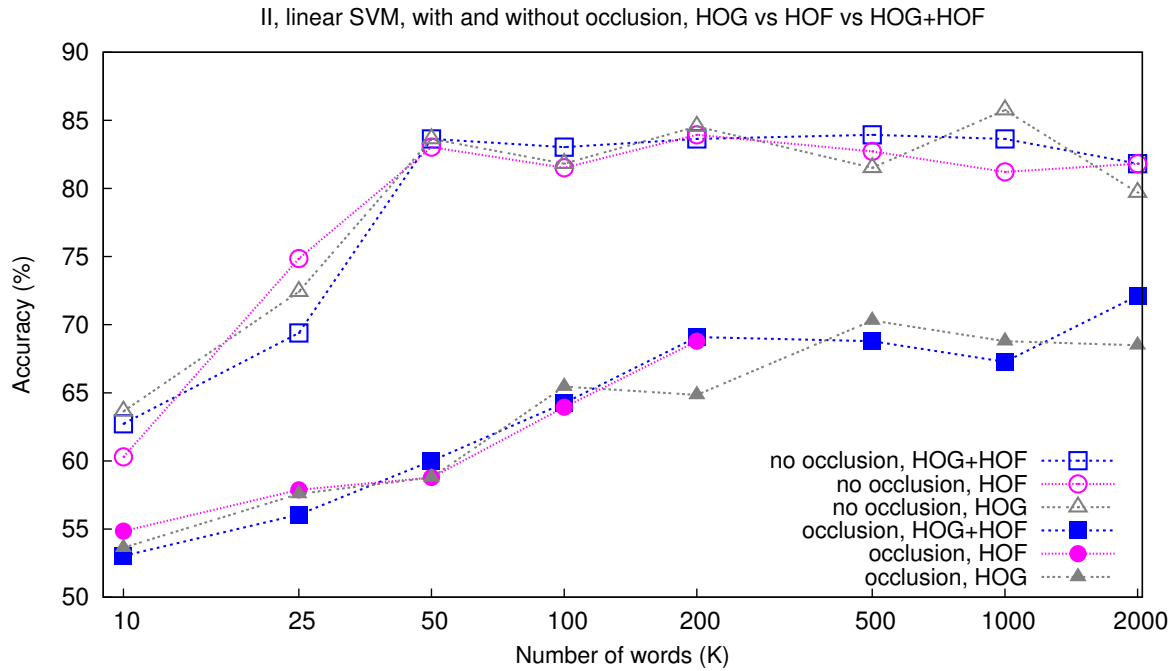

Figura 3.10: Reconocimiento de gestos en imagen integral con y sin oclusión para tres descriptores distintos (HOG, HOF y HOG+HOF). 


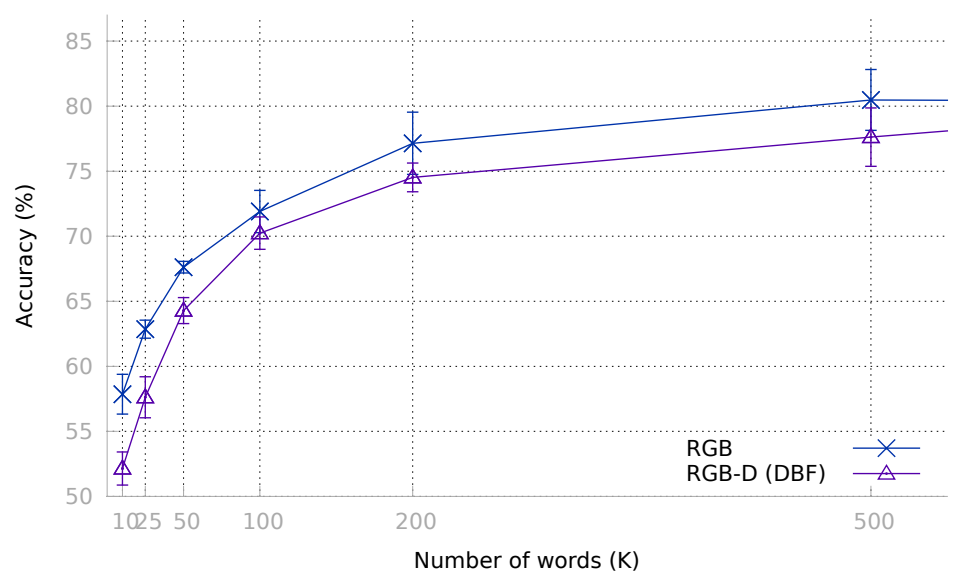

(a) Vocabularios pequeños

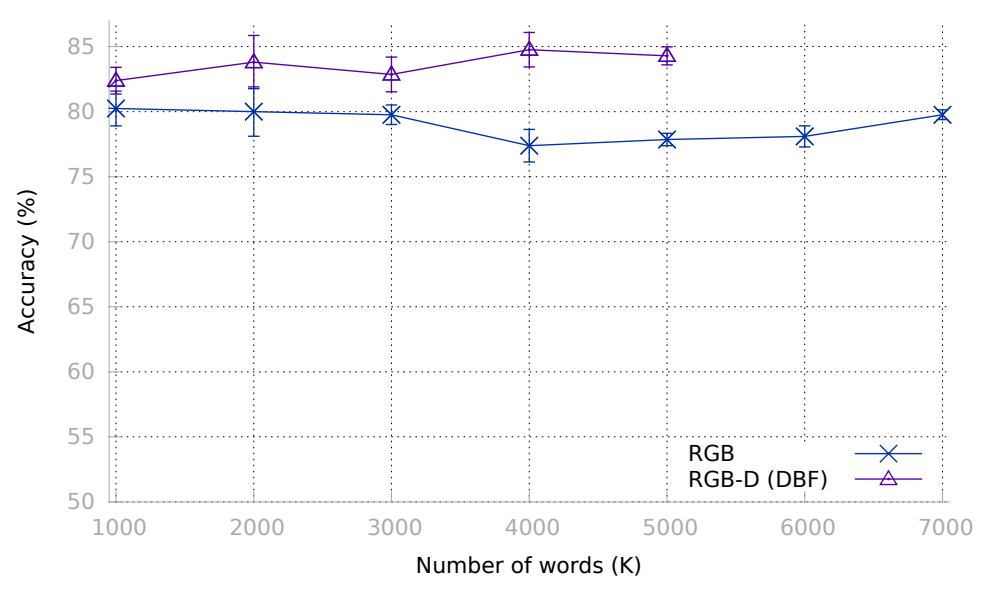

(b) Vocabularios grandes

Figura 3.11: Resultados de clasificación para los vídeos de Kinect con el conjunto de todos los STIPs detectados (RGB) y con los STIPs filtrados según la profundidad de los mismos $(\mathrm{RGB}+\mathrm{DBF})$, para vocabularios pequeños y grandes. 


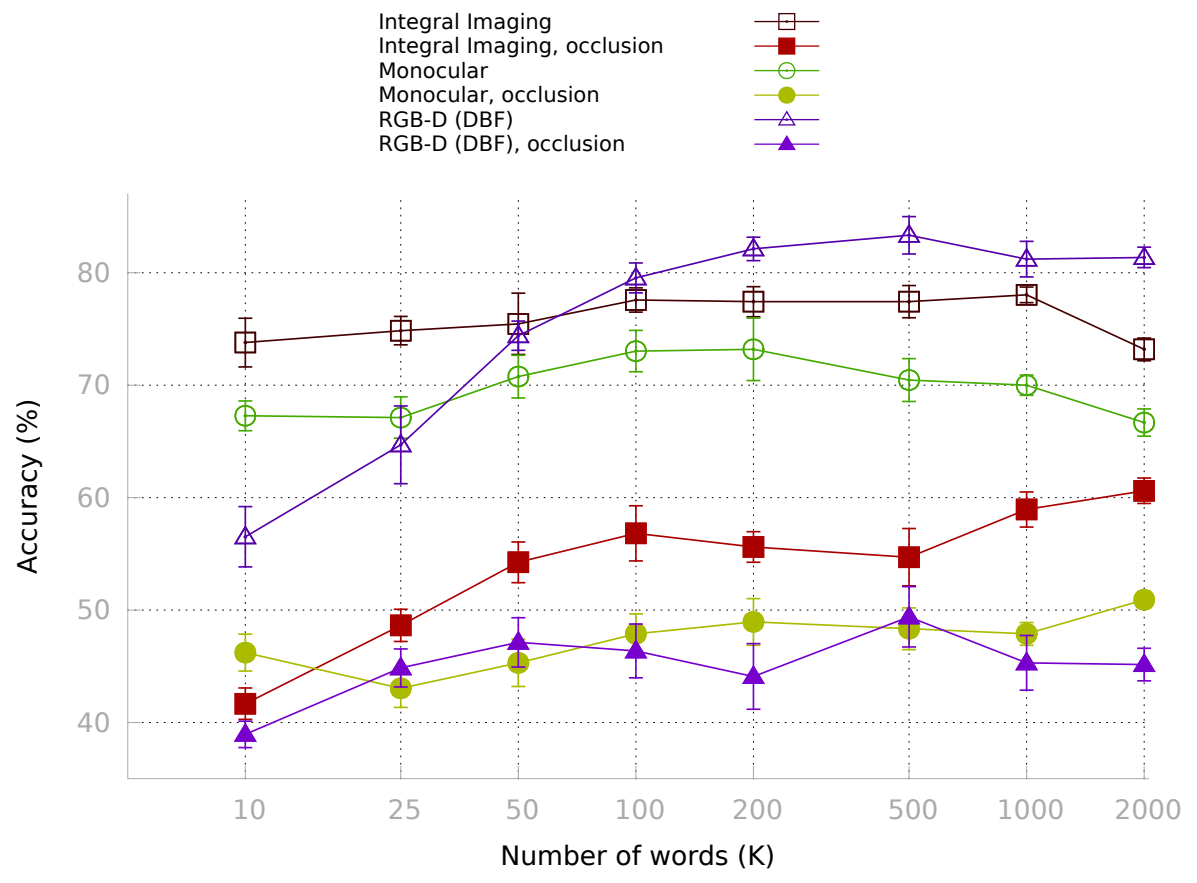

Figura 3.12: Resultados de clasificación para imagen monocular, RGB-D e imagen integral, en los tres casos, con y sin oclusión. El eje horizontal se muestra en escala logarítmica para representar más fácilmente el amplio rango de valores del número de palabras $K$. 


\title{
Capítulo 4
}

\section{Imagen 3D con cámaras de un solo píxel}

\author{
There are all sorts of detectors \\ used in the physics lab, now most of them \\ can be used to make images too.
}

Kevin Kelly, 2006

\begin{abstract}
RESUMEN: En entornos en los que resulta difícil obtener una imagen mediante técnicas convencionales, existe en la actualidad una alternativa al método tradicional de obtención de imágenes bidimensionales. Se trata de las cámaras single-pixel, que a diferencia de los sensores tradicionales que forman una imagen con un sólo disparo, realizan un muestro secuencial de la escena con patrones estructurados. En este capítulo se describe esta nueva modalidad de formación de imagen estudiando sus ventajas e inconvenientes. Uno de los inconvenientes principales de las cámaras de un solo píxel es que el tiempo de adquisición crece a medida que aumenta la resolución de las imágenes. Por ello, en este capítulo se propone una técnica de muestreo adaptativo para resolver este inconveniente. Además, se proponen diversas alternativas para reducir el coste de este nuevo modelo de cámaras y para la obtención de imagen en color. Por último, se describen varias aproximaciones que permiten capturar imagen 3D utilizando las cámaras single-pixel.
\end{abstract}




\subsection{Introducción}

Los sensores más habituales para formar imágenes bidimensionales son los que se encuentran en las cámaras digitales. Las dos tecnologías más extendidas son los sensores CCD (Charge Coupled Divice) y los CMOS (Complementary Metal Oxide Semiconductor). Ambos tipos de detectores están formados, en esencia, por semiconductores y los sensores están distribuidos en forma matricial. De este modo, para formar una imagen $2 \mathrm{D}$, cada elemento de la matriz captura información de un punto de la escena (Fig. 4.1).
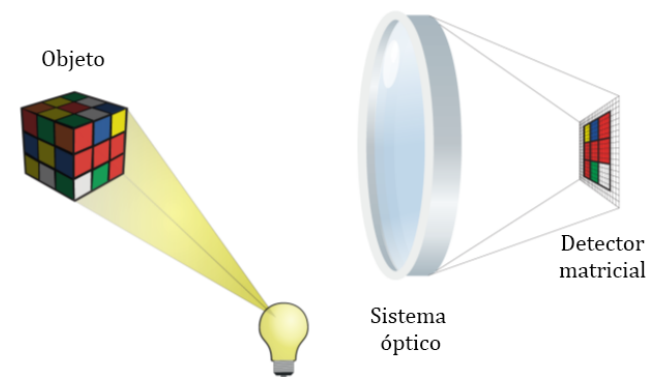

Figura 4.1: Obtención de imagen 2D con detectores matriciales.

Sin embargo, las cámaras de un sólo píxel se han convertido en una alternativa real a estos sensores, ya que son capaces de obtener información difícil de capturar con los sensores tradicionales. Tal y como su propio nombre indica, con las cámaras single-pixel es posible obtener imágenes bidimensionales utilizando un detector sin resolución espacial. Esto les ha convertido en una técnica muy atractiva ya que, para medir determinados parámetros físicos es mucho más sencilla la fabricación de un detector con un sólo sensor, que un detector con millones de sensores. Una forma de capturar información bidimensional utilizando un detector sin resolución espacial consiste en escanear la escena como muestra la figura 4.2a. De este modo, un barrido secuencial (raster scanning) de la escena, proporciona una imagen de la misma. Sin embargo, en general se entiende por cámara de un sólo píxel aquella que utiliza patrones microestructurados para muestrear el objeto. Se trata de un sistema de adquisición capaz de formar imagen con la proyección sobre la escena de un conjunto de patrones bidimensionales (Figa. 4.2b). Tras la proyección secuencial del conjunto de patrones, el sistema de formación de la imagen integra la intensidad reflejada por cada patrón y utiliza estos datos para obtener la información 2D de la escena. Así pues, del mismo modo que un sistema de captura de imagen 3D activo utiliza luz estructurada para resolver la tercera dimensión utilizando un detector bidimensional, en este caso la luz estructurada se utiliza para resolver la segunda dimensión al utilizar un detector sin resolución espacial. Estas cámaras se diferencian de las técnicas de raster scanning en que en cada captura del detector no se recibe información únicamente de una región de la escena, sino de diferentes partes de la misma. 


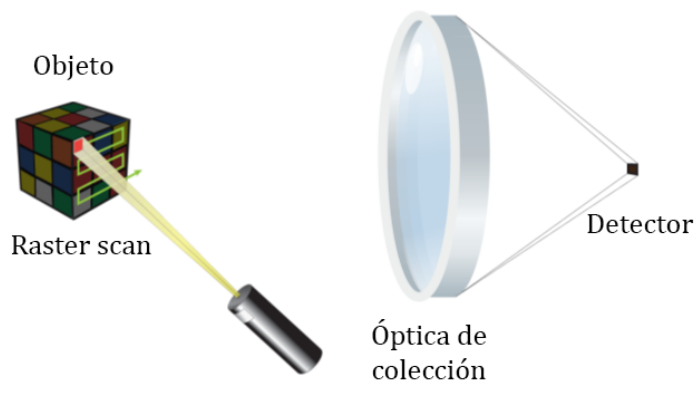

(a) Raster Scanning

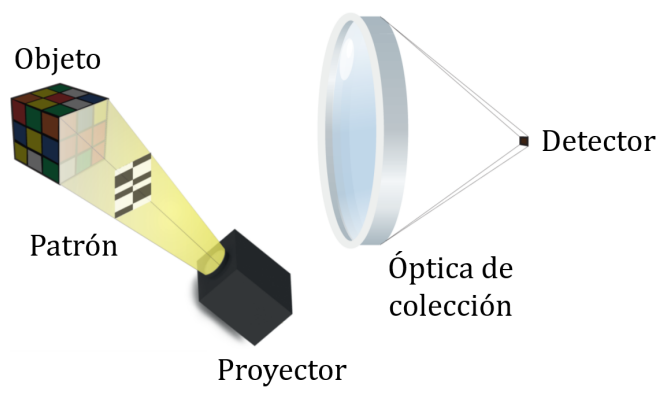

(b) Single Pixel

Figura 4.2: Detectores sin resolución espacial para imagen 2D.

En los últimos años son muchos los estudios que giran en torno al desarrollo de las cámaras de un solo píxel ya que permiten resolver problemas que los sensores convencionales no pueden afrontar. Por ejemplo, con esta tecnología es posible adquirir imágenes en el rango espectral de las ondas milimétricas [70, 71] y el infrarrojo [72], con niveles de iluminación inferiores al pico-watt [73] o de objetos inmersos en medios turbios [74-76. En esta tesis nos proponemos estudiar este tipo de cámaras y analizar la posibilidad de combinarlas con la tecnología 3D, para aportar nuevas propuestas con ventajas frente a soluciones anteriores.

Como describe Duarte [77, una cámara de un solo píxel no es más que un sistema que mide secuencialmente el producto escalar entre el campo de luz de una escena y un conjunto de funciones bidimensionales de muestreo. De este modo, el funcionamiento básico de una cámara single-pixel consiste en superponer un conjunto de máscaras sobre una escena y recuperar, para cada uno de los patrones, la intensidad total de luz transmitida o reflejada por la escena. Así pues, con un simple detector sin resolución espacial, como puede ser un fotodiodo, se captura la señal asociada a cada patrón y la imagen se reconstruye utilizando algoritmos matemáticos. Para muestrear la escena con el conjunto de funciones existen dos aproximaciones ópticamente análogas; se puede formar la imagen de la escena so- 
bre los patrones, o bien proyectar los patrones sobre la escena. La primera opción consiste en utilizar un sistema óptico para proyectar la imagen de la escena sobre un modulador espacial de luz. El modulador codifica el conjunto de patrones bidimensionales, muestreando de este modo la escena. La luz reflejada por el modulador es integrada por un detector que proporciona el producto escalar deseado. En la figura $4.3 \mathrm{a}$ se muestra un esquema en el que se representa el funcionamiento de este modelo de cámara de un solo píxel. Por otro lado, existe una solución análoga que consiste en proyectar los patrones de luz sobre la escena, tal y como muestra la figura 4.3b. En este caso, el modulador espacial de luz codifica el conjunto de patrones y se utiliza un sistema óptico de proyección para proyectar los patrones sobre la escena. Un sistema óptico colecta la luz reflejada por la escena en un detector que proporciona de la señal eléctrica deseada. Esta es la aproximación utilizada a lo largo de todo el capítulo.

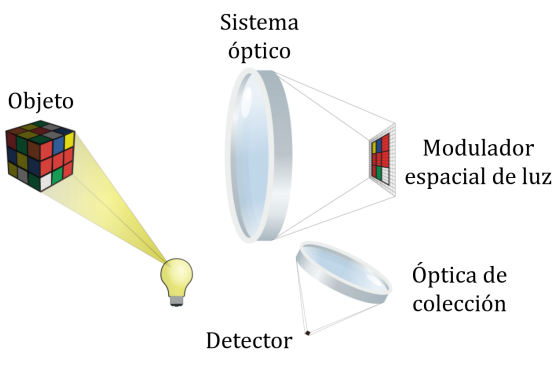

(a)

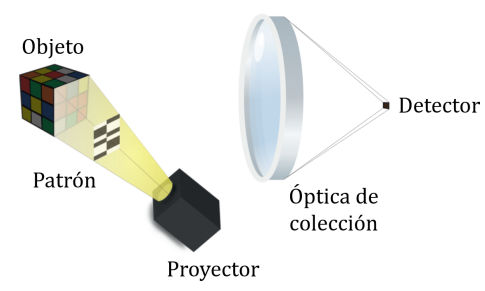

(b)

Figura 4.3: Esquema de las dos alternativas de cámara single-pixel. A la izquierda un sistema óptico forma una imagen de la escena sobre un modulador espacial de luz. El modulador codifica la secuencia de patrones binarios y un detector puntual captura la intensidad reflejada para cada patrón. A la derecha, una secuencia de patrones binarios se proyecta sobre el objeto. La intensidad asociada a cada patrón es capturada por un detector sin resolución espacial.

El número de patrones necesario para recuperar una imagen single-pixel depende de la resolución deseada. Incluso para imágenes de baja resolución de $64 \times 64$ píxeles, se requieren una gran cantidad de proyecciones $\left(64^{2}\right)$. A pesar de que se usan moduladores espaciales de luz rápidos, esto limita la velocidad del proceso de adquisición. Para resolver este problema, las técnicas de muestreo compresivo ( $\mathrm{Com}$ presive Sensing, CS) proporcionan un método que permite recuperar la imagen con un número de medidas menor que el número total de píxeles de la imagen [78]. Sin embargo, aunque se reduzcan el número total de proyecciones, los algoritmos de reconstrucción son computacionalmente muy complejos. Por eso, en los últimos años se han propuesto múltiples técnicas de muestreo adaptativo para conseguir reducir tanto el número de máscaras como la complejidad computacional de los algoritmos de reconstrucción. Algunas de estas técnicas utilizan información a priori de la escena para proyectar sólo las máscaras más relevantes 79 . Otro trabajo adopta una 
estrategia inspirada en los sistemas de visión focalizados que se encuentran en el reino animal. Una región foveal de alta resolución sigue el movimiento dentro de la escena y cada fotograma proporciona nueva información espacial [80. En este capítulo se propone una alternativa que utiliza la transformada wavelet para detectar las zonas de la escena que contienen información de interés. El algoritmo utiliza máscaras de baja resolución que van reduciendo su tamaño para conseguir mayores resoluciones sólo en las zonas relevantes. Ideas similares se han propuesto para mejorar el rendimiento de las técnicas de Ghost Imaging (GI) [81, 82] y fotografía dual (dual photography) 83 .

Una vez resuelto el problema del tiempo de adquisición, en este capítulo se describe cómo aumentar la dimensionalidad de las imágenes obtenidas con una cámara single-pixel. En primer lugar se propone una solución para obtener una imagen en color de la escena. En 2009 Nagesh y Li [84] propusieron utilizar técnicas de CS para aprovechar adecuadamente la fuerte correlación entre diferentes canales para obtener imagen en color. La propuesta de Welsh et. al [85] para recuperar la información de color consiste en colocar un divisor de haz dicroico que descompone la luz reflejada por los objetos en tres canales cromáticos distintos (rojo, verde y azul). En cada una de estas salidas se coloca un fotodiodo que mide la intensidad reflejada para cada color. En este capítulo se propone una solución alternativa con la que es posible reconstruir imágenes en color utilizando únicamente un fotodiodo. Para ello se aprovecha el procedimiento de codificación de color, basado en multiplexado temporal, utilizado por el proyector de vídeo empleado para generar los patrones.

En este capítulo se proponen dos estrategias para obtener información 3D utilizando detectores sin resolución espacial. Este ha sido un campo de gran interés en los últimos años, por lo que encontramos en la literatura múltiples soluciones posibles. Algunas propuestas para imagen 3D con cámaras single-pixel aplican algoritmos de fotometría estéreo [86, 87. La técnica consiste en utilizar múltiples imágenes de un mismo objeto con distintas condiciones de iluminación para obtener la información de profundidad. Para ello, a partir de los datos de intensidad de las imágenes, se calculan los gradientes superficiales que permiten reconstruir el objeto $3 \mathrm{D}$.

Otros métodos aplican técnicas de medida de tiempo de vuelo, de modo que al enviar el conjunto de máscaras, no miden simplemente la intensidad integrada por cada patrón, sino que analizan la la forma temporal de la señal utilizando un detector muy rápido [73, 88, 92. La señal resuelta en el tiempo da información de la profundidad a la que se encuentran los objetos de la escena y la intensidad integrada en cada patrón se utiliza para obtener la imagen de la escena. Además, estas técnicas de tiempo de vuelo se han empleado en métodos de imagen basados en GI con el mismo fin [93, 94].

Por otro lado, también se ha utilizado la información de disparidad para recuperar información 3D [95]. En esta propuesta en particular se hace rotar un objeto 
sobre una plataforma para recuperar distintas perspectivas del mismo. A partir de la información de disparidad es posible determinar la profundidad de la escena.

Finalmente, también se ha combinado la cámara single-pixel con técnicas de luz estructurada. Los métodos convencionales de luz estructurada utilizan un proyector y una cámara. Para obtener la información 3D de la escena se proyectan patrones conocidos y la cámara captura la deformación que estos sufren al interaccionar con el objeto. Además, para poder obtener información de profundidad utilizando restricciones geométricas, es necesario calibrar los parámetros de la cámara y el proyector. Los sistemas tradicionales basados en el empleo de luz estructurada utilizan los parámetros de calibración de la cámara para calibrar el proyector. Por la propiedad de la reversibilidad de los rayos de luz (o principio de reciprocidad de Helmholtz) sabemos que la imagen que se recupera con la cámara single-pixel se obtiene con la perspectiva que obtendría una cámara que se colocase en la posición del proyector. Por ello, la empresa Ajile propone un método de calibración del proyector utilizando la imagen reconstruida por single-pixel [96. Por otro lado, utilizando esta misma propiedad de la luz Zhan et. al [97] colocan una rejilla delante de un detector para conseguir implementar la técnica de luz estructurada utilizando una cámara single-pixel. Las dos alternativas propuestas en este capítulo para obtención de imagen 3D se basan, la primera en una cámara estereoscópica y la segunda en la técnica de fotometría estéreo.

\subsection{Teoría básica}

A continuación se hace una descripción formal del problema de obtención de imágenes bidimensionales con la cámara de un sólo píxel. Una secuencia de patrones de luz microestructurados con una distribución de irradiancia $\Psi_{i}(m, n)$, siendo $m$ y $n$ coordenadas espaciales discretas y $i=1, \ldots, N$, se proyecta sobre el objeto de estudio. La luz reflejada por el objeto la recoge un detector puntual, como puede ser un fotodiodo. Si denominamos $R(m, n)$ a la distribución de reflectancia del objeto en los puntos muestreados por los patrones de luz, entonces el fotodiodo mide secuencialmente los productos:

$$
I_{i}=\sum_{n=1}^{\sqrt{N}} \sum_{m=1}^{\sqrt{N}} \Psi_{i}(m, n) \cdot R(m, n),
$$

donde $N$ es el número de píxeles del patrón de luz microestructurada. Esta operación de muestreo implica que la resolución espacial de esta técnica de imagen viene determinada por la resolución de los patrones proyectados. Diferentes enfoques de imagen single-pixel utilizan distintas funciones de muestreo $\Psi_{i}(m, n)$. Por un lado, se puede utilizar un conjunto de patrones aleatorios para muestrear la escena, siendo este enfoque muy similar a las técnicas de GI computacional [98]. Por otro lado, se puede escoger un conjunto determinista de patrones como pueden ser funciones pertenecientes a una base completa tales como Fourier, Haar o Walsh-Hadamard 
[99 101. En este trabajo los patrones de muestreo utilizados son funciones 2D pertenecientes a la base de Walsh-Hadamard (WH). Una matriz de Walsh es una matriz cuadrada de dimensiones potencia de 2 , valores de $+1-1$ y con la propiedad de que el producto escalar de dos filas (o columnas) distintas es cero, es decir, las filas son ortogonales entre sí. Estas matrices se pueden crear con la construcción de Sylvester, que obtiene recursivamente las matrices a partir del siguiente algoritmo:

$$
\begin{gathered}
\mathcal{H}\left(2^{1}\right)=\left[\begin{array}{ll}
+1 & +1 \\
+1 & -1
\end{array}\right], \\
\mathcal{H}\left(2^{2}\right)=\left[\begin{array}{llll}
+1 & +1 & +1 & +1 \\
+1 & -1 & +1 & -1 \\
+1 & +1 & -1 & -1 \\
+1 & -1 & -1 & +1
\end{array}\right],
\end{gathered}
$$

y en general:

$$
\mathcal{H}\left(2^{k}\right)=\left[\begin{array}{cc}
\mathcal{H}\left(2^{k-1}\right) & \mathcal{H}\left(2^{k-1}\right) \\
\mathcal{H}\left(2^{k-1}\right) & -\mathcal{H}\left(2^{k-1}\right)
\end{array}\right]=\mathcal{H}(2) \otimes \mathcal{H}\left(2^{k-1}\right) .
$$

La implementación de estas funciones en un modulador de amplitud no es directa ya que el modulador tendría que estar formado por elementos de transmitancia 1 y -1. En cambio, si el modulador utilizado solo refleja o transmite la radiación, es necesario descomponer las funciones de $\mathrm{WH}$ en otras funciones que si se puedan codificar. Para ello, cualquier función de WH se puede expresar como la resta de dos funciones complementarias:

$$
\mathcal{H}=\mathcal{H}^{+}-\mathcal{H}^{-}
$$

donde $\mathcal{H}^{+}$se construye a partir de $\mathcal{H}$ reemplazando los -1 por 0 y $\mathcal{H}^{-}$es la complementaria de $\mathcal{H}^{+}$. Estas funciones binarias ya se pueden implementar fácilmente con cualquier modulador espacial de luz.

En el tratamiento digital de imágenes es habitual considerar la imagen 2D como un vector $1 \mathrm{D}$, que expresa el conjunto de filas de la imagen concatenadas en un único vector. La codificación de las funciones $\mathrm{WH}$ se hace también por filas. La forma en la que se almacenan estas funciones se muestra en la figura 4.4. En esta figura se muestra también el orden en el que se envían estos patrones a la escena. Como se puede observar, el envío se realiza lanzando en primer lugar los patrones de frecuencias más bajas. Aunque independientemente del orden en que se envíen los patrones se obtiene la misma reconstrucción, en el caso de no mandar todas las funciones de la base, en general se obtienen mejores resultados si se envían aquellos con frecuencias más bajas.

La elección de esta base proporciona varias ventajas. En primer lugar, como los patrones son funciones de una base ortogonal, la intensidad medida, $I_{i}$, proporciona directamente la proyección del objeto sobre esa base. Esto también significa que, 


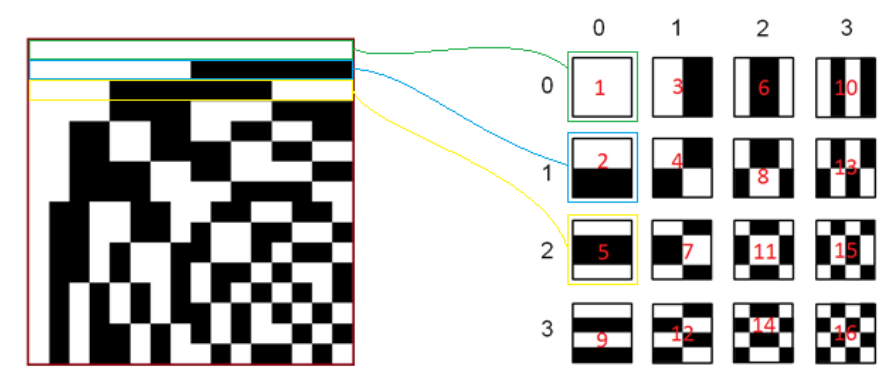

Figura 4.4: Representación de la matriz de Walsh Hadamard $\mathcal{H}\left(2^{3}\right)$ (izquierda) y conjunto de patrones $2 \mathrm{D}$ construidos a partir de dicha matriz (derecha). Cada fila de la matriz se corresponde con un patrón. Los números rojos indican el orden de envío de los patrones.

en principio, al utilizar todas las funciones de la base, el objeto puede ser perfectamente recuperado para una frecuencia de muestreo dada. En segundo lugar, las imágenes naturales tienden a ser dispersas (sparse) en la base de WH, siendo por lo tanto esta base muy útil para aplicar técnicas de muestreo compresivo, como se explicará más adelante. Finalmente, al tratarse de patrones binarios, la codificación utilizando moduladores espaciales de luz es muy sencilla.

Así pues, teniendo en cuenta la definición de las matrices WH es sencillo mostrar que para cualquier par de patrones con índices $i$ y $j$,

$$
\sum_{n=1}^{\sqrt{N}} \sum_{m=1}^{\sqrt{N}} H_{i}(m, n) \cdot H_{j}(m, n)=N \cdot \delta_{i j},
$$

donde $\delta_{i j}$ es la delta de Kronecker. Por lo tanto, utilizando una secuencia de $N$ patrones de $\mathrm{WH}$, la distribución de irradiancia del objeto en 4.2.4 se puede estimar aplicando simplemente el principio de superposición del siguiente modo:

$$
T^{\prime}(m, n)=\frac{1}{N} \sum_{i=1}^{N} I_{i} \cdot H_{i}(m, n),
$$

Es importante tener en cuenta que en ausencia de ruido, utilizando una secuencia de $N$ patrones de $\mathrm{WH}, 4.2 .7$ se proporciona una réplica exacta del objeto con una resolución de muestreo de $N$ píxeles. Además, es fácil comprobar que este enfoque es muy similar a las técnicas de GI computacional [98 si nos percatamos de que la operación en la ecuación 4.2.7 se puede entender como una correlación entre la secuencia de irradiancias medidas $I_{i}$, y la secuencia de irradiancia de luz que ilumina cada píxel $H_{i}(m, n)$.

Al contrario de lo que sucede con las cámaras tradicionales, con las que es posible obtener una imagen con un solo disparo, con las cámaras single-pixel el muestreo se realiza secuencialmente en el tiempo, mediante la proyección de una serie de patrones binarios sobre la escena. Es por ello que la mayor limitación de las 
cámaras single-pixel es que pueden requerir largos tiempos de adquisición. Estos tiempos dependen del número $M$ de máscaras proyectadas, la tasa de proyección de patrones $R_{S L M}$ y el tiempo de integración $t_{i n t}$ del detector de luz, a través de la ecuación:

$$
T_{a}=M\left(\frac{1}{R_{S L M}}+t_{\text {int }}\right) .
$$

Idealmente, el tiempo de integración debería ser lo más corto posible y la frecuencia tan alta como la permitida por el proyector digital de luz. Por lo tanto, una forma de disminuir el tiempo de adquisición consiste en reducir el número de patrones que se envían. Sin embargo este número aumenta con la resolución.

Las cámaras single-pixel se popularizaron en el 2006 con la aparición de la técnica de muestreo compresivo, CS [5, 177, 102. La idea parte de una pregunta muy simple, ¿para qué capturar una escena con sensores de millones de píxeles si posteriormente se van a utilizar algoritmos de compresión de imagen para almacenarla o transmitirla? ¿Por qué no realizar la compresión en el proceso de captura? Empleando técnicas de CS se pueden obtener imágenes de alta calidad muestreando las escenas por debajo del límite de Shannon-Nyquist [103]. Este límite establece que la frecuencia de muestreo mínima que se requiere tiene que ser mayor que el doble de la frecuencia máxima de la señal. De este modo, la teoría de CS establece que una imagen de dimensión $\sqrt{N} \times \sqrt{N}$ se puede reconstruir utilizando un número $M<N$ de coeficientes escogidos aleatoriamente. Por lo tanto, la técnica de CS optimiza la adquisición de datos realizando la compresión en el propio proceso de muestreo de la señal. Esto es posible dado que las imágenes naturales tienden a ser sparse en el espacio de frecuencias de ciertas bases y en particular en la de WH, es decir, se pueden expresar utilizando únicamente unos pocos coeficientes significativos.

Esta idea se puede expresar escribiendo de nuevo el proceso de medida en la ecuación 4.2.6 de forma matricial como:

$$
\vec{I}=\Phi \cdot \vec{t}=\Phi(\Gamma \cdot \vec{s})=\Theta \cdot \vec{s},
$$

donde $\vec{I}$ es un vector $M \times 1$ que contiene los coeficientes medidos, y $\vec{t}$ y $\vec{s}$ son vectores $N \times 1$ que representan el objeto en el espacio de muestreo y en el espacio de frecuencias de WH, respectivamente. La matriz $\Phi$ es una matriz $M \times N$ que contiene un subconjunto aleatorio de $M$ patrones de WH codificados en diferentes filas y la matriz $\Gamma$ es la matriz de transformación entre el espacio de muestreo y el espacio WH. Con el producto de las matrices $\Phi$ y $\Gamma$ se obtiene la matriz $\Theta$, que actúa directamente sobre $\vec{s}$. En los algoritmos de CS, la solución de la ecuación matricial indeterminada en la ecuación 4.2 .9 se obtiene mediante algoritmos off-line de reconstrucción, tales como los basados en optimización convexa. En particular, en este capítulo utilizamos algoritmos basados en la minimización de la norma $l_{1}$ de 
$\vec{s}$ sujetos a la restricción dada por la ecuación 4.2.9. Concretamente, la estimación del objeto, $\overrightarrow{t^{\prime}}$, se obtiene resolviendo:

$$
\operatorname{mín}_{s^{\prime}}\left\|\overrightarrow{s^{\prime}}\right\|_{l_{1}} \text { sujeto a } \overrightarrow{\Theta s^{\prime}}=\vec{I} .
$$

Hay que tener en cuenta que, con la utilización de estos algoritmos de CS, el tiempo de adquisición en la ecuación 4.2.8 se reduce a costa de un tiempo de postprocesado al reconstruir la imagen final. Así pues, las técnicas de CS permiten reducir el tiempo al muestrear la escena ya que son necesarios un menor número de patrones. Sin embargo, los algoritmos de minimización requieren grandes tiempos de cálculo y a medida que aumenta la resolución de la imagen, este tiempo aumenta exponencialmente. Por lo tanto, para aplicaciones de obtención de vídeos a tiempo real, se hace difícil su utilización ya que al tiempo de adquisición $T_{a}$ hay que añadirle el tiempo de postprocesado, $T_{p}$ :

$$
T_{a}=M\left(\frac{1}{R_{S L M}}+t_{i n t}\right)+T_{p} .
$$

En este capítulo se propondrá una técnica de muestreo adaptativo que permite reducir, no sólo el número de máscaras $M$, sino también el tiempo de postprocesado $T_{p}$.

\subsection{Desarrollo experimental de una cámara single- pixel}

Los componentes principales para obtener una imagen con una cámara singlepixel se muestran en la figura 4.5. El sistema de formación de imágenes está compuesto por un sistema de proyección, un fotodiodo, una tarjeta digitalizadora y un ordenador. A continuación se describen los distintos componentes del sistema, especialmente las distintas configuraciones posibles para el sistema de proyección de luz, que es el dispositivo clave.

\subsubsection{Proyección con tecnología DMD}

Para la proyección de los patrones, una primera opción consiste en utilizar un proyector con pantalla de cristal líquido (Liquid Crystal Display, LCD), sin embargo esta tecnología nos permite trabajar como máximo a frecuencias de cientos de hercios. Por otra parte, los moduladores espaciales de luz basados en micro-espejos (Digital Micromirror Device, DMD) pueden alcanzar tasas de refresco de hasta $22.7 \mathrm{kHz}$. Inventados en 1987 por Texas Instruments, los DMDs son un dispositivo formado por un conjunto de mico-espejos controlables electrónicamente de forma individual. En la figura 4.6 se muestra un esquema de funcionamiento del DMD. Los espejos, que tienen únicamente dos orientaciones posibles $\left(+12^{\circ}\right.$ y $\left.-12^{\circ}\right)$ respecto a su posición de espera, dirigen un haz de luz incidente hacia dos direcciones distintas (ON u OFF). Aunque el DMD es un dispositivo binario de amplitud, dada su alta 


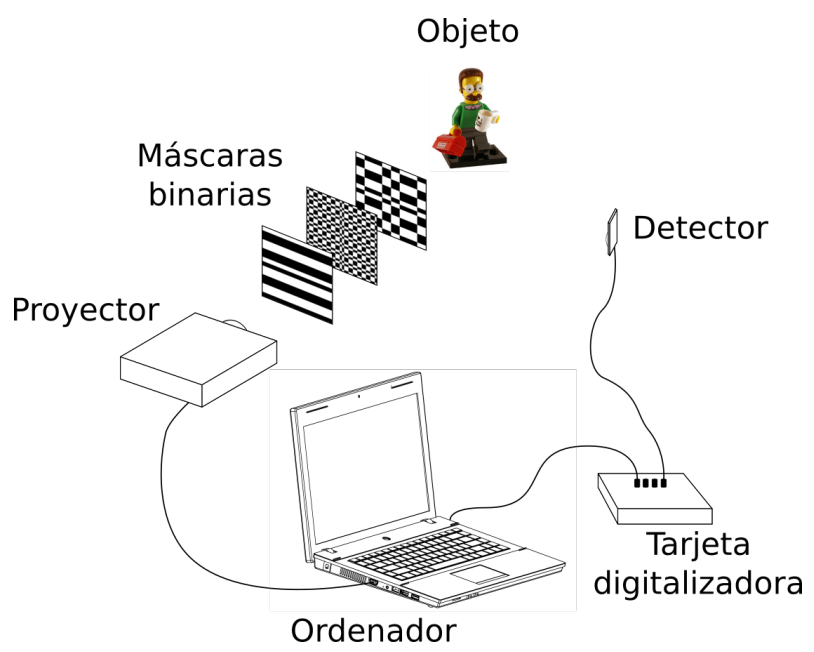

Figura 4.5: Esquema experimental para la reconstrucción de objetos utilizando una cámara single-pixel.

velocidad de conmutación es posible generar patrones de iluminación con niveles de gris para sistemas estándar de proyección. Dado que el sistema de visión humana solo distingue imágenes individuales cuando estas se proyectan a frecuencias de entre 10 y 12 imágenes por segundo, trabajando a frecuencias mayores y variando la cantidad de tiempo que los espejos se encuentran en la posición ON u OFF se pueden conseguir diferentes niveles de gris. Si el receptor es una cámara en lugar de una persona, será necesario ajustar la velocidad de conmutación del DMD y el tiempo de integración de la cámara, de modo que esta no resuelva los cambios de posición ON-OFF de los espejos durante la proyección de un nivel de gris.

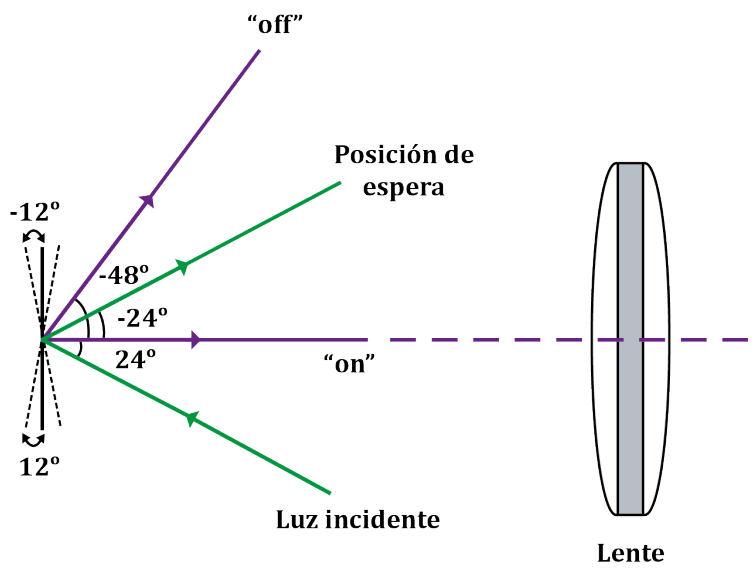

Figura 4.6: Esquema de funcionamiento del DMD. La luz incidente se refleja en dos direcciones ON y OFF dependiendo de la posición del microespejo. 
Los DMDs son el componente principal de los proyectores actuales con tecnología DLP (del acrónimo en inglés Digital Light Processing). En la figura 4.7 se muestra un esquema de funcionamiento de un proyector DLP. La luz proveniente de una lámpara de luz blanca atraviesa una rueda dividida en varios sectores, cada uno de los cuales contiene un filtro de color. La rueda de colores filtra la luz de modo que esta cambia secuencialmente entre las componentes cromáticas azul, rojo y verde. Algunos proyectores añaden además un segmento transparente para mejorar la proyección de la luz. De este modo, la tecnología DLP es una alternativa económica a los DMDs de uso científico que además incorpora la fuente de luz, y permite la codificación en color de los patrones de salida.

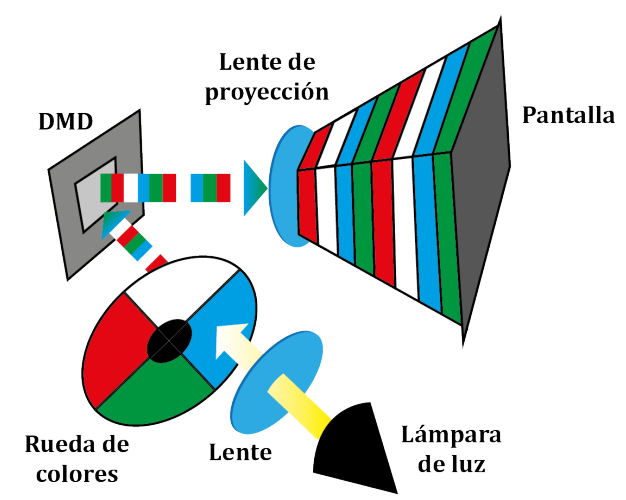

Figura 4.7: Esquema de funcionamiento de un proyector con tecnología DLP. La luz proveniente de una lámpara de luz blanca pasa a través de una rueda de filtros e incide sobre un DMD. El DMD codifica la imagen y un sistema de proyección la envía a una pantalla.

\subsubsection{Proyección con una matriz de LEDs}

Aunque los DMDs de uso científico proporcionan tasas de refresco de hasta $22 \mathrm{kHz}$, el coste de estos dispositivos es muy elevado. En este capítulo, para reducir el coste se proponen soluciones económicas de proyectores comerciales con tecnología DLP. Sin embargo, una de las desventajas de esta propuesta es el límite de velocidad en el envío de patrones. Esto se traduce en grandes tiempos de captura de imágenes single-pixel, lo que imposibilita la captura de vídeos a tiempo real. Con el fin de construir una versión más económica de este tipo de cámaras se puede utilizar también una matriz de LEDs para la codificación de patrones binarios. Aunque las matrices de LEDs se utilizan comúnmente en paneles informativos y anuncios, en los últimos años han sido ampliamente utilizadas en el ámbito científico en aplicaciones como captura de campos de luz 4D [104, imagen de contraste de fase [105, 106] y pticografía de Fourier [107-109. Además, estas matrices se pueden controlar muy fácilmente utilizando placas Arduino. Para conseguir mayores tasas de refresco, se pueden controlar con una FPGA (Field Programmable Gate Array). Una vez los patrones se codifican en la matriz de LEDs, la idea consiste en utilizar 
un sistema óptico sencillo para formar una imagen de la matriz de LEDs sobre la escena. De este modo conseguimos, de nuevo, proyectar los patrones sobre la escena a altas frecuencias (hasta $20 \mathrm{kHz}$ ), pero con un reducido coste.

\subsubsection{Sistema de detección}

Para obtener una imagen single-pixel, un detector sin resolución espacial recoge la luz reflejada por el objeto para cada uno de los patrones proyectados. La elección del detector dependerá de la aplicación. Por ejemplo, si la luz es escasa es conveniente utilizar un tubo fotomultiplicador [72]; si el objetivo es medir la polarización puede emplearse un polarímetro [110]; para obtener imágenes hiperespectrales puede utilizarse un espectrómetro [111] o para aplicaciones de tiempo de vuelo, un contador de fotones [73. Sin embargo, para todos los experimentos de este capítulo se utiliza como detector un fotodiodo. Los fotodiodos utilizados son de silicio, sensibles a longitudes de onda entre 200-1100 nm con áreas activas entre 0,8 y $75,4 \mathrm{~mm}^{2}$. La señal de intensidad integrada capturada por el fotodiodo se digitaliza utilizando una tarjeta de adquisición de datos (Data AcQuisition, DAQ). La tarjeta digitalizadora registra la señal del fotodiodo que es almacenada en la memoria del PC. Para ello, se ha de sincronizar el envío de los patrones con la captura del fotodiodo. Esta sincronización se puede realizar por software (enviando patrones de control) o por hardware (utilizando una señal de sincronía del DMD o de la tarjeta digitalizadora).

\subsection{Muestreo adaptativo}

Uno de los mayores inconvenientes de las cámaras single-pixel es el tiempo de adquisición. Mientras que en una cámara convencional una imagen se toma con un solo disparo, en las cámaras single-pixel es necesario codificar muchas máscaras para posteriormente reconstruir la imagen. Como se ha visto en la ecuación 4.2 las técnicas de CS permiten reducir el número de máscaras necesarias para reconstruir una imagen pero necesitan grandes tiempos de postprocesado. Por ello, en esta sección se propone una alternativa a la técnica de CS basada en el muestreo inteligente de la escena. La idea consiste en muestrear a alta resolución sólo aquellas zonas de la escena que lo requieran. Para ello se utiliza un conjunto de máscaras de baja resolución que se redimensionan adaptativamente cuando ciertas zonas de la escena necesitan muestrearse a mayor resolución. Finalmente, la imagen se recupera utilizando las medidas a distintas resoluciones recombinadas usando el método de la transformada de wavelet.

En GI computacional se han propuesto algoritmos de muestreo adaptativo para conseguir reducir el número de máscaras que se envían a la escena 81, 82. Sin embargo, en esta propuesta las máscaras utilizadas para muestrear la escena son aleatorias, por lo que el número de patrones sigue siendo alto. Por eso, en el siguiente apartado se describe una propuesta de muestreo adaptativo en la que se utilizan 
patrones de WH para conseguir obtener imágenes de alta resolución utilizando la cámara single-pixel.

\subsubsection{Introducción a la transformada wavelet}

Para poder entender el funcionamiento del algoritmo de muestreo adaptativo es necesario entender cómo funciona la transformada de wavelet. Esta permite descomponer la señal original utilizando un filtro pasa baja (Low Pass Filter, LPF) y un filtro pasa alta (High Pass Filter, HPF). A su vez, la señal resultante tras aplicar el filtro pasa baja puede descomponerse nuevamente formado así un árbol de frecuencias denominado árbol wavelet. Tal y como se muestra en la figura 4.8 una señal con $\mathrm{N}$ elementos puede expresarse a través de su transformada wavelet de nivel 3 mediante la suma de las señales L1 (N/2), L2 (N/4), L3 (N/8) y H3 (L/8). Esta descomposición se conoce como árbol de wavelet de una función.

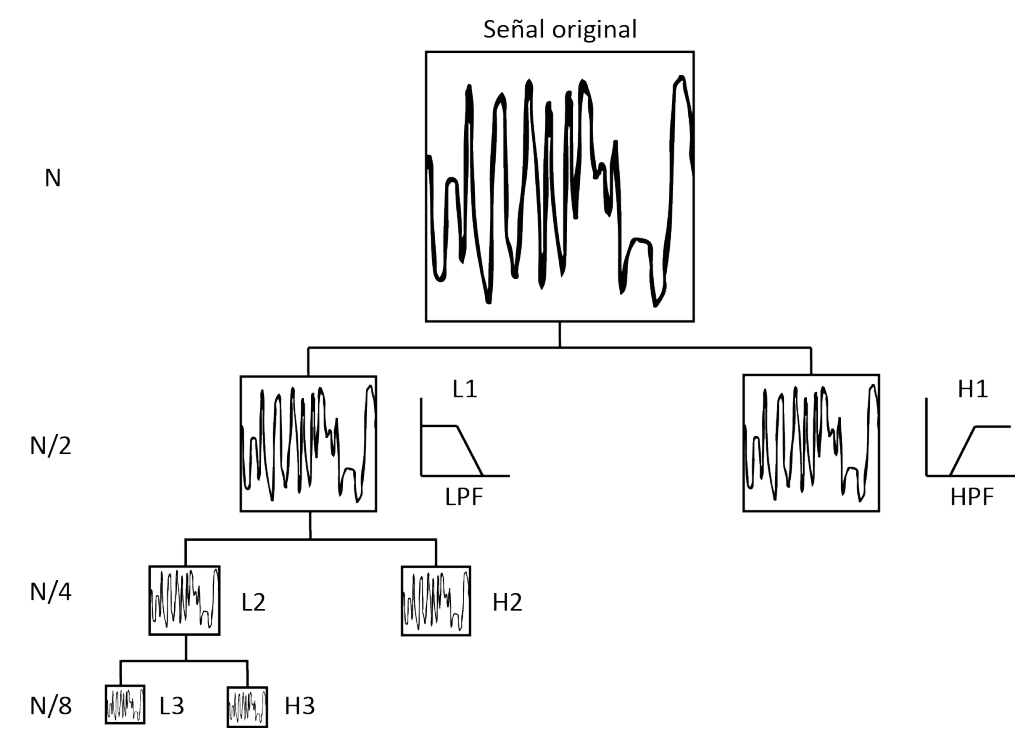

Figura 4.8: Representación esquemática de un árbol wavelet de nivel 3 para señales 1D. Cada nivel está formado por dos señales obtenidas mediante un filtro pasa baja (LPF) y un filtro pasa alta ( $\mathrm{HPF})$.

Aunque el árbol anterior se aplica en señales de una sola dimensión, el procedimiento puede extenderse para señales bidimensionales, como son las imágenes. En este caso, la descomposición de wavelet de una imagen se obtiene a partir de cuatro combinaciones distintas de filtros pasa baja y pasa alta: LL (pasa baja en $\mathrm{x}$ e $\mathrm{y}$ ), LH (pasa baja en $\mathrm{x}$, pasa alta en $\mathrm{y}$ ), HL(pasa alta en $\mathrm{x}$, pasa baja en $\mathrm{y}$ ) y HH (pasa alta en x e y). Así pues, en el caso bidimensional, en cada nivel se descompone la señal en cuatro componentes. Una representación esquemática del proceso se muestra en la figura 4.9 . 


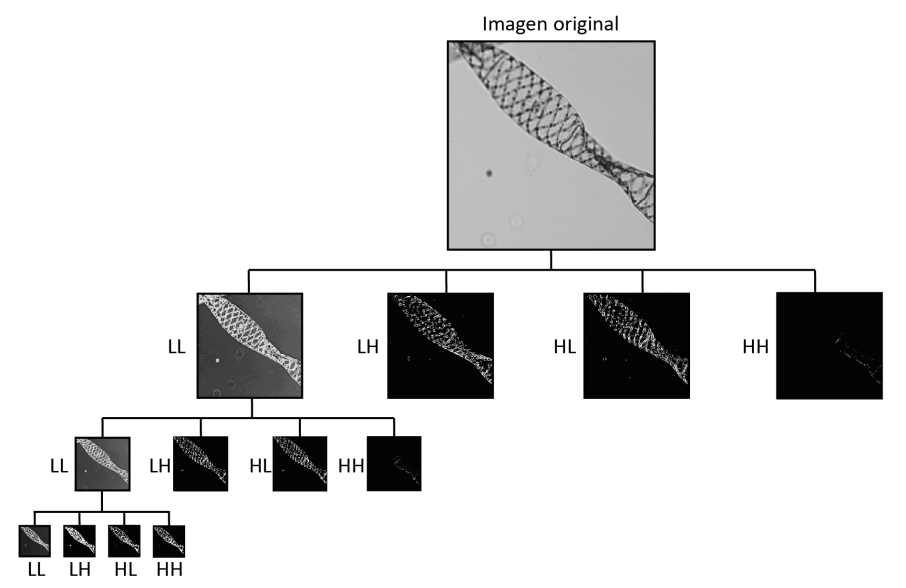

Figura 4.9: Representación esquemática de un árbol wavelet de nivel 3 para señales 2D (imágenes). Cada nivel está formado por cuatro imágenes distintas obtenidas mediante el uso de 4 filtros distintos.

Esta descomposición obtiene como resultado la componente LL, en la que se encuentra una nueva versión de la imagen a menos resolución, y las tres restantes, que nos dan información sobre los bordes verticales, horizontales y diagonales de la imagen. Por lo tanto, dada una imagen de dimensión $\sqrt{N} \times \sqrt{N}$, se obtienen cuatro cuadrantes de dimensión $\sqrt{N} / 2 \times \sqrt{N} / 2$. Como en el caso de señales 1D, la componente de bajas frecuencias (LL) se puede descomponer nuevamente, y este proceso se puede ir repitiendo secuencialmente.
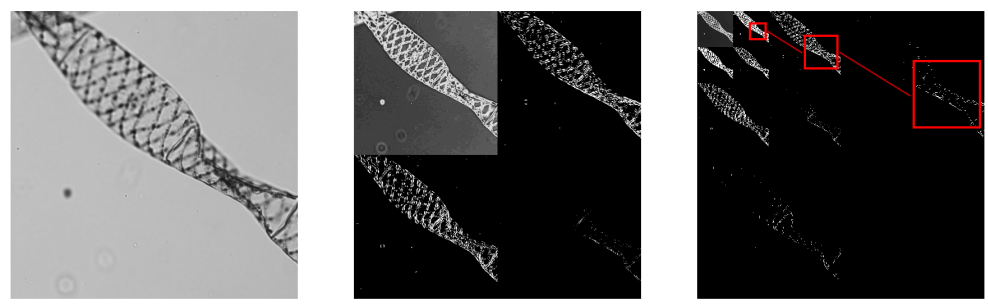

Figura 4.10: Imagen original, transformada de wavelet de nivel 1 y nivel 3 respectivamente. Los píxeles claros de la transformada de wavelet representan los bordes de la escena.

Otra forma habitual de representar el árbol de wavelet de la figura 4.9 se muestra a la derecha de la figura 4.10. En esta nueva representación, la componente LL de cada nivel se sustituye por su transformada de wavelet. En la figura 4.10 se muestra la transformada de wavelet de nivel 3, sin embargo el proceso de descomposición se puede repetir numerosas veces, hasta que el píxel en la esquina superior izquierda contiene la energía total de la escena y el resto de la imagen contiene la información de los bordes de la escena. Como se puede observar en la transformada de wavelet del ejemplo anterior, son pocos los píxeles que contienen información de los bordes de la 
escena, por lo que con pocos coeficientes se puede recuperar una imagen muy similar a la original. Esto se debe a que la imagen es sparse en el dominio de wavelet. En los algoritmos de compresión de wavelet, se eligen un número de iteraciones (niveles) y en cada nivel sólo se almacenan los coeficientes con valores mayores a un valor límite predeterminado, reduciendo de este modo el tamaño del fichero de la imagen sin una pérdida significativa de su calidad. Como las operaciones para calcular esta transformada son lineales, se trata de una excelente opción, ya que requieren un bajo coste computacional y de memoria.

\subsubsection{Descripción del algoritmo}

La transformada de wavelet se utiliza para reducir el número de patrones, $M$, necesarios para reconstruir una imagen single-pixel. A partir de la información de la transformada, se detectan cuales de las zonas de la escena han de ser nuevamente escaneadas a mayor resolución. De este modo, el primer paso del algoritmo propuesto de formación de imagen con compresión adaptativa (ACI), consiste en muestrear la escena con un conjunto de máscaras de baja resolución. A continuación, se realiza la transformada de wavelet de la imagen obtenida y esta descomposición nos da información sobre qué partes de la escena contiene regiones de interés (regiones con una alta densidad de bordes). La imagen se divide en cuatro cuadrantes y, si alguno de estos no tiene información de bordes, no se vuelven a proyectar patrones a dicha región. Este proceso se repite hasta alcanzar la resolución deseada tal y como se muestra en la figura 4.11 donde se representa el resultado de una simulación llevada a cabo con una imagen real.

En este ejemplo concreto el objetivo es recuperar una imagen de $256 \times 256$ píxeles de un grupo de células. El conjunto de máscaras inicial elegido es la base de WH de $64 \times 64$, por lo tanto, serán necesarios tres niveles para alcanzar la máxima resolución. En la primera etapa, el algoritmo adquiere una imagen de baja resolución de la escena (al redimensionar los patrones de $64 \times 64$ a $256 \times 256$ ). Si alguno de los cuadrantes tiene un número de bordes menor a un umbral predefinido, dicho cuadrante será descartado en las próximas etapas, reduciendo de este modo el número de máscaras proyectadas. En la segunda etapa del algoritmo, los patrones de $64 \times 64$ se redimensionan a $128 \times 128$, ocupando así una cuarta parte de la escena original. Si ninguno de los cuadrantes se ha descartado en la etapa anterior, el algoritmo toma en esta segunda etapa cuatro subimágenes, obteniendo así más resolución en dichas zonas. Si uno o más cuadrantes se han descartado, el algoritmo no vuelve a proyectar los patrones en las zonas descartadas. Una vez adquiridas las imágenes de esta etapa, se calculan las transformadas de wavelet de nivel uno de cada una de las imágenes. A medida que el algoritmo sigue explorando más niveles, las zonas de búsqueda son cada vez más pequeñas y el conjunto de máscaras sólo se proyecta en cada etapa en las zonas de alta resolución espacial. En la última etapa, las máscaras se proyectan en las regiones con detalles más finos de la escena. Finalmente, cuando todas las regiones han sido medidas a mayor o menor resolución, se utilizan las transformadas de wavelet obtenidas en cada etapa para 


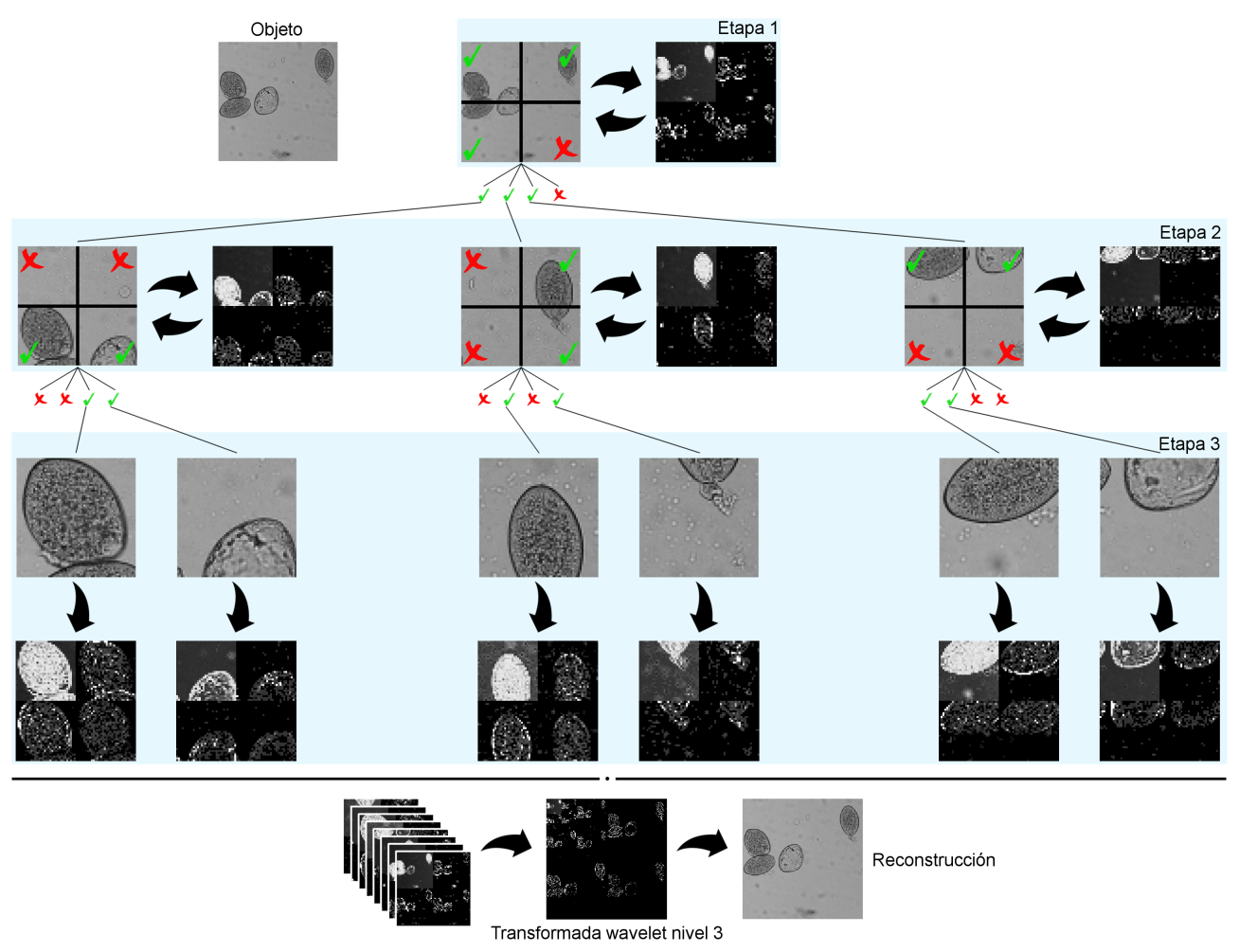

Figura 4.11: Algoritmo ACI. Objeto: Imagen de 256x256 píxeles de las células de Fasciola hepatica capturada con un microscopio comercial. Etapa 1: Imagen a baja resolución (64x64 y su transformada de wavelet de nivel 1. Se descarta el cuarto cuadrante ya que no tiene información relevante. Etapa 2: Cuadrantes de la imagen original y de nuevo sus transformadas de wavelet de nivel 1. En esta etapa se descartan 6 cuadrantes sin información de bordes. Etapa 3: Cuadrantes no descartados del nivel anterior con sus transformadas de wavelet de nivel 1 . Utilizando las transformadas de wavelet de cada una de las etapas el algoritmo construye la transformada de wavelet de nivel 3 del objeto original. A partir de la transformada inversa de wavelet se obtiene la reconstrucción de la escena original. En este ejemplo la imagen se reconstruye utilizando un $62 \%$ de las $256^{2}$ medidas establecidas por el criterio de Nyquist.

construir la transformada de wavelet de nivel 3 que se muestra en la figura 4.11 La imagen final de $256 \times 256$ píxeles se obtiene mediante la transformada inversa de wavelet.

Esta propuesta de muestreo adaptativo presenta numerosas ventajas en comparado con las técnicas tradicionales de CS. Para demostrar estos beneficios, compararemos la técnica de compresión propuesta (ACI) con el algoritmo GPSR-Basic de Figuereido et. al. [112. En esta comparación tendremos en cuenta tanto el tamaño de almacenamiento como la calidad de la imagen recuperada y el tiempo de 
computación. En primer lugar mencionaremos las ventajas de almacenamiento en memoria del nuevo algoritmo propuesto. Como se ha indicado anteriormente, para recuperar una imagen $\sqrt{N} \times \sqrt{N}$ con una cámara single-pixel, es necesario proyectar un número $M=N$ máscaras. Utilizando técnicas de CS, el número de proyecciones $M$ se reduce típicamente hasta un rango que va desde el $10 \%$ al $40 \%$ del total, sin una pérdida significativa en la calidad de la imagen. Sin embargo, como se ha visto en el apartado anterior, esta reducción implica el uso de algoritmos de optimización convexa para recuperar la imagen. Los requisitos de tiempo y memoria de estos algoritmos aumentan con el tamaño de la imagen y el número de máscaras, de modo que incluso si no se tienen limitaciones de tiempo, los requisitos de memoria pueden limitar el tamaño máximo de las imágenes a recuperar. Por ejemplo, en los experimentos llevados a cabo con un ordenador de 24 GB de RAM y un procesador Intel Xeon X5690 a $3.47 \mathrm{GHz}$, el tamaño máximo de imagen que se puede reconstruir debido a limitaciones de memoria del algoritmo de CS es de $256 \times 256$ píxeles. Dado que con el algoritmo ACI sólo se han de almacenar un conjunto reducido de máscaras de baja resolución y el vector de medidas, estas limitaciones de memoria no aparecen. De hecho, en la figura 4.12 se muestra una simulación de una imagen de 4 Megapíxeles (MP) de resolución recuperada con el algoritmo ACI propuesto. Como se puede observar, las regiones de interés de la escena se pueden recuperar a la máxima resolución mientras que las zonas sin información relevante tienen un menor detalle.
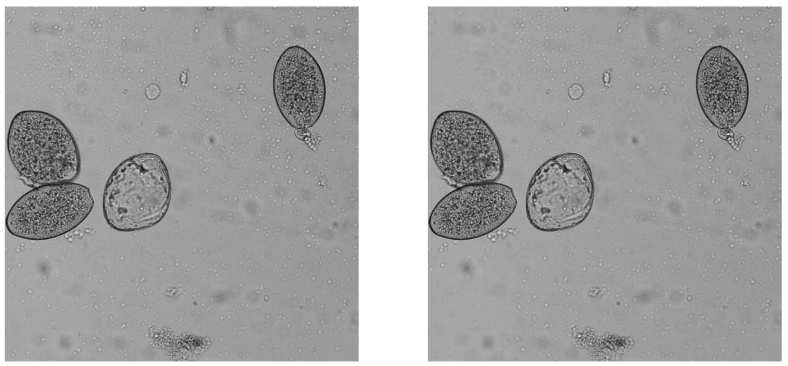

Figura 4.12: Imagen de $4 \mathrm{MP}$ de la Fasciola hepatica (izquierda) y su reconstrucción utilizando el algoritmo ACI (derecha). La reconstrucción ACI se ha adquirido con aproximadamente un $25 \%$ de las $2048^{2}$ medidas establecidas por la relación de Nyquist.

Al trabajar con imágenes de alta resolución, los tiempos de reconstrucción son también cruciales. Algunos algoritmos de compresión, como el propuesto por Radwell et. al. [79] alivian esta limitación utilizando información a priori de la escena para acelerar el proceso de reconstrucción. Sin información a priori, y siguiendo la ecuación 4.2.11. el objetivo es reducir tanto el número de patrones, $M$, como el tiempo de postprocesado, $T_{p}$. Como se ha visto, en las técnicas tradicionales de single-pixel, se requieren $M$ máscaras pero el tiempo de postprocesado, $T_{p}$, es despreciable, mientras que las técnicas de CS, reducen $M$ pero aumentan $T_{p}$. Por ello se proponen algoritmos adaptativos que reducen tanto $M$ como $T_{p}$. En la fi- 
gura 4.13 se muestra la comparación entre los algoritmos de CS y ACI. Como se puede observar, para un mismo número de medidas, la calidad de reconstrucción de ambos algoritmos es similar. Sin embargo, si nos fijamos en el tiempo de adquisición de ambos métodos, se hace evidente que la técnica ACI requiere tiempos de reconstrucción mucho menores. Este tiempo ha sido obtenido teniendo en cuenta también el tiempo de proyección de las máscaras sobre la escena. Como se puede deducir de los resultados mostrados, se pueden obtener imágenes de gran calidad con un número de medidas rondando el $50 \%$ de las establecidas por el criterio de Nyquist. Además, con esas tasas de medida y los DMDs actuales que pueden funcionar hasta a $22.7 \mathrm{kHz}$, se pueden adquirir imágenes de $128 \times 128$ a velocidades que rondan los $3 \mathrm{~Hz}$.
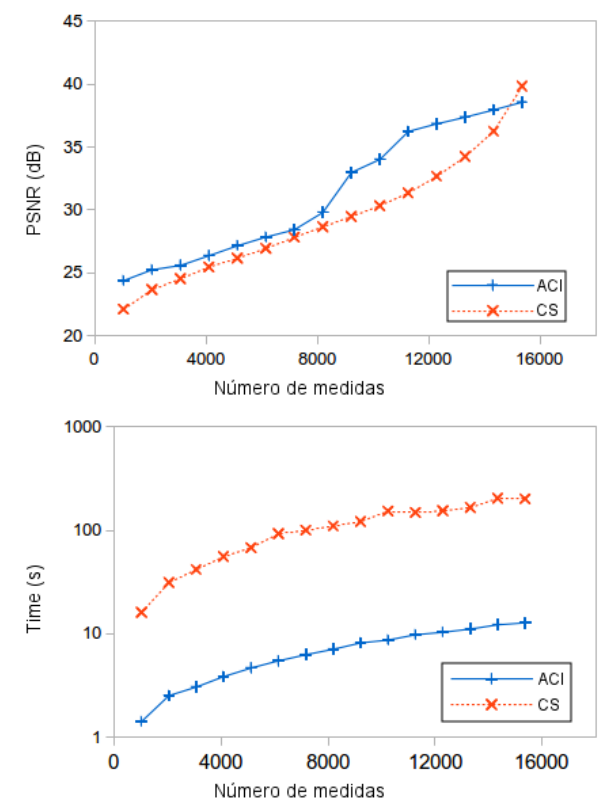

Figura 4.13: Comparación de calidad y tiempo de adquisición para los algoritmos ACI y CS.

Para llevar a cabo las comparaciones anteriores se han utilizado las tres imágenes biológicas de test que se encuentran en la figura 4.14. En esta figura se muestra además otra de las ventajas del algoritmo propuesto. Con el algoritmo ACI, las regiones de interés (Region Of Interest, ROI) se recuperan con mayor calidad que utilizando las técnicas de CS tradicionales. Para poder comprobar esta afirmación en las imágenes de la figura 4.14 se seleccionan regiones de interés y se estudia la calidad de la imagen en estas regiones para los dos algoritmos de compresión. Como la técnica de CS proyecta máscaras que cubren la escena completa, la calidad de toda la imagen aumenta con el número de máscaras enviadas, independientemente de la región de interés elegida. Sin embargo, esto no sucede con los algoritmos ACI, porque las máscaras se envían a diferentes regiones de la escena. En este caso, las 
curvas ACI tienen un comportamiento escalonado, donde cada escalón se corresponde con una etapa del algoritmo. Si existen pocas regiones de interés en la escena, los escalones se concentran en las medidas iniciales (ver curva verde), mientras que si la escena está llena de bordes, la máxima calidad en la región se alcanza más tarde (ver curva naranja). En microscopía, donde por lo general las muestras se encuentran en regiones específicas de la escena, esta característica se puede utilizar para recuperar especímenes con un número muy bajo de mediciones o para localizar regiones de interés de forma muy rápida.

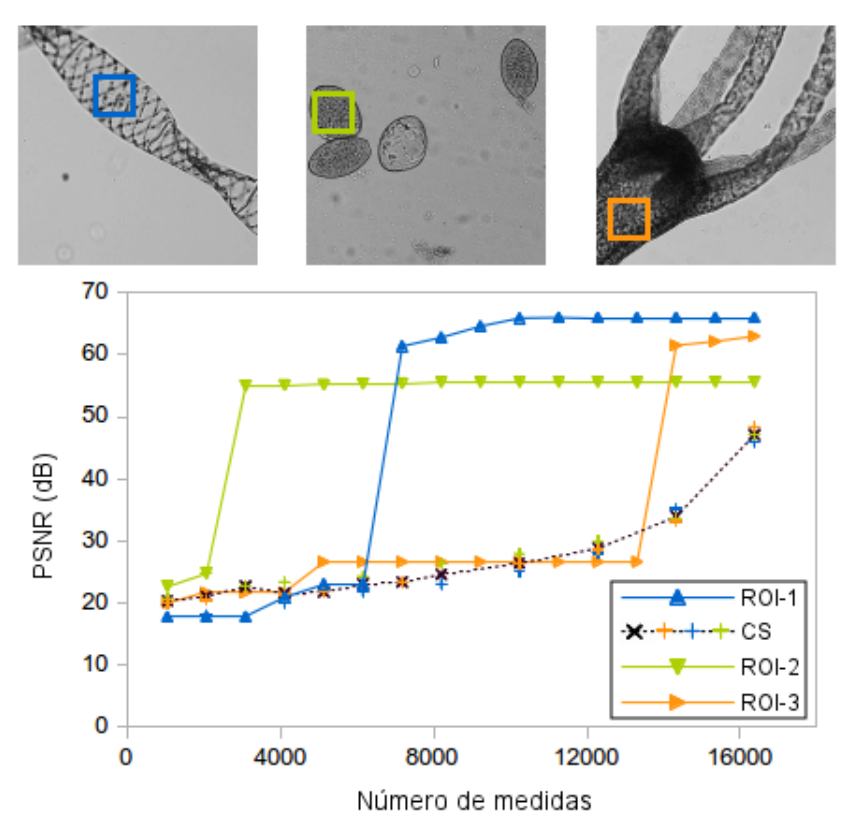

Figura 4.14: Comparación de calidad de imágenes entre ACI y CS para regiones de interés (ROI).

\subsubsection{Resultados experimentales}

Con el fin de evaluar el funcionamiento del algoritmo, se diseña el montaje experimental mostrado en la figura 4.5. El proyector envía el conjunto de máscaras a las distintas regiones del objeto, redimensionándolas al tamaño necesario. Todas las máscaras necesarias se encuentran almacenadas previamente en el ordenador y un programa escrito en LabVIEW selecciona en cada etapa las máscaras adecuadas. Dado que se envía un conjunto de máscaras de baja resolución, la carga computacional del algoritmo de reconstrucción disminuye. Tal y como se ha descrito en apartados anteriores, para obtener una imagen single-pixel el detector sin resolución espacial recoge la luz reflejada por el objeto para cada uno de los patrones. La tarjeta digitalizadora registra la señal del fotodiodo y almacena los coeficientes asociados a cada patrón. Estos coeficientes son utilizados para reconstruir las 
imágenes de cada etapa y un programa escrito en Matlab se encarga realizar las transformadas wavelet y determinar qué cuadrantes deben seguir siendo explorados.

En la figura 4.15 se muestran los resultados de dos reconstrucciones experimentales. La primera escena es la imagen de un objeto de LEGO obtenida con una resolución de $256 \times 256$. En este caso el algoritmo ACI se ejecuta en tres etapas, siendo por tanto la resolución de los patrones de WH a utilizar de $64 \times 64$. A diferencia de las técnicas de CS, el tiempo de reconstrucción depende únicamente de la tasa de refresco del SLM y no del tiempo de postprocesado. Para esta reconstrucción en particular se ha enviado el $88 \%$ del total de $256^{2}$ medidas establecidas por el criterio de Nyquist. En este experimento se ha utilizado el proyector de Texas Intruments DLP LightCrafter 4500. Aunque la máxima tasa de repetición del dispositivo es de $4225 \mathrm{~Hz}$, cuando el número de patrones a enviar es alto, los patrones no se pueden almacenar en la memoria interna, teniendo que ser enviados por la entrada de vídeo del dispositivo. Esto limita la velocidad de vídeo a $120 \mathrm{~Hz}$. Si en cada uno de los frames, que se codifica mediante 24 bits, enviamos 24 patrones binarios distintos, entonces la velocidad máxima es de $2880 \mathrm{~Hz}$ [113. Teniendo esto en cuenta, el tiempo de adquisición con nuestro sistema es de 20.02 segundos. Sin embargo, si se utilizase un modulador espacial de luz basado en micro-espejos (DMD) para uso científico, descrito en la siguiente sección, y que permite tasas de refresco de hasta $22.7 \mathrm{kHz}$, esta misma escena se podría reconstruir en 2.54 segundos.
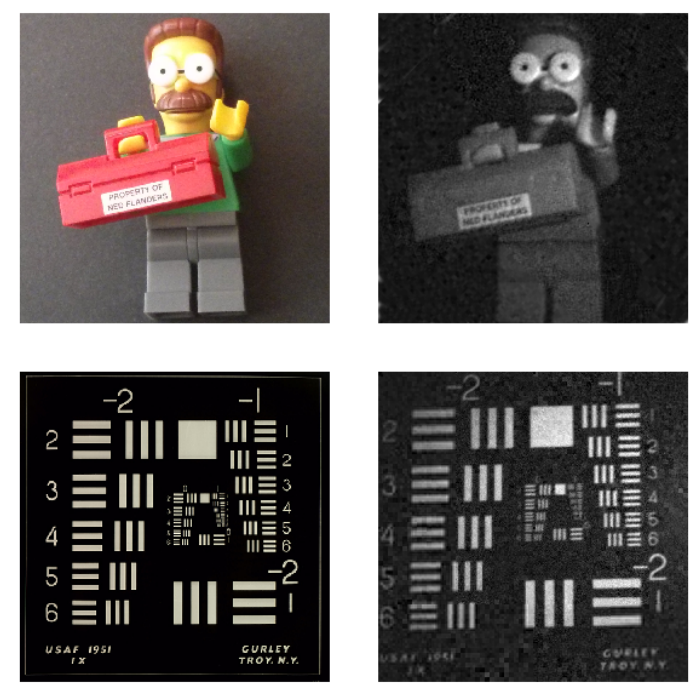

Figura 4.15: Resultados experimentales. Las imágenes de la izquierda se han obtenido con una cámara digital convencional de alta resolución, mientras que a la derecha se muestran las imágenes obtenidas con la técnica de single-pixel. En la fila superior se reconstruye una figura de LEGO a una resolución de $256 \times 256$. En la fila inferior se muestra la reconstrucción de un test de USAF1951 a una resolución de $512 \times 512$. El único post procesado hecho a las imágenes ha sido un balance de blancos. 
Como se ha mencionado anteriormente, el algoritmo propuesto destaca al capturar imágenes de gran resolución. Debido a las especificaciones del proyector, las máscaras cuadradas más grandes que se pueden proyectar tienen un tamaño de $512 \times 512$. En la segunda fila de la figura 4.15 se muestra una reconstrucción de un test de USAF a dicha resolución. En este caso, de nuevo se utilizan los patrones de WH de $64 \times 64$ pero el algoritmo ACI se ejecuta en cuatro etapas. A medida que la imagen es más grande, el número de regiones descartadas tiende a crecer, por lo que los ratios de compresión que se obtienen son mayores manteniendo una gran semejanza con la escena original. En particular, para este segundo ejemplo sólo se han medido el $55 \%$ de las $512^{2}$ medidas establecidas por el criterio de Nyquist y el tiempo de adquisición con nuestro montaje es de 50.06 segundos. De nuevo, utilizando un DMD de altas prestaciones el tiempo de adquisición se reduciría hasta los 6.35 segundos.

\subsection{Soluciones económicas para imagen en color}

Tal y como se ha visto en los apartados anteriores, los elementos principales para implementar una cámara single-pixel son un modulador espacial de luz para muestrear el objeto con un conjunto de patrones microestructurados, un detector para recoger la luz reflejada para cada patrón, una tarjeta de adquisición para digitalizar dichas adquisiciones y un ordenador para reconstruir la imagen final. Las imágenes recuperadas hasta el momento han sido en escala de grises. En esta sección se van a proponer dos alternativas para reducir el coste de la cámara single-pixel y conseguir además imágenes en color. La primera propuesta consiste en utilizar un proyector comercial de bajo coste para el envío de los patrones y la segunda en una matriz de LEDs.

\subsubsection{Resultados experimentales}

\subsubsection{Proyector comercial}

En nuestra primera propuesta de cámara single-pixel en color se utiliza un proyector comercial para codificar los patrones binarios. En particular, el proyector utilizado en los experimentos es el modelo Dell M110 Ultra-Mobile con el DMD 0.45" WXGA S450. En el montaje experimental se utiliza además como detector el fotodiodo de Thorlabs, DET36A EC para recoger la luz reflejada por el objeto. La señal de salida del fotodiodo es digitalizada por la tarjeta DAQ NI USB-6003 conectada a un ordenador.

En nuestra propuesta, únicamente es necesario un fotodiodo para recuperar la información de color. Esto se consigue aprovechando el procedimiento de codificación de color utilizado por el DLP para la proyección de vídeo. De este modo, obtenemos la información de color proyectando patrones binarios de Hadamard y midiendo con el fotodiodo en el intervalo de tiempo correspondiente a cada color. 
En particular, el proyector utilizado dispone de una rueda de cuatro filtros, uno por cada color cromático RGB y un sector transparente. Esta secuencia está representada por las barras horizontales de la zona inferior de la figura 4.16, que muestra la señal recogida por un fotodiodo para dos patrones distintos. Como se puede observar, el proyector utilizado codifica cada frame utilizando 16 bits. Cada uno de estos bits se corresponde secuencialmente con los filtros azul, rojo, verde y transparente de la rueda de colores por lo que para codificar un único frame, la rueda de filtros gira cuatro veces. La altura de estas barras indica la cantidad de luz reflejada para cada uno de los colores y esta información es la que se utiliza para obtener los coeficientes correspondientes a cada color. La barra correspondiente al blanco se utiliza para llevar a cabo la sincronización.

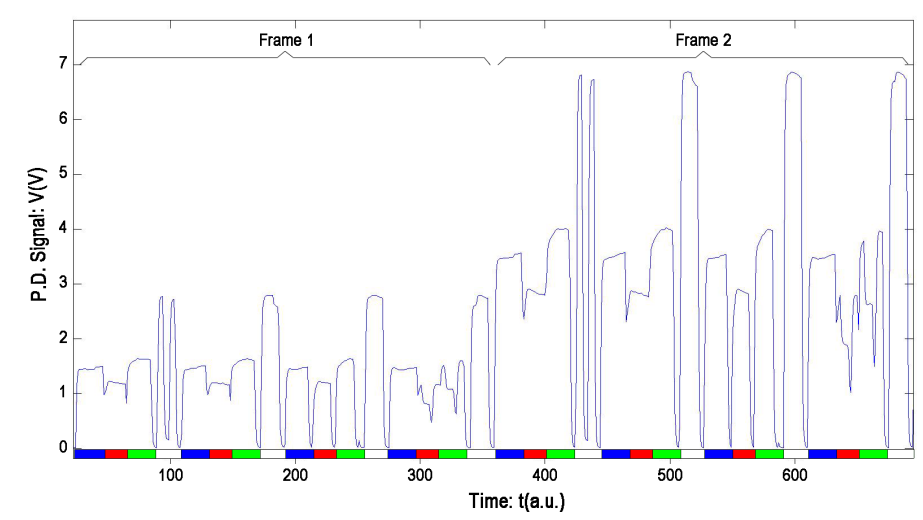

Figura 4.16: Señal eléctrica generada por el fotodiodo al enviar un par de patrones de Hadamard a la escena.

En la figura 4.17a se muestra el montaje experimental utilizado. La figura 4.17b muestra la imagen obtenida con el sistema anterior. Para este ejemplo en particular se han utilizado los patrones de Hadamard de tamaño $256 \times 256$. Estos patrones se han proyectado sobre la escena, localizada a $30 \mathrm{~cm}$ del proyector. El tamaño de los patrones a dicha distancia es de $3,5 \mathrm{~cm} \times 3,5 \mathrm{~cm}$. Utilizando CS, el número total de medidas para recuperar la escena es 6500 , el $10 \%$ de las $256^{2}$ medidas establecidas por el criterio de Nyquist. Como el envío de patrones se realiza a la velocidad de vídeo, que en este caso es $60 \mathrm{~Hz}$, la imagen se recupera en 1 min $40 \mathrm{~s}$.

\subsubsection{Matriz de LEDs}

En la figura 4.18 se muestra un esquema del funcionamiento de la cámara singlepixel con una matriz de LEDs y una FPGA. La idea consiste en utilizar un sistema óptico sencillo para formar una imagen de la matriz de LEDs sobre la escena. La FPGA se encarga del almacenamiento de los patrones binarios y del control de la matriz de LEDs. Los patrones almacenados en la FPGA se codifican en la matriz y 


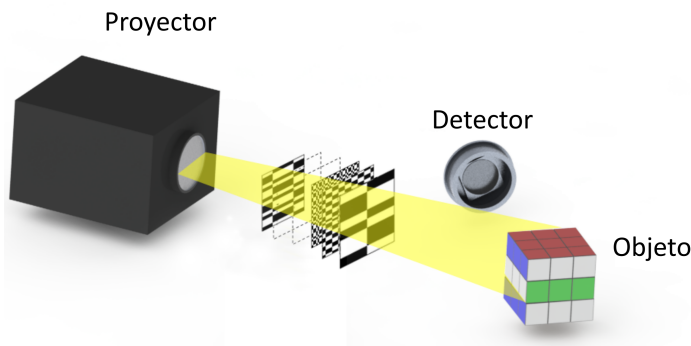

(a)

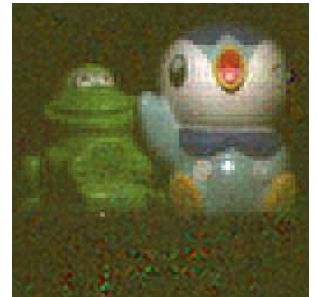

(b)

Figura 4.17: (a) Esquema experimental de cámara single-pixel. (b) Imagen en color con resolución $256 \times 256$ obtenida con dicho montaje.

un sistema óptico los proyecta sobre la escena. Un fotodiodo recoge la luz reflejada por el objeto y la propia FPGA digitaliza y almacena los datos proporcionados por el fotodiodo. Una vez se obtienen los coeficientes de cada patrón, ya se puede reconstruir la imagen single-pixel. Se trata por tanto de una propuesta de cámara single-pixel de muy bajo coste ya que se prescinde de la tarjeta digitalizadora, el DMD y el ordenador.

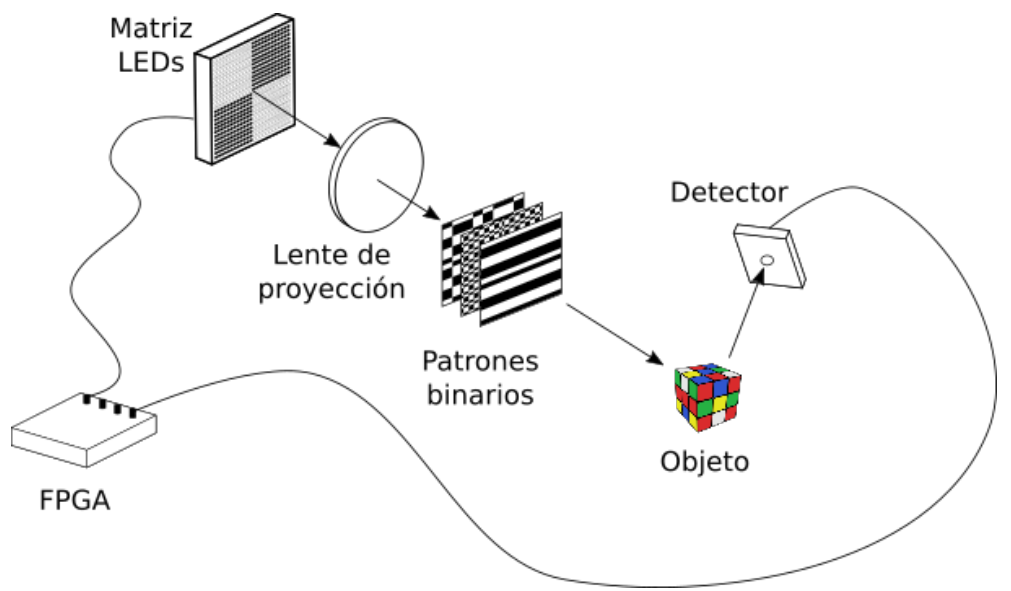

Figura 4.18: Esquema de cámara single-pixel utilizando una matriz de LEDs y una FPGA. La matriz de LEDs codifica los patrones almacenados en la FPGA y un sistema óptico los proyecta sobre el objeto. Un fotodiodo recoge las intensidades reflejadas por cada patrón.

En la figura 4.19 se muestra una fotografía del montaje experimental de la cámara single-pixel construida utilizando una matriz de LEDs. La matriz utilizada es de $32 \times 32$ LEDs, con una separación entre ellos de $4 \mathrm{~mm}$. A una distancia de $35 \mathrm{~cm}$ de la matriz se coloca una lente de focal $f=100 \mathrm{~mm}$ y esta forma una imagen de $4 \times 4 \mathrm{~cm}$ de los patrones sobre el objeto. El fotodiodo utilizado es el PDA 100A-EC y la FPGA es la DE1-SoC programada mediante Quartus Prime para codificar los 
patrones de $\mathrm{WH}$ a una frecuencia de muestreo de $10 \mathrm{kHz}$. Dado que la resolución de los patrones de WH viene limitada por la matriz de LEDS, la máxima resolución alcanzada es de $32 \times 32$. Para reconstruir una imagen se envían los 1024 patrones de la base, con lo que es posible recuperar una imagen en escala de grises en $0.2 \mathrm{~s}$.

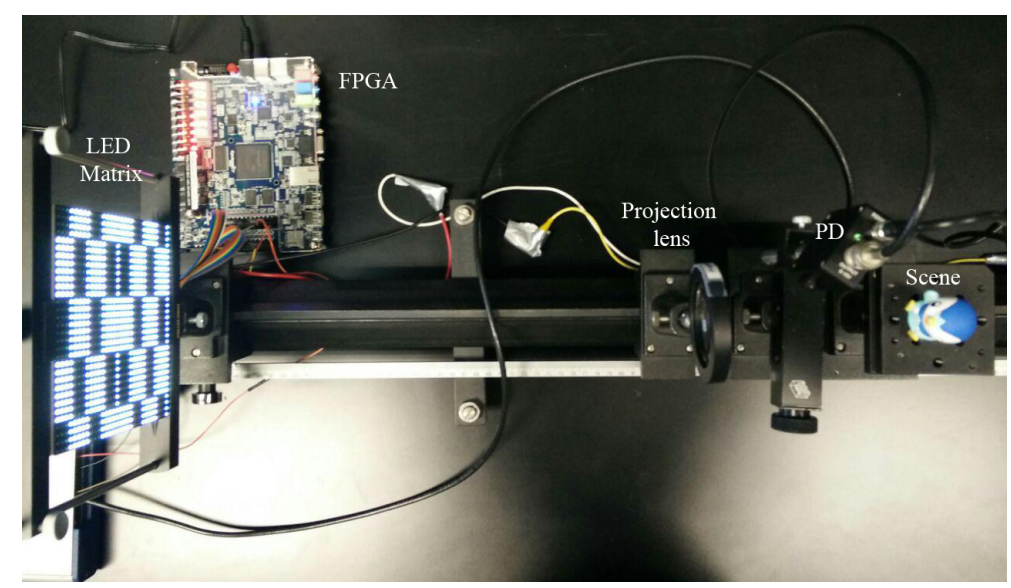

Figura 4.19: Montaje experimental de una cámara single-pixel utilizando una matriz de LEDs y una FPGA.

Aunque no aparecen en la imagen, en esta primera prueba de concepto del sistema también se utiliza la tarjeta de adquisición DAQ USB 6351 para almacenar los datos recogidos por el fotodiodo. Además, un ordenador controla, mediante un programa de LabVIEW, el registro de estos datos y posterior reconstrucción de la imagen single-pixel. Sin embargo, el objetivo en el futuro es lograr integrar todas estas operaciones en la FPGA. Hasta el momento lo que se ha conseguido con este montaje ha sido capturar vídeos single-pixel a una velocidad de 5 fps. En la figura $4.20 \mathrm{a}$ se muestra un frame de un vídeo capturado con el montaje anterior. Además, también se puede obtener imagen en color enviando los patrones secuencialmente en rojo, verde y azul. La imagen en color que se muestra en la figura $4.20 \mathrm{~b}$ se ha obtenido en $0.6 \mathrm{~s}$.

Como se puede observar en la parte central de las imágenes capturadas aparece una línea horizontal oscura. Este defecto se debe al funcionamiento de la matriz de LEDs y sólo aparece al trabajar a altas frecuencias. Para emplear la matriz como fuente de luz estructurada, es necesario controlar el encendido y apagado de todos los LEDs, y estos vienen ya interconectados para evitar tener que utilizar tantos pines de control como LEDs tiene la matriz. En nuestro dispositivo, estas interconexiones están hechas de forma que la fila 1 y la 17 , la 2 y la $18 . .$. están conectadas. De este modo, la matriz se ilumina mediante un barrido que recorre en paralelo la mitad superior e inferior de la matriz. Aunque la tasa de refresco de todas las líneas de la matriz es la misma, la velocidad efectiva de la última iteración del barrido es mayor. Esto significa que la fila 16 y la fila 32 de la matriz permanecen 


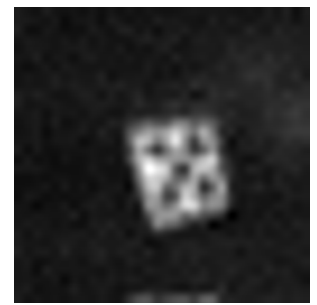

(a)

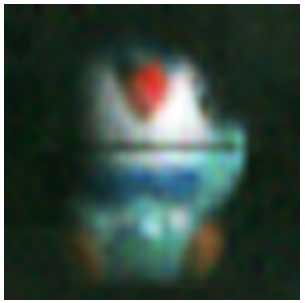

(b)

Figura 4.20: Imágenes obtenidas utilizando el montaje experimental de la figura 4.18 (a) Frame de un vídeo capturado a 5 fps. (b) Imagen en color obtenida al enviar una secuencia de patrones en rojo, verde y azul. Para una mejor visualización se ha realizado una interpolación bicúbica y se ha aumentado el brillo.

iluminadas un menor tiempo, lo que se traduce en defectos de la imagen single-pixel en estas líneas. Para corregir este defecto, en el futuro se puede definir una menor tasa de refresco para esas líneas o multiplicar el valor de la señal final por un factor que compense el menor tiempo de exposición.

\subsection{Imagen $3 \mathrm{D}$ con sensores de un sólo píxel}

En esta sección se describe una cámara estereoscópica single-pixel para visualizar escenas 3D y se muestran los resultados experimentales obtenidos. También se describe el desarrollo de una técnica de fotometría estéreo para recuperar el modelo $3 \mathrm{D}$ de un objeto. Ambas propuestas se basan en las versiones económicas de cámaras single-pixel descritas en el apartado anterior.

\subsubsection{Estereoscopía}

Cuando el objetivo no es obtener una reconstrucción del modelo completo en 3D sino que se pretende obtener una visualización 3D de la escena, la mejor opción consiste en imitar el proceso estereoscópico que siguen los humanos para obtener la información de profundidad. En principio, se podría pensar que desplazando un detector sin resolución espacial en la configuración de cámara single-píxel, sería posible obtener varias perspectivas $2 \mathrm{D}$ de la escena $3 \mathrm{D}$. Sin embargo, en las cámaras single-pixel no es la posición del detector sino la posición del proyector lo que proporciona distintas perspectivas 2D. Con el fin de aclarar la diferencia entre capturar la escena con varios fotodiodos y capturarla con varios proyectores, se realiza el experimento representado en la figura 4.21. La escena se muestrea con una secuencia de patrones mientras dos fotodiodos situados en distintas posiciones recuperan la señal de intensidad de la luz. 


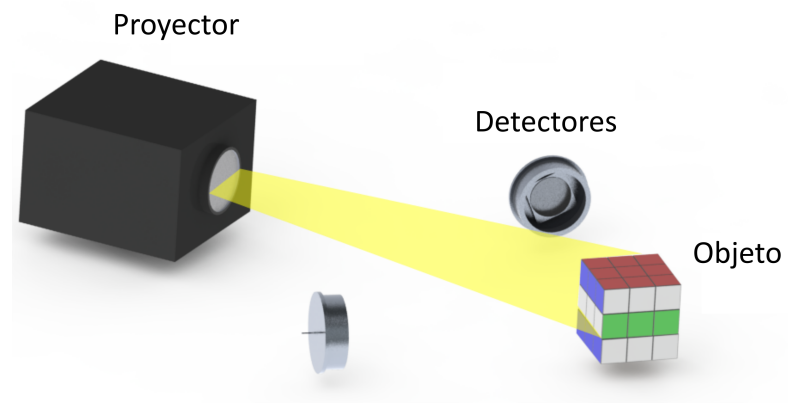

Figura 4.21: Montaje experimental para conseguir imagen single-pixel con dos fotodiodos. La imagen obtenida con cada fotodiodo se corresponde con la que se obtendría al colocar una fuente de luz puntual en la posición del fotodiodo.

En este primer montaje se coloca un objeto a $32 \mathrm{~cm}$ del proyector. El tamaño de los patrones y el tamaño del píxel a esa distancia son $3,2 \times 3,2 \mathrm{~cm}$ y $250 \mu \mathrm{m}$ respectivamente. Las dos imágenes en color obtenidas utilizando la aproximación descrita en la figura 4.21 se muestran en la figura $4.22 \mathrm{~b}$ y $4.22 \mathrm{c}$. La figura $4.22 \mathrm{a}$ es una imagen capturada con una cámara CCD, la figura 4.22b es la imagen reconstruida a partir de la señal recogida por el fotodiodo de la izquierda y la figura $4.22 \mathrm{c}$ es la que se obtiene al utilizar los datos del fotodiodo de la derecha. Como se puede observar comparando las figuras b y c, se trata de una imagen con la misma perspectiva de la escena por lo que no proporciona información de disparidad. Sin embargo, las imágenes parecen estar iluminadas desde distintos puntos de vista. Esto se puede confirmar comparando la apariencia del dado en ambas imágenes. Como se puede comprobar, el número 4 del dado sólo se distingue en la imagen capturada por el fotodiodo de la izquierda mientras que el número 5 sólo se observa en la imagen de la derecha. Por lo tanto, cada imagen se obtiene del mismo modo que se capturaría colocando una cámara convencional en la posición del proyector y una fuente puntual de luz blanca en la posición del fotodiodo, como puede demostrarse con el principio de reciprocidad de Helmholtz.

Estas imágenes con distintas iluminaciones se pueden utilizar para hacer una reconstrucción tridimensional del objeto. Pero si el objetivo es sólo visualizar la escena en tres dimensiones utilizando una cámara single-pixel, es más sencillo realizar el montaje experimental que se muestra en la figura 4.23 . En esta configuración cada patrón de $\mathrm{WH}$ se proyecta sobre la escena 3D desde dos direcciones distintas, al desplazar el mismo patrón a dos posiciones distintas del proyector. Un divisor de haz de $90^{\circ}$ y dos espejos, separados una distancia aproximadamente igual a la distancia interocular, se colocan de forma que ambos patrones se superponen en un mismo plano de la escena 3D. En este montaje se utiliza de nuevo el proyector comercial Dell M110 Ultra-Mobile para proyectar los patrones sobre un objeto colocado a $30 \mathrm{~cm}$ del proyector. Se elige este proyector porque a pesar de ser más 


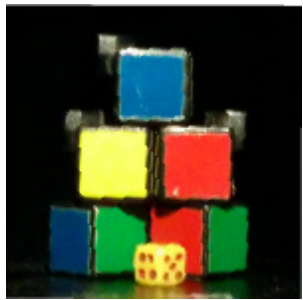

(a)

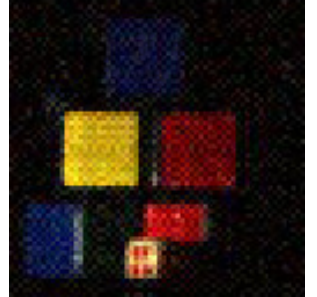

(b)

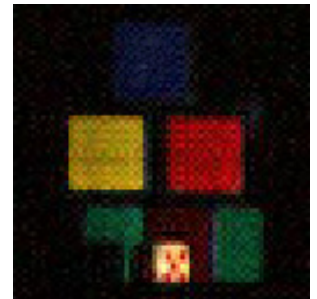

(c)

Figura 4.22: Resultados obtenidos con el montaje experimental de la figura 4.21. (a) Imagen capturada con una cámara CCD. (b) Imagen obtenida con los coeficientes obtenidos con el fotodiodo de la izquierda. (c) Imagen obtenida con los coeficientes obtenidos con el fotodiodo de la derecha.

lento que la matriz de LEDs, se pueden obtener imágenes de mayor resolución, que nos proporcionarán una mejor visualización $3 \mathrm{D}$.

En principio, cada patrón del par utilizado para generar dos perspectivas distintas se debería proyectar secuencialmente sobre el objeto para medir en cada iteración los coeficientes asociados a cada perspectiva. Sin embargo, una alternativa más rápida consiste en enviar un par de patrones con colores cromáticamente opuestos, tal y como muestra la figura 4.23 . Esto nos proporcionará directamente el anaglifo resultante, es decir, una imagen en la que se superponen dos imágenes estereoscópicas del objeto en dos colores complementarios. De nuevo, para conseguir la información de color se aprovecha el modo de funcionamiento del proyector, que codifica secuencialmente la información de color tal y como muestra la figura 4.7 . A pesar de que el anaglifo no es la mejor opción para visualizar imágenes estereoscópicas, es la única técnica que nos permite mostrar resultados experimentales en papel, y facilita una visualización 3D con las gafas apropiadas.

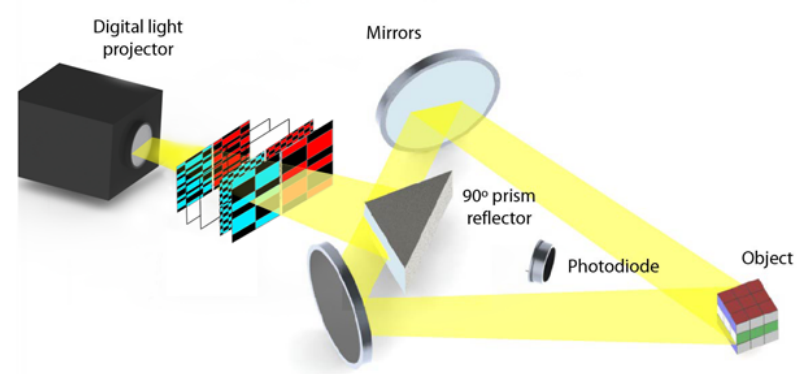

Figura 4.23: Montaje experimental para reconstruir un par estereoscópico de imágenes en color utilizando un fotodiodo. Un par de patrones de Hadamard con colores cromáticamente opuestos se superponen en un plano 3D de la escena. La señal capturada por el fotodiodo permite reconstruir directamente el anaglifo. 
Los resultados experimentales de la figura 4.24 muestran un par de imágenes con dos perspectivas distintas. La imagen de la izquierda de la figura 4.24 muestra la imagen en color obtenida cuando se utiliza la señal del fotodiodo de la figura 4.23 al enviar un conjunto de patrones binarios desde el espejo de la izquierda, y la imagen central de la figura 4.24 es la equivalente obtenida utilizando los patrones de luz que provienen del espejo de la derecha. Finalmente, la imagen de la derecha de la figura 4.24 es el anaglifo obtenido con las dos imágenes anteriores, que es equivalente al que se obtiene enviando los patrones rojo y cian simultáneamente, tal y como se ha descrito anteriormente. En este experimento hemos utilizado los patrones de WH de $256 \times 256$. El tamaño de los patrones y el píxel sobre el objeto son $6 \times 6 \mathrm{~cm}$ y $234 \mu \mathrm{m}$ respectivamente. En este caso, la máxima frecuencia del proyector utilizado es de $60 \mathrm{~Hz}$. Dado que sólo utilizamos el $10 \%$ de los patrones establecidos por el criterio de Nyquist, la imagen del anaglifo se obtiene en 109 segundos.
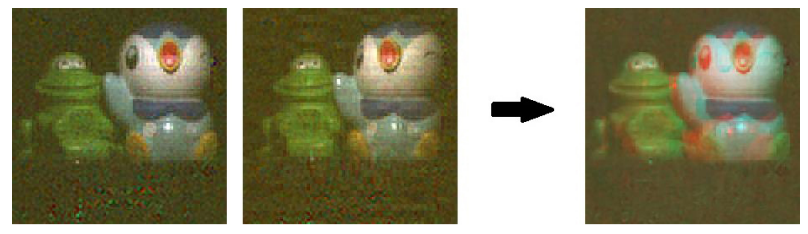

Figura 4.24: Imágenes recuperadas utilizando el montaje experimental de la figura 4.23 Para una mejor visualización a la imagen del anaglifo se le ha aumentado el brillo y reducido el ruido.

\subsubsection{Fotometría estéreo}

Como se ha adelantado en la sección anterior, a partir de varias imágenes con distintas iluminaciones de un objeto, se puede obtener una reconstrucción tridimensional del mismo utilizando la técnica de fotometría estéreo. Esta técnica estima las normales a la superficie de un objeto mediante la observación del mismo bajo diferentes condiciones de iluminación. La fotometría estéreo se basa en el hecho de que la cantidad de luz reflejada por una superficie depende de su orientación en relación con la fuente de luz y el observador. Midiendo la cantidad de luz reflejada en cada punto es posible estimar la normal a la superficie, con lo que al mapear el objeto completo, obtendremos una reconstrucción 3D del mismo [114]. Existen dos metodologías distintas para abordar este problema denominadas fotometría estéreo con calibración y sin calibración. Estas dos técnicas se diferencian en que en la segunda no es necesario conocer las posiciones de las fuentes de luz, mientras que en las calibradas, este parámetro de entrada es obligatorio.

Para poder trabajar con algoritmos de fotometría estéreo sin calibración, es necesario asumir que la superficie del objeto es lambertiana, lo que nos permite reducir en el número de incógnitas [115]. Además, se pueden aplicar restricciones 
adicionales basadas en condiciones de la geometría de la superficie del objeto, para reducir el número final de variables. Esta última restricción se conoce generalmente como la ambigüedad de bajo relieve generalizado (Generalized Bas-Relief, GBR).

En nuestro experimento hemos utilizado el código descrito en [116, 117]. Para reducir las ambigüedades derivadas de los algoritmos de fotometría estéreo sin calibración, este método utiliza la información de los puntos de la escena donde la reflexión lambertiana es máxima. Además, los autores proponen como restricción GBR asumir como condición en la geometría de los objetos un modelo basado en semicírculos en el espacio 3D. Gracias a esto, no es necesario proporcionar información de la posición de las fuentes de luz, o en el caso de cámara single-pixel, de los detectores puntuales. Este algoritmo únicamente necesita como parámetros de entrada varias imágenes de la escena con distinta iluminación.

Para capturar dichas imágenes con una cámara single-pixel económica y rápida utilizamos el montaje experimental de la figura 4.18. Colocando un mismo fotodiodo en cinco posiciones distintas, y moviéndolo de izquierda a derecha, obtenemos las imágenes que se muestran en la figura 4.25. Estas imágenes se pasan como entrada al algoritmo que nos devuelve la información de profundidad que se muestra en la figura 4.26. La imagen de la izquierda representa la información de profundidad del objeto, donde el color azul indica mayor profundidad y el rojo, una profundidad menor. Para una visualización más clara, a partir de la imagen de la izquierda se puede obtener la imagen en relieve del objeto, como se muestra a la derecha. Como se puede observar, se obtiene una buena reconstrucción del objeto tridimensional a pesar de utilizar patrones de baja resolución. Sin embargo, como sucede con muchos algoritmos de fotometría estéreo, con esta técnica pueden aparecer resultados erróneos, cuando existen saltos abruptos en la profundidad.

Finalmente cabe mencionar que en este capítulo se han propuesto dos alternativas para la formación de imagen 3D con cámaras de un sólo píxel. La primera alternativa de estereoscopía, será más apropiada cuando el objetivo sea la visualización de una escena en tres dimensiones, mientras que la técnica de fotometría estéreo, será más apropiada para conseguir una reconstrucción tridimensional de un objeto.

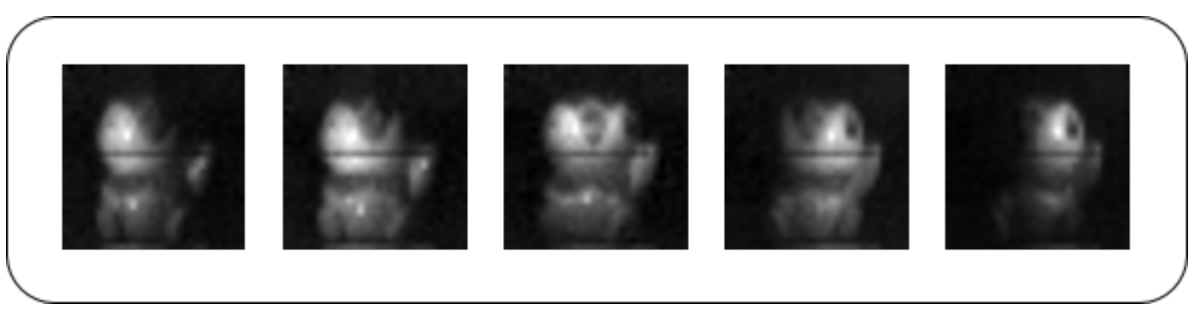

Figura 4.25: Imágenes obtenidas utilizando el montaje experimental de la figura 4.18 desplazando el fotodiodo de la izquierda a la derecha del objeto. 

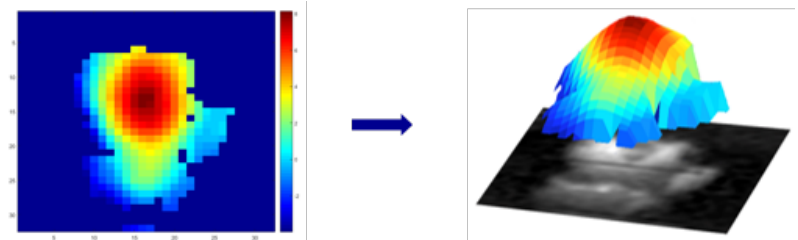

Figura 4.26: Imagen 3D del objeto utilizando la técnica de fotometría estéreo con las imágenes de la figura 4.25 



\title{
Capítulo 5
}

\section{Conclusiones y trabajo futuro}

\author{
Este adiós no maquilla un hasta luego, \\ este nunca no esconde un ojalá, \\ esta ceniza no juega con fuego, \\ este ciego no mira para atrás.
}

Joaquín Sabina

Resumen: Tal y como se ha descrito en la introducción, no existe una única tecnología de imagen 3D y esto se debe a que, dependiendo de la aplicación, unas técnicas son más apropiadas que otras. En esta tesis se han estudiado diferentes alternativas para la captura y visualización de imagen 3D. En primer lugar, se ha propuesto una solución para la visualización pasiva de imagen 3D. Para ello, ha planteado un modelo de calibración y rectificación de múltiples cámaras que ha permitido la generación de vistas virtuales intermedias. Posteriormente, se ha utilizado la técnica de imagen integral para mejorar los resultados de clasificación de gestos respecto a los obtenidos con imagen 2D o con la técnica de luz estructurada. Finalmente, se han desarrollado métodos para obtener imagen 3D con la técnica de detección con un solo píxel. En particular, se han utilizado dos métodos distintos: estereoscopía, para visualizar la escena en tres dimensiones y fotometría estéreo, para obtener el modelo 3D del objeto capturado. Además, se ha propuesto un algoritmo capaz de reducir el tiempo de captura con este nuevo modelo de cámara. 


\subsection{Aportaciones}

A día de hoy los dispositivos más comunes para visualización $3 \mathrm{D}$ son los estereoscópicos, con los que es necesario utilizar gafas u otros dispositivos que resultan molestos a los usuarios finales. Dadas las limitaciones de otras tecnologías de imagen 3D como la holografía digital o los dispositivos 3D volumétricos, los mayores avances tecnológicos para la visualización 3D giran en torno a los dispositivos autoestereoscópicos multivista. Dado que uno de los mayores inconvenientes de esta tecnología reside en la creación de contenido, se ha propuesto un algoritmo de generación de vistas sintéticas. En el capítulo dos de esta tesis se ha propuesto un algoritmo en cuatro pasos que permite obtener todas las vistas necesarias para visualizar una escena real, en una pantalla autoestereoscópica multivista. El método consiste en capturar la escena utilizando un número limitado de cámaras y, a partir de las imágenes obtenidas, sintetizar las vistas necesarias para una correcta visualización en el dispositivo multivista. Los pasos para llevar a cabo el proceso han sido la calibración y rectificación del sistema óptico, la construcción de mapas de disparidad y, finalmente, el algoritmo de obtención de vistas sintéticas. Los resultados obtenidos se han evaluado cuantitativamente y cualitativamente, proporcionando resultados satisfactorios y prometedores.

Aunque en esta tesis se ha propuesto la obtención de un vector de 8 imágenes, que son las vistas necesarias para realizar una visualización $3 \mathrm{D}$ en una pantalla concreta, el método se puede extender para generar el número de vistas requeridos por otros dispositivos autoestereoscópicos. Por lo tanto, la principal ventaja de este algoritmo es la habilidad de crear contenido para cualquier dispositivo autoestereoscópico multivista a partir de un limitado número de cámaras.

En cuanto a los métodos de captura de imagen 3D, la imagen integral es una solución muy utilizada debido a que se trabaja con luz incoherente o luz ambiente, lo que permite configurar un sistema pasivo. Además, la disposición matricial de las cámaras ofrece paralaje en los dos ejes, el vertical y el horizontal. Por ello, en el capítulo tres hemos aplicado la técnica de detección pasiva 3D conocida como imagen integral para el reconocimiento de gestos. El análisis y los resultados de clasificación obtenidos con el método de bolsa de palabras (bag of words) revelan que la información capturada con la técnica de imagen integral permite obtener mejores resultados en la clasificación de gestos. Esto se debe al poder de seccionado de esta técnica que permite enfocar a profundidades particulares de la escena, lo que facilita la captura de información más discriminativa que en los vídeos monoculares convencionales.

Nuestros resultados del capítulo tres muestran además que, en presencia de oclusiones, se acentúa la mejora en la tarea de reconocimiento de acciones con imagen integral. Si se comparan los resultados de clasificación sin oclusión con otro sistema de formación de imagen 3D popular, como es la imagen con información de rango, se obtienen resultados similares. Sin embargo, bajo oclusión, la imagen 
integral no supera únicamente a la imagen monocular, sino también a otras tecnologías de obtención de imagen 3D. A pesar de que el conjunto de datos recopilado y utilizado es relativamente pequeño, es lo suficientemente representativo como para tener una evaluación prospectiva de las capacidades de imagen integral frente a otras modalidades de sensores tridimensionales, especialmente en entornos con oclusión.

Las cámaras de un solo píxel son una alternativa prometedora a las técnicas de imagen convencional en aplicaciones tales como la obtención de imágenes polarimétricas y multiespectrales, o para tratar bandas espectrales exóticas. Además, se han aplicado con éxito en obtención de imágenes de objetos inmersos en medios turbios. En el capítulo cuatro de esta tesis se han propuesto diversos métodos de obtención de imagen $3 \mathrm{D}$ con la técnica de cámara de un solo píxel. Asimismo, se han propuesto soluciones económicas para la construcción de este tipo de cámaras y se ha diseñado un algoritmo para reducir el tiempo de adquisición de las imágenes. Estos nuevos enfoques pueden ser el primer paso para extender todas las aplicaciones de la cámara de un solo píxel a la imagen 3D.

Para mejorar las prestaciones de este tipo de dispositivos hemos diseñado un algoritmo adaptativo que permite recuperar imágenes de alta resolución con tiempos más bajos en comparación con los enfoques tradicionales de CS. Además, hemos demostrado computacionalmente la eficacia de la técnica para recuperar perfectamente las regiones de interés de una imagen con tasas de muestreo inferiores al límite establecido por el criterio de Nyquist. En comparación con otras técnicas, no es necesario tener un conocimiento previo de la escena para lograr mayores velocidades. Además, hasta el momento la técnica de single-pixel no ha podido proporcionar imágenes de alta resolución debido a restricciones de tiempo y memoria. Sin embargo, en la solución propuesta no aparecen restricciones de memoria y el único factor limitante reside en la tasa de refresco del modulador espacial de luz. Por lo tanto, con la técnica descrita es posible obtener imágenes experimentales de alta resolución con dimensiones comparables al número de píxeles del modulador.

En el campo de la imagen 3D con detectores de un sólo píxel, hemos demostrado la posibilidad de producir imágenes estereoscópicas en color con un único fotodiodo y un proyector comercial. Este sistema de bajo coste permite capturar un par de imágenes que se pueden utilizar como entrada en una pantalla tridimensional. En principio, el tiempo necesario para proyectar patrones de luz implica una velocidad de captura baja. Hemos propuesto para ello otra solución económica distinta basada en una matriz de LEDs. En este caso no sólo se ha abaratado el coste de este tipo de cámaras sino que también se ha propuesto una solución tan rápida como la proporcionada por los DMDs de uso científico. Además, a partir de los dos sistemas propuestos hemos aclarado la diferencia entre el uso de varios fotodiodos y varias perspectivas en la proyección. En el primer caso se presenta una reconstrucción 3D de un objeto utilizando la técnica de fotometría estéreo mientras que el segundo 
método la información 3D de la escena se puede inferir a partir de la disparidad en las imágenes capturadas.

\subsection{Trabajo futuro}

En todas las soluciones propuestas en esta tesis existe un factor limitante común para la obtención de imagen $3 \mathrm{D}$, el tiempo de adquisición. Un reto para el futuro consiste en diseñar algoritmos capaces de trabajar a tiempo real. Aunque la cámara Kinect es un sistema que permite la captura de información de profundidad a tiempo real, se trata de un sistema activo que requiere iluminar la escena, lo que limita las profundidades obtenidas. Otra solución para la obtención de imagen 3D a tiempo real son las cámaras plenópticas o de imagen integral. En este caso la matriz de microlentes limita la resolución espacial de las imágenes obtenidas, por lo que es común utilizar arreglos de cámaras, tal y como se ha propuesto en esta tesis. Para trabajar con estos sistemas pasivos de obtención de imagen 3D en alta resolución, los avances en el tratamiento de imagen pueden ser claves. Uno de los problemas más estudiados, es el problema de la correspondencia de puntos entre cámaras. La optimización de estos algoritmos de correspondencia y la obtención de resultados más fiables supondrán una gran mejora en el futuro.

Por otro lado, los sensores tridimensionales generan una enorme cantidad de información que debe almacenarse o transmitirse. El diseño de algoritmos de compresión para reducir la cantidad de información necesaria para representar la imagen 3D es también un reto. Una solución podría ir encaminada a utilizar algoritmos adaptativos en la captura, que sólo recojan información de profundidad detallada de las zonas que lo requieran, mientras que en las zonas de la escena con poco detalle capturarían información 3D con menor resolución. Además, para agilizar los cálculos necesarios para la obtención de la información en profundidad, será necesario optimizar los algoritmos utilizados y ejecutarlos en el hardware gráfico o utilizar, como se ha propuesto en esta tesis, una FPGA.

Como observación final cabe señalar que, como ya se ha adelantado, no existe una única tecnología óptima de imagen 3D para todas las aplicaciones. Además, en esta tesis hemos visto que existe una amplia variedad de limitaciones técnicas que se deben resolver en cada una de las tecnologías disponibles. Existen muchos retos para resolver en el futuro y puede que la clave para alcanzar la tecnología 3D ideal se encuentre en la adopción de un método que combine diferentes técnicas de imagen 3D o incluso que incorpore en su definición el modelo de cámara de un sólo píxel. La adopción de una tecnología 3D económica y rápida serviría, no sólo como se ha demostrado en esta tesis, para mejorar los resultados de clasificación en el reconocimiento de gestos, sino también para multitud de aplicaciones. 


\section{Bibliografía}

[1] Y.-S. Kang and Y.-S. Ho, "An efficient image rectification method for parallel multi-camera arrangement," IEEE Transactions on Consumer Electronics, vol. 57, no. 3, pp. 1041-1048, 2011.

[2] R. A. Jarvis, "A perspective on range finding techniques for computer vision," IEEE Transactions on Pattern Analysis and Machine Intelligence, no. 2, pp. 122-139, 1983.

[3] B. Curless, "From range scans to 3d models," ACM SIGGRAPH Computer Graphics, vol. 33, no. 4, pp. 38-41, 1999.

[4] M. J. Golay, "Multi-slit spectrometry," JOSA, vol. 39, no. 6, pp. 437-444, 1949.

[5] M. B. Wakin, J. N. Laska, M. F. Duarte, D. Baron, S. Sarvotham, D. Takhar, K. F. Kelly, and R. G. Baraniuk, "An architecture for compressive imaging," in 2006 International Conference on Image Processing. IEEE, 2006, pp. $1273-1276$.

[6] C. Wheatstone, "Contributions to the physiology of vision.-part the first. on some remarkable, and hitherto unobserved, phenomena of binocular vision," Philosophical transactions of the Royal Society of London, vol. 128, pp. 371$394,1838$.

[7] T. Okoshi, Three-dimensional imaging techniques. Elsevier, 2012.

[8] J. Geng, "Three-dimensional display technologies," Advances in optics and photonics, vol. 5, no. 4, pp. 456-535, 2013.

[9] T. Järvenpää and M. Salmimaa, "Optical characterization of autostereoscopic 3-d displays," Journal of the Society for Information Display, vol. 16, no. 8, pp. 825-833, 2008.

[10] W. Matusik and H. Pfister, "3d tv: a scalable system for real-time acquisition, transmission, and autostereoscopic display of dynamic scenes," $A C M$ Transactions on Graphics (TOG), vol. 23, no. 3, pp. 814-824, 2004. 
[11] A. Stern and B. Javidi, "Three-dimensional image sensing, visualization, and processing using integral imaging," Proceedings of the IEEE, vol. 94, no. 3, pp. 591-607, 2006.

[12] J.-H. Park, Y. Kim, J. Kim, S.-W. Min, and B. Lee, "Three-dimensional display scheme based on integral imaging with three-dimensional information processing," Optics express, vol. 12, no. 24, pp. 6020-6032, 2004.

[13] K. Dimitropoulos, T. Semertzidis, and N. Grammalidis, "3d content generation for autostereoscopic displays," in 2009 3DTV Conference: The True Vision-Capture, Transmission and Display of 3D Video. IEEE, 2009, pp. $1-4$.

[14] M. Magnor et al., "3d-tv-the future of visual entertainment," in Proc. of Multimedia Databases and Image Communications (MDIC?04), 2004.

[15] N. S. Holliman, N. A. Dodgson, G. E. Favalora, and L. Pockett, "Threedimensional displays: a review and applications analysis," IEEE Transactions on Broadcasting, vol. 57, no. 2, pp. 362-371, 2011.

[16] C. Van Berkel, "Image preparation for 3d lcd," in Electronic Imaging'99. International Society for Optics and Photonics, 1999, pp. 84-91.

[17] R. B. Johnson and G. A. Jacobsen, "Advances in lenticular lens arrays for visual display," in Optics and Photonics 2005. International Society for Optics and Photonics, 2005, pp. 587 406-587 406.

[18] M. Levoy, K. Pulli, B. Curless, S. Rusinkiewicz, D. Koller, L. Pereira, M. Ginzton, S. Anderson, J. Davis, J. Ginsberg et al., "The digital michelangelo project: 3d scanning of large statues," in Proceedings of the 27th annual conference on Computer graphics and interactive techniques. ACM Press/AddisonWesley Publishing Co., 2000, pp. 131-144.

[19] C. Fehn, "Depth-image-based rendering (dibr), compression, and transmission for a new approach on 3d-tv," in Electronic Imaging 2004. International Society for Optics and Photonics, 2004, pp. 93-104.

[20] P. Kauff, N. Atzpadin, C. Fehn, M. Müller, O. Schreer, A. Smolic, and R. Tanger, "Depth map creation and image-based rendering for advanced 3dtv services providing interoperability and scalability," Signal Processing: Image Communication, vol. 22, no. 2, pp. 217-234, 2007.

[21] S. M. Seitz and C. R. Dyer, "View morphing," in In Proc. SIGGRAPH 96, 1996, pp. 21-30.

[22] A. Shashua and N. Navab, "Relative affine structure: Theory and application to 3d reconstruction from perspective views," in Computer Vision and Pattern Recognition, 1994. Proceedings CVPR'94., 1994 IEEE Computer Society Conference on. IEEE, 1994, pp. 483-489. 
[23] O. Faugeras, Three-dimensional computer vision: a geometric viewpoint. MIT press, 1993.

[24] Z. Zhang, "A flexible new technique for camera calibration," IEEE Transactions on pattern analysis and machine intelligence, vol. 22, no. 11, pp. 1330-1334, 2000.

[25] N. Ayache and C. Hansen, "Rectification of images for binocular and trinocular stereovision," in Pattern Recognition, 1988., 9th International Conference on. IEEE, 1988, pp. 11-16.

[26] C. Loop and Z. Zhang, "Computing rectifying homographies for stereo vision," in Computer Vision and Pattern Recognition, 1999. IEEE Computer Society Conference on., vol. 1. IEEE, 1999, pp. 125-131.

[27] Y.-S. Kang, C. Lee, and Y.-S. Ho, "An efficient rectification algorithm for multi-view images in parallel camera array," in 3DTV Conference: The True Vision-Capture, Transmission and Display of 3 D Video, 2008. IEEE, 2008, pp. 61-64.

[28] Y.-S. Kang and Y.-S. Ho, "Geometrical compensation for multi-view video in multiple camera array," in ELMAR, 2008. 50th International Symposium, vol. 1. IEEE, 2008, pp. 83-86.

[29] F. Boutarel and V. Nozick, "Epipolar rectification for autostereoscopic camera setup," in EAM Mechatronics 2010, 2010, pp. 133-136.

[30] J. Yang, F. Guo, H. Wang, and Z. Ding, "A multi-view image rectification algorithm for matrix camera arrangement," Artificial Intelligence Research, vol. 3, no. 1, p. 18, 2013.

[31] C. L. Zitnick and T. Kanade, "A cooperative algorithm for stereo matching and occlusion detection," IEEE Transactions on pattern analysis and machine intelligence, vol. 22 , no. 7 , pp. 675-684, 2000.

[32] D. Marr and T. Poggio, "Cooperative computation of stereo disparity," in From the Retina to the Neocortex. Springer, 1976, pp. 239-243.

[33] T. Poggio and D. Marr, "A computational theory of human stereo vision," Proceedings of the Royal Society of London B: Biological Sciences, vol. 204, no. 1156, pp. 301-328, 1979.

[34] A. Fusiello, S. Caldrer, S. Ceglie, N. Mattern, and V. Murino, "View synthesis from uncalibrated images using parallax," in Image Analysis and Processing, 2003. Proceedings. 12th International Conference on. IEEE, 2003, pp. 146151.

[35] A. Colombari, A. Fusiello, and V. Murino, "Continuous parallax adjustment for 3d-tv," in Proc. IEE European Conf. on Visual Media Production. Citeseer, 2005, pp. 194-200. 
[36] A. Shashua and N. Navab, "Relative affine structure: Canonical model for 3d from 2d geometry and applications," IEEE Transactions on Pattern Analysis and Machine Intelligence, vol. 18, no. 9, pp. 873-883, 1996.

[37] J. Lewis, "Fast normalized cross-correlation," in Vision interface, vol. 10, no. 1,1995 , pp. $120-123$.

[38] J. K. Aggarwal and M. S. Ryoo, "Human activity analysis: A review," $A C M$ Computing Surveys (CSUR), vol. 43, no. 3, p. 16, 2011.

[39] G. Cheng, Y. Wan, A. N. Saudagar, K. Namuduri, and B. P. Buckles, "Advances in human action recognition: a survey," arXiv preprint arXiv:1501.05964, 2015.

[40] S. Herath, M. Harandi, and F. Porikli, "Going deeper into action recognition: A survey," arXiv preprint arXiv:1605.04988, 2016.

[41] R. Poppe, "A survey on vision-based human action recognition," Image and vision computing, vol. 28, no. 6, pp. 976-990, 2010.

[42] D. Weinland, R. Ronfard, and E. Boyer, "A survey of vision-based methods for action representation, segmentation and recognition," Computer vision and image understanding, vol. 115, no. 2, pp. 224-241, 2011.

[43] L. Chen, H. Wei, and J. Ferryman, "A survey of human motion analysis using depth imagery," Pattern Recognition Letters, vol. 34, no. 15, pp. 1995-2006, 2013.

[44] M. Cho, A. Mahalanobis, and B. Javidi, "3d passive photon counting automatic target recognition using advanced correlation filters," Optics letters, vol. 36, no. 6, pp. 861-863, 2011.

[45] M. Cho and B. Javidi, "Three-dimensional visualization of objects in turbid water using integral imaging," Journal of Display Technology, vol. 6, no. 10, pp. 544-547, 2010.

[46] M. Ghaneizad, H. Aghajan, and Z. Kavehvash, "Three-dimensional reconstruction of heavily occluded pedestrians using integral imaging," in Proceedings of the 10th International Conference on Distributed Smart Camera. ACM, 2016, pp. 1-7.

[47] S.-H. Hong and B. Javidi, "Distortion-tolerant 3d recognition of occluded objects using computational integral imaging," Optics express, vol. 14, no. 25, pp. $12085-12095,2006$.

[48] T. Yang, W. Ma, S. Wang, J. Li, J. Yu, and Y. Zhang, "Kinect based realtime synthetic aperture imaging through occlusion," Multimedia Tools and Applications, pp. 1-19, 2015. 
[49] G. Lippmann, "La photographie integrale," French Academy of Sciences, pp. 446-451, 1908.

[50] W. C. D. Fredwill, "Apparatus for making a composite stereograph," Dec. 15 1936, uS Patent 2,063,985.

[51] J. T. Gruetzner, "Means for obtaining three-dimensional photography," Nov. 22 1955, uS Patent 2,724,312.

[52] T. Okoshi, "Optimum design and depth resolution of lens-sheet and projection-type three-dimensional displays," Applied optics, vol. 10, no. 10, pp. 2284-2291, 1971.

[53] R. L. de Montebello, "Wide-angle integral photography-the integram system," in 21st Annual Technical Symposium. International Society for Optics and Photonics, 1977, pp. 73-91.

[54] R. L. De Montebello, R. P. Globus, and H. S. Buck, "Integral photography apparatus and method of forming same," Mar. 22 1988, uS Patent 4,732,453.

[55] M. Levoy and P. Hanrahan, "Light field rendering," in Proceedings of the 23rd annual conference on Computer graphics and interactive techniques. ACM, 1996, pp. 31-42.

[56] S. J. Gortler, R. Grzeszczuk, R. Szeliski, and M. F. Cohen, "The lumigraph," in Proceedings of the 23rd annual conference on Computer graphics and interactive techniques. ACM, 1996, pp. 43-54.

[57] Z. Zalevsky, A. Shpunt, A. Malzels, and J. Garcia, "Method and system for object reconstruction," Mar. 19 2013, uS Patent 8,400,494. [Online]. Available: https://www.google.com/patents/US8400494

[58] Z. Zhang, "Microsoft kinect sensor and its effect," IEEE multimedia, vol. 19, no. 2, pp. 4-10, 2012.

[59] H. Wang, M. M. Ullah, A. Klaser, I. Laptev, and C. Schmid, "Evaluation of local spatio-temporal features for action recognition," in BMVC 2009-British Machine Vision Conference. BMVA Press, 2009, pp. 124-1.

[60] I. Laptev, "On space-time interest points," International Journal of Computer Vision, vol. 64, no. 2-3, pp. 107-123, 2005.

[61] E. Dolatabadi, "Space-time interest points," 2011. [Online]. Available: https://www.di.ens.fr/ laptev/download.html

[62] C. Harris and M. Stephens, "A combined corner and edge detector." in Alvey vision conference, vol. 15. Citeseer, 1988, p. 50.

[63] A. K. Jain, "Data clustering: 50 years beyond k-means," Pattern recognition letters, vol. 31, no. 8, pp. 651-666, 2010. 
[64] A. Veladi and B. Fulkerson, "An open and portable library of computer vision algorithms," 2008. [Online]. Available: https://www.vlfeat.org/]

[65] K. Schindler and L. Van Gool, "Action snippets: How many frames does human action recognition require?" in Computer Vision and Pattern Recognition, 2008. CVPR 2008. IEEE Conference on. IEEE, 2008, pp. 1-8.

[66] Z. Jiang, Z. Lin, and L. Davis, "Recognizing human actions by learning and matching shape-motion prototype trees," IEEE Transactions on Pattern Analysis and Machine Intelligence, vol. 34, no. 3, pp. 533-547, 2012.

[67] A. M. Andrew, "An introduction to support vector machines and other kernelbased learning methods by nello christianini and john shawe-taylor, cambridge university press, cambridge, 2000, xiii +189 pp., isbn 0-521-78019-5 (hbk,£ 27.50)." 2000.

[68] C.-C. Chang and C.-J. Lin, "Libsvm: a library for support vector machines," ACM Transactions on Intelligent Systems and Technology (TIST), vol. 2, no. 3, p. 27, 2011. [Online]. Available: http://www.csie.ntu.edu.tw/ ${ }^{\sim}$ cjlin/ libsvm/

[69] E. Dolatabadi, "Kinect stream saver," 2014. [Online]. Available: https: //kinectstreamsaver.codeplex.com/releases/view/121887

[70] C. M. Watts, D. Shrekenhamer, J. Montoya, G. Lipworth, J. Hunt, T. Sleasman, S. Krishna, D. R. Smith, and W. J. Padilla, "Terahertz compressive imaging with metamaterial spatial light modulators," Nature Photonics, vol. 8, no. 8, pp. 605-609, 2014.

[71] J. Hunt, T. Driscoll, A. Mrozack, G. Lipworth, M. Reynolds, D. Brady, and D. R. Smith, "Metamaterial apertures for computational imaging," Science, vol. 339, no. 6117 , pp. 310-313, 2013.

[72] M. P. Edgar, G. M. Gibson, R. W. Bowman, B. Sun, N. Radwell, K. J. Mitchell, S. S. Welsh, and M. J. Padgett, "Simultaneous real-time visible and infrared video with single-pixel detectors," Scientific reports, vol. 5, 2015.

[73] G. A. Howland, D. J. Lum, M. R. Ware, and J. C. Howell, "Photon counting compressive depth mapping," Optics express, vol. 21, no. 20, pp. 23822 $23837,2013$.

[74] E. Tajahuerce, V. Durán, P. Clemente, E. Irles, F. Soldevila, P. Andrés, and J. Lancis, "Image transmission through dynamic scattering media by singlepixel photodetection," Optics express, vol. 22, no. 14, pp. 16 945-16 955, 2014.

[75] A. Liutkus, D. Martina, S. Popoff, G. Chardon, O. Katz, G. Lerosey, S. Gigan, L. Daudet, and I. Carron, "Imaging with nature: Compressive imaging using a multiply scattering medium," Scientific reports, vol. 4, 2014. 
[76] Y. Choi, C. Yoon, M. Kim, W. Choi, and W. Choi, "Optical imaging with the use of a scattering lens," IEEE Journal of Selected Topics in Quantum Electronics, vol. 20, no. 2, pp. 61-73, 2014.

[77] M. F. Duarte, M. A. Davenport, D. Takhar, J. N. Laska, T. Sun, K. E. Kelly, R. G. Baraniuk et al., "Single-pixel imaging via compressive sampling," IEEE Signal Processing Magazine, vol. 25, no. 2, p. 83, 2008.

[78] J. Romberg, "Imaging via compressive sampling," IEEE Signal Processing Magazine, vol. 25, no. 2, pp. 14-20, 2008.

[79] N. Radwell, K. J. Mitchell, G. M. Gibson, M. P. Edgar, R. Bowman, and M. J. Padgett, "Single-pixel infrared and visible microscope," Optica, vol. 1, no. 5, pp. 285-289, 2014.

[80] D. B. Phillips, M.-J. Sun, J. M. Taylor, M. P. Edgar, S. M. Barnett, G. G. Gibson, and M. J. Padgett, "Adaptive foveated single-pixel imaging with dynamic super-sampling," arXiv preprint arXiv:1607.08236, 2016.

[81] M. Aßmann and M. Bayer, "Compressive adaptive computational ghost imaging," arXiv preprint arXiv:1304.0243, 2013.

[82] W.-K. Yu, M.-F. Li, X.-R. Yao, X.-F. Liu, L.-A. Wu, and G.-J. Zhai, "Adaptive compressive ghost imaging based on wavelet trees and sparse representation," Optics express, vol. 22, no. 6, pp. 7133-7144, 2014.

[83] P. Sen, B. Chen, G. Garg, S. R. Marschner, M. Horowitz, M. Levoy, and H. Lensch, "Dual photography," in ACM Transactions on Graphics (TOG), vol. 24 , no. 3. ACM, 2005, pp. $745-755$.

[84] P. Nagesh and B. Li, "Compressive imaging of color images," in Acoustics, Speech and Signal Processing, 2009. ICASSP 2009. IEEE International Conference on. IEEE, 2009, pp. 1261-1264.

[85] S. S. Welsh, M. P. Edgar, R. Bowman, P. Jonathan, B. Sun, and M. J. Padgett, "Fast full-color computational imaging with single-pixel detectors," $O p$ tics express, vol. 21, no. 20, pp. 23068-23074, 2013.

[86] B. Sun, M. P. Edgar, R. Bowman, L. E. Vittert, S. Welsh, A. Bowman, and M. Padgett, "3d computational imaging with single-pixel detectors," Science, vol. 340 , no. 6134 , pp. $844-847,2013$.

[87] Y. Zhang, M. P. Edgar, B. Sun, N. Radwell, G. M. Gibson, and M. J. Padgett, "3d single-pixel video," Journal of Optics, vol. 18, no. 3, p. 035203, 2016.

[88] G. A. Howland, P. B. Dixon, and J. C. Howell, "Photon-counting compressive sensing laser radar for 3d imaging," Applied optics, vol. 50, no. 31, pp. 59175920, 2011. 
[89] A. Kirmani, A. Colaço, F. N. Wong, and V. K. Goyal, "Exploiting sparsity in time-of-flight range acquisition using a single time-resolved sensor," Optics Express, vol. 19, no. 22, pp. 21 485-21 507, 2011.

[90] A. Colaço, A. Kirmani, G. A. Howland, J. C. Howell, and V. K. Goyal, "Compressive depth map acquisition using a single photon-counting detector: $\mathrm{Pa}$ rametric signal processing meets sparsity," in Computer Vision and Pattern Recognition (CVPR), 2012 IEEE Conference on. IEEE, 2012, pp. 96-102.

[91] M.-J. Sun, M. P. Edgar, G. M. Gibson, B. Sun, N. Radwell, R. Lamb, and M. J. Padgett, "Single-pixel three-dimensional imaging with time-based depth resolution," Nature Communications, vol. 7, 2016.

[92] M. Edgar, M.-J. Sun, G. Spalding, G. Gibson, and M. J. Padgett, "Firstphoton 3d imaging with a single-pixel camera," in Frontiers in Optics. Optical Society of America, 2016, pp. FF1D-2.

[93] N. D. Hardy and J. H. Shapiro, "Computational ghost imaging versus imaging laser radar for three-dimensional imaging," Physical Review A, vol. 87, no. 2, p. $023820,2013$.

[94] W. Gong, C. Zhao, H. Yu, M. Chen, W. Xu, and S. Han, "Three-dimensional ghost imaging lidar via sparsity constraint," Scientific reports, vol. 6, 2016.

[95] W.-K. Yu, X.-R. Yao, X.-F. Liu, L.-Z. Li, and G.-J. Zhai, "Three-dimensional single-pixel compressive reflectivity imaging based on complementary modulation," Applied Optics, vol. 54, no. 3, pp. 363-367, 2015.

[96] A. R. B. Jeremy Gribben and A. Boukerche, "Calibration for 3d imaging with a single-pixel camera," vol. 10117. International Society for Optics and Photonics, 2017, pp. 1011 709-1011 709-12.

[97] Z. Zhang and J. Zhong, "Three-dimensional single-pixel imaging with far fewer measurements than effective image pixels," Optics letters, vol. 41, no. 11, pp. 2497-2500, 2016.

[98] J. H. Shapiro, "Computational ghost imaging," Physical Review A, vol. 78, no. 6 , p. $061802,2008$.

[99] M. y. N. J. S. Harwit, Hadamard transform optics. Academic Press, 1979.

[100] W. K. Pratt, J. Kane, and H. C. Andrews, "Hadamard transform image coding," Proceedings of the IEEE, vol. 57, no. 1, 1969.

[101] R. N. Bracewell and R. N. Bracewell, The Fourier transform and its applications. McGraw-Hill New York, 1986, vol. 31999.

[102] E. J. Candès and M. B. Wakin, "An introduction to compressive sampling," IEEE signal processing magazine, vol. 25, no. 2, pp. 21-30, 2008. 
[103] C. E. Shannon, "A mathematical theory of communication," ACM SIGMOBILE Mobile Computing and Communications Review, vol. 5, no. 1, pp. 3-55, 2001.

[104] G. Zheng, C. Kolner, and C. Yang, "Microscopy refocusing and dark-field imaging by using a simple led array," Optics letters, vol. 36, no. 20, pp. 39873989, 2011.

[105] Z. Liu, L. Tian, S. Liu, and L. Waller, "Real-time brightfield, darkfield, and phase contrast imaging in a light-emitting diode array microscope," Journal of biomedical optics, vol. 19, no. 10, pp. 106 002-106 002, 2014.

[106] L. Tian, J. Wang, and L. Waller, "3d differential phase-contrast microscopy with computational illumination using an led array," Optics letters, vol. 39, no. 5, pp. 1326-1329, 2014.

[107] G. Zheng, R. Horstmeyer, and C. Yang, "Wide-field, high-resolution fourier ptychographic microscopy," Nature photonics, vol. 7, no. 9, pp. 739-745, 2013.

[108] L. Tian, X. Li, K. Ramchandran, and L. Waller, "Multiplexed coded illumination for fourier ptychography with an led array microscope," Biomedical optics express, vol. 5, no. 7, pp. 2376-2389, 2014.

[109] L. Tian and L. Waller, "3d intensity and phase imaging from light field measurements in an led array microscope," Optica, vol. 2, no. 2, pp. 104-111, 2015 .

[110] V. Durán, P. Clemente, M. Fernández-Alonso, E. Tajahuerce, and J. Lancis, "Single-pixel polarimetric imaging," Optics letters, vol. 37, no. 5, pp. 824-826, 2012.

[111] F. Soldevila, E. Irles, V. Durán, P. Clemente, M. Fernández-Alonso, E. Tajahuerce, and J. Lancis, "Single-pixel polarimetric imaging spectrometer by compressive sensing," Applied Physics B, vol. 113, no. 4, pp. 551-558, 2013.

[112] M. A. Figueiredo, R. D. Nowak, and S. J. Wright, "Gradient projection for sparse reconstruction: Application to compressed sensing and other inverse problems," IEEE Journal of selected topics in signal processing, vol. 1, no. 4, pp. 586-597, 2007.

[113] M. A. Herman, J. Tidman, D. Hewitt, T. Weston, L. McMackin, and F. Ahmad, "A higher-speed compressive sensing camera through multi-diode design," Compressive Sensing II, Baltimore, Maryland, pp. 871706-871706, 2013.

[114] R. J. Woodham, "Photometric method for determining surface orientation from multiple images," Optical engineering, vol. 19, no. 1, pp. 191 139-191 139, 1980. 
[115] H. Hayakawa, "Photometric stereo under a light source with arbitrary motion," JOSA A, vol. 11, no. 11, pp. 3079-3089, 1994.

[116] A. Yuille and D. Snow, "Shape and albedo from multiple images using integrability," in Computer Vision and Pattern Recognition, 1997. Proceedings., 1997 IEEE Computer Society Conference on. IEEE, 1997, pp. 158-164.

[117] P. Favaro and T. Papadhimitri, "A closed-form solution to uncalibrated photometric stereo via diffuse maxima," in Computer Vision and Pattern Recognition (CVPR), 2012 IEEE Conference on. IEEE, 2012, pp. 821-828. 
Artículos 



\title{
Display-based light field model for auto-stereo image visualization
}

\author{
Eva Salvador-Balaguer, Carlos González, José M. Sotoca and Filiberto Pla \\ Institute of New Imaging Technologies, University Jaume I, 12071 Castellón, Spain \\ Tel.:+34 964 728359, E-mail: [salvadoe, cgonzale, sotoca, pla]@uji.es
}

Keywords: Auto-stereoscopic displays, light fields, planar parameterization

\begin{abstract}
Autostereoscopic displays allow viewers to obtain a $3 D$ perception of a scene. This kind of display emits different views of a scene in several directions. Therefore, each eye receives a different image depending on its location, creating a 3D perceptual feeling. In this work we present a display-based light field model for generating autostereoscopic contents. In particular, a planar light field structure has been used. The model is intended to be useful for synthetic and real content visualization.
\end{abstract}

\section{Introduction}

3D autostereoscopic displays generate a real depth perception for multiple viewers without any special aids like stereo glasses [1]. Auto-stereoscopic displays create a 3D image in the brain through pairs of $2 \mathrm{D}$ images by providing a stereo parallax view for the user. Therefore, each eye sees a different image, which has been calculated to appear from two eye positions.

Among various techniques, autostereoscopic displays using lenticular lens together with flat panel displays have been long recognized and developed [2]. To partially overcome the drawback of the reduction of horizontal and vertical resolution, the use of slanted optical element has been proposed for the multi-view 3D system [3]. Viewing zone of autostereoscopic $3 \mathrm{D}$ is determined mainly by the position of the RGB-stripe sub-pixels structure [4] and the optical elements that control light directions. Thus, if the parallax of an object is fixed, its stereoscopic depth is proportional to the viewing distance, which is related to the focal length of lenticular lens [5]. Thus, different considerations of these two elements significantly affect the design of the device.

Another important issue is how to introduce contents from virtual and real scenes through the device. The strategies used to obtain information about the scene are based on image modeling techniques. Light fields are included in this type of techniques [6] [7].

A light field represents the amount of radiance flowing through all the points in the 3D space in all possible directions. The calculation of this measure has an enormous complexity, and for practical purposes it is resolved by searching approaches that limit the difficulty of the problem.

A simplification of the light field function is to consider the values that radiance takes in free space. By free space we mean the space outside the convex hull of an object or inside a closed environment with static objects. In practice it implies that we only allow inward or outward looking views. With this limitation, the light field function can be reduced to 4D.

In this paper a model for auto-stereoscopic visualization using planar light fields is presented. The aim is to integrate the contents from virtual and real scenes with multiple views. The proposal integrates a 4D light field function with the information collected from the scene to generate the input for the device.

\section{Display-centered planar light field model}

Formally, light fields can be described by a $5 \mathrm{D}$ function called plenoptic function [8] that is defined by the position ( $\mathrm{x}$, $y, z)$ and direction $(\theta, \varphi)$ of every ray. It has to be known that in an occlusion-free $3 \mathrm{D}$ space, the function is reduced to $4 \mathrm{D}$ due to the radiance does not change along the rays.

We can consider two types of structured parameterization of the rays: planar and spherical [9]. The planar model parameterizes each line in the light field among two intersections points with two parallel planes, while in the spherical model, rays pass through the sphere so each line is defined by the two points intersected. In this paper, we propose a planar parameterization to model the received radiance through a 4D planar light field.

The aim of the present work is to visualize realistic quality 3D scenes using a planar light field model centered in the auto-stereoscopic display. Thus, we attempt to adjust the generation of the content to the hardware of the display.

First, we define a virtual plane located inside the synthetic or real scene. This plane is defined by its 3D world coordinates and it is related with the dimensions of the display. This virtual plane is divided into rows and columns, where each sub-pixel is associated to $V$ views emitted by the display.

Moreover, a set of $N$ cameras is placed in the $3 \mathrm{D}$ space in arbitrary positions in front of the virtual plane. To generate the content for the planar light field, the intrinsic and extrinsic parameters of the cameras are calculated. The intrinsic parameters specify the internal characteristics of the cameras such as focal length, internal coordinate system and aspect ratio. The extrinsic parameters denote the rotation and translation transformations. To obtain these parameters in the real world, the Zhang's calibration algorithm has been used [10].

The different $V$ views associated to each pixel are obtained by casting a ray from the auto-stereoscopic virtual plane 
located into the scene to the array of $N$ cameras. The rays will be traced imitating the orientation of the views in the display. For each pixel of each different image we choose the nearest camera to the intersection point obtained after casting a ray from the virtual plane to the array of cameras.

\section{Experimental results}

A preliminary experimental study has been done by using a 46" XYZ 3D Display designed by Zero Creative [11] with 8 different horizontal parallax views and a resolution of 1920x1080. The proposed model has been tested with several synthetic and real scenes, offering a realistic 3D perception.

For the generation of synthetic content we have integrated this model in the Unity game engine and used 8 perspective cameras. This generation was produced in an Intel ${ }^{\circledR}$ Core $^{\mathrm{TM}} \mathrm{i} /$ CPU $930 @ 2.80 \mathrm{GHz}$ with an nVidia GeForce GTX 480 graphics card. In real scenarios, a set of 8 STINGRAY F080B/C IEEE-1394b cameras were used. For the calibration, Zhang's algorithm in OpenCV 2.2 software for Windows with 64 bits was used. The synchronization was performed through the bus. The motherboard is provided by two PCI Express 2.0 with $2.5 \mathrm{~Gb} / \mathrm{sec}$ of bandwidth.

With the configuration of the system described in the previous section we obtain eight different images which are used in a fragment shader to generate an interlaced image accepted by the display. This interlaced image is useful for distributing the corresponding image colors into the different subpixels of the lenses. The shader accepts as input a texture with the images obtained by the proposed planar light field (Figure 1) and returns the interlaced image used by the display (Figure 2). We have worked with a $3 \times 3$ image composition where the ninth image is discarded by the shader. This composition is used in order to preserve the aspect ratio of the images with respect to the display.

\section{Conclusions}

In this paper a display-based light field model for autostereoscopic visualization has been proposed, in order to generate the adequate content for the visualization of 3D to a given display hardware. Therefore, depending on the different directions the display emits the views, the model computes the most appropriate display information through the proposed planar display-based light field.

Preliminary experiments generating synthetic and real auto-stereoscopic images have been made, obtaining encouraging results, providing realistic 3D sensation on an auto-stereoscopic display.

\section{Acknowledgments}

Work partially supported by projects TIN2009-14103-C0301 and CSD2007-00018 from the Spanish Ministry of Science and Innovation, P1-1B2009-45 from UJI-Fundació CaixaCastelló and PROMETEO/2010/028 from Generalitat Valenciana.

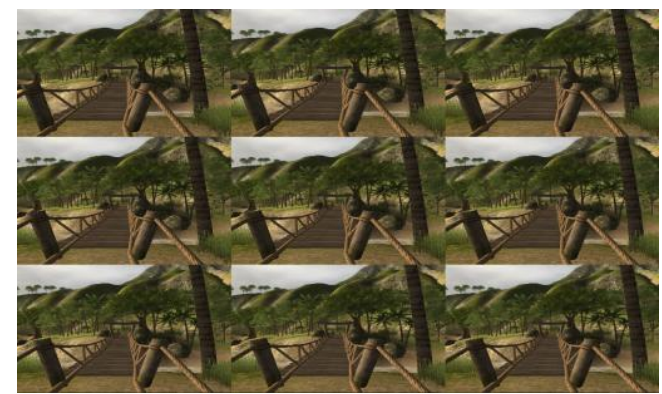

Figure 1. Texture composition with $3 \times 3$ slightly separated views.

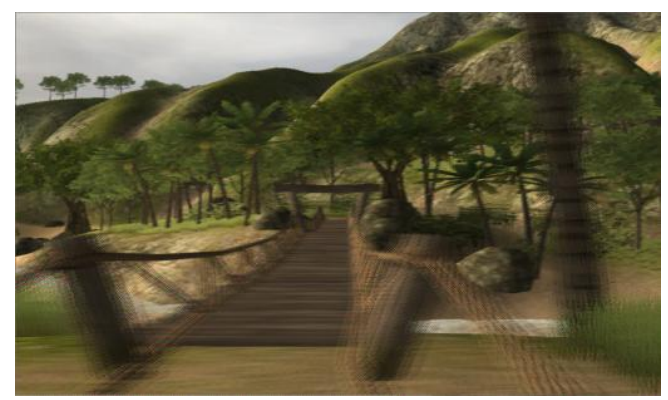

Figure 2. Interlaced image generated by the fragment shader.

\section{References}

1. T. Okoshi. Three Dimensional Imaging Techniques (1976).

2. T. Jarvenpaa and M. Salmimaa. Optical characterization of autostereoscopic 3-D displays. Journal of The Society for Information Display, vol. 16, no. 8, pp. 825-833 (2008).

3. C. Van Berkel. Image preparation for 3D-LCD. In proceedings of SPIE, 3639, pp. 84-91 (1999).

4. J. Park, B. Lee, H. Hong and H. Shin. Autostereoscopic multi-view 3D system using square subpixel structure. International Display Workshop, pp. 1365-1366, (2006).

5. J. Y. Son, V. Saveljev, J-S Kim, S-S Kim, and B. Javidi. Viewing zones in three-dimensional imaging systems based on lenticular. Applied Optics, Vol. 43, Issue 26, pp. 4985-4992 (2004).

6. M. Levoy and P. Hanrahan. Light field rendering. In proceedings of SIGGRAPH'96, pp. 31-42. (1996).

7. S. J. Gortler, R. Grzeszczuk, R. Szeliski, M. F. Cohen. The lumigraph. SIGGRAPH'96, pp. 43-54, (1996).

8. E. H. Adelson and J. R. Bergen. The phenotic function and the elements of early vision. Computational Models of Visual Processing, pp. 3-20, (1991).

9. M. Escrivá, J. Blasco, F. Abad, E. Camahort, R. Vivó. Autostereoscopic Rendering of Multiple Light Fields. Computer Graphics Forum, 28(8), pp. 2057-2067, (2009).

10. Z. Zhang. A Flexible New Technique for Camera Calibration. IEEE Ttransactions on Pattern Analysis and Machine Intelligence, 22(11), (2000).

11. xyZ 3D Displays. Autostereoscopic 3D TV. http://www.xyz3d.tv/ 


\title{
Síntesis de vistas para la generación de campos de luz en visualización autoestereoscópica
}

\author{
Eva Salvador-Balaguer, Jose M. Sotoca y Filiberto Pla* \\ Institute of New Imaging Technologies, 12071 Castellón, España \\ *E-mail: \{salvadoe, sotoca, pla\}@uji.es
}

Las pantallas autoestereoscópicas permiten la reproducción tridimensional de escenas que pueden ser visualizadas por varios usuarios sin necesidad de utilizar gafas $u$ otros dispositivos adicionales. La principal desventaja de esta tecnología reside en la generación de contenido ya que son necesarias múltiples imágenes de entrada para poder crear la sensación 3D.

En este artículo se describe un modelo de campo de luz planar basado en el concepto de imagen integral para visualización autoestereoscópica y se propone un algoritmo de síntesis de imágenes para generar las vistas que se capturarían al desplazar una cámara virtual a lo largo de un eje. El objetivo es pues integrar la información capturada por un conjunto reducido de cámaras convencionales junto con las imágenes virtuales generadas para la construcción del campo de luz y posterior visualización de escenas reales y virtuales en pantallas autoestereoscópicas.

En este contexto, la construcción de imágenes elementales para conseguir una imagen integral es parte de la metodología que se está convirtiendo en una de las técnicas más viables para suministrar eficientemente las vistas necesarias a un dispositivo autoestereoscópico. En la imagen integral, la información multiperspectiva de una escena 3D se almacena en imágenes 2D. Cada una de estas imágenes no es más que una muestra del campo de luz emitido por la escena 3D.

Para la definición de un campo de luz con parametrización planar centrado en el dispositivo autoestereoscópico se utiliza la terminología propuesta en [1]. Según esta parametrización, cualquier rayo de un campo de luz se define a partir de los puntos de intersección con dos planos paralelos. De este modo, dado un plano virtual con coordenadas $u$ y $v$ y un conjunto de cámaras situadas en un plano paralelo con coordenadas $s$ y $t$, cualquier punto de este campo de luz planar se define a partir de las cuatro coordenadas $(s, t, u, v)$ (ver Fig. 1).

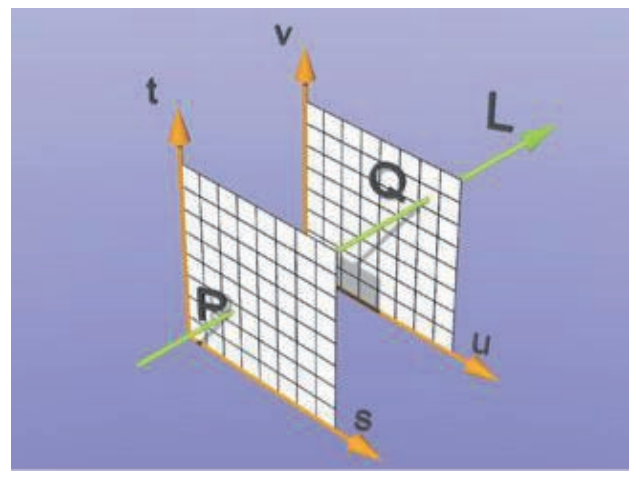

Fig. 1: Campo de luz planar 
Para construir el modelo de campo de luz definido serán necesarias las imágenes capturadas por las cámaras y las nuevas vistas sintetizadas de la escena que no han sido recogidas por ninguna cámara (ver Fig. 2). Existen diversos algoritmos para construir vistas virtuales pero para evitar utilizar mapas de profundidad este trabajo se ha inspirado en el algoritmo de "View Morphing" presentado por Seitz y Dyes [2]. El primer paso en este algoritmo consiste en prewarp (rectificar) las imágenes antes de fusionarlas (morphing). Tras la fusión, se lleva a cabo un proceso denominado postwarp para conseguir que la imagen final tenga la posición y orientación deseada. En la técnica propuesta en este trabajo se realizan únicamente las etapas de prewarp y morphing donde el morphing se lleva a cabo un utilizando un algoritmo similar al propuesto por Colombari en [3]. Siguiendo este algoritmo, para la creación de las imágenes virtuales se utiliza el concepto de relative affine structure [4].
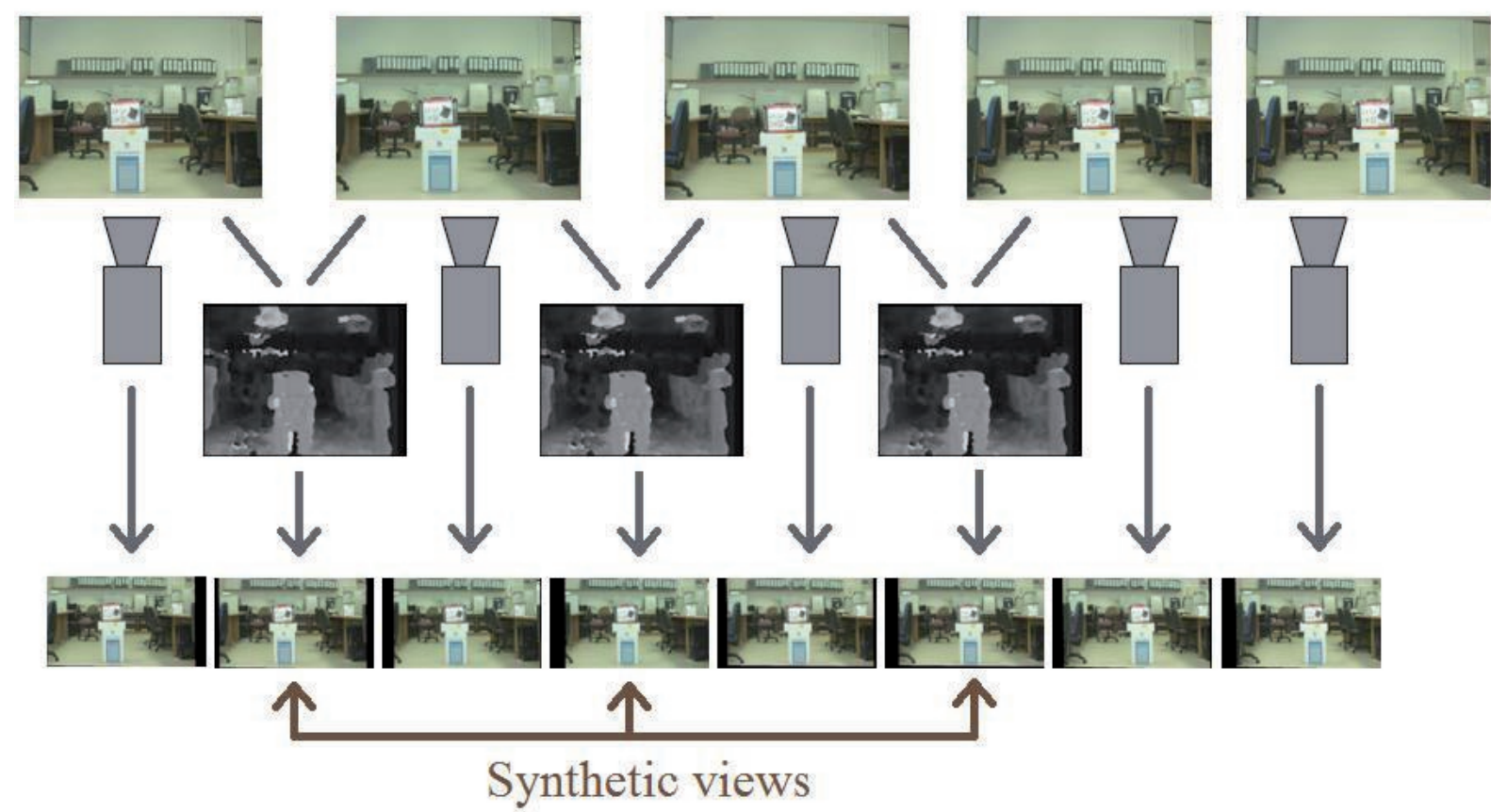

Fig. 2: Ejemplo en el que la escena se captura utilizando 5 cámaras reales y se sintetizan 3 vistas virtuales para conseguir las 8 vistas necesarias para un dispositivo 3D particular.

[1] S.J.Gortler, R.Grzeszczuk, R.Szeliski and M. F.Cohen. “The Lumigraph”, Proc. of SIGGRAPH, p. $43-54$ (1996).

[2] S. M.Seitz and C. R.Dyer. "View Morphing", Proc of SIGGRAPH, p. 21-30 (1996).

[3] A.Colombari, A.Fusiello and V.Murino. "Continuous Parallax Adjustment for 3D-TV" International Conference on Image Analysis and Processing, p. 146-151 (2003).

[4] A.Shashua and N.Navab. "Relative Affine Structure: Canonical Model for 3D from 2D Geometry and Applications", IEEE Transactions on Pattern Analysis and Machine Intelligence, p. 873-883 (1996). 


\title{
View Synthesis for Real Scene Visualisation on Autostereoscopic Displays ${ }^{\star}$
}

\author{
Eva Salvador-Balaguer, Jose Martinez Sotoca, and Filiberto Pla Bañón \\ Institute of New Imaging Technologies, University Jaume I, 12071 Castellón, Spain \\ $\{$ salvadoe, sotoca, pla\}@uji.es
}

\begin{abstract}
This paper presents a view synthesis algorithm to generate intermediate views that allows moving a virtual camera along a 1-D path. Instead of relying on accurate depth maps, the proposed method uses a disparity map that provides a dense pixel correspondence. The algorithm is able to generate images of complex real scenes that are ready to be displayed on an autostereoscopic device. Experiments illustrate the quality of the virtual views showing a comparison between the synthetic views obtained and the real ones.
\end{abstract}

Keywords: novel view synthesis, view morphing, 3DTV, autostereoscopic displays, multi-view rectification.

\section{Introduction}

$3 \mathrm{D}$ visualisation technologies are increasingly present in our lives. Nowadays, most popular technologies require glasses or other devices that bother the final user. Due to that drawback, autostereoscopic displays, which allow glasses-free $3 \mathrm{D}$ perception, are expected to be the next technological step in $3 \mathrm{D}$ visualisation [1].

The main drawback in generating content for autostereoscopic displays is that they require multiple input views. Depending on the autostereoscopic display, the number of views used to generate the 3D perception differs. Therefore, the scene should be captured using as many cameras as the number of views of the display. Neither using cameras with eight or more lens nor capturing the scene from an array of multiples cameras is a suitable choice due to cost and space problems. Thus, the purpose of this work is to capture the scene using fewer cameras and synthesise intermediate views.

View synthesis allows obtaining an image of the scene from a new viewpoint, using the information of the rest of the cameras. Some strategies require the reconstruction of the full scene structure to synthesise novel views [2]. Uncalibrated view-synthesis offers a solution that only needs the estimation of disparities [3-5]. In this case, point transfer techniques use image-to-image constraints such as fundamental matrices, trilinear tensors or plane+parallax.

* Work partially supported by projects TIN2009-14103-C03-01 from the Spanish Ministry of Science and Innovation, P1-1B2009-45 from UJI-Pla de promoció de la investigació and PROMETEO/2010/028 from Generalitat Valenciana. 
Other approaches use Depth Image Based Rendering (DIBR) [7, 8] to synthesise multiple images. The main problem of those methods is that the quality of synthetic views depends on the accuracy of depth maps. Therefore, all depths maps artifacts that appear due to occlusions between objects decrease the accuracy of the virtual image.

In order to avoid using depth maps, we were inspired by the view morphing algorithm presented by Seitz and Dyes [9]. The main idea consists of prewarping (rectifying) the images before morphing (merging) them. After morphing rectified images, they postwarp the result to transform the image to its desired position and orientation. To do so, the requirements are: different images representing views of the same $3 \mathrm{D}$ object, their cameras projection matrices and a correspondence map between pixels in the images.

The main difference between Seitz algorithm and ours lies in the last step. In our approach, we do not postwarp images. Instead, we recover the relative affine structure to synthesise novel views along a 1-D path. Then, the aim is to ensure that synthetic cameras move in the same horizontal line and with the same rotation.

The remainder of this paper is structured as follows: In Section 2 an overview of the view synthesis algorithm is outlined. In particular, it is divided in four different sections which describe each step of the method proposed in this paper. Section 3 shows the experimental results and finally, conclusions are drawn in Section 4.

\section{System Overview}

This section describes all steps involved in the generation of the virtual views. In particular we propose an adaptation of several existing algorithms to obtain the virtual views needed. Fig. 1 shows the complete process. Each of the four steps are explained in following sections.

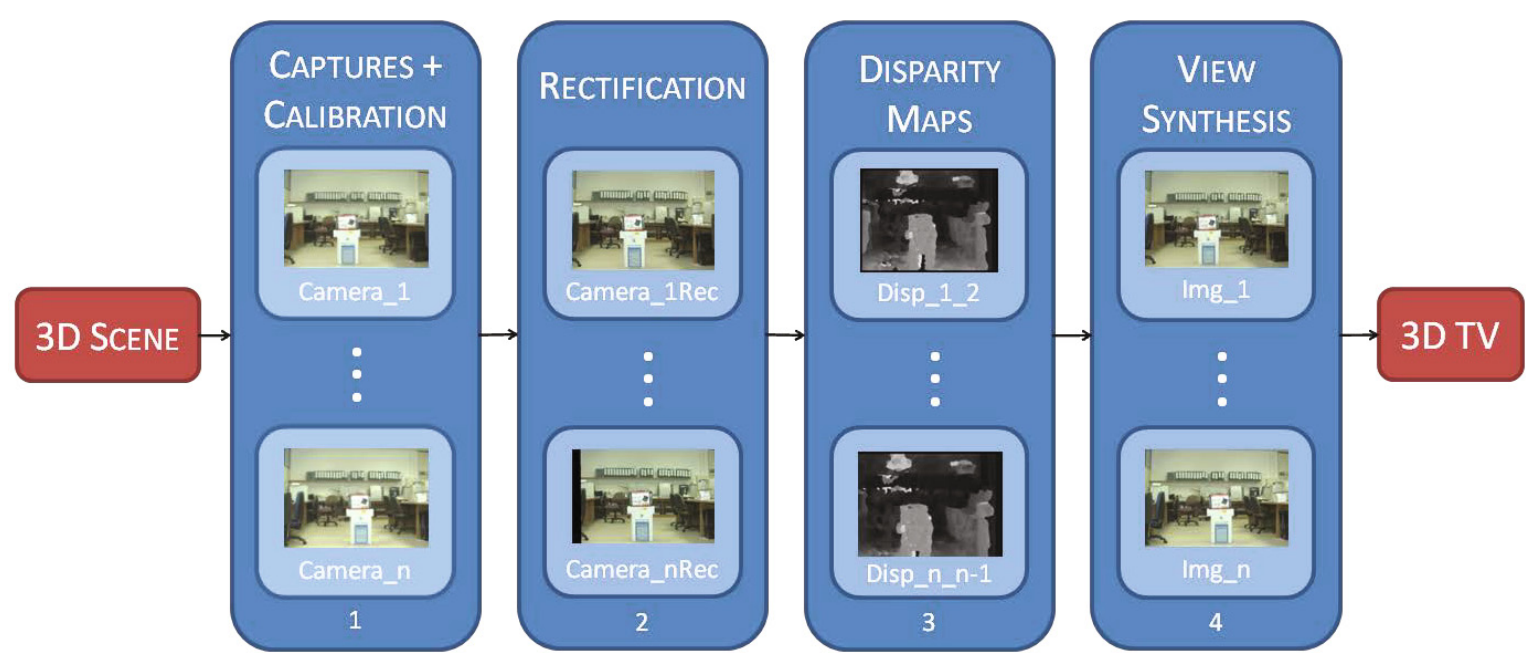

Fig. 1. Description of the four-step algorithm used to synthesise all views needed 


\subsection{Image Acquisition and Camera Calibration}

The scene is captured using an array of multiples cameras capable of recording synchronized multiple-views. In particular we use a set of 8 STINGRAY F080B/C IEEE-1394b cameras synchronised through the bus.

After capturing the scene, camera calibration is a crucial problem for further image processing. For the calibration, Zhang's algorithm has been used [10]. This method computes the lens distortion and all the intrinsic and extrinsic camera parameters. Extrinsic parameters are expressed by the rotation $(R)$ and translation $(T)$ matrices and intrinsic parameters $(K)$ give information about the camera internal geometry. Using those parameters, the projection matrix of the camera $n$ is defined as:

$$
P_{n}=\left[K_{n} \cdot\left[R_{n} \mid T_{n}\right]\right]
$$

The projection matrices obtained will be used in the rectification process.

\subsection{Multiview Image Rectification}

This process consists of transforming the original images to align their epipolar lines. Although the cameras setup is horizontal, there always exists misalignment with the positions and orientations. For this reason, the original images are transformed to obtain the ideal distribution.

Our algorithm is based on the method described in [11]. The basic idea is to transform the original images captured from an array of cameras to obtain the images of an ideal multi-camera arrangement. Then, as Seitz [9] does with non-parallel views, we will have images prewarped and ready to morph.

In the ideal arrangement, all cameras are allocated on a line in 3D space and they are equally oriented. The rectified images are obtained by applying to each camera an homographic transformation between the original camera and the ideal one (see Fig. 2).

To calculate the homography, we need the projection matrices obtained in the calibration process. In particular, for each camera, we obtain the homography between the original and the ideal image plane as follows:

$$
H_{n}=P_{\text {ideal }, n} \cdot P_{n}^{+}
$$

where $P_{\text {ideal }, n}$ is the projection matrix of the ideal configuration of camera $n$ and $P_{n}^{+}$is the pseudo inverse matrix of $P_{n} . P_{n}$ is obtained in the calibration process described in expression (1) while $P_{\text {ideal }}$ is calculated as follows: First we set a rotation matrix $R_{\text {ideal }}$ that represents the camera arrangement and we consider it as the basis axes. Then, we find the ideal translation for each camera in order to obtain a co-linear arrangement with the same distance between adjacent cameras $\left(T_{\text {ideal }, n}\right)$. Finally, we determine the common intrinsic matrix $K_{\text {ideal }}$ for the ideal multi-camera arrangement and we get the ideal projection matrix as:

$$
P_{\text {ideal }, n}=\left[K_{\text {ideal }} \cdot\left[R_{\text {ideal }} \mid T_{\text {ideal }, n}\right]\right]
$$




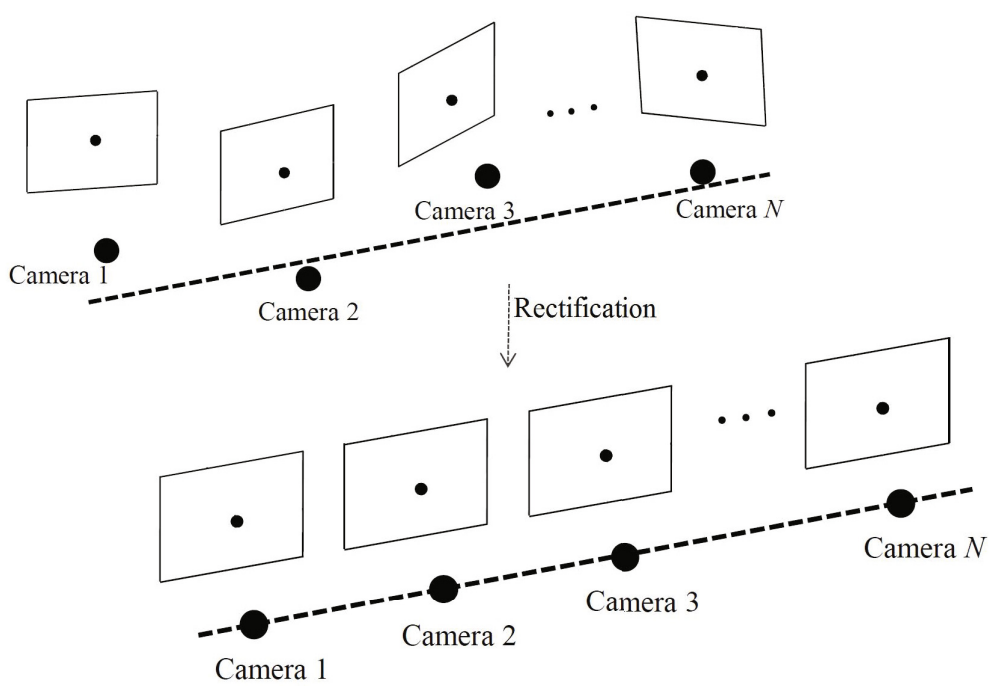

Fig. 2. Multiple view rectification

With the projection matrices calculated, an array of rectified images $\left(I_{1}, \ldots, I_{n}\right)$ is obtained. Those images can be directly used as an input of the autostereoscopic display. If the number of images obtained is lower than the number of views of the autostereoscopic display, then a view synthesis process is necessary.

\subsection{Disparity Map Generation}

For each pair of consecutive rectified images $\left(I_{1}, I_{2}\right)$, we obtain their disparity maps using the stereo algorithm described in [12]. This algorithm receives as an input the maximum and minimum disparity values of a particular image. For each pixel of the image $(r, c)$ this method initially sets a match value using an image similarity function $\delta$ :

$$
L_{0}(r, c, d)=\delta\left(I_{1}(r, c), I_{2}(r, c+d)\right)
$$

This match value is iteratively updated using (4) until it converge.

$$
L_{n+1}(r, c, d)=L_{0}(r, c, d) *\left(\frac{S_{n}(r, c, d)}{\sum_{(r ", c ", d ") \in \Psi(r, c, d)} S_{n}\left(r ", c ", d^{\prime \prime}\right)}\right)^{\alpha}
$$

In the previous equation $S_{n}(5)$ is the amount of local support within a $3 \mathrm{D}$ area $\Phi$ and $\Psi(r, c, d)$ denotes the set of elements which overlap element $(r, c, d) .{ }^{1}$

$$
S_{n}(r, c, d)=\sum_{\left(r^{\prime}, c^{\prime}, d^{\prime}\right) \in \Phi} L_{n}\left(r+r^{\prime}, c+c^{\prime}, d+d^{\prime}\right)
$$

\footnotetext{
${ }^{1}$ For further explanation see [12].
} 
Therefore, for each pixel $(r, c)$ an array of match values is obtained. We find the element $(r, c, d)$ with the maximum match value and it is the output disparity for the pixel $(r, c)$.

\subsection{View Synthesis Algorithm}

Finally, to generate new viewpoints of the scene we use a view synthesis algorithm similar to the one described in [3] and [13]. The main idea is to obtain the homographic plane $H_{12}$ that relates two conjugate points $m_{1}$ and $m_{2}$ :

$$
m_{2}=H_{12} m_{1}+e_{21}
$$

This equation only works for 3D points (M) belonging to a particular plane. If $\mathrm{M}$ is not in the plane there is a residual displacement called parallax. This distance is proportional to the relative affine structure of $M$ [14]. For each pair of consecutive images $\left(I_{1} ; I_{2}\right)$ the algorithm is the following:

- Using the disparity values, obtain a set of conjugate pairs

$$
\left(m_{1}^{k} ; m_{2}^{k}\right) \quad k=1, \ldots, m
$$

- From projection matrices of rectified views, recover the epipole $e_{21}$ and the homography $H_{12}$

- For each conjugate pair, compute the relative affine structure as:

$$
\gamma^{k}=\frac{\left(m_{2}^{k} \times e_{21}\right)^{T} \cdot\left(H_{12} m_{1}^{k} \times m_{2}\right)}{\left\|m_{2}^{k} \times e_{21}\right\|^{2}}
$$

- Specify a new epipole $e_{31}$ and a new homography $H_{13}$ and for each conjugate pair, calculate the new location of the pixel as:

$$
m_{3}^{k}=H_{13} m_{1}^{k}+e_{31} \gamma^{k}
$$

As original cameras are already rectified along a 1-D path, $e_{31}$ and $H_{13}$ can be recovered. They can be obtained from the ideal projection matrix of a new view where the only difference is a rigid horizontal displacement. Then, with the previous algorithm any number of intermediate views can be synthesised.

\section{Experimental Results}

All experiments have been done in order to be visualised on a 46" XYZ 3D display designed by Zero Creative with 8 horizontal parallax views and a resolution of 1920x1080. An array of 8 Stingray cameras horizontally aligned has been placed in front of the scene.

In the first experiment, we have placed 8 cameras on an horizontal setup and we have rectified the images obtained. Then, those images have been visualised on the display and a good 3D perception has been achieved. To display the result 


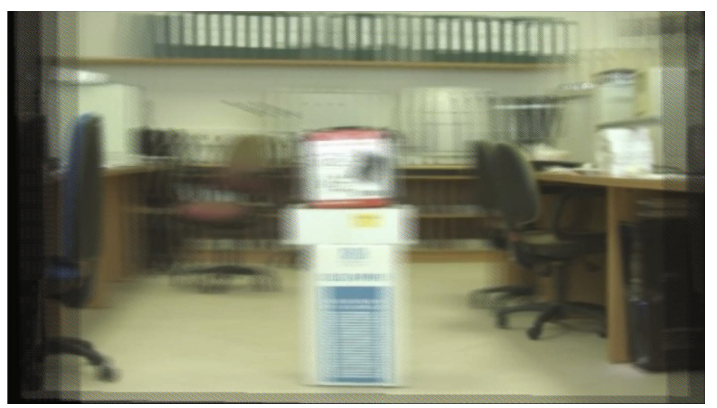

Fig. 3. Interlaced image generated by the fragment shader

on the television a fragment shader has been used. It gets as input a texture with the final images and it returns the interlaced image accepted by the display. The interlaced image generated by the fragment shader is shown on Fig. 3.

Our main contribution is shown on the second experiment. It consists of removing the images obtained by some cameras and synthesising those views. In particular, we have synthesised 3 intermediate views (see Fig. 4) using the fourstep algorithm described in the previous section. As it is depicted, views 2, 4 and 6 are synthetic views while the rest are rectified images of the original captures.

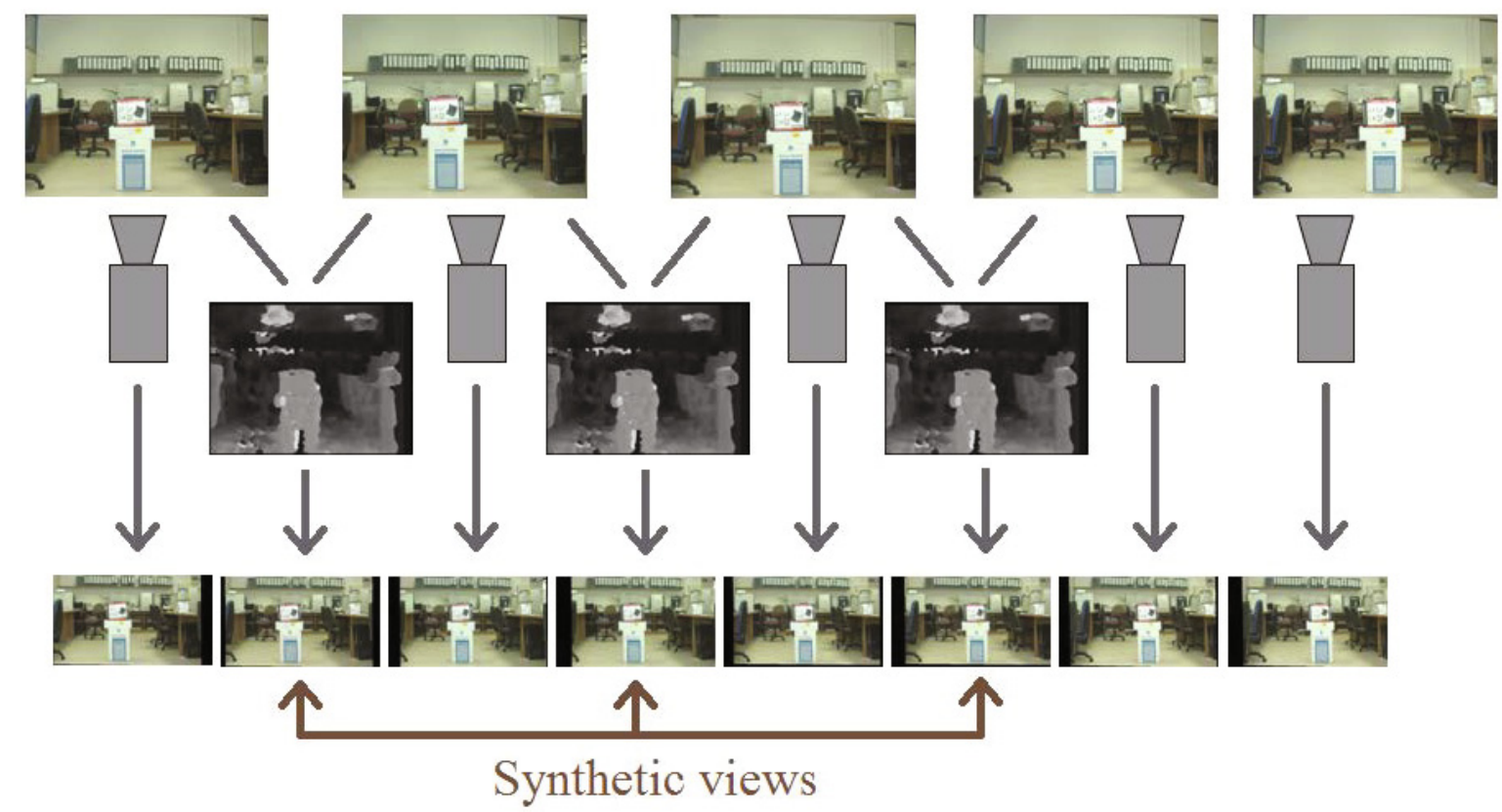

Fig. 4. The scene is captured from 5 cameras and using our 4-step algorithm we obtain the 8 views needed by the 3D display

As we also have the real images captured from views 2, 4 and 6, we can compare the images obtained using our algorithm with the ones that we should have obtained (the real ones). Fig. 5 shows on the left the real view captured and on the middle the synthetic view obtained with our method. The main differences 
between both images is shown on the right. This last image has been obtained using the stereo algorithm proposed by Lewis on [15]. Blue colour represents no differences between the two images while red reflects dissimilarity(inequality). Due to major differences appear on homogeneous parts of the scene, those errors are not trivially seen by the final user and a good 3D perception is obtained. However, to get better results, the disparity map algorithm should be improved. It can be done using smoothing techniques that reduce the inconsistencies found.
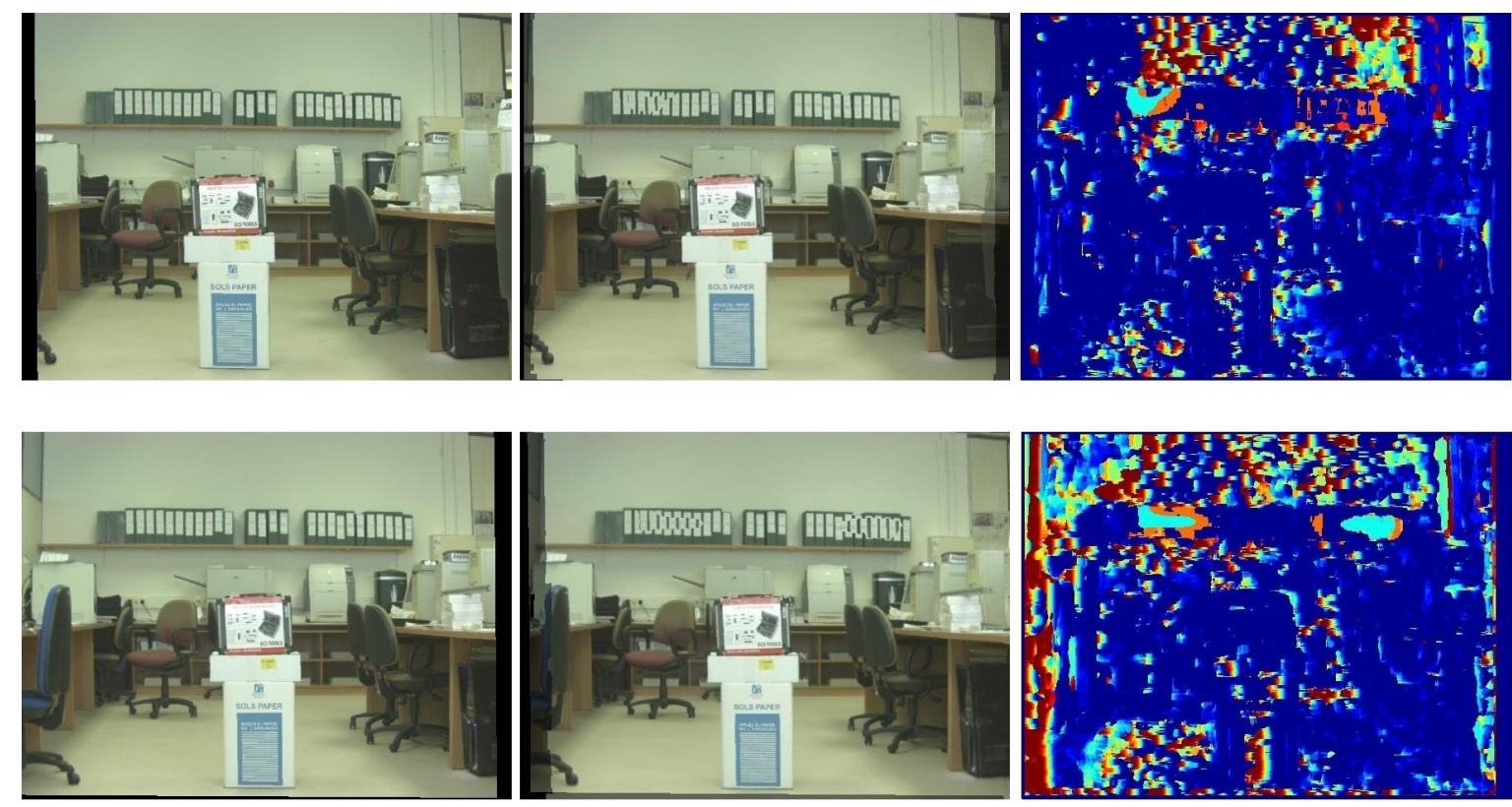

Fig. 5. Rows 1 and 2 represent the results of cameras 2 an 4 . In particular, the real image captured (left), the corresponding synthetic view (middle) and the difference between both images (right).

Our technique makes possible to create an entire sequence of virtual views. Nevertheless, to get a good 3D perception in our autostereoscopic 3D display we just use the 8 different images given at the bottom of Fig. 4. Considering the satisfactory results obtained, four-step view synthesis algorithm is a desirable technique to be used.

\section{Conclusions}

In this paper, a four-step algorithm has been proposed to synthesise all images required to visualise a real scene on an autostereoscopic 3D display. The method consists of capturing the scene using a limited number of cameras transforming them and synthesising views in order to obtain a 1-D path to construct a multi-view structure adequate for autostereoscopic displays with horizontal parallax. The view synthesis algorithm has also been qualitative and quantitatively evaluated providing satisfactory and promising results. 
The main advantage of the algorithm is the ability to create content for any autostereoscopic display using a limited number of cameras. Further work is directed to improve the interpolation based on image correspondence calculation and extending it for full parallax frameworks.

\section{References}

1. Magnor, M.: 3D-TV - The Future of Visual Entertainment. In: Proceedings of Multimedia Databases and Image Communications, pp. 105-112 (2004)

2. Levoy, M.: The digital Michelangelo project. In: Proceeding of the 3-D Digital Imaging and Modeling, vol. 19, pp. 2-11 (1999)

3. Fusiello, A., Caldrer, S., Ceglie, S., Mattern, N., Murino, V.: View synthesis from uncalibrated images using parallax. In: 12th International Conference on Image Analysis and Processing, pp. 146-151 (2003)

4. Irani, M., Hassner, T., Anandan, P.: What Does the Scene Look Like from a Scene Point? In: Heyden, A., Sparr, G., Nielsen, M., Johansen, P. (eds.) ECCV 2002, Part II. LNCS, vol. 2351, pp. 883-897. Springer, Heidelberg (2002)

5. Laveau, S., Faugeras, O.: 3-D Scene Representation as a Collection of Images and Fundamental Matrices. Technical Report 22 (1994)

6. Chen, S.E., Willians, L.: View interpolation for image synthesis. Computer Graphics, 279-288 (1993)

7. Fehn, C.: Depth-image-based rendering (DIBR), compression, and transmission for a new approach on 3D-TV. In: Proceedings of the SPIE, Stereoscopic Displays and Virtual Reality Systems XI, vol. 5291, pp. 93-104 (2004)

8. Kauff, P., et al.: Depth map creation and image-based rendering for advanced 3DTV services providing interoperability and scalability. Signal Processing: Image Communication 22, 217-234 (2007)

9. Seitz, S.M., Dyer, C.R.: View Morphing. In: Proc. SIGGRAPH, pp. 21-30 (1996)

10. Zhang, Z.: A Flexible New Technique for Camera Calibration. IEEE Transactions on Pattern Analysis and Machine Intelligence 22, 1330-1334 (2000)

11. Kang, Y.-S., Ho, Y.-S.: An efficient image rectification method for parallel multi-camera arrangement. IEEE Transactions on Consumer Electronics 57(3), 1041-1048 (2011)

12. Zitnick, C.L., Kanade, T.: A Cooperative Algorithm for Stereo Matching and Occlusion Detection. Proc. IEEE Trans. Pattern Analysis and Machine Intelligence 22(7), 675-684 (2000)

13. Colombari, A., Fusiello, A., Murino, V.: Continuous parallax adjustment for 3DTV. In: 2nd IEE European Conference on Visual Media Production, pp. 194-200 (2005)

14. Shashua, A., Navab, N.: Relative Affine Structure: Canonical Model for 3D from 2D Geometry and Applications. In: IEEE Transactions on Pattern Analysis and Machine Intelligence, pp. 873-883 (1996)

15. Lewis, J.P.: Fast normalized cross-correlation. Vision Interface, 120-123 (1995) 


\title{
Human gesture recognition using 3D integral imaging
}

\author{
V. Javier Traver, ${ }^{1}$ Pedro Latorre-Carmona, ${ }^{1}$ Eva Salvador-Balaguer, ${ }^{1}$ Filiberto $\mathrm{Pla},{ }^{1}$ and Bahram Javidi ${ }^{2}$ \\ ${ }^{1}$ Institute of New Imaging Technologies (INIT), \\ Universitat Jaume I, Castellón de la Plana, SPAIN \\ ${ }^{2}$ Electrical 83 Computer Engineering Department, University of Connecticut, Storrs, 06269-2157 USA
}

compiled: May 2, 2014

\begin{abstract}
Three-dimensional Integral Imaging allows one to reconstruct a 3D scene, including range information, and provides sectional re-focused imaging of $3 \mathrm{D}$ objects at different ranges. This paper explores the potential use of $3 \mathrm{D}$ passive sensing Integral Imaging for human gesture recognition tasks from sequences of reconstructed $3 \mathrm{D}$ video scenes. As a preliminary testbed, the 3D Integral Imaging sensing is implemented using an array of cameras with the appropriate algorithms for 3D scene reconstruction. Recognition experiments are performed by acquiring $3 \mathrm{D}$ video scenes of multiple hand gestures performed by ten people. We analyze the capability and performance of gesture recognition using 3D Integral Imaging representations at given distances and compare its performance with the use of standard $2 \mathrm{D}$ single-camera videos. To the best of our knowledge, this is the first report on using 3D Integral Imaging for human gesture recognition.

OCIS codes: (100.6890) Three-dimensional image processing; (110.6880) Three-dimensional image acquisition; (150.6910) Three-dimensional sensing; (100.5010) Pattern recognition; (040.7290) Video

http://dx.doi.org/10.1364/XX.99.099999
\end{abstract}

\section{Introduction}

Applications of three-dimensional (3D) optical image sensing and visualization technologies span a wide range of areas including TV broadcasting, 3D displays, entertainment, medical sciences and robotics. An advantage of $3 \mathrm{D}$ in relation to traditional $2 \mathrm{D}$ imaging techniques is their capability to capture the structural information of the different objects that are in a scene. One promising 3D approach is based on Integral Imaging or Integral Photography, which is an autostereoscopic imaging method used to capture 3D information and to visualize it in $3 \mathrm{D}$ either optically or computationally [1-21]. The system operates under incoherent or ambient light, thus sensing can be performed passively unlike holography or LADAR that require lasers [22, 23]. Integral Imaging can provide the $3 \mathrm{D}$ profile and range of the objects in the scene, thus it is attractive for $3 \mathrm{D}$ object recognition [24-26].

Recognizing human activity from visual sources has been receiving a significant attention from the computer vision and machine learning communities over the last decades. Recent surveys such as [27] provide good accounts of the visual representations and classification approaches that have been proposed to address the many challenging practical issues behind activity recognition. In spite of all the progress made, effective, robust, scalable, and efficient solutions have been elusive so far.

Regarding the visual source, most of the past work on action recognition has focused on monocular gray-level $2 \mathrm{D}$ sequences. Recently, some efforts have been paid to use depth information, mainly due to the popular- ization of RGB-D systems. Three main approaches for depth sensing are based on stereo, time of flight, and structured light [28] and they have been applied to human sensing in general, and for gesture recognition in particular. While Integral Imaging has been applied to other classification/recognition tasks [29], to the best of our knowledge this is the first attempt to apply integral images for action recognition. Integral Imaging can contribute to the area because of its capability to reconstruct 3D scenes at different depths. This information can arguably be used and help in the action recognition process.

In this paper, we propose to integrate $3 \mathrm{D}$ passive sensing Integral Imaging and human activity recognition from sequences of reconstructed 3D video scenes focused at certain regions of interest. The 3D scene is captured by 3D Integral Imaging and the 3D objects including range information and sectional images of $3 \mathrm{D}$ objects at different ranges are computationally reconstructed. Gesture recognition experiments are performed by acquiring 3D videos of the hand gestures [30]. These short-duration human activities performed by a part of the body such as a hand are better categorized as gestures [27]. However, the described proposal is general, and applicable to the recognition of actions and other human activities.

We analyze the potential of gesture recognition using 3D Integral Imaging and compare its performance with using $2 \mathrm{D}$ single-camera videos. The experiments provide evidence on the feasibility of gesture recognition with Integral Imaging. Integral Imaging provides the 3D 
reconstruction of the hand gestures and allows sectional imaging to focus on the areas of the scene where the gesture is being made. In this work, sectional reconstructed representations of the objects in the scene are processed by gesture recognition strategies.

The rest of the paper is organized as following. An overview of $3 \mathrm{D}$ integral imaging with a focus on the scene capture stage and numerical 3D reconstruction of the scene is first presented (Sect. 2). Then, the experimental set-up used to acquire $3 \mathrm{D}$ videos and the procedure to build the gesture dataset are described (Sect. 3). The methodology for video characterization and classification, applied to gesture recognition from the acquired $3 \mathrm{D}$ videos is then detailed (Sects. 4.A-4.D). Finally, the recognition performances for both integral imaging and conventional monocular data are analysed (Sect. 4.E), and conclusions drawn (Sect. 5).

\section{Overview of 3D Integral Imaging}

In this section, we present a brief overview of the integral imaging technique used to perform 3D sensing and reconstruction of gestures. Integral imaging (also known as Integral Photography) was originally proposed by the Nobel Laureate G. Lippmann in 1908 [1]. Integral Imaging (II) is an autostereoscopic imaging method used to capture 3D information and to visualize it in $3 \mathrm{D}$ optically or computationally. The historical origins of integral photography may be linked to Sir Wheatstone invention of stereoscopic viewing device which uses the principle of disparity for $3 \mathrm{D}$ visualization [2]. With some exceptions [3-7], there was no substantial activity in integral photography for most of the twentieth century due to the lack of enabling technologies, including optical and optoelectronic devices, detectors, components, and hardware. With the important advances in optical detectors such as CCD and CMOS technologies, display devices such as Liquid Crystal Devices (LCDs), consumer electronics, and computer hardware, the field has been significantly propelled forward. In the late 20th century, the pioneering works by Okano and his co workers at NHK and other groups demonstrated the suitability of Integral Imaging for 3D displays [8-11]. Currently, integral imaging is subject to much research, it has been pursued for various applications [12-21], and it is considered as a promising technology for 3D displays and $3 \mathrm{D}$ TV. Unlike holography that requires a coherent source [22, 23], integral imaging can work under ambient or incoherent light. For example, the sensing can be performed passively.

Acquisition and visualization of $3 \mathrm{D}$ objects using II can be divided into two different stages, called pickup and reconstruction. In the pickup stage, multiple $2 \mathrm{D}$ images (referred to as elemental images) are captured through an array of small lenses (lenslet array) or an array of cameras. Each lenslet contains a unique projective transformation that maps the $3 \mathrm{D}$ object space onto $2 \mathrm{D}$ elemental images and is a function of the lenslet position and the focal length. As a result, an array of inverted real images is formed on the image sensor. Regarding

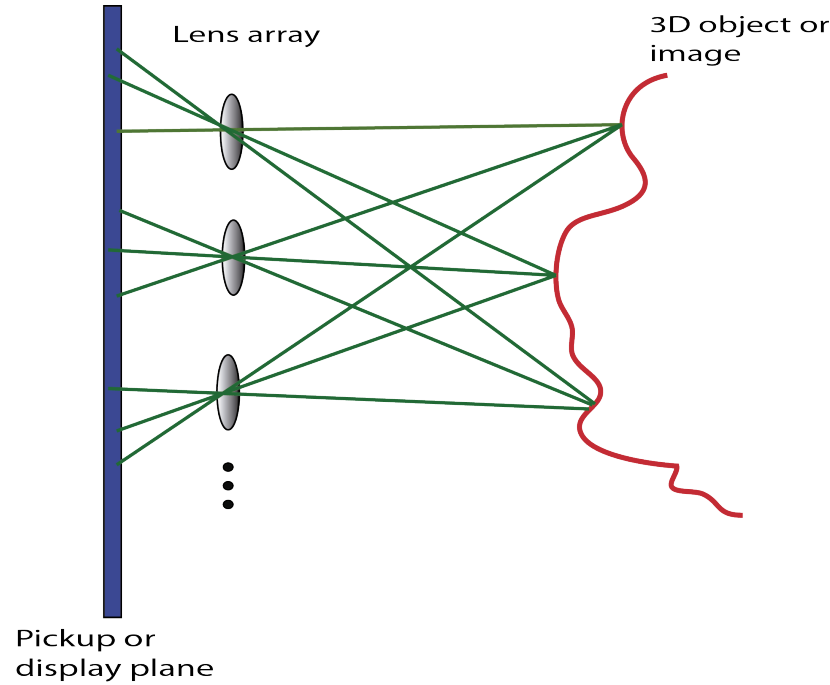

Fig. 1. Principle of Integral Imaging capture and display. The object depth information is encoded into lateral relative shift between different views of the scene known as elemental images.

the reconstruction stage, $3 \mathrm{D}$ scene reconstruction can be made optically or computationally. Computational reconstruction of the 3D image (the one used in this paper) can be achieved by simulating the optical backprojection of elemental images in the computer. This reconstruction method uses a computer synthesized virtual pinhole array for inverse mapping of each elemental image into the object space. All elemental images are computationally overlapped afterwards. With this process, the intensity distribution can be reconstructed at arbitrary planes inside the 3D object volume, as we shall demonstrate in the next sections.

\section{A. Capture and display stages of integral imaging}

Figure 1 illustrates the principle of Integral Imaging for both acquisition and display purposes. The object depth information is encoded into lateral relative shift between different views of the scene known as elemental images. The 3D scene including the depth information can be recovered by post-processing the elemental images. Each elemental image is back-projected through its own viewpoint (Figure 2(a)) and the superposition of the ray cones projected from the elemental images reconstructs the 3D scene. In Fig. 2(a), $g$ is the focal length of the imaging optics; $p$ is the pitch of the cameras, and $M$ is the Magnification factor $\left(M=\frac{z}{g}\right)$. Superposition of properly shifted elemental images provides the 3D reconstructed images as follows [31] (Figure 2(b)):

$$
I(x, y, z)=\frac{1}{O(x, y)} \sum_{k=0}^{K-1} \sum_{l=0}^{L-1} E_{k l}\left[x^{\prime}, y^{\prime}\right]
$$


with

$$
\begin{aligned}
& x^{\prime}=x-k \frac{N_{x} \cdot p}{c_{x} \cdot M}, \\
& y^{\prime}=y-l \frac{N_{y} \cdot p}{c_{y} \cdot M},
\end{aligned}
$$

where $I(x, y, z)$ represents the intensity of the reconstructed $3 D$ image at depth $z, x$ and $y$ are the indexes of the pixel, $E_{k l}$ represents the intensity of the $k$ th row and lth column elemental image, $N_{x} \times N_{y}$ is the total number of pixels for each elemental image, $M$ is the magnification factor, $c_{x}, c_{y}$ is the size of the camera sensor and $O(x, y)$ is the overlapping number matrix.

There are alternative ways to capture 3D information to the lenslet-based approach. One idea is the use of image sequences [32]; another one uses an array of image sensors distributed in an homogeneous or (alternatively) random grid such as Synthetic Aperture Integral Imaging (SAII) [33], which is the acquisition strategy used in this work. The longitudinal resolution of the system is given by [24]:

$$
\triangle z_{\min }=\frac{\mu z^{2}}{P_{m} g-\mu z}
$$

where $\mu$ is the pixel size, $z$ is the object range, $P_{m}$ is the maximum parallax, and $g$ is the distance between the imaging lens and the sensor. This minimum longitudinal resolution is subject to the following constraints:

$$
P_{m} g \leq \frac{z N_{\{x, y\}} \mu}{2}
$$

where $N_{\{x, y\}}$ is the number of camera pixels in each direction, $(x, y)$.

\section{Experimental set-up for Integral image acquisition and scene reconstruction}

In our experimental set-up, a $3 \times 3$ array of Stingray F080B/C cameras was used (Figure 3). Using a synchronization through the 1394 bus, the nine synchronized videos were captured at a speed of 15 frames per second and a resolution of $1024 \times 768$ pixels. In order to eliminate errors generated due to uncertainty in location and orientation of the cameras, the acquired videos were subsequently rectified in an off-line stage. The aim of the image rectification process is to project two or more images onto a common image plane to correct for the misalignment in relation to the positions and orientations of the original cameras [34]. For each camera, the rectified image is obtained by applying an homography transformation between the original camera and the ideal one, following a well-known calibration method [35]. For the camera $n$, its homography $\mathbf{H}_{n}$ is obtained as:

$$
\mathbf{H}_{n}=\mathbf{P}_{\text {ideal }, n} \cdot \mathbf{P}_{n}^{+},
$$

where $\mathbf{P}_{n}$ is the projection matrix for camera $n$, obtained through the calibration process, $\mathbf{P}_{n}^{+}$is its pseudo inverse, and $\mathbf{P}_{\text {ideal }, n}$ is computed as

$$
\mathbf{P}_{\text {ideal }, n}=\mathbf{K}_{\text {ideal }} \cdot\left[\mathbf{R}_{\text {ideal }} \mid \mathbf{T}_{\text {ideal }, n}\right],
$$

where $\left[\mathbf{R}_{\text {ideal }} \mid \mathbf{T}_{\text {ideal, },}\right]$ is a matrix resulting from the addition of $\mathbf{T}_{\text {ideal }, n}$ to the right of matrix $\mathbf{R}_{\text {ideal }}$. In this case, a rotation matrix $\mathbf{R}_{\text {ideal }}$ that represents the camera arrangement is considered as the basis axes. Then, the ideal translation for each camera is found in order to obtain the $3 \times 3$ arrangement with the same distance between adjacent cameras $\left(\mathbf{T}_{\text {ideal,n }}\right)$. Finally, the common intrinsic matrix $\mathbf{K}_{\text {ideal }}$ is determined for the ideal multi-camera arrangement.

In order to explore the capabilities of using II in gesture recognition, a series of two repetitions of three different gestures performed by ten people were acquired. The three gestures, made using the right arm extended, were:

- opening and closing the hand (Open)

- go to the left gesture (Left)

- deny gesture, made with the forefinger (Deny)

The ten people were in front of the camera array at a distance of approximately $2.5 \mathrm{~m}$. The gestures were acquired in a laboratory with no other movement apart from the person doing the gesture. For each of the 3 actions $\times 10$ people $\times 2$ repetitions $=60$ recorded videos, a $3 \mathrm{D}$ volume was reconstructed for its first frame to find out the distance where the hand was in focus. Then, this distance was used for reconstructing the volume for the rest of the frames. In this process, we considered every frame of each video as an elemental image for that video. From the 9 elemental images corresponding to each video frame, a $3 D$ volume was made, and we only retained the reconstructed distance for which the hand gesture was in focus. The volumetric (depth) reconstruction method for each frame starts with the elemental images and projects them directly through a virtual pinhole array. In particular, for a fixed distance from this pinhole array, each elemental image is inversely projected through each synthesized pinhole in the array. Each inversely projected image is magnified applying the magnification factor which is the ratio of the distance between the pinhole array and the plane of reconstruction at a particular reconstruction distance (see Section 2.A for details). In order to assess the volumetric information, this process is repeated for all the reconstruction planes. The range of distances from which the reconstruction was made was from $1 \mathrm{~m}$ to $3.5 \mathrm{~m}$ (the origin of distances is the plane of the $3 \times 3$ camera array) in $10 \mathrm{~mm}$ steps.

As an example, Figure 4 shows three images corresponding to three different reconstruction of refocused planes of the same person and the same gesture. In each of these planes, one part of the scene is reconstructed to 


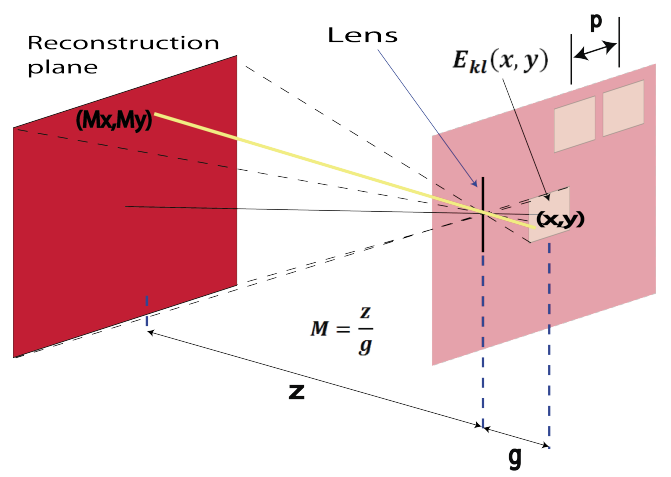

(a)

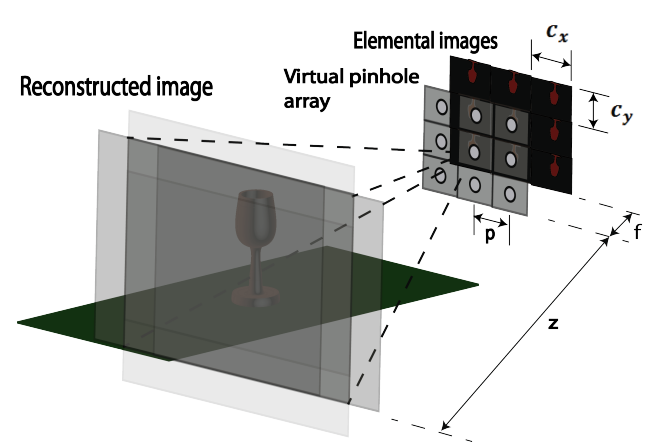

(b)

Fig. 2. 3D scene reconstruction by back projecting the elemental images through virtual pinholes. (a) A single elemental image is back-projected through its own viewpoint. (b) The superposition of the ray cones projected from the elemental images reconstructs the $3 \mathrm{D}$ scene.

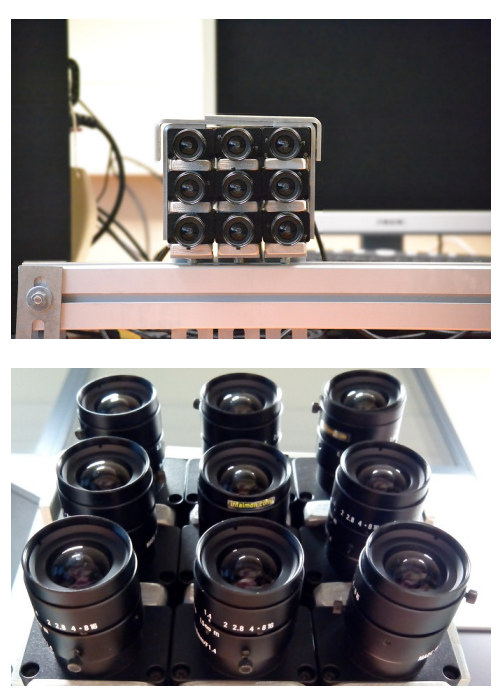

Fig. 3. Two views of the array of $3 \times 3$ cameras used to acquire the videosof the $3 \mathrm{D}$ gestures

be in focus, either the background computers, the subject's face, or the subject's hand. This illustrates the segmentation and sectional re-focusing capability of the integral imaging technique that might prove useful for gesture recognition, by exploiting the fact that only the object of interest is focused and the rest of the scene is blurred. An example of the scenes for the three gestures reconstructed for the distance where the hand is in focus is shown in Figure 5. The resulting videos from these reconstruction are used for gesture recognition.

An overview of the proposed system is offered in Fig. 6, with the two main parts: integral imaging (this section) and gesture recognition (Section 4).

\section{Gesture recognition using integral imaging: methodology and experiments}

The methodology to characterize and recognize gestures is described first (Sects. 4.A-4.D). It applies to the videos reconstructed with $3 \mathrm{D}$ integral imaging exactly as it is applied to conventional videos from single-camera views. In fact, we used both data sources for comparison, and results of recognition performance are reported in Sect. 4.E.

The procedure for gesture recognition follows a standard "bag of visual words" approach (e.g. [36]), whose pipeline is as follows:

1. Detecting and describing spatio-temporal interest points (STIPs) for each video

2. Quantizing the resulting descriptors in a number of visual words (i.e., the vocabulary or codebook)

3. Building the Bag-of-Words (BoW) representation for each video using its STIPs and the resulting codebook

4. Classifying unseen videos from their BoW representations

\section{A. From videos to local descriptors}

Spatio-temporal interest points (STIPs) were generated following [37] using the software available at [38]. The overall idea is that videos are treated as $3 \mathrm{D}$ volumes $(x, y, t)$ and points within this volume are locally characterized using histograms of gradients (HOG) and/or histograms of optic flow (HOF) within small 3D volumes.

Although details can be found elsewhere [37], we include some specific information to make the presentation more self-contained. The 3D volume corresponding to the image sequence, $f: \mathbb{R}^{3} \mapsto \mathbb{R}$, is convolved with an anisotropic Gaussian Kernel: 


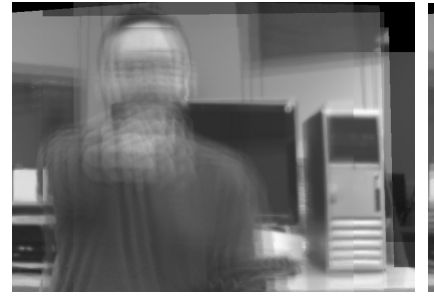

(a) reconstructed background

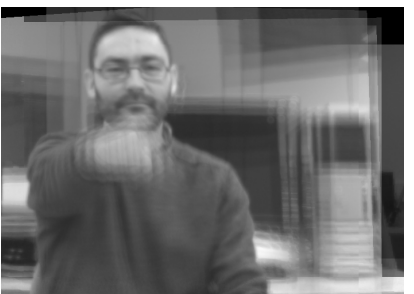

(b) reconstructed face

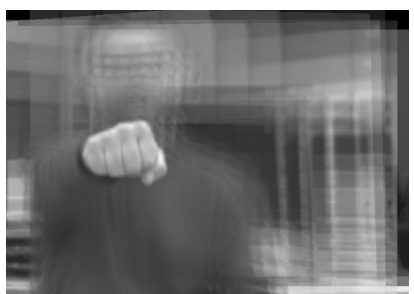

(c) reconstructed fist

Fig. 4. Images corresponding to three different reconstruction distances for the same person and gesture

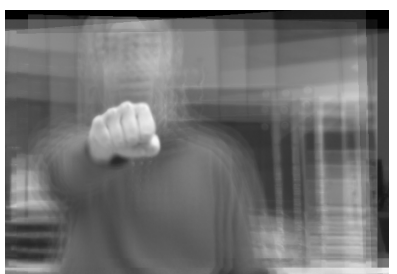

Open

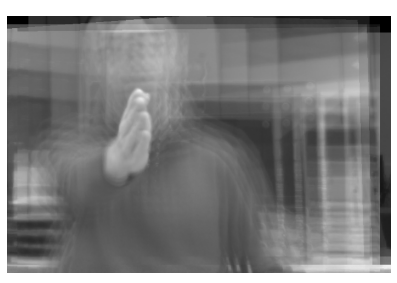

Left

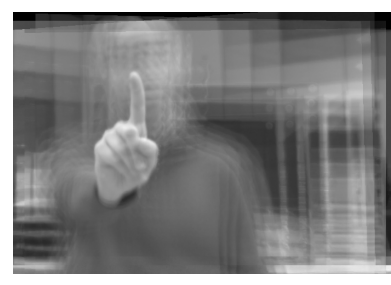

Deny

Fig. 5. Images corresponding to the reconstruction distance for which the hand is in focus in each of the three hand gestures considered

$$
\begin{gathered}
L\left(\cdot ; \sigma_{l}^{2}, \tau_{l}^{2}\right)=g\left(\cdot ; \sigma_{l}^{2}, \tau_{l}^{2}\right) * f(\cdot), \\
g\left(x, y, t ; \sigma_{l}^{2}, \tau_{l}^{2}\right)=\frac{1}{\sqrt{(2 \pi)^{3} \sigma_{l}^{4} \tau_{l}^{2}}} \cdot e^{-\frac{x^{2}+y^{2}}{2 \sigma_{l}^{2}}-\frac{t^{2}}{2 \tau_{l}^{2}}} .
\end{gathered}
$$

where $x, y$ and $t$ refer to the two spatial an the temporal dimensions, and $\sigma_{l}^{2}$ and $\tau_{l}^{2}$ are the spatial and temporal scales, respectively. Here, we assume that $z$ is fixed at the reconstructed plane of STIPs. Given the partial derivatives of $L, L_{a}, a \in\{x, y, t\}$, the first-order derivative matrix

$$
\mathbf{M}^{\prime}=\left(\begin{array}{ccc}
L_{x}^{2} & L_{x} L_{y} & L_{x} L_{t} \\
L_{x} L_{y} & L_{y}^{2} & L_{y} L_{t} \\
L_{x} L_{t} & L_{y} L_{t} & L_{t}^{2}
\end{array}\right)
$$

is convolved to give the second-order matrix $\mathbf{M}=$ $g\left(\cdot ; \sigma_{i}^{2}, \tau_{i}^{2}\right) * \mathbf{M}^{\prime}$, with $\sigma_{i}^{2}=s \sigma_{l}^{2}$ and $\tau_{i}^{2}=s \tau_{l}^{2}$ for a given $s$.

Finally, a 3D Harris function $H$ is defined inspired on the 2D Harris function [39],

$$
H=\operatorname{det}(\mathbf{M})-k \operatorname{trace}^{3}(\mathbf{M}) .
$$

Local maxima of $H$ identifies spatio-temporal interest points of $f$, i.e. points that exhibit large variations along both the spatial and temporal dimensions. This is known as the Harris3D detector. A multi-scale approach is followed and scales $\left\{\sigma_{l}=2^{\frac{l+1}{2}}: l \in\{1,2, \ldots, 6\}\right\}$ and $\left\{\tau_{l}=2^{l}: l \in\{1,2\}\right\}$ are used.

As a pre-processing before STIP detection, the frame rate of input videos was increased so that the videos were longer [40]. This allowed the software to be able to process shorter videos and produce more STIPs. In addition, frames from the monocular camera as well as from the integral images were resized to $481 \times 271$ pixels, and only the red channel used. Examples of detected STIPs on the II sequences are given in Fig. 7 .

Once interest points were detected, they were described using local information. Following [36, 41], the size of the local $3 \mathrm{D}$ volume $\left(\delta_{x}, \delta_{y}, \delta_{t}\right)$ around each interest point is a function of the considered scale: $\delta_{x}=$ $\delta_{y}=18 \sigma_{l}, \delta_{t}=8 \tau_{l}$. Each local $3 \mathrm{D}$ volume was subdivided into a regular grid of $n_{x} \times n_{y} \times n_{t}$ cuboids, with $n_{x}=n_{y}=3, n_{t}=2$. The histograms of oriented gradients (HOG) and the histograms of oriented optic flow (HOF) were computed within each cuboid, with as few as 4 and 5 bins, respectively. Then, the histogram for each cuboid was normalized, and the histograms for all cuboids within the local $3 \mathrm{D}$ volume of an interest point were concatenated to form the descriptors for that interest point, with dimensionality 72 (HOG), 90 (HOF), and $162(\mathrm{HOG}+\mathrm{HOF})$.

\section{B. From descriptors to visual words}

The descriptors were quantized into visual words through an unsupervised clustering. We used the $k$ means [42] implementation of the VLFeat library [43]. Given $n$ data points $\left\{\mathbf{x}_{i}\right\}_{i=1}^{n}$, each of dimension $d$, the goal of $k$-means is to find a partition of these points into $K$ clusters $\left\{C_{j}\right\}_{j=1}^{K}$ so that the sum of the distances of each data point to the mean of its cluster, $\boldsymbol{\mu}_{i}$ (i.e. the cluster centre), 
Integral imaging video processing

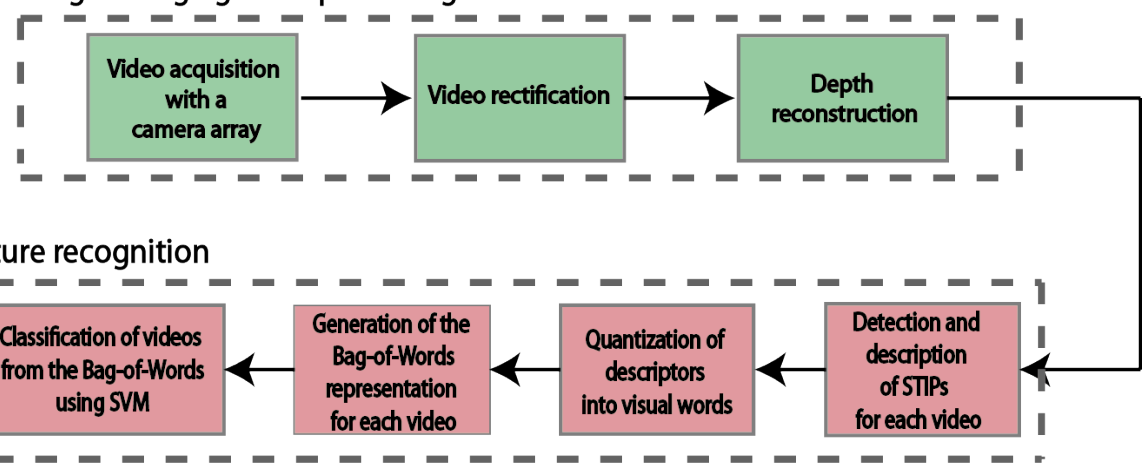

Fig. 6. Building blocks of the proposed system

$$
\sum_{j=1}^{K} \sum_{\mathbf{x}_{i} \in C_{j}}\left\|\mathbf{x}_{i}-\boldsymbol{\mu}_{j}\right\|^{2}
$$

is minimized. Since this optimization problem is known to be NP-hard, $k$-means follows a greedy strategy by iteratively updating the cluster center and assigning each data point to its closest cluster, until convergence [42].

In our case, the STIPs of the subset of the videos in a training set were used to find the clusters. Then, each STIP of this subset of videos, and those of the test set, are assigned a cluster. Each cluster number represents a codeword (a visual word).

Since the result of $k$-means is initialization-dependent, we ran it five times on the same data, and the clustering corresponding to minimal energy (i.e. minimum value of Eq. 9) is used. For efficiency, the Elkan approach was used, which reduced the number of comparisons between data points and cluster centers by using triangular inequalities.

\section{C. From visual words to BoW}

Following the typical BoW approach, each video was represented by building a histogram of codewords [36]. This histogram has $K$ bins, where $K$ corresponds to the number of clusters. Formally, let $\left\{\mathbf{x}_{i}\right\}_{i=1}^{n}$ be the descriptors of the $n$ STIPs detected in an input video, and $\left\{\boldsymbol{\mu}_{j}\right\}_{j=1}^{K}$ the centers of the $K$ clusters found with $k$-means applied to the training videos. Then, the histogram $\left\{\boldsymbol{h}_{j}\right\}_{j=1}^{K}$ of that video is computed as follows:

$$
\boldsymbol{h}_{j}=\sum_{i=1}^{n}\left[c\left(\mathbf{x}_{i}\right)=j\right], \quad j \in\{1,2, \ldots, K\},
$$

with [.] being the Iverson bracket notation for the Kronecker delta function, $\boldsymbol{h}_{j}$ is the $j$-th bin of histogram $\boldsymbol{h}$, and $c(\mathbf{x})$ is the closest cluster of data point $\mathbf{x}$ :

$$
c(\mathbf{x})=\arg \min _{i \in\{1, \ldots, K\}}\left\|\mathbf{x}-\boldsymbol{\mu}_{i}\right\|^{2} .
$$

\section{D. From BoWs to gesture prediction}

In order to estimate the gesture recognition performance, a "leave-one-subject-out" protocol was followed, as in common practice (e.g. [44, 45]). Given $S$ subjects, the BoWs of all videos (all actions and repetitions) for $S-1$ subjects are used for training whereas the BoWs for the videos of the remaining subject are used for testing. The process is repeated $S$ times, once per subject. The average performance over these $S$ results is therefore reported.

For classification, Support Vector Machines (SVM) [46] were chosen, since they are widely-used classifiers with good generalization abilities thanks to is max-margin formulation. Given a (training) dataset $\left\{\left(\mathbf{x}_{i}, y_{i}\right): \mathbf{x}_{i} \in \mathbb{R}^{d}, y_{i} \in\{-1,1\}\right\}_{i=1}^{n}$ of data points $\mathbf{x}_{i}$ and their corresponding class labels $y_{i}$, SVM aims at solving

$$
\arg \min _{\mathbf{w}, \boldsymbol{\xi}, b} \frac{1}{2}\|\mathbf{w}\|^{2}+C \sum_{i=1}^{n} \xi_{i},
$$

subject to

$$
y_{i}\left(\mathbf{w} \cdot \mathbf{x}_{i}-b\right) \geq 1-\xi_{i}, \quad \xi_{i} \geq 0,
$$

where $\frac{1}{\|\mathbf{w}\|}$ determines the margin around the decision boundary that is to be maximised, $\boldsymbol{\xi}=\left\{\xi_{i}\right\}_{i=1}^{n}$ are the so-called slack variables that account for the misclassification errors, and $C$ is a regularization parameter that allows a trade-off solution balancing a large margin (good generalization) but yet small misclassification (good fitting to training data). The predicted class $\hat{y}$ for a novel input $\mathbf{x}, \hat{y}(\mathbf{x})$, is found through the learned parameters $(\mathbf{w}, b)$ by the decision function $\hat{y}(\mathbf{x})=\operatorname{sign}\left(\mathbf{w}^{T} \mathbf{x}+b\right)$.

We used a multi-class linear SVM (implementation of LibSVM library [47]). The regularization parameter $C$ in (12) was chosen through validation from the value in the set $10^{\{-4,-3, \ldots, 4\}}$ that gives the best average validation accuracy. At each validation round when training 
with $S-1$ subjects, $S-2$ subjects are used for training and the remaining one is used for testing.

Prior to learning and classification, histograms (the BoW representation) were $L_{1}$-normalized. Then, each feature was individually re-scaled to the range $[0,1]$. The smallest and largest values of training data, used for the scaling, were kept so that test data was re-scaled using these values from the training set. Finally, histograms were $L_{2}$ normalized.

Due to the random component of $k$-means, the descriptor quantization and the learning and prediction steps were repeated 10 times. The reported performance is the average classification accuracy over these repetitions.

\section{E. Experimental results}

Our goal was to explore the feasibility of gesture recognition with integral imaging. To that end we applied the BoW scheme to both the integral imaging data (II) and the original monocular data (Monocular) coming from one of the cameras of the $3 \times 3$ array. In particular, we chose the input from the central camera. STIPs were detected on both data sources with a zero threshold for the Harris3D detector so that all possible STIPS were used. The number of visual words was varied as $K \in\{10,25,50,100,200\}$. Finally, three possible descriptors were considered (HOG, HOF and $\mathrm{HOG}+\mathrm{HOF}$ ), since they may give rise to different performances when applied to the two different input visual data.

Results (Fig. 8) show that Monocular outperforms II when using HOF, but II outperforms the monocular cues both with $\mathrm{HOG}$ and $\mathrm{HOG}+\mathrm{HOF}$. An interpretation for this is that motion information is better retained in the original image, whereas part of it is lost by keeping a particular depth in the integral image reconstruction. A remedy would be to use $3 \mathrm{D}$ volume of the gesture rather than a $2 \mathrm{D}$ reconstructed image of integral imaging, so that temporal information is retained more effectively. In contrast, the focusing operation makes the gradient information more distinctive in II than in Monocular. When both descriptors are combined $(\mathrm{HOG}+\mathrm{HOF})$ through early fusion (i.e. features are just concatenated), higher recognition is obtained with II. For convenience and easier assessment, a common range for the accuracy axis is used in all plots, and the numerical values also provided (Table 1).

The fact of Monocular and II having complementary performance suggests their proper combination might boost performance with respect to any of them used separately. It is generally known that combining features of different nature usually results in higher performance. For instance, in the context of action recognition, shape and motion cues can be favourably combined [44]. Some possibilities for fusing multi-modal data include diverse forms of early and late fusion schemes [48-50].

In absolute terms, when comparing the best descriptor in each case (i.e., $\mathrm{HOF}$ for Monocular and $\mathrm{HOF}+\mathrm{HOG}$ for II), it can be seen (Fig. 9) that II (slightly) outperforms Monocular for all tested $K$ except for $K=50$.

\section{Conclusions}

In this paper, we have applied 3D passive sensing integral imaging to gesture recognition. This exploratory analysis and the results obtained with a bag-of-words approach reveal that integral imaging provides complementary distinctive information to that of using visual cues from a single camera. In our experiments, depending on the visual descriptor being used, integral imaging may outperform the monocular case. By suitably combining the elemental images of an array of cameras, integral imaging offers the ability of focusing a scene at particular depths. It has been observed that properly focusing at relevant spots in the scene can help visual descriptors based on spatial gradients to capture more discriminative information than in conventional monocular videos. This opens the door to advances in action recognition technology that were not possible to date.

\section{References}

[1] G. Lippmann, "La photographie integrale," ComptesRendus Academie des Sciences 146, 446-451 (1908).

[2] C. Wheatstone, "On some remarkable, and hitherto unobserved, phenomena of binocular vision," Philosophical Transactions of the Royal Society of London 128, 371394 (1838).

[3] A. P. Sokolov, Autostereoscopy and Integral Photography by Professor Lippmann's Method (Moscow State University Press, 1911).

[4] H. E. Ives, "Optical properties of a lippmann lenticuled sheet," Journal of the Optical Society of America 21, 171-176 (1931)

[5] C. B. Burckhardt, "Optimum parameters and resolution limitation of integral photography," Journal of the Optical Society of America 58, 71-76 (1968).

[6] Y. Igarishi, H. Murata, and M. Ueda, "3D display system using a computer-generated integral photograph," Japan Journal of Applied Physicis 17, 1683-1684 (1978).

[7] T. Okoshi, "Three-dimensional displays," Proceedings of the IEEE 68, 548-564 (1980).

[8] F. Okano, J. Arai, K. Mitani, and M. Okui, "Realtime integral imaging based on extremely high resolution video system," Proceedings of the IEEE 94, 490$501(2006)$.

[9] J. Arai, F.Okano, H. Hoshino, and I. Yuyama, "Gradient-index lens-array method based on real-time integral photography for three-dimensional images," Applied Optics 37, 2034-2045 (1998).

[10] H. Hoshino, F.Okano, H. Isono, and I. Yuyama, "Analysis of resolution limitation of integral photography," Journal of the Optical Society of America A 15, 20592065 (1998)

[11] L. Yang, M. McCornick, and N. Davies, "Discussion of the optics of a new 3-D imaging system," Applied Optics 27, 4529-4534 (1988).

[12] B. Javidi, F. Okano, and J.-Y. Son, Threedimensional Imaging, Visualization, and Display Technology (Springer, 2008). 

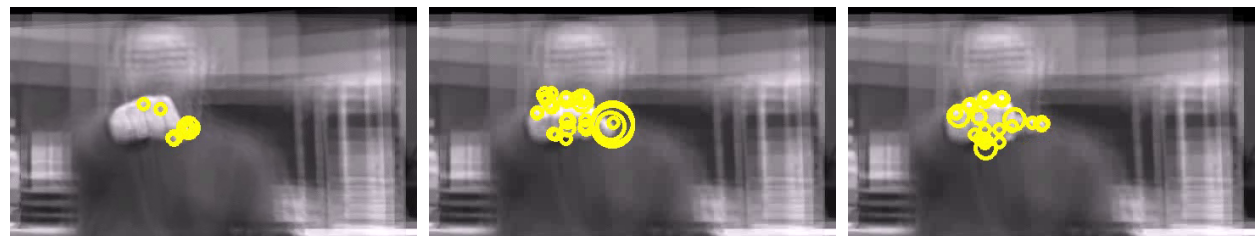

(a) Open gesture
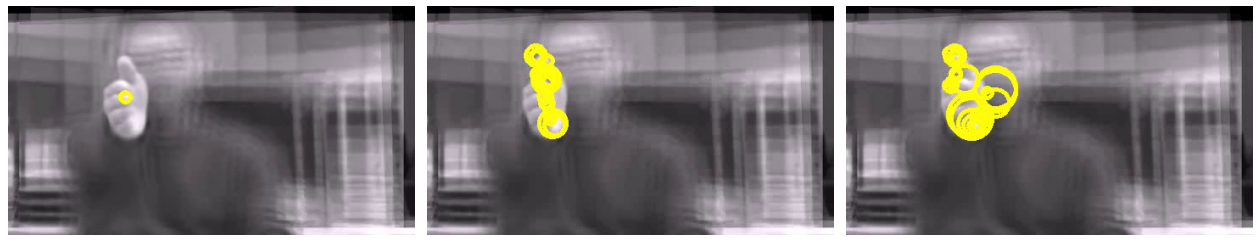

(b) Left gesture
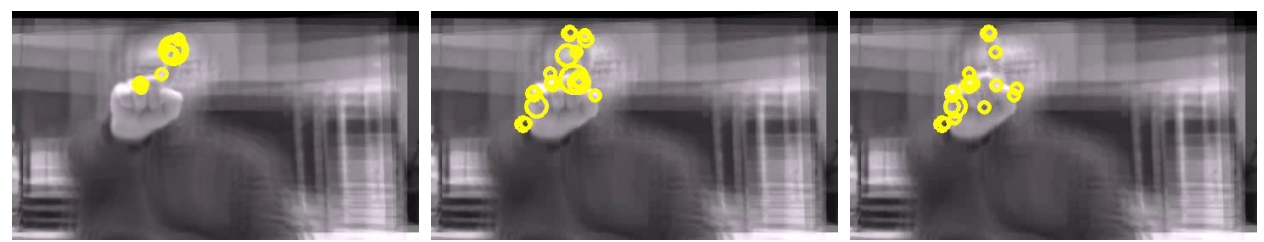

(c) Deny gesture

Fig. 7. Examples of spatio-temporal interest points (STIPS) detected (yellow circles) at a few frames of the videos of the three gestures performed by one of the subjects. The input is the reconstructed integral image at hand's depth. The size of each circle represents the scale the STIP was detected at.

Table 1. Recognition rates (\%) for both Monocular and II with the three descriptors. Averages and standard deviations are shown, rounded to one decimal place precision

\begin{tabular}{|c|c|c|c|c|c|}
\hline \multicolumn{6}{|c|}{ Monocular } \\
\hline & \multicolumn{5}{|c|}{ Number of words (K) } \\
\hline Descriptor $\nabla$ & 10 & 25 & 50 & 100 & 200 \\
\hline $\mathrm{HOF}$ & $70.1(4.2)$ & $81.5(5.1)$ & $88.7(3.4)$ & $90.9(3.5)$ & $92.6(2.0)$ \\
\hline HOG & $66.4(5.0)$ & $75.2(4.1)$ & $76.8(5.4)$ & $76.3(3.7)$ & $78.0(4.4)$ \\
\hline $\mathrm{HOG}+\mathrm{HOF}$ & $64.0(5.2)$ & $78.7(6.8)$ & $84.7(3.1)$ & $86.2(2.8)$ & $89.1(3.1)$ \\
\hline \multicolumn{6}{|c|}{ Integral Imaging } \\
\hline & \multicolumn{5}{|c|}{ Number of words (K) } \\
\hline Descriptor $\nabla$ & 10 & 25 & 50 & 100 & 200 \\
\hline $\mathrm{HOF}$ & $48.0(4.0)$ & $66.2(5.0)$ & $73.3(4.1)$ & $78.8(3.7)$ & $82.3(4.2)$ \\
\hline $\mathrm{HOG}$ & $74.7(4.6)$ & $84.3(4.1)$ & $84.2(3.5)$ & $84.5(4.9)$ & $85.1(3.8)$ \\
\hline $\mathrm{HOG}+\mathrm{HOF}$ & $83.2(4.0)$ & $85.1(2.9)$ & $87.9(3.2)$ & $93.7(3.6)$ & $95.0(3.1)$ \\
\hline
\end{tabular}

[13] A. Stern and B. Javidi, "Three-dimensional image sensing, visualization and processing using integral imaging," Proceedings of the IEEE 94, 591-607 (2006).

[14] J.-Y. Son, W.-H. Son, S.-K. Kim, K.-H. Lee, and B. Javidi, "Three-dimensional imaging for creating realworld-like environments," Proceedings of the IEEE 101, 190-205 (2013).

[15] M. Martínez-Corral, B. Javidi, R. Martínez-Cuenca, and G. Saavedra, "Integral imaging with improved depth of field by use of amplitude modulated microlens array," Applied Optics 43, 5806-5813 (2004).
[16] L. Hongen, N. Hata, S. Nakajima, M. Iwahara, I. Sakuma, and T. Dohi, "Surgical navigation by autostereoscopic image overlay of integral videography," IEEE Trans. Inf. Technol. Biomed. 8, 114-121 (2004).

[17] B. Javidi, S.-H. Hong, and O. Matoba, "Multidimensional optical sensor and imaging system," Applied Optics 45, 2986-2994 (2006).

[18] R. Martínez-Cuenca, G. Saavedra, M. Martínez-Corral, and B. Javidi, "Progress in 3-D multiperspective display by integral imaging," Proceedings of the IEEE 97, 10671077 (2009). 

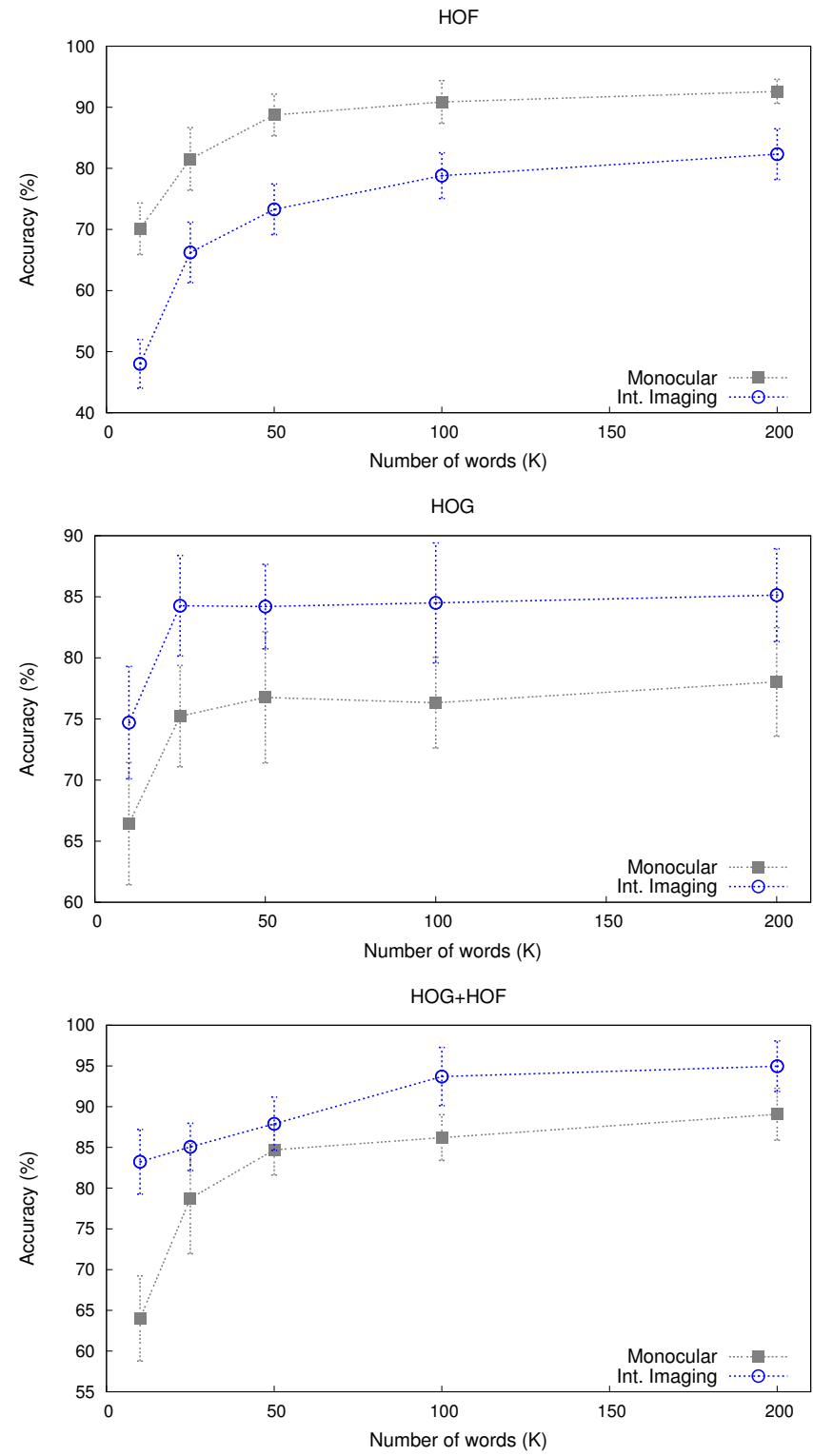

Fig. 8. Recognition results with 2D Monocular and 3D integral imaging under three descriptors (HOF, HOG, and HOG $+\mathrm{HOF}$ ). Intervals correspond to the standard deviation.

[19] M. Cho, M. Dansehpanah, I. Moon, and B. Javidi, "Three-dimensional optical sensing and visualization using integral imaging," Proceedings of the IEEE 99, 556575 (2011).

[20] M. Daneshpanah and B. Javidi, "Profilometry and optical slicing by passive three-dimensional imaging," Optics Letters 34, 1105-1107 (2009).

[21] J. Arai, F. Okano, M. Kawakita, M. Okui, Y. Haino, M. Yoshimura, M. Furuya, and M. Sato, "Integral threedimensional television using a 33-megapixel imaging system," IEEE Journal of Display Technology 6, 422-430 (2010).

[22] J. W. Goodman, Introduction to Fourier Optics (McGraw-Hill, 1996).
[23] S. A. Benton and V. M. Bove, Holographic Imaging (Wiley-Interscience, 2008).

[24] S. Kishk and B. Javidi, "Improved resolution 3-D object sensing and recognition using time multiplexed computational integral imaging," Optics Express 11, 35283541 (2003).

[25] S.-H. Hong and B. Javidi, "Distortion-tolerant 3D recognition of occluded object using computational integral imaging," Optics Express 14, 12085-12095 (2006).

[26] R. Schulein, C. Do, and B. Javidi, "Distortion-tolerant $3 \mathrm{D}$ recognition of underwater objects using neural networks," Journal of the Optical Society of America A 27, 461-468 (2010). 


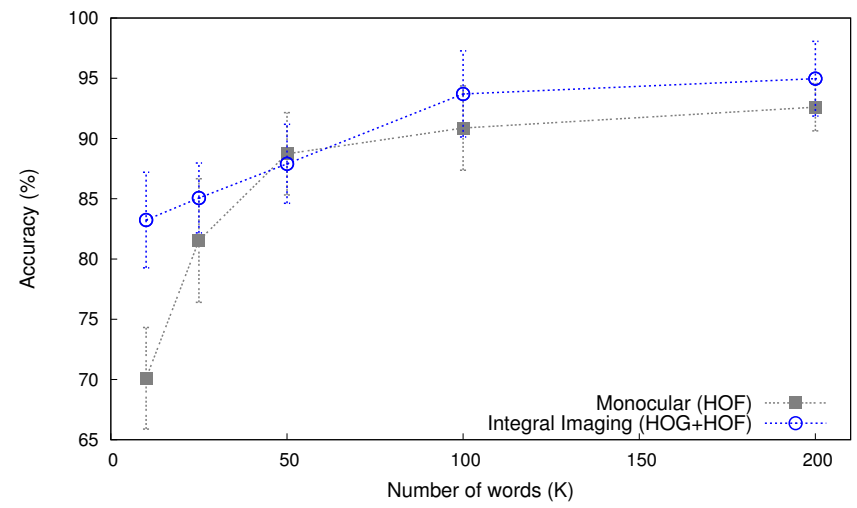

Fig. 9. Recognition results with the best-performing descriptor in each case (Monocular and II)

[27] J. Aggarwal and M. Ryoo, "Human activity analysis: A review," ACM Comput. Surv. 43, 16:1-16:43 (2011).

[28] L. Chen, H. Wei, and J. Ferryman, "A survey of human motion analysis using depth imagery," Pattern Recognition Letters 34, 1995-2006 (2013).

[29] C. M. Do, R. Martínez-Cuenca, and B. Javidi, "Threedimensional object-distortion-tolerant recognition for integral imaging using independent component analysis," Journal of the Optical Society of America A 26, 245-251 (2009).

[30] We refer to "3D videos" as regular videos built from 3D integral imaging.

[31] S.-H. Hong, J.-S. Jang, and B. Javidi, "Threedimensional volumetric object reconstruction using computational integral imaging," Optics Express 3, 483-491 (2004).

[32] M. Pollefeys, R. Koch, M. Vergauwen, and L. V. Gool, "Automated reconstruction of $3 \mathrm{D}$ scenes from sequences of images," ISPRS Journal Of Photogrammetry And Remote Sensing 44, 251-267 (2000).

[33] J.-S. Jang and B. Javidi, "Three-dimensional synthetic aperture integral imaging," Optics Letters 27, 11441146 (2002).

[34] N. Ayache and C. Hansen, "Rectification of images for binocular and trinocular vision," in "9th International Conference on Pattern recognition," , vol. 1 (1988), vol. 1.

[35] Z. Zhang, "A flexible new technique for camera calibration," IEEE Transactions on Pattern Analysis and Machine Intelligence 22, 1330-1334 (2000).

[36] H. Wang, M. M. Ullah, A. Kläser, I. Laptev, and C. Schmid, "Evaluation of local spatio-temporal features for action recognition." in "British Machine Vision Conference," (BMVA Press, 2009).

[37] I. Laptev, "On space-time interest points," Int. J. Comput. Vision 64, 107-123 (2005).

[38] I. Laptev, "Space-time interest points (STIP)," (2011). Software available at http://www.di.ens.fr/ laptev/ download.html.

[39] C. Harris and M. Stephens, "A combined corner and edge detector," in "Proceedings of the Alvey Vision Confer- ence," (Alvety Vision Club, 1988).

[40] We used ffmpeg -vsync 1 -i originalVideo -r 50 outputVideo.

[41] I. Laptev, M. Marszalek, C. Schmid, and B. Rozenfeld, "Learning realistic human actions from movies," in "IEEE Conf. on Computer Vision and Pattern Recognition," (2008), pp. 1-8.

[42] A. K. Jain, "Data clustering: 50 years beyond k-means," Pattern Recogn. Lett. 31, 651-666 (2010).

[43] A. Vedaldi and B. Fulkerson, "VLFeat: An open and portable library of computer vision algorithms," http: //www.vlfeat.org/ (2008).

[44] K. Schindler and L. J. V. Gool, "Action snippets: How many frames does human action recognition require?" in "Computer Vision and Pattern Recognition (CVPR)," (2008).

[45] Z. Lin, Z. Jiang, and L. S. Davis, "Recognizing human actions by learning and matching shape-motion prototype trees," IEEE Trans. on Pattern Analysis and Machine Intelligence (PAMI) 34, 533-547 (2012).

[46] N. Cristianini and J. Shawe-Taylor, An Introduction to Support Vector Machines and Other Kernel-based Learning Methods (Cambridge University Press, 2000).

[47] C.-C. Chang and C.-J. Lin, "LIBSVM: A library for support vector machines," ACM Transactions on Intelligent Systems and Technology 2, 27:1-27:27 (2011). Software available at http://www.csie.ntu.edu.tw/ cjlin/libsvm.

[48] Z.-z. Lan, L. Bao, S.-I. Yu, W. Liu, and A. G. Hauptmann, "Double fusion for multimedia event detection," in "Proceedings of the 18th international conference on Advances in Multimedia Modeling," (Springer-Verlag, 2012), pp. 173-185.

[49] J. Kittler, M. Hatef, R. P. Duin, and J. Matas, "On combining classifiers," IEEE Transactions on Pattern Analysis and Machine Intelligence (PAMI) 20, 226-239 (1998).

[50] M. Gönen and E. Alpaydın, "Multiple kernel learning algorithms," Journal of Machine Learning Research 12, 2211-2268 (2011). 


\title{
Integral imaging acquisition and processing for human gesture recognition
}

\author{
F. Pla ${ }^{\mathrm{a}}$, P. Latorre-Carmona ${ }^{\mathrm{a}}$, E. Salvador-Balaguer ${ }^{\mathrm{a}}$, B. Javidi ${ }^{\mathrm{b}}$ \\ ${ }^{a}$ Institute of New Imaging Technologies, Universidad Jaume I Campus del Riu Sec s/n, 12071

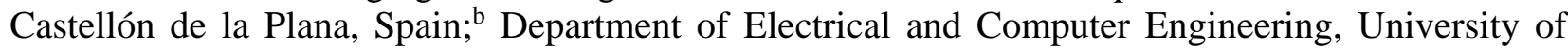 \\ Connecticut, Storrs, CT, 06269 USA \\ Email:Bahram.Javidi@uconn.edu
}

\begin{abstract}
In this keynote address paper, we present an overview of our previously published work on the application of pattern recognition techniques and integral imaging for human gesture recognition.
\end{abstract}

Keywords: Human gesture recognition, integral imaging.

\section{INTRODUCTION}

Three-dimensional (3-D) optical image sensing and visualization technologies have been received a considerable amount of attention during the last two decades. Application fields are as diverse as TV broadcasting, entertainment, medical sciences, robotics, to name a few [1]-[3]. As opposed to traditional 2-D imaging, 3-D sensing technologies can potentially capture the structural information of the scene. In many instances, the capabilities of 3-D imaging and display systems have revolutionized the progress of these disciplines, enabling new detection/display abilities that would not have been otherwise possible. There are different methods to display 3D images. Some of them make use of special glasses, which may create adverse effects like sickness, etc. Other methods use parallax barriers in order to avoid using glasses, adapting their parameters to the viewer position [4]. Content-adaptive parallax barriers for which display elements are optimized for the multi-view content are also being developed [5]. Others imply the use of multiple cameras located at several positions.

As one of the promising methods in the area of 3-D sensing and display, Integral Imaging is an autostereoscopic 3D imaging method that offers passive and relatively inexpensive way to capture 3-D information and to visualize it optically or computationally [6]-[9]. The integral imaging technique belongs to the broader class of multiview imaging techniques. Recently, it has been shown that the spatial 3D resolution obtained with the Integral Imaging method is better than the resolution obtained when using multiple cameras [10]. Integral imaging provides a window to the 3-D world through a collection of 2-D projections of real-world objects. There are two separate procedures for acquisition and visualization of 3-D objects which are referred to as pickup and reconstruction stages, respectively

Computer vision and machine learning scientists have been intensively working during the last few decades to derive methodologies that might be able to give information related to recognition of human activities from different types of sensors [11]. However, there still exist many challenges ahead in terms of efficiency, scalability and robustness.

Depth sensing can be obtained using different types of approaches: (a) stereo pairs, (b) time-of-flight technologies, and (c) structured light strategies [12]. Integral imaging has been used for classification tasks [13], however, the work in [14] is the first research work where integral imaging has been applied to action recognition. This paper presents an overview of the work and some of the results presented in [14].

\section{THREE-DIMENSIONAL INTEGRAL IMAGING}

Integral imaging is a 3D imaging technique that is able to provide the 3D profile and range of the objects in a scene. Integral Imaging can be performed either using an array of high resolution imaging sensors, or in a synthetic aperture mode (see Fig. 1(a)). When a single sensor translates on a 2D plane to capture multiple 2D images, this enables one to obtain larger Field of View (FOV) 2D images. Three-dimensional reconstruction of images can be achieved by computationally 
simulating the optical back-projection of the elemental images. In particular, a computer-synthesized virtual pinhole array is used to inversely map the elemental images into the object space (see Fig. 1(b)). Superposition of properly shifted elemental images provides the 3D reconstructed images:

$$
I(x, y, z)=\frac{1}{O(x, y)} \cdot \sum_{k=0}^{K-1} \sum_{l=0}^{L-1} E_{k l}\left(x-k \frac{N_{x} \cdot p}{c_{x} \cdot M}, y-l \frac{N_{y} \cdot p}{c_{y} \cdot M}\right)
$$

where $I(x, y, z)$ represents the intensity of the reconstructed 3D image at depth $z, x$ and $y$ are the indexes of the pixel, $E_{k l}$ represents the intensity of the kth row and lth column elemental image, $p$ is the pitch of the cameras, $N_{x} \times N_{y}$ is the total number of pixels for each elemental image, $M=\frac{z}{f}$ is the magnification factor, $c_{x} \times c_{y}$ is the physical size of the camera sensor, and $O(x, y)$ is the overlapping number matrix.

The methodology we considered in our research is based on the acquisition of 3D videos of the hand gestures using an integral imaging system formed by an array of $3 \times 3$ cameras. We analyze the potential of gesture recognition using $3 \mathrm{D}$ Integral Imaging and compare its performance to 2D single-camera videos. The experiments provide evidence of the feasibility of gesture recognition with Integral Imaging.

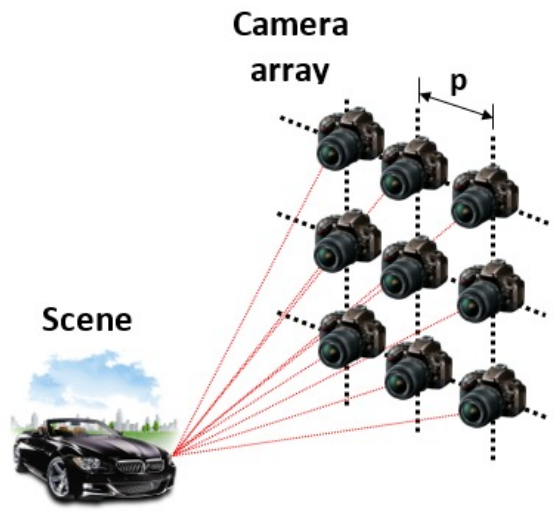

(a)

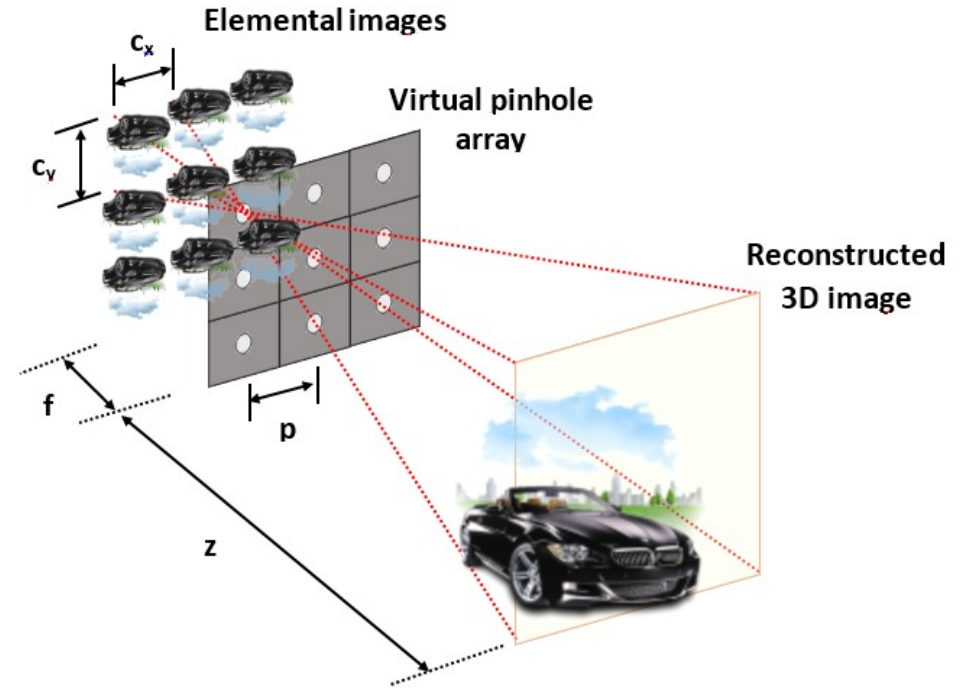

(b)

Figure 1. Synthetic Aperture Integral Imaging (SAII) acquisition and computational reconstruction method. (a) Image sensors are located in a "grid" whose spacing is given by the "pitch" parameter. (b) Optical 3D reconstruction using a virtual pinhole array and optical back-projection of the acquired elemental images

\section{EXPERIMENTAL SET-UP FOR INTEGRAL IMAGE ACQUISITION AND SCENE RECONSTRUCTION}

A $3 \times 3$ array of Stingray F080C cameras was used in our experimental set-up. In general, the Synthetic Aperture Integral Imaging (SAII) systems allow to obtain higher resolution values in the computational depth reconstructions when compared to the Integral Imaging systems based on a microlens array, because in the SAII acquisition methodology, the full CCD resolution of each camera is used. During the acquisition of each action, 9 videos (one per camera of the $3 \times 3$ array) were synchronized through a 1394 bus, acquired at a speed of 15 frames per second. Video resolution was $1024 \times$ 768 pixels. These videos were subsequently rectified [15]. A series of two repetitions of three different gestures performed by ten people were made and acquired by the camera array. The three gestures, made using the right arm extended, were: (a) opening and closing the hand, (b) go to the left gesture, (c) deny gesture, made with the forefinger. 
All the cameras had their focus plane located at around $2 \mathrm{~m}$ from plane of the lenses. All the elements in the scene (including people) were "sharply" seen in the range of depths from 0.5 to $3.5 \mathrm{~m}$. The ten people were situated in front of the camera array at a distance of approximately $2.5 \mathrm{~m}$. The gestures were acquired indoors (in a laboratory of the group) with no additional movements in the scene apart from the gestures. Sixty videos (corresponding to: 3 actions x 10 people x 2 repetitions) were finally recorded and a depth reconstruction (from 1 to $3.5 \mathrm{~m}$ in $10 \mathrm{~mm}$ steps) was made for the first frame to locate the distance where the hand was in focus. This distance was subsequently used for the rest of the video frames of each action, repetition and person. Figure 2 shows the depth reconstruction for one typical frame of the action recognition experiment. Figure 2(a) shows the distance where the hand is in focus. Figure 2(b) the distance where the person face is in focus and Figure 2(c) shows the distance where a part of the background is in focus. Figure 3 shows the reconstructed plane where the action is in focus for the three different actions to be considered in this research: (a) Left gesture, (b) Deny gesture, (c) Open/closure gesture.

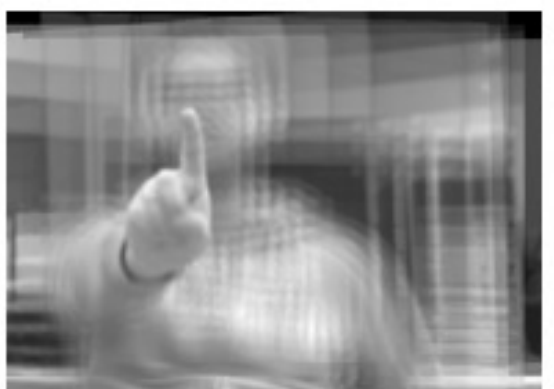

(a)

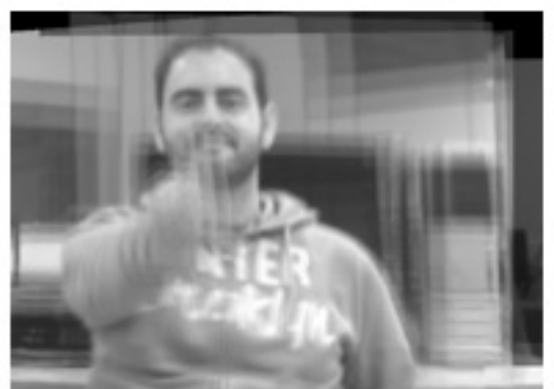

(b)

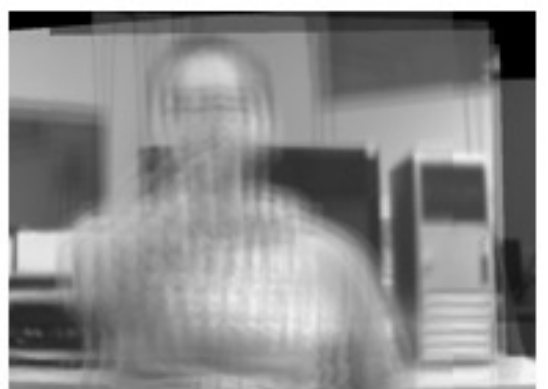

(c)

Figure 2. Depth reconstruction of the Deny gesture. (a) Distance where the hand is in focus. (b) Distance where the face is in focus. (c) Distance where part of the background is in focus.

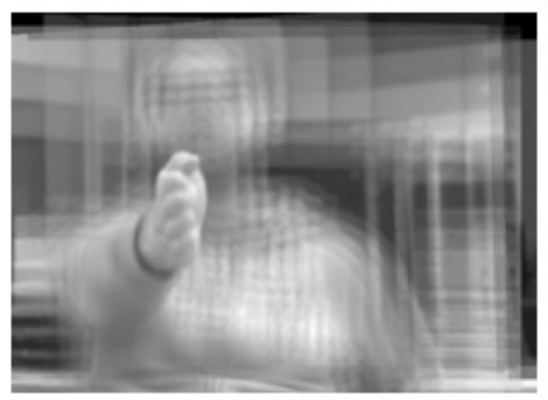

(a)

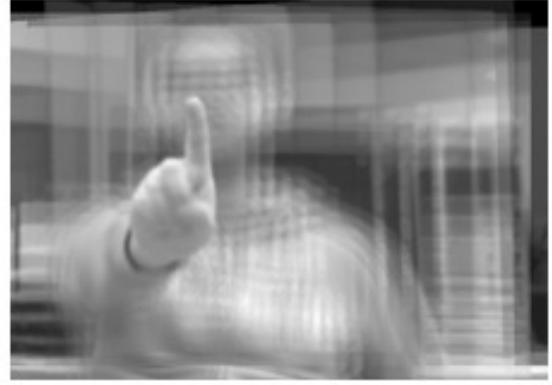

(b)

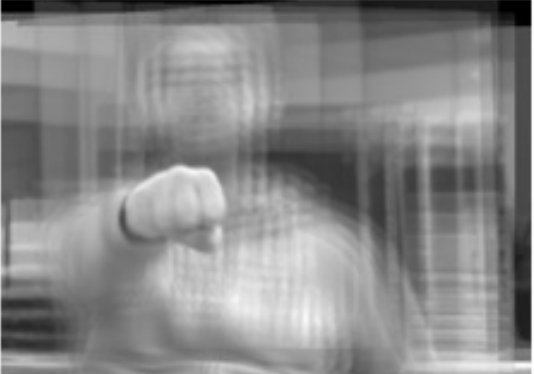

(c)

Figure 3. The three gestures used in our research. (a) Left gesture (b) Deny gesture. (c) Open/Close gesture (originally appeared in [14]).

\section{GESTURE RECOGNITION USING INTERAL IMAGING: EXPERIMENTS AND RESULTS}

The methodology to characterize and recognize gestures can be summarized as follows [16]:

- $\quad$ Infer the spatio-temporal interest points (STIPs) for each video

- Quantize the resulting descriptors in a number of visual words (also called the vocabulary or codebook)

- $\quad$ Create the corresponding bag-of-words $(\mathrm{BoW})$ representation for each video using its STIPs and the resulting codebook

- Classify test videos from their BoW description. 


\section{Videos $\rightarrow$ Local descriptors}

Spatio-temporal interest points (STIPs) were generated following [17]. These points are characterized by the fact that they exhibit large variations along both the spatial and temporal dimensions. Once interest points were detected, they were described using local 3D volume information. The histograms of oriented gradients (HOG) and the histograms of oriented optic flow (HOF) were computed within each 3D volume centered at the STIPs. Finally, the histograms within the local 3D volume of an interest point were concatenated to form vectors of dimensionality 72 (HOG), 90 (HOF), and 162 (HOG+HOF).

\section{Local descriptors $\rightarrow$ Visual words}

The local descriptors were quantized into visual words through k-means clustering. In particular, the STIPs of the subset of the videos in a training set were used to find the clusters. Each STIP of this subset of videos, and those of the test set, were assigned a cluster afterwards. Each cluster number represents a codeword (a visual word). In order to deal with kmeans initialization problems, the clustering process was ran five times on the same data, and the clustering corresponding to minimal energy was the one that was selected. Figure 4 shows some examples of detected STIPs on the Integral Imaging sequences.
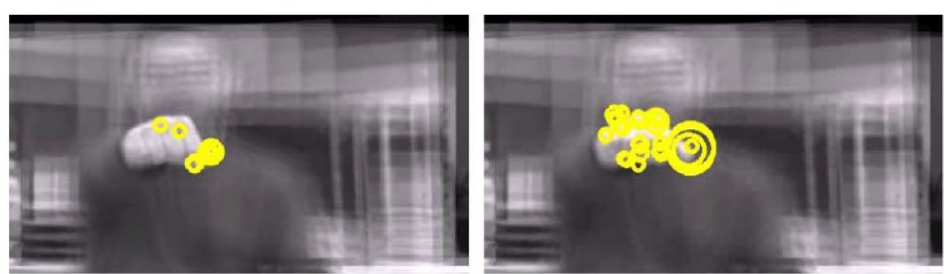

(a)
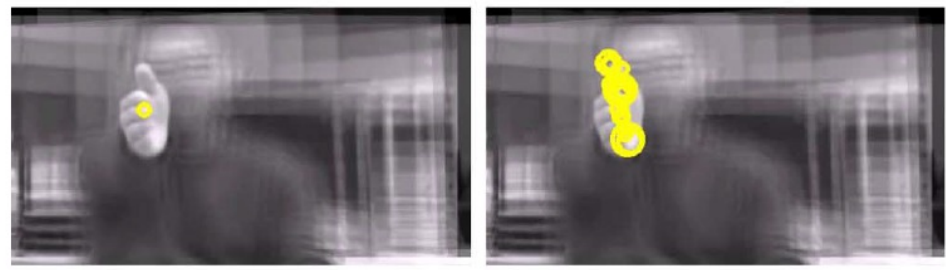

(b)
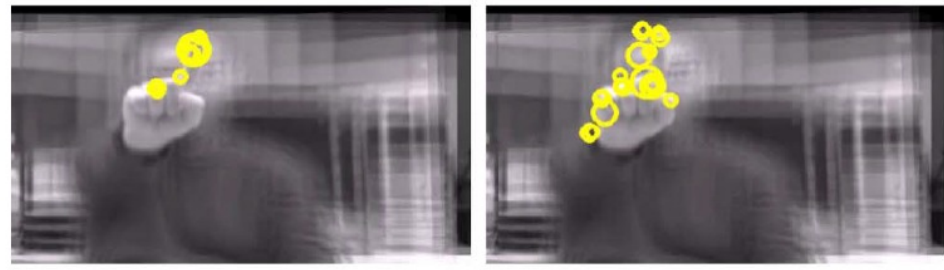

(c)
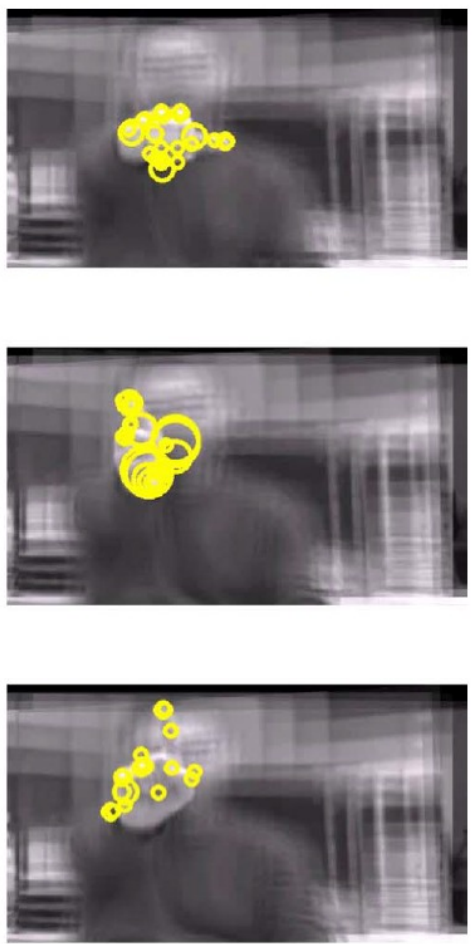

Figure 4. Results showing the detected STIPs (yellow circles) at three different frames (each column) in the videos of the three gestures (each row) performed by one (and the same) person. The STIPs size corresponds to the scale the STIP was detected at. Actions are: (a) Open gesture, (b) Left gesture, and (c) Deny gesture (originally appeared in [14]).

\section{Visual words $\rightarrow$ Bag-of-Words (BoWs)}

Each video was represented through the creation of a histogram of codewords [17].

\section{$\underline{\text { BoWs } \rightarrow \text { Gesture prediction }}$}

In order to make an estimation of the gesture recognition performance, a "leave-one-subject-out" protocol was applied ([18], [19]). Given S subjects, the BoWs of all actions and repetitions for $S-1$ subjects are used for training and the BoWs for the videos of the remaining subject are used for testing. The process is repeated $S$ times, once per subject. The average performance over these S results is therefore reported. For classification, Support Vector Machines (SVM) [20] were chosen, due to its capability to deal with low number of training samples and high dimensional classification problems 
(the so-called curse of dimensionality phenomenon). Histograms (the BoW representation) were $\mathrm{L}_{1}$-normalized before the classification step, and each feature was individually re-scaled to the range[0,1]. Finally, histograms were $\mathrm{L}_{2}$-normalized. The descriptor quantization and the learning and prediction steps were repeated 10 times. The reported performance is the average classification accuracy over these repetitions.

The BoW scheme was applied to both the Integral Imaging data and the original monocular data from the central camera in the $3 \times 3$ array. The number of visual words was varied as $K=\{10,25,50,100,200\}$. The descriptors: HOG, HOF and HOG+HOF were finally considered.

Recognition rates when using the monocular (central camera) acquisition and $K=200$ words were (results over 10 repetitions): $92.6 \pm 2.0$ for HOF, $78.0 \pm 4.4$ for HOG and 89.1 \pm 3.1 for HOG+HOF. On the other hand, recognition rates when considering 3D Integral Imaging and $K=200$ words were (results over 10 repetitions): $82.3 \pm 4.2$ for HOF, $85.1 \pm 3.8$ for HOG and $95.0 \pm 3.1$ for HOG + HOF. Therefore, we can see that Integral Imaging outperforms the best monocular recognition result $(95.0 \pm 3.1$ vs $92.6 \pm 2.0)$.

In addition, in absolute terms, when comparing the best descriptor in each case (i.e. HOF for Monocular and HOF+HOG for Integral Imaging), for different K values, Integral Imaging outperformed the acquisition with the single/central camera, for all the tested $\mathrm{K}$ values except for $\mathrm{K}=50$.

\section{CONCLUSIONS}

We have summarized our work made on the application of 3D passive sensing Integral Imaging for human gesture recognition ([14]). The results obtained with our gesture recognition approach (through our bag-of-words strategy) reveal that Integral Imaging may provide distinctive information in relation to that of using visual cues from a single camera, which may be a first step into advances in action recognition technology that were not possible to date.

\section{ACKNOWLEDGMENTS}

The authors greatfully acknowledge financial support from project PROMETEOII/2014/062 funded by the Generalitat Valenciana (regional government).

\section{REFERENCES}

[1] R. Martinez-Cuenca, G. Saavedra, M. Martinez-Corral, and B. Javidi, "Progress in 3-D Multiperspective Display by Integral Imaging,” Proceedings of the IEEE, 97, 6, pp. 1067-1077, 2009.

[2] J.-Y.Son, W.-H.Son, S.-K. Kim, K.-H. Lee, B. Javidi, “Three-dimensional imaging for creating real-world-like environments”, Proceedings of the IEEE, 101, 1, pp. 190-205, 2013.

[3] M. Cho, M. Daneshpanah, I. Moon, and B. Javidi, “Three-Dimensional Optical Sensing and Visualization Using Integral Imaging,” Proceedings of the IEEE, 99, 4, pp. 556-575, 2011.

[4] X. Xiao, B. Javidi, M. Martinez-Corral, A. Stern, “Advances in Three-Dimensional Integral Imaging: Sensing, Display, and Applications,” Applied Optics 52, 4, pp. 546-560, 2013.

[5] D.Lanman, M.Hirsch, Y.Kim, R. Raskar. “Content-adaptive parallax barriers: optimizing dual-layer 3D displays using low-rank light field factorization”, SIGGRAPH Asia, 29, 6, pp. 163:1-163:10, 2010.

[6] J.Arai, F. Okano, M. Kawakita, M. Okui, Y. Haino, M. Yohimura, M. Furuya, M. Sato, “Integral three-dimensional television using a 33-megapixel imaging system”, Journal of Display Technology, 6, 10, pp. 422-430, 2010. 
[7] F. Okano, J. Arai, K. Mitani, M. Okui, “Real-time integral imaging based on extremely high resolution video system”, Proceedings of the IEEE, 94, 3, pp. 490-501, 2006.

[8] H. H. Tran, H. Suenaga, K. Kuwana, K. Masamune, T. Dohi, S. Nakajima, H. Liao, “Augmented reality system for oral surgery using 3D stereoscopic visualization”, Lecture Notes in Computer Science, 6891, pp. 81-88, 2011.

[9] H. Liao, T. Inomata, I. Sakuma, T. Dohi, “3-D augmented reality for MRI-guided surgery using integral videography autostereoscopic image overlay”, IEEE Transactions on Biomedical Engineering, 57, 6, pp. 1476-1486, 2010.

[10] H.Navarro, M.Martinez-Corral, G.Saavedra-Tortosa, B.Javidi, "Is it worth using an array of cameras to capture the spatio-angular information of a 3D scene or is it enough with just two?” Proceedings of SPIE, 8384, pp. 838406-1: 8384066, 2012.

[11] J. Aggarwal and M. Ryoo, “Human activity analysis: a review,” ACM Computing Surveys, 43, pp. 1-43, 2011.

[12] L. Chen, H. Wei, and J. Ferryman, “A survey of human motion analysis using depth imagery,” Pattern Recognition Letters, 34, pp. 1995-2006, 2013.

[13] C. M. Do, R. Martínez-Cuenca, and B. Javidi, “Three-dimensional object-distortion-tolerant recognition for integral imaging using independent component analysis,” Journal of the Optical Society of America A, 26, pp. 245-251, 2009.

[14] V. Javier Traver, P. Latorre-Carmona, E. Salvador-Balaguer, F. Pla, B. Javidi, "Human gesture recognition using three-dimensional integral imaging”, Journal of the Optical Society of America A, 31, pp. 2312-2320, 2014.

[15] Z. Zhang, “A flexible new technique for camera calibration,” IEEE Transactions on Pattern Analysis and Machine Intelligence 22, pp. 1330-1334, 2000.

[16] H. Wang, M. M. Ullah, A. Kläser, I. Laptev, and C. Schmid, "Evaluation of local spatio-temporal features for action recognition”, British Machine Vision Conference (BMVC), pp. 1-11, 2009.

[17] I. Laptev, “On space-time interest points,” International Journal of Computer Vision, 64, pp. 107-123, 2005.

[18] K. Schindler and L. J. V. Gool, “Action snippets: How many frames does human action recognition require?”, IEEE Computer Vision and Pattern Recognition (CVPR), pp. 1-8, 2008.

[19] Z. Lin, Z. Jiang, and L. S. Davis, "Recognizing human actions by learning and matching shape-motion prototype trees,” IEEE Transactions on Pattern Analysis and Machine Intelligence, 34, pp. 533-547, 2012.

[20] N. Cristianini and J. Shawe-Taylor, An Introduction to Support Vector Machines and Other Kernel-based Learning Methods (Cambridge University Press, 2000). 


\title{
Three-dimensional Integral Imaging for Gesture Recognition under Occlusions
}

\author{
V. Javier Traver, Pedro Latorre-Carmona, Eva Salvador-Balaguer, Filiberto Pla, Bahram Javidi, Fellow, IEEE
}

\begin{abstract}
Over the last years, three-dimensional (3D) imaging has been applied to human action and gesture recognition, usually in the form of depth maps from RGB-D sensors. An alternative which has not been explored is 3D integral imaging, aside from a recent preliminary study which shows that it can be an effective sensory modality with some advantages over the conventional monocular imaging. Since integral imaging has also been shown to be a powerful tool in other visual tasks (e.g. object reconstruction and recognition) under challenging conditions (e.g. low illumination, occlusions), and its passive longrange operation brings benefits over active close-range devices, a natural question is whether these advantages also hold for gesture recognition. Furthermore, occlusions are present in many real-world scenarios in gesture recognition, but it is an elusive problem which has scarcely been addressed. As far as we know, this work analyzes for the first time the potential of integral imaging for gesture recognition under occlusions, by comparing it to monocular imaging and to RGB-D sensory data. Empirical results corroborates the benefits of $3 \mathrm{D}$ integral imaging for gesture recognition, mainly under occlusions.
\end{abstract}

Index Terms-Gesture recognition, integral imaging, camera array, RGB-D sensors, occlusion, classification.

\section{INTRODUCTION}

Over the last decade, and due to its wide range of applications, vision-based action and gesture recognition are among the most studied topics in computer vision and machine learning [26], [2], [36], [7], [13]. Even more recent is the trend to incorporate $3 \mathrm{D}$ sensory due to its potential to segment (parts of) the human body and disambiguate actions [5], [8], [27].

Although literature on action recognition widely acknowledges the importance of the robustness against occlusion, it is an issue which is rarely studied in practice, and it can actually be considered an open issue [33]. Several reasons can explain this fact, such as the difficulty of addressing the problem, the elusiveness of the term and the complexity of formalizing it, and the lack of datasets [4] which include occlusions to promote a systematic study and benchmarking. Often, the occlusion considered is self-occlusion or, in the case of hand gestures, the occlusion due to the hand-manipulated object [8]. Recently, the influence of external occlusion on different known action descriptors has been studied [18].

Robustness to occlusions can be obtained by using different viewpoints or even include occlusion in training data [35].

Copyright (c) 2015 IEEE. Personal use of this material is permitted. However, permission to use this material for any other purposes must be obtained from the IEEE by sending a request to pubs-permissions@ieee.org

All authors but the last one are with the Institute of New Imagin Technologies, Univ. Jaume I, Castelló (Spain). B. Javidi is with the Electrical \& Computer Engineering Dep., Univ. of Connecticut, Storrs, USA. (e-mails: \{vtraver,latorre,salvadoe,pla\}@uji.es, bahram@engr.uconn.edu)
Similarly, but out of the context of action recognition, the reconstruction of occluded objects can be dealt with the use of multiple sensors [25]. Other sensible approaches include higher-level representations, such as body parts and skeleton which can be derived from depth, usually by elaborated algorithms [27]. For instance, occluded parts can be identified and made to contribute less to the predicted action class [31].

Therefore, in general, occlusion is addressed by explicit and complex handling strategies. In sharp contrast, our work addresses the problem by exploring how the sensor itself might mitigate it, with no further assumption of the nature of the action, or occlusion, or representational issues. Certainly, this sensor-based approach is orthogonal to explicit occlusion handling strategies, but the possibility of combining them is out of the scope of this paper. It is also worth looking at the problem from the perspective of information fusion. The use of 3D Integral Imaging to fuse information from multiple sources is in essence what other approaches (multi-view cameras, RGB-D) also do, albeit differently. A novel means of computing integral images has recently been proposed [14]. Although depth information for action or gesture recognition has been exploited lately [24], [6], [22], [39], [34], [23], [29], integral imaging is not used.

To contextualize our work, it has been previously shown [30] the capabilities of integral imaging and its potential advantages and complementary properties with respect to monocular imaging for gesture recognition. Unlike RGB-D active devices such as Kinect which work in close-range indoor scenes, passive integral imaging can operate in longrange applications [21], and has shown promise to deal with challenging imaging conditions, such us turbid water [9], low illumination [10], or occlusions [16], [38], [12].

It is therefore natural to study how these methodologies perform for the particular problem of gesture recognition under occlusion, which is the main purpose of this work. Then, the main contributions of this work are:

- experiments with a new hand gesture dataset, and a study with the occlusion condition; and

- a comparison with both monocular case and another 3D imaging sensor (an off-the-shelf RGB-D device).

Throughout the paper we refer to "RGB-D" sensor as an imaging device providing color (RGB) images from a single camera plus the corresponding depth data. Although there are several technologies providing range data [5], in our experiments we will use the data from the well-known Kinect sensor [40]. On the other hand, we refer to "integral imaging" as a particular type of multi-perspective imaging using an array of cameras. In particular, we use an array of nine cameras. 


\section{Methodology}

The three methodological aspects of the work are the computation of integral images, the gesture representation and recognition, and a depth-based mechanism to mimic the filtering effect of integral imaging on a conventional RGB-D sensor. These aspects are introduced subsequently.

Integral Imaging. Synthetic Aperture Integral Imaging (SAII) is an auto-stereoscopic technique based on the use of an array of cameras (or one moving camera) to acquire a series of images (the elemental images) of a scene from slightly different perspectives. Since each of the elemental images provides a different view of the $3 \mathrm{D}$ scene, the $3 \mathrm{D}$ scene can be reconstructed using a computer synthesized virtual pinhole array for inverse mapping of each elemental image into the so-called object space [37]. To that end, the elemental images are computationally overlapped according to [15]:

$$
I(x, y, z)=\frac{1}{O(x, y)} \sum_{r=0}^{R-1} \sum_{c=0}^{C-1} E_{r c}\left(x^{\prime}, y^{\prime}\right)
$$

with

$$
x^{\prime}=x-r \cdot \frac{N_{x} \cdot p_{x}}{s_{x} \cdot M}, \quad \quad y^{\prime}=y-c \cdot \frac{N_{y} \cdot p_{y}}{s_{y} \cdot M} .
$$

where $I(x, y, z)$ is the reconstructed $3 D$ image intensity at depth $z$, that will be referred to as the integral image; $x$ and $y$ are the indexes associated to each pixel position; $E_{r c}$ is the intensity of the elemental image acquired by the camera at the $r$-th row and $c$-th column in the array; $N_{x} \times N_{y}$ are the dimensions of the images (in pixels); $p_{x}\left(p_{y}\right)$ is the horizontal (vertical) pitch ( $\mathrm{mm}$ ) between neighbouring cameras; $M$ is the magnification factor; $s_{x} \times s_{y}$ is the physical size of each camera sensor; and $O(x, y)$ is the overlapping number matrix, representing the number of cameras contributing to each $(x, y)$ position.

Gesture recognition. A standard Bag of visual Words (BoW) built from local spatio-temporal interest points (STIPs) [19] was followed, with the main steps being:

Interest points detection: The STIP detector available at [20] was used, and all detected STIPs were kept by using a zero threshold in the function evaluating large spatio-temporal variations.

Local descriptors and their quantization: In turn, these STIPs are locally characterized by spatial gradients and optical flow. The resulting descriptors were vector quantized by unsupervised clustering by using $k$-means [17]. The number of user-set clusters $K$ defines the size of the vocabulary [30].

Video representation: Since a different number of STIPs are detected in each video, a histogram of words is computed per video by counting the memberships of the descriptors to the existing clusters. Therefore, each video is represented by a fixed-length feature vector (a $K$-bin histogram).

Recognition by classification: Finally, any standard supervised learning scheme can be used for gesture recognition by using the histogram representation of the videos for both training a classifier, and evaluating its predictive performance on unseen gestures.

Further details of these steps can be found elsewhere [30].

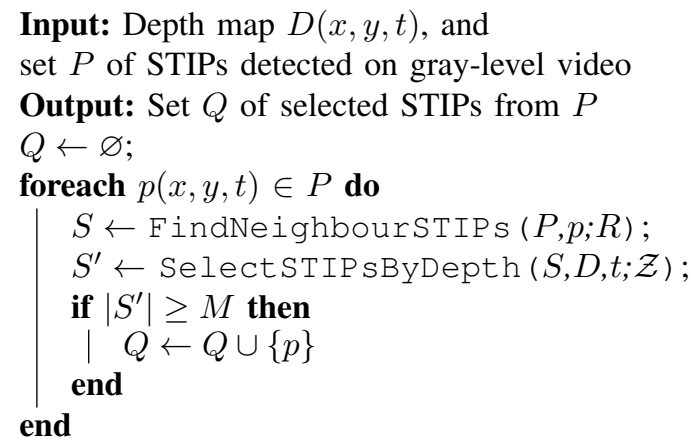

Input: Depth map $D(x, y, t)$, and

set $P$ of STIPs detected on gray-level video

Output: Set $Q$ of selected STIPs from $P$

$Q \leftarrow \varnothing$

foreach $p(x, y, t) \in P$ do

$S \leftarrow$ FindNeighbourSTIPs $(P, p ; R)$;

$S^{\prime} \leftarrow$ SelectSTIPsByDepth $(S, D, t ; \mathcal{Z})$

if $\left|S^{\prime}\right| \geq M$ then

$Q \leftarrow Q \cup\{p\}$

end

end

return $Q$

Algorithm 1: Depth-based STIP selection

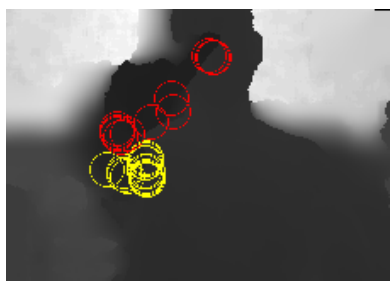

(a) about half are kept (15/29) (b) almost all are removed (32 / 37)

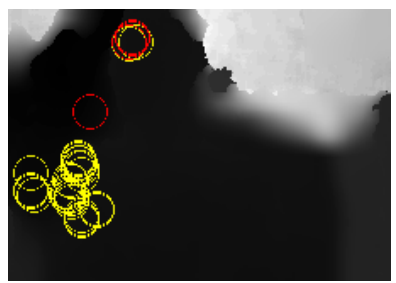

Fig. 1. Examples of STIPs kept (red) and removed (yellow) by DBF. STIP locations are drawn on the depth maps, but they are actually detected on the RGB videos

Depth-based filtering in RGB-D. The integral images used were those reconstructed at a depth where the hand was subjectively judged to be mostly at focus. Therefore, for comparison purposes, we apply a procedure that has a similar effect in RGB-D sensors and makes use of the same "oracle" (prior knowledge of hand depths). In particular, STIPs were detected on the RGB images and then filtered (kept or removed) based on the corresponding depth. The intuitive idea is to keep STIPs that are surrounded by others at similar depths and close to hand depth. More concretely, a STIP at location $(x, y)$ is kept if and only if at least $M$ other STIPs at frame $t$ are found within a square of size $2 R$ centered at $(x, y)$ that have a depth value within a given set $\mathcal{Z}$ of depth values. Algorithm 1 formalizes this notion.

The values for the minimum number of points $M$ and the maximum neighbourhood size $R$ were heuristically set as $M=15$ and $R=10$, and the set of allowed depths was the interval $\mathcal{Z}=[d-100, d+100]$, with $d$ being the depth value selected interactively from the depth maps. Depth units are millimeters and distance units are pixels. A hole filling procedure was applied to the depth maps with a cross-bilateral filter [28].

In general, it is noticeable the reduction in the number of STIPs due to the depth-based filtering (DBF). At least in some cases it is observed that most STIPs are removed in videos with more noisy STIPs (i.e. those found at the face or in parts other than the hand). This suggests that noisy STIPs are generally filtered out, and therefore this DBF can potentially be helpful in better characterizing gestures. The effect of DBF is illustrated in Fig. 1; typical STIPs that can be noisy and are filtered out correspond to those in the forearm (Fig. 1a). 


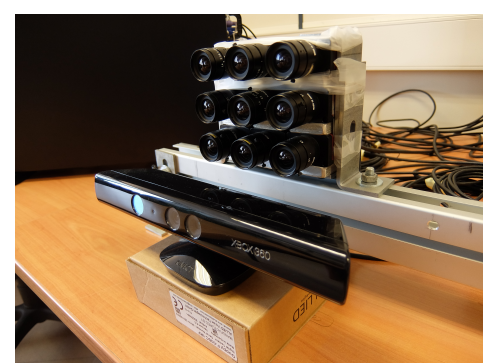

Fig. 2. The two sensors used in the experiments: the $3 \times 3$ camera array on top and the Kinect below

\section{EXPERIMENTS AND RESULTS}

Setup. Two 3D imaging methodologies are used and compared. On the one hand, integral images were generated by synthetic aperture integral imaging from a $3 \times 3$ camera array. On the other hand, for the RGB-D data, the popular Kinect device was used. Eleven subjects were asked to perform three different gestures twice in front of the camera array, both with an unoccluded view and with the occlusion of a plant. The Kinect was placed just under the camera array so that the gestures were recorded from a very similar viewpoint (Fig. 2). The same gesture was recorded at the same time by the nine array cameras as well as by Kinect. A detailed description of the dataset is available at [1].

Kinect's images have larger field-of-view (FOV) but less resolution $(640 \times 480)$ than the images of the cameras of the array $(1024 \times 768)$ and, in turn, than the integral images. Therefore, in order to perform a fair comparison, cropping and resizing were done accordingly to have comparable effective resolutions of the region of interest (subjects' upper bodies).

Sample images (Fig. 3) illustrate the visual data under RGB-D, monocular, and integral imaging in unoccluded and occluded views. It is worth noticing the significant amount of occlusion of the plant, how noisy the depth map is under occlusion, and how integral images manages to "smooth out" much of the occluding leaves by properly focusing at the hand's depth by means of the synthetic aperture reconstruction process. The videos taken by the central camera of the array are used for the monocular condition.

Three different local visual descriptors were tested: histogram of gradients (HOG), histogram of optic flow (HOF) and their concatenation (HOG+HOF). Recognition performance was similar in the three cases, and therefore only the performance with one of them $(\mathrm{HOG}+\mathrm{HOF})$ is reported. Histograms were $L_{1}$-normalized, then individual features independently re-scaled to the range $[0,1]$, and finally the histograms were $L_{2}$ normalized. Since different performances can be expected from visual vocabularies of different sizes, but there is no clear guideline of which size is most appropriate in which condition, then a range of vocabulary sizes $K \in\{10,25,50,100,200,500,1000,2000\}$ was tested. The $k$-means implementation of the VLFeat library [32] was used.

For classification, two Support Vector Machines (SVMs) [11] were tested: a linear one, and a non-linear one with a Radial-Basis Function (RBF) kernel. Since similar performance was observed in both cases, only the performance
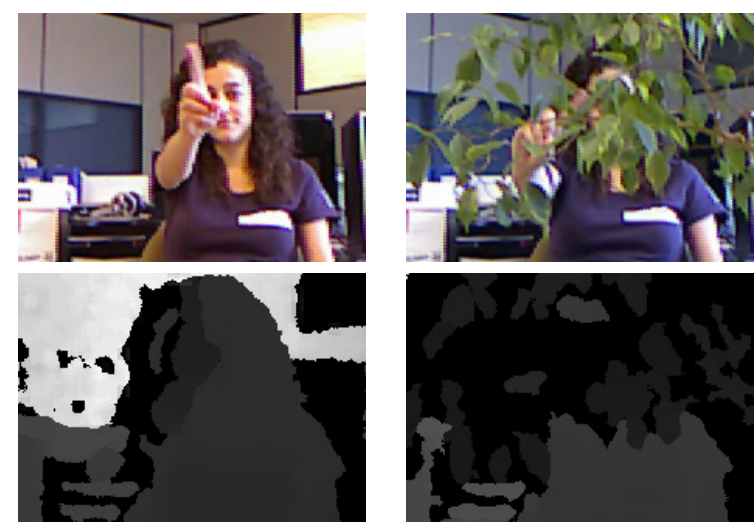

(a) RGB-D data: color images (up) and depth maps (down)
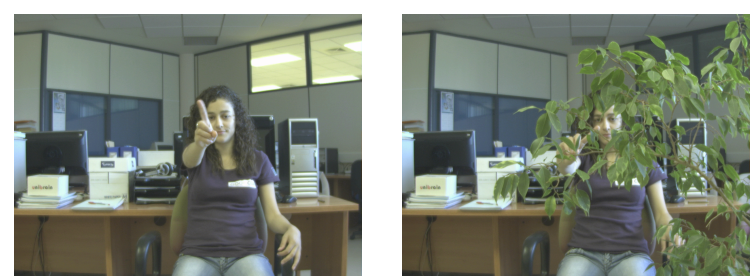

(b) Monocular (central camera of the array)
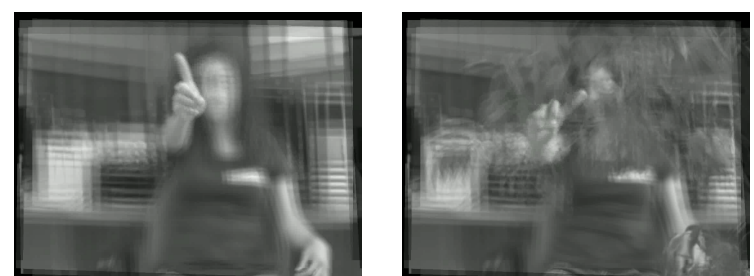

(c) Integral images (hand-depth plane)

Fig. 3. Illustrative images of (a) RGB-D data, (b) monocular, and (c) integral imaging without occlusion (left) and with occlusion (right).

with the linear SVM is reported. The LIBSVM [3] implementation of SVM was used. The parameter $C$ in SVMs was chosen from the set $\left\{10^{e}: e \in\{-4,-3, \ldots, 4\}\right\}$ by cross validation. To estimate gesture performance, a "leave-one-subject-out" protocol was used. Additionally, given the random nature of $k$-means, the entire process (clustering + learning + classification) was repeated $n=10$ times and the average accuracy reported. The performance plots include these averages and their standard errors as a measure of variance. In some cases, it may occur that the number of data points is less than the size $K$ of the vocabulary, and therefore the clustering cannot be carried out for that particular size and larger ones.

In the occlusion case, only the STIPs from videos of the non-occluded gestures are used at training time, since in practice one usually has only "clean" gestures for training, and occlusions happen unpredictably at test time. In other words, using occlusions at training time would imply we know in advance which particular kind of occlusion will happen and in which context, but this rarely happens in practical settings.

Effect of DBF. To study the effectiveness of the DBF procedure, we compare the performance of using the whole set of STIPs detected in the RGB Kinect's images with the filtered 
set of STIPs resulting from the DBF. It was found that DBF is effective as long as the vocabulary is large enough $(K>500)$. For instance, the accuracy was about 2 percent points higher than with RGB (for $K=1000$ ). In fact, we tested with larger $K(K \in\{3000, \ldots, 7000\})$ so as to find out what happened with even larger vocabularies. A steady better performance of DBF was observed, even with more remarkable differences of about 8 percent points for $K=4000$ and $K=5000$. However, since less number of STIPs results from DBF, not enough data points were available to use $K \geq 6000$ clusters. The performance trend was however clear with the tested $K$.

Comparing the three sensory modalities. When comparing the three sensory modalities with and without occlusion (Fig. 4) the following observations can be made:

Occlusion: All modalities are very sensitive to the occlusion condition, which is also an indication of its severity. A drop of about 20 percent points occurs in all cases. In general, compared to the no-occlusion case, larger vocabularies are required under occlusion to get better performance.

II vs Monocular: As expected, better performance is achieved with II than with monocular images. The difference is more noticeable under occlusion, and the performance gap roughly increases with the vocabulary size. This clearly suggests the superiority of integral images to cope with occlusions.

II vs RGB-D: Without occlusion, integral imaging is more effective than RGB-D for small vocabularies, but RGB-D (through the DBF mechanism) outperforms II for larger vocabularies. It is interesting to note how II achieves very good performance even for the smallest vocabularies, which suggests these visual words are more expressive, and lend themselves to more efficient computations and less memory requirements. However, although the DBF has some positive effect without occlusions (as also discussed above), it is not sufficient to deal with occlusions, where integral imaging is clearly a better option. To understand the reasons behind this different performance between II and RGB-D, it might be good to remind what each of them is performing: in RGB-D, DBF removes some potentially noisy STIPs detected at monocular (RGB) images, whereas the STIPs detected from the integral imaging are different from the monocular case.

$R G B-D$ vs Monocular: Without occlusion, RGB-D outperforms monocular imaging, but under occlusion DBF tends to work worse than monocular. This may be due to the fact that STIPs are removed with the DBF procedure, and this may filter out some "good" as well as "bad" STIPs.

It is important to note that no explicit occlusion-handling strategy is used; integral imaging deals naturally with occlusion, as a built-in feature resulting from its focusing ability.

It can be noticed that very few words (just 10) suffice to have reasonable and steady performance with Monocular and II. For II, we checked with $K<10$ to find out the minimum vocabulary size, and performance drops to $\approx 65 \%$ with $K=5$. Therefore, $K \approx 10$ seems the minimum required number of words.

Resolution issue (Table I). Without occlusion, a higher spatial resolution benefits similarly Monocular and II, with an accuracy increase of about 5 percent points. At higher

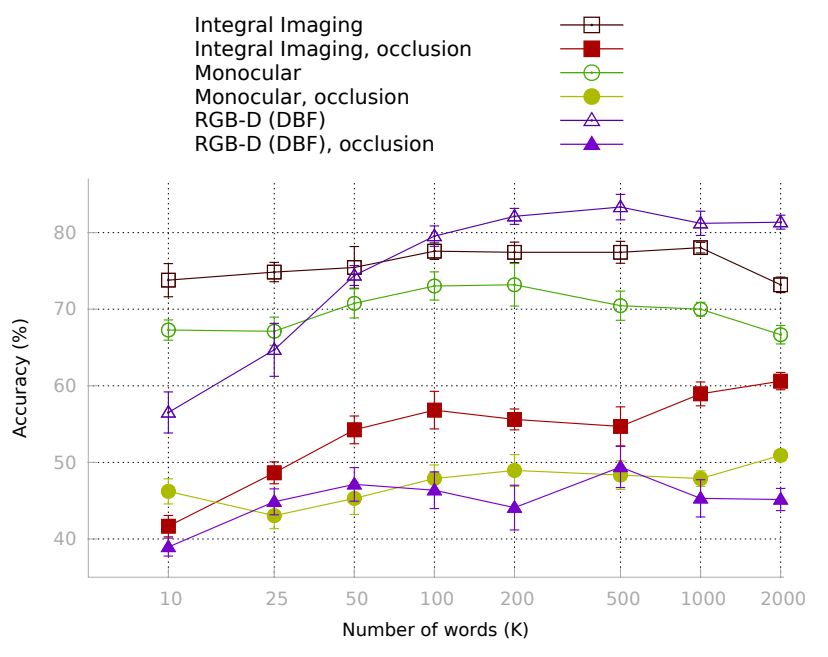

Fig. 4. Comparing Monocular, RGB-D and Integral imaging, in the three cases both without and with occlusion. The horizontal axis is shown in logarithmic scale to better accommodate the wide range of vocabulary sizes.

TABLE I

CHANGE IN AVG. ACCURACY (\%) WITH RESPECT TO THE LOW RESOLUTION CASE, IN MONOCULAR AND II $(*=$ OCCLUSION)

\begin{tabular}{lcccccccc}
\hline$K$ & 10 & 25 & 50 & 100 & 200 & 500 & 1000 & 2000 \\
\hline Mono & -20.8 & 0.0 & +2.7 & +2.3 & +4.4 & +7.0 & +6.8 & +6.5 \\
II & -12.9 & -1.8 & +6.2 & +3.6 & +4.7 & +5.6 & +5.2 & +7.1 \\
- Mono* $^{*}--\overline{1} 2 . \overline{6}$ & $--\overline{5} . \overline{5}$ & -4.2 & $-6 . \overline{2}$ & $-3 . \overline{9}$ & +2.8 & +9.7 & +6.3 \\
II & +3.3 & +3.0 & +0.3 & -0.8 & +4.1 & +10.0 & +2.4 & -0.5 \\
\hline
\end{tabular}

resolution, bigger vocabularies are required to get a steady performance, possibly because more STIPs are found. Under occlusion and in monocular, performance improves with resolution at larger vocabularies $(K \geq 500)$. In general, these results can be interpreted as that the performance decays with resolution more clearly in Monocular case than in II, a sign that II can rely on its focusing ability besides the resolution quality.

\section{CONCLUSIONS}

Experimental results suggest that passive 3D integral imaging offers advantages over monocular imaging even with the presence of occlusions. Without occlusion, integral imaging behaves roughly "on par" with RGB-D with the simple depthbased STIP filtering mechanism. In some cases (e.g. large visual vocabularies), RGB-D is even more effective than integral imaging. However, under occlusion, integral imaging outperforms RGB-D.

It has also been observed that good spatial resolution is much more important in monocular images than in integral images since the latter can additionally rely on a good "focusing" operation.

Despite the fact that the dataset collected and used is small, it is representative enough to have a prospective assessment of integral imaging capabilities in relation to other $3 \mathrm{D}$ sensor modalities, specially for the case when there are occlusions.

Acknowledgments. This work has been partly supported by Generalitat Valenciana (through grant PROMETEOII/2014/062). 


\section{REFERENCES}

[1] Hand gesture dataset for testing integral imaging under occlusions. http://www.vision.uji.es/II-hand-gestures, Nov. 2016. Computer Vision Group, Institute of New Imaging Technologies, Jaume-I University.

[2] J. Aggarwal and M. Ryoo. Human activity analysis: A review. ACM Comput. Surv., 43(3):16:1-16:43, Apr. 2011

[3] C.-C. Chang and C.-J. Lin. LIBSVM: A library for support vector machines. ACM Transactions on Intelligent Systems and Technology, 2:27:1-27:27, 2011. Software available at http://www.csie.ntu.edu.tw/ $\sim$ cjlin/libsvm.

[4] J. M. Chaquet, E. J. Carmona, and A. Fernández-Caballero. A survey of video datasets for human action and activity recognition. Comp. Vision \& Image Understanding, 117(6):633-659, 2013.

[5] L. Chen, H. Wei, and J. Ferryman. A survey of human motion analysis using depth imagery. Pattern Recognition Letters, 34(15):1995-2006, 2013.

[6] L. Chen, H. Wei, and J. Ferryman. Readingact RGB-D action datase and human action recognition from local features. Pattern Recognition Letters, 50:159-169, 2014.

[7] G. Cheng, Y. Wan, A. N. Saudagar, K. Namuduri, and B. P. Buckles. Advances in human action recognition: A survey. CoRR, abs/1501.05964, 2015.

[8] H. Cheng, L. Yang, and Z. Liu. A survey on 3D hand gesture recognition. IEEE Transactions on Circuits and Systems for Video Technology, PP(99):1-1, 2015.

[9] M. Cho and B. Javidi. Three-dimensional visualization of objects in turbid water using integral imaging. Journal of Display Technology, 6(10):544-547, Oct. 2010.

[10] M. Cho, A. Mahalanobis, and B. Javidi. 3D passive photon counting automatic target recognition using advanced correlation filters. Optics Letters, 36(6):861-863, Mar. 2011.

[11] N. Cristianini and J. Shawe-Taylor. An Introduction to Support Vector Machines and Other Kernel-based Learning Methods. Cambridge University Press, 2000.

[12] M. Ghaneizad, H. Aghajan, and Z. Kavehvash. Three-dimensional reconstruction of heavily occluded pedestrians using integral imaging. In Proc. of the 10th Intl. Conf. on Distributed Smart Camera, pages 1-7. ACM, 2016.

[13] S. Herath, M. T. Harandi, and F. Porikli. Going deeper into action recognition: A survey. CoRR, abs/1605.04988, 2016.

[14] S. Hong, D. Shin, B. G. Lee, A. Dorado, G. Saavedra, and M. MartínezCorral. Towards 3D television through fusion of Kinect and integralimaging concepts. Journal of Display Technology, 11(11):894-899, Nov. 2015.

[15] S.-H. Hong, J.-S. Jang, and B. Javidi. Three-dimensional volumetric object reconstruction using computational integral imaging. Optics Express, 12(3):483-491, Feb. 2004

[16] S.-H. Hong and B. Javidi. Distortion-tolerant 3D recognition of occluded object using computational integral imaging. Optics Express, 14(25):12085-12095, Dec. 2006.

[17] A. K. Jain. Data clustering: 50 years beyond K-means. Pattern Recogn. Lett., 31(8):651-666, June 2010.

[18] I. Jargalsaikhan, C. Direkoglu, S. Little, and N. E. O’Connor. An evaluation of local action descriptors for human action classification in the presence of occlusion. In International Conference on Multimedia Modeling, pages 56-67. Springer International Publishing, 2014.

[19] I. Laptev. On space-time interest points. Int. J. Comput. Vision, 64(23):107-123, Sept. 2005.
[20] I. Laptev. Space-time interest points (STIP), 2011. Software available at http://www.di.ens.fr/ laptev/download.html.

[21] D. LeMaster, B. Karch, and B. Javidi. Mid-wave infrared 3D integral imaging at long range. J. Display Technol., 9(7):545-551, July 2013.

[22] C. Liang, E. Chen, L. Qi, and L. Guan. Improving action recognition using collaborative representation of local depth map feature. IEEE Signal Processing Letters, 23(9):1241-1245, Sept. 2016.

[23] A.-A. Liu, W.-Z. Nie, Y.-T. Su, L. Ma, T. Hao, and Z.-X. Yang. Coupled hidden conditional random fields for RGB-D human action recognition. Signal Processing, 112:74-82, 2015.

[24] C. Lu, J. Jia, and C. K. Tang. Range-sample depth feature for action recognition. In Proc. IEEE Comp. Vision and Pattern Recog. (CVPR), pages 772-779, June 2014.

[25] T. Nasrin, F. Yi, S. Das, and I. Moon. Partially occluded object reconstruction using multiple Kinect sensors. In Proc. SPIE, volume 9117, pages 91171G-91171G-5, 2014.

[26] R. Poppe. A survey on vision-based human action recognition. Image and Vision Computing, 28(6):976-990, 2010.

[27] L. L. Presti and M. L. Cascia. 3D skeleton-based human action classification: A survey. Pattern Recognition, 53:130-147, 2016.

[28] N. Silberman. NYU Depth Dataset V2. http://cs.nyu.edu/ silberman/ datasets/nyu_depth_v2.html.

[29] Y. Song, S. Liu, and J. Tang. Describing trajectory of surface patch for human action recognition on RGB and depth videos. IEEE Signal Processing Letters, 22(4):426-429, Apr. 2015.

[30] V. J. Traver, P. Latorre-Carmona, E. Salvador-Balaguer, F. Pla, and B. Javidi. Human gesture recognition using three-dimensional integral imaging. J. Opt. Soc. Am. A, 31(10):2312-2320, Oct 2014.

[31] J. S. Tsai, Y. P. Hsu, C. Liu, and L. C. Fu. An efficient part-based approach to action recognition from RGB-D video with bow-pyramid representation. In IEEE/RSJ International Conference on Intelligent Robots and Systems, pages 2234-2239, Nov. 2013.

[32] A. Vedaldi and B. Fulkerson. VLFeat: An open and portable library of computer vision algorithms. http://www.vlfeat.org/, 2008.

[33] M. Vrigkas, C. Nikou, and I. Kakadiaris. A review of human activity recognition methods. Frontiers in Robotics and AI, 2(28), 2015.

[34] J. Wan, G. Guo, and S. Z. Li. Explore efficient local features from RGB-D data for one-shot learning gesture recognition. IEEE Trans. on Pattern Analysis and Machine Intelligence (PAMI), 38(8):1626-1639, Aug. 2016.

[35] D. Weinland, M. Özuysal, and P. Fua. Making action recognition robust to occlusions and viewpoint changes. In European Conf. on Computer Vision, pages 635-648, Berlin, Heidelberg, 2010. Springer Berlin Heidelberg.

[36] D. Weinland, R. Ronfard, and E. Boyer. A survey of vision-based methods for action representation, segmentation and recognition. Comp. Vision \& Image Understanding, 115(2):224-241, 2011.

[37] X. Xiao, B. Javidi, M. Martínez-Corral, and A. Stern. Advances in three-dimensional integral imaging: sensing, display, and applications. Applied Optics, 52(4):546-560, 2013.

[38] T. Yang, W. Ma, S. Wang, J. Li, J. Yu, and Y. Zhang. Kinect based realtime synthetic aperture imaging through occlusion. Multimedia Tools and Applications, 75(12):6925-6943, 2016.

[39] M. Yu, L. Liu, and L. Shao. Structure-preserving binary representations for RGB-D action recognition. IEEE Trans. on Pattern Analysis and Machine Intelligence (PAMI), 38(8):1651-1664, Aug. 2016.

[40] Z. Zhang. Microsoft kinect sensor and its effect. IEEE MultiMedia, 19(2):4-10, Feb. 2012. 



\title{
Fast high resolution single-pixel imaging
}

\author{
F. Soldevila, Eva Salvador-Balaguer, P. Clemente, E. Tajahuerce, and J. Lancis \\ GROC·UJI, Institute of New Imaging Technologies, Universitat Jaume I, 12070 Castelló, Spain
}

\begin{abstract}
During the past few years, the emergence of spatial light modulators operating at tens of $\mathrm{kHz}$ has enabled new imaging modalities based on single-pixel photodetectors. The nature of single-pixel imaging enforces a reciprocal relationship between frame rate and image size. Here, we introduce an adaptive compressive technique based on wavelet trees to better suit the needs for real time operation.
\end{abstract}

In the latter years, single-pixel imaging has established as a powerful tool in life sciences. One of the main characteristics of the technique is that it uses very simple sensors (bucket detectors such as photodiodes) and mathematical algorithms to recover an image [1]. This reduction in complexity on the device causes an increase of computational time to recover an image, compared to conventional techniques. In the visible region of the spectrum, where pixelated sensors have acquired very high performances with low costs, this may not seem like a good trade-off. Nevertheless, in conditions where light is scarce or scattered by biological mediums, single-pixel imaging is able to provide good quality images [2]. Furthermore, in other regions of the spectra, such as infrared and terahertz, where pixelated sensors do not have such good specifications, this technique can provide huge benefits [3].

Single-pixel imaging needs to project the scene onto a basis of functions, whose size depends on the desired resolution of the image. For low resolution images of $64 \times 64$ pixels, this requires 4096 projections. Even if fast spatial light modulators such as digital micromirror devices are used, this limits the speed of the acquisition time. In order to solve this problem, compressive sensing techniques propose a method to recover the images with a number of measurements lower than the total number of pixels [4]. Despite lowering the total number of projections, the reconstruction algorithms require high computational times, which also limits the technique to low resolution images if the user wants high speed acquisition and display (video rate). Here we propose a novel method that recovers pictures with a number of measurements lower than the number of pixels of the scene, with higher quality than compressive sensing techniques and lower reconstruction times. Our method is based on smart sampling of the scene with patterns of different resolutions and recovering the information by using fast wavelet transforms. Both numerical and experimental examples (Fig. 1), are shown with resolutions up to one megapixel.

(a)

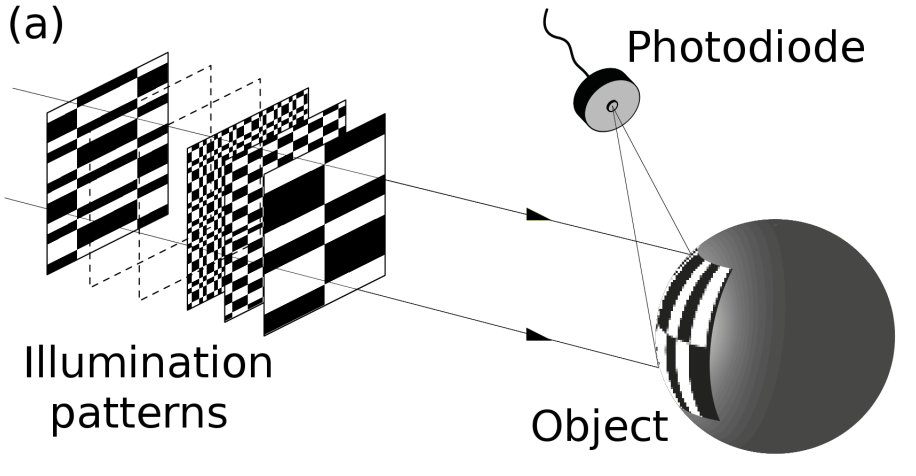

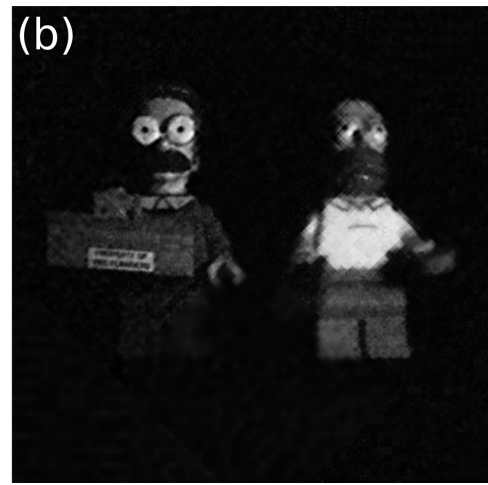

Figure 1.- Adaptive compressive imaging. (a) Single-pixel camera scheme. A series of patterns are projected onto the object. The reflected light is measured with a bucket detector. (b) $512 \times 512$ image acquired using only $42 \%$ of the total number of measurements required by single-pixel conventional techniques.

\section{References}

[1] M. F. Duarte, M. A. Davenport, D. Takhar, J. N. Laska, T. Sun, K. F. Kelly, and R. G. Baraniuk, "Single-pixel imaging via compressive sampling,” IEEE Signal Process. Mag. 25(2), 83 (2008).

[2] E. Tajahuerce, V. Durán, P. Clemente, E. Irles, F. Soldevila, P. Andrés, and J. Lancis, "Image transmission through dynamic scattering media by single-pixel photodetection," Opt. Express 22, 16945 (2014).

[3] C. M. Watts, D. Shrekenhamer, J. Montoya, G. Lipworth, J. Hunt, T. Sleasman, S. Krishna, D. R. Smith, and W. J. Padilla, "Terahertz compressive imaging with metamaterial spatial light modulators," Nat. Photonics 8, 605 (2014).

[4] E. J. Candès and M. B. Wakin, “An introduction to compressive sampling,” IEEE Signal Process. Mag. 25(2), 21 (2008). 



\title{
SCIENTIFIC REP

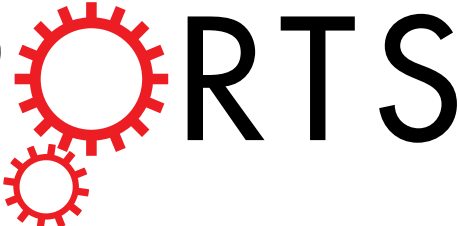

\section{OPEN High-resolution adaptive imaging with a single photodiode}

\author{
F. Soldevila ${ }^{1,2, *}$, E. Salvador-Balaguer ${ }^{1,2, *}$, P. Clemente ${ }^{1,2,3}$, E. Tajahuerce ${ }^{1,2}$ \& J. Lancis ${ }^{1,2}$
}

Received: 16 June 2015

Accepted: 18 August 2015

Published: 18 September 2015
During the past few years, the emergence of spatial light modulators operating at the tens of $\mathrm{kHz}$ has enabled new imaging modalities based on single-pixel photodetectors. The nature of single-pixel imaging enforces a reciprocal relationship between frame rate and image size. Compressive imaging methods allow images to be reconstructed from a number of projections that is only a fraction of the number of pixels. In microscopy, single-pixel imaging is capable of producing images with a moderate size of $128 \times 128$ pixels at frame rates under one $\mathrm{Hz}$. Recently, there has been considerable interest in the development of advanced techniques for high-resolution real-time operation in applications such as biological microscopy. Here, we introduce an adaptive compressive technique based on wavelet trees within this framework. In our adaptive approach, the resolution of the projecting patterns remains deliberately small, which is crucial to avoid the demanding memory requirements of compressive sensing algorithms. At pattern projection rates of $22.7 \mathrm{kHz}$, our technique would enable to obtain $128 \times 128$ pixel images at frame rates around $3 \mathrm{~Hz}$. In our experiments, we have demonstrated a cost-effective solution employing a commercial projection display.

In the latter years, single-pixel imaging (SPI) has been established as a suitable tool in life sciences. One of the main characteristics of the technique is that it uses very simple sensors (bucket detectors such as photodiodes or photomultiplier tubes) and mathematical algorithms to recover an image ${ }^{1}$. This reduction in complexity on the sensing device gives these systems the capability to work efficiently in conditions where light is scarce ${ }^{2}$. Furthermore, single-pixel cameras have been demonstrated to obtain images at shallow depth overcoming the scattering problem ${ }^{3-5}$. There are also several approaches that exploit the simplicity of the detectors in order to acquire multidimensional information, such as $3 \mathrm{D}$, polarization and spectral images ${ }^{6-10}$. However, this complexity reduction in the sensor entails an increase of computational time to recover an image when compared to conventional techniques. In the visible region of the spectrum, where pixelated sensors have acquired very high performances with low costs, this may not seem like a good trade-off. Nevertheless, in other regions of the spectra, such as infrared and terahertz, where pixelated sensors do not have such good specifications, this technique can provide huge benefits ${ }^{11-14}$

To recover an image, SPI needs to overlap a set of masks onto the scene under study and recover the total intensity of light transmitted or reflected by the scene. The size of this set depends on the desired resolution of the image. Even for low resolution images of $64 \times 64$ pixels, this requires a huge amount of projections $\left(64^{2}\right)$. In spite of the fact that fast spatial light modulators (digital micromirror devices, or DMD) are usually used in these single-pixel camera architectures, this limits the speed of the acquisition process.

In order to solve this problem, compressive sensing (CS) techniques provide a method to recover the images with a number of measurements lower than the total number of pixels. This is possible because natural images tend to be sparse (i.e. only a small fraction of these projections have relevant information) in some basis of functions ${ }^{15}$. Despite lowering the total number of projections, the reconstruction algorithms require high computational power, which also limits the technique to low resolution images if

${ }^{1}$ GROC.UJI, Departament de Física, Universitat Jaume I, E12071 Castelló, Spain. ${ }^{2}$ Institute of New Imaging Technologies (INIT), Universitat Jaume I, E12071 Castelló, Spain. 3Servei Central d'Instrumentació Científica (SCIC), Universitat Jaume I, E12071 Castelló, Spain. *These authors contributed equally to this work. Correspondence and requests for materials should be addressed to F.S. (email: fsoldevi@uji.es) 

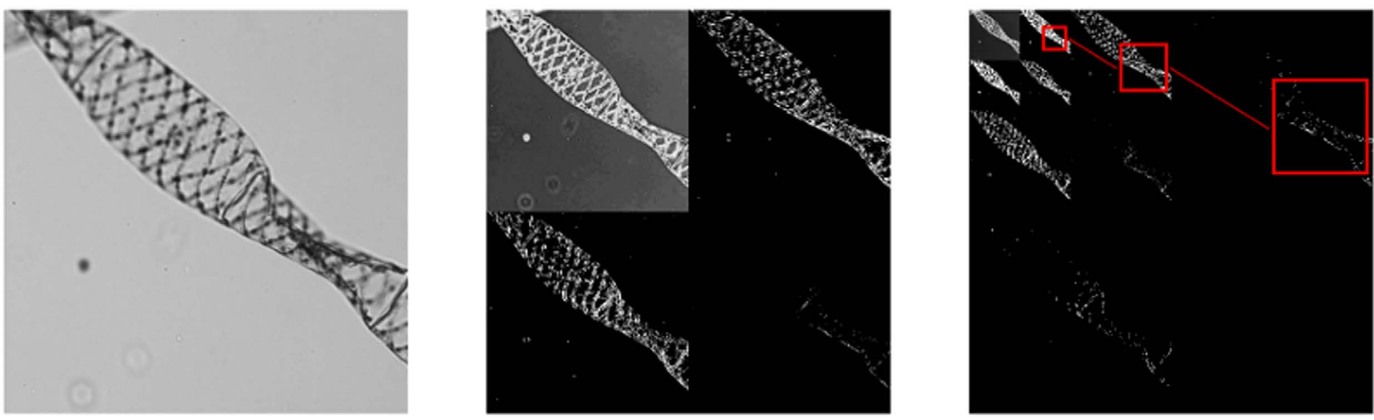

Figure 1. Spirogyra algae image $(512 \times 512$ pixels $)$, its first level and third level wavelet transforms, respectively. The bright pixels on the wavelet transform represent the edges of the scene. In the wavelet representation, a region of the scene is represented by a set of wavelet coefficients arranged in a tree structure, as shown in the right panel.

the user wants high speed acquisition and high-speed display in real-time. Some other techniques tackle this problem by using temporal sparsity ${ }^{16,17}$

Recently, a technique has been reported operating at sub- $\mathrm{Hz}$ rates with image sizes up to $128 \times 128$ pixels ${ }^{18}$. The key element of the technique is to project only the functions of the basis that have most of the information about the scene and recover the picture without using CS algorithms, thus speeding-up the display stage. Even though this approach solves the problem of the reconstruction time of the CS algorithms, to project only the important masks one must know beforehand which ones have the relevant information about the scene. Moreover, if the scene changes quickly, the a priori information of the relevant functions is rapidly lost. In order to achieve real time frame rates, it would be preferable to have a technique that does not use a priori information about the scene maintaining the benefits discussed above.

Here we propose an adaptive method for SPI that recovers images with a number of measurements lower than the number of pixels of the scene, with finer details than CS techniques (given the same number of measurements) and lower reconstruction times. This approach does not need to have a priori knowledge of the object and only collects information about the relevant parts of the scene in an adaptive way. It is based on smart sampling of the scene with a small set of masks. These masks are adaptively resized when the part of the scene needs to be recorded with higher resolution. The image is finally recovered by using fast wavelet transforms. Similar ideas have been proposed to improve the performance of ghost and dual photography imaging systems ${ }^{19-21}$. This method is very suitable when the user wants to capture big size images for two main reasons. One, even though the size of the final image can be big (in our experiments, $2048 \times 2048$ pixels), the number of projected masks remains small due to the nature of the adaptive algorithm. And two, even if this number cannot be reduced due to object characteristics (i.e. objects with very complex spatial features or texture-like images), with this approach only a low resolution set of masks needs to be stored. This characteristic is very suitable from the computational point of view, as small deterministic matrices require low amounts of memory to be stored and can be easily used in fast mathematical operations, providing massive computational gains ${ }^{22,23}$. For example, in the recovery stage of the aforementioned image classical SPI techniques would have to store $2048^{2}$ different masks with $2048^{2}$ elements each. Nevertheless, with the adaptive approach we are able to recover the image operating with a set of $128^{2}$ masks with $128^{2}$ elements each. With these characteristics in mind, we have been able to design a high-resolution fast-operation SPI system with an off-the-shelf DMD and a mid-range laptop. This kind of system can be easily coupled with available commercial microscopes to take advantage from the SPI benefits discussed above.

\section{Results}

Adaptive Compressive Imaging (ACl). To better understand the ACI algorithm one has to figure out how the $2 \mathrm{D}$ wavelet transform technique works. The process is depicted in Fig. 1 . Given an $N \times N$ image, the wavelet transform consists of applying four bandpass filters to the image. As a result, four $N / 2 \times N / 2$ quadrants are obtained; a low resolution version of the image and three more quadrants with the information of the horizontal, vertical and diagonal edges. This process can be applied again to the low resolution version of the image, giving the tree-structured image shown in the right image of Fig. 1 where the upper left quadrant (the low resolution image) has been replaced by its wavelet transform. This procedure can be repeated up to $\sqrt{N}$ times, when the pixel in the upper left corner contains the total energy of the scene and the rest of the image has the information about the edges of the scene. As it can be seen, the number of pixels containing information of sharp edges is scarce thus few coefficients are enough to get an image similar to the original one. Wavelet compression algorithms choose a number of iterations (levels) and only store the coefficients with values higher than a predetermined threshold, 


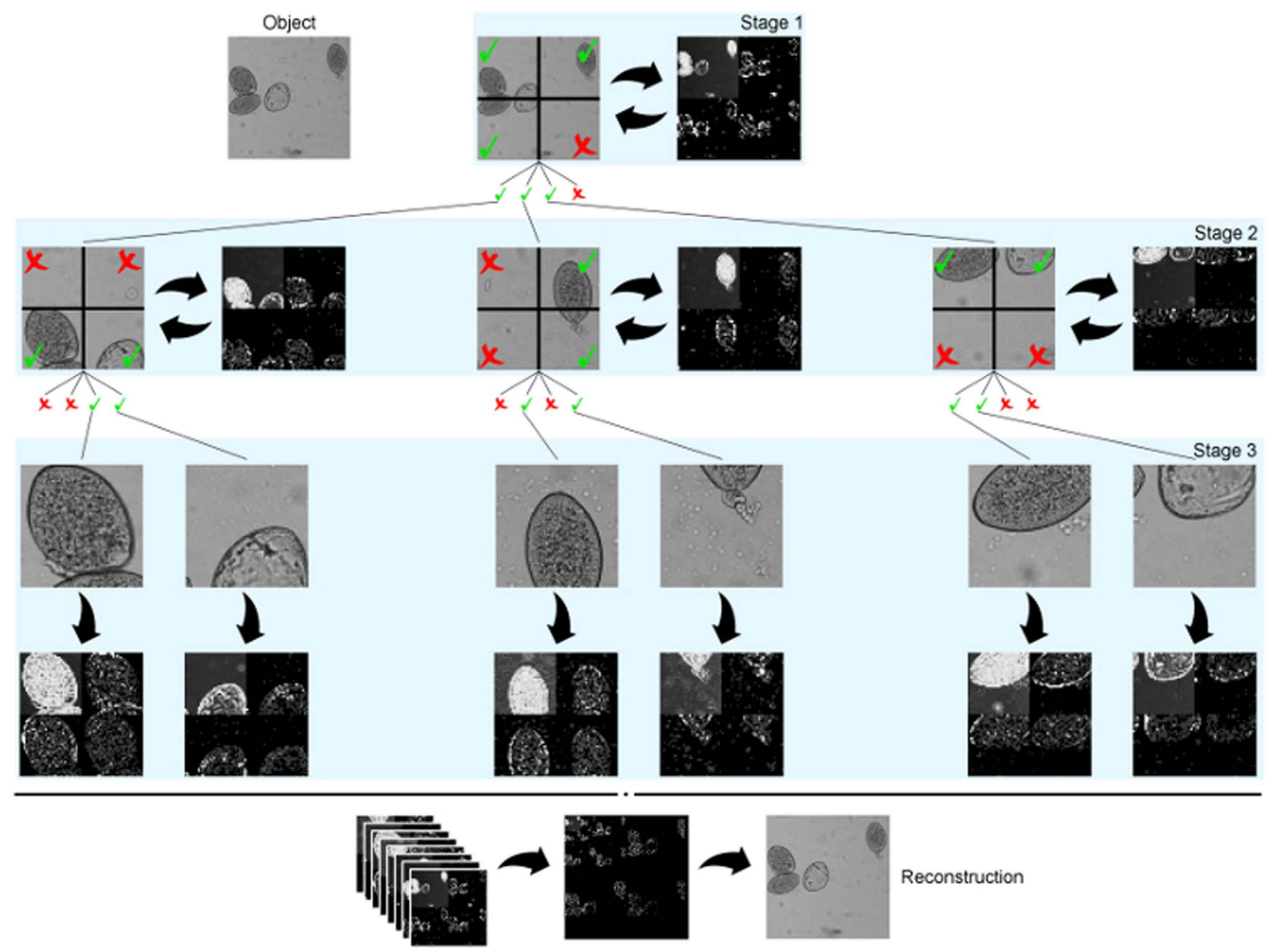

Figure 2. Adaptive Compressive Imaging operation scheme. Object: $256 \times 256$ Fasciola hepatica cells image captured with a commercial microscope. Stage 1: Coarse picture and its level one wavelet transform inspection. As the fourth quadrant has no relevant information, it is discarded. Stage 2: Higher resolution images of the non-discarded zones with their level one wavelet transforms inspection. In this stage, six regions are discarded. Stage 3: Highest resolution images of the non-discarded zones and their level one wavelet transforms. As this is the last stage, no more zones will be discarded so there is no wavelet inspection process. Using all the level one wavelet transforms, the algorithm builds the level three wavelet transform. By doing its inverse wavelet transform, the reconstruction of the scene is acquired. In this example, the total number of measurements to recover the scene was $62 \%$ of the $256^{2}$ measurements established by the Nyquist criterion.

reducing in this way the size of the digital file without a significant loss in quality. As the operations needed to calculate this transform are linear, they are an excellent option for fast algorithms because they require low computational power and memory usage.

The idea behind the ACI technique is to reduce the number of masks needed to reconstruct an image, using high resolution masks only on the high resolution regions of the image. To that end, we first sample the scene with a low resolution set of masks and only continue sampling with higher resolution masks the parts of the image with regions of interest (i.e. the regions with high density of sharp edges). If the algorithm detects a zone in the scene with no borders, it does not project patterns again on this region, as more resolution is not needed. This process is repeated until we arrive at the final desired resolution. As a demonstration of the technique, in Fig. 2 we show a simulation done with a real microscopy image.

In this case, the goal is to recover an image of $256 \times 256$ pixels of a group of cells. The set of masks chosen is the $2 \mathrm{D}$ Hadamard basis of $64 \times 64$ pixels. In the first stage, the algorithm acquires a coarse picture of the full scene with our set of masks (resizing the $64 \times 64$ Hadamard patterns to $256 \times 256$ pixels). Once the image is recovered, it calculates its level one wavelet transform and searches for the quadrants with higher density of borders. If one of the quadrants has a number of borders below a predefined threshold, it will be discarded on the next stages, thus reducing the total number of masks projected. Once this step is complete, the second stage of the algorithm starts. Now, the $64 \times 64$ patterns are resized to $128 \times 128$ pixels, therefore occupying a quarter of the original scene. If none of the quadrants has been discarded in the previous stage, here the algorithm takes four more pictures, recovering then the scene with finer details. If one or more of the quadrants were discarded on the previous stage, the algorithm does not project the set of patterns in the discarded quadrants. In this stage, the algorithm repeats the level one wavelet transformations to each image in order to search again for new zones with no borders. As the algorithm goes on, the search zones get smaller and smaller, and the following sets of smaller masks are only projected on the high spatial resolution zones of the scene. In the last stage, masks are 

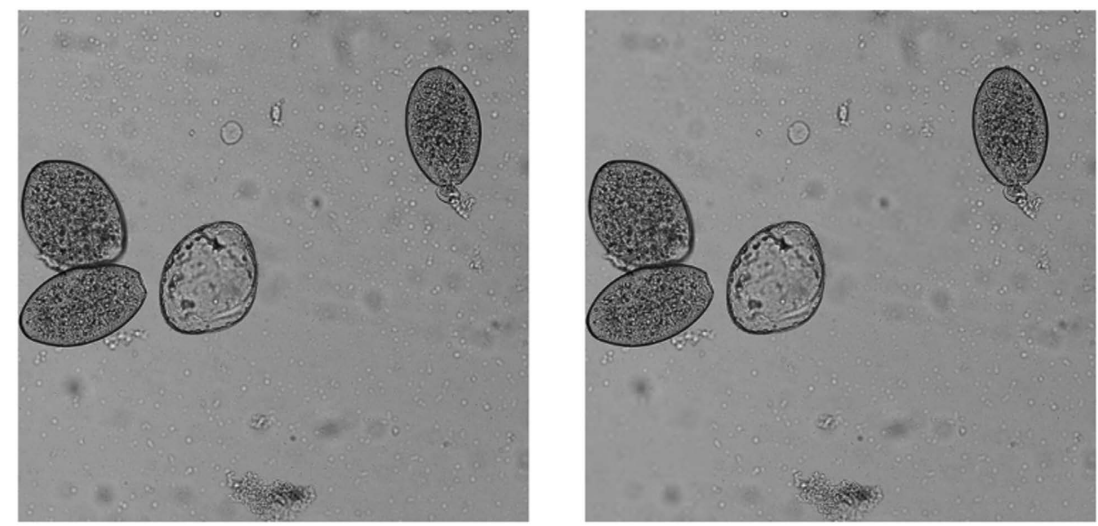

Figure 3. Fasciola hepatica 4 MP image (left panel) and its ACI reconstruction (right panel). The ACI reconstruction is acquired with roughly a $25 \%$ of the $2048^{2}$ measurements stablished by the Nyquist ratio.

projected onto the regions with finer details of the scene. Once all the regions have been measured with the required resolutions, all the wavelet transforms are used to build the third level wavelet transform shown in Fig. 2. The final $256 \times 256$ image is recovered via inverse wavelet transform. In contrast with traditional CS techniques, which usually require off-line reconstruction, this step is not computationally consuming. As it will be further discussed in the text, when using ACI this process can be done on the fly with low end computers.

The ACI approach has several remarkable benefits when compared with the traditional SPI-CS approach. These can be grouped into three categories: image size, resolution and temporal benefits. In order to prove those benefits, throughout this paper, we will compare our technique with the GPSR-Basic algorithm by Figuereido et al. ${ }^{24}$. First, we will discuss the image size benefits. As stated before, to recover a $N \times N$ picture, SPI needs to project $M=N^{2}$ masks. When using CS techniques, those $M$ projections are reduced (typical compression ratios tend to be between $10 \%$ and $40 \%$ without a significant quality loss). However, this reduction entails the use of convex optimization algorithms to recover the image. The memory and time requirements of the algorithms increase with the size of the image and the number of measurements made. Even if speed is not a crucial requirement for some applications, the memory requirements limit the maximum size of the images recovered. In our experiments, carried on a computer with 24GB of RAM and a Intel Xeon Processor X5690 at $3.47 \mathrm{GHz}$, the maximum image size that can be reconstructed due to memory limitations with CS algorithms is $256 \times 256$ pixels, with compression ratios around $50 \%$. When using the ACI algorithm, only a small set of masks of low resolution and the measurements vector need to be stored. In practice, we did simulations of images with sizes up to 4 Megapixel (MP), even though this is not the limit of our equipment. As can be seen in Fig. 3, the regions of interest of the scene are recovered with perfect resemblance, and the zones with no information have lower detail.

When dealing with higher resolutions like the one shown above, the reconstruction time starts to be a crucial factor to be reckoned. A general approach made by researchers is to sacrifice some quality in their reconstructions in order to achieve higher frame rates. This can be made by applying high compression rates or by novel approaches like the one proposed by Radwell et al. ${ }^{18}$. This procedures either aren't fast enough to achieve high resolution real time imaging or need a priori information about the scene to speed-up the reconstruction process. In SPI systems, the image acquisition time, $t_{a}$, depends on the number of projected masks, $M$, which is determined by the size of the image. Defining the projection rate of the SLM as $R_{S L M}$, the image acquisition time is given by $t_{a}=M \cdot\left(1 / R_{S L M}+t_{\text {int }}\right)+t_{P}$, where $t_{P}$ is the post-processing time to recover the picture from the measurements made, $M$, and $t_{\text {int }}$ is the integration time of the bucket detector. Ideally, both $M$ an $t_{p}$ should be as low as possible. As single-pixel detectors work at higher frequencies than SLM's, $t_{i n t}$ is negligible in all the scenarios considered here where lighting conditions are not extreme. Whereas traditional single pixel imaging requires $M$ to be equal to the number of pixels of the image, $N^{2}$, and has negligible $t_{p}$, CS techniques reduce $M$ but increase $t_{p}$. Furthermore, CS techniques need to solve a convex optimization problem to recover an image, which requires high amounts of memory. Adaptive imaging techniques are known to reduce $M$ while keeping negligible $t_{p}{ }^{19,20}$. Nevertheless, due to the nature of ACI, increasing the size of the scene does not necessarily imply increasing memory requirements. If there is a memory limitation, the number of stages to reconstruct a scene will be increased, and consequently the size of the masks reduced.

In Fig. 4 we show two comparisons between CS and ACI algorithms. We have verified the PSNR and reconstruction time to behave similar for several biological images. To carry out the simulation we have used three different biological test images (shown in Fig. 5), with a size of $128 \times 128$ pixels. The ACI algorithm number of stages was set to three, thus using the $32 \times 32$ Hadamard masks. The first graph 

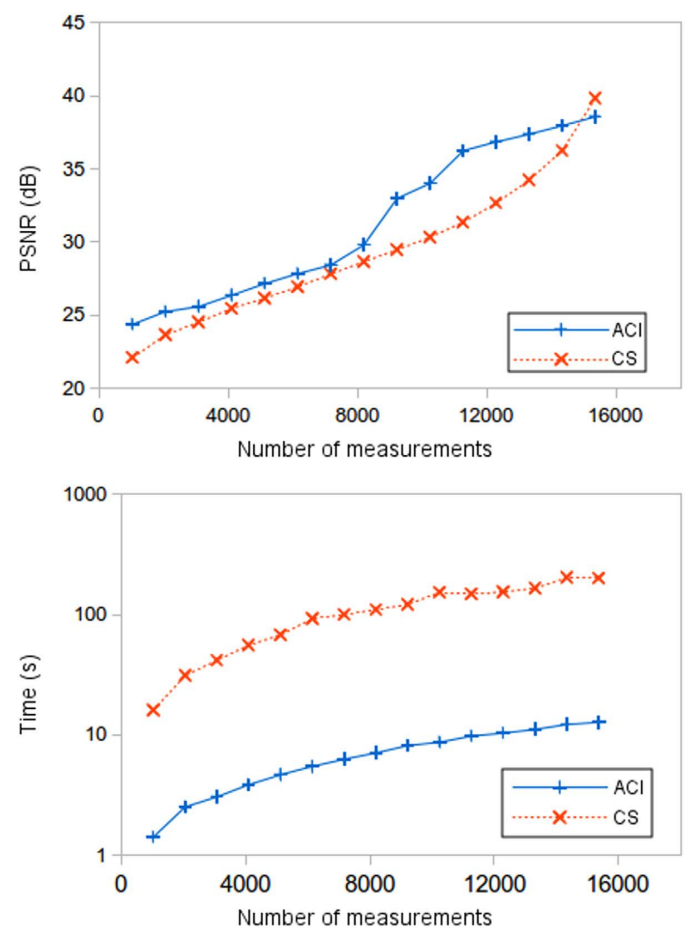

Figure 4. Full frame quality and time comparison between CS and ACI techniques. The full scene resemblance is measured with the PSNR comparison in the top graph. Given the same amount of measurements, the quality is similar in both methods. However, the time comparison shows that the ACI technique outspeeds the traditional CS technique.
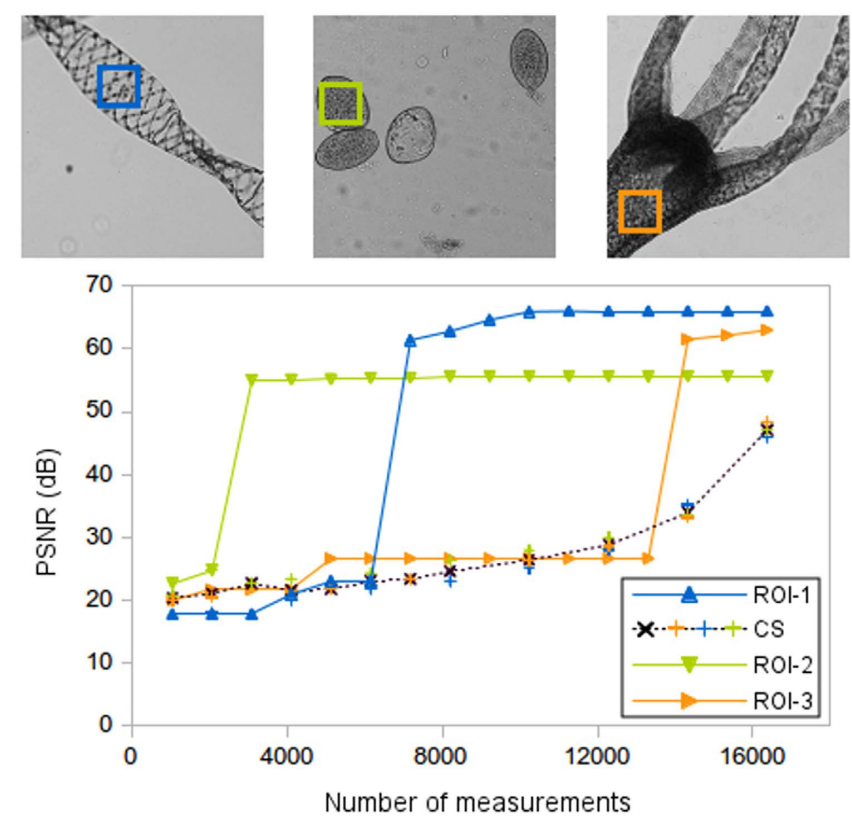

Figure 5. ROI quality comparison between CS and ACI techniques. Three biological samples are selected for the analysis. In each sample, one ROI is studied. Due to the adaptive nature of the ACI approach, its PSNR curves present a steplike behaviour, acquiring higher resemblance than the traditional CS technique. In order to ease the visualization, the CS curve is the average of the three ROI's, as the results were almost equal in all the images. 


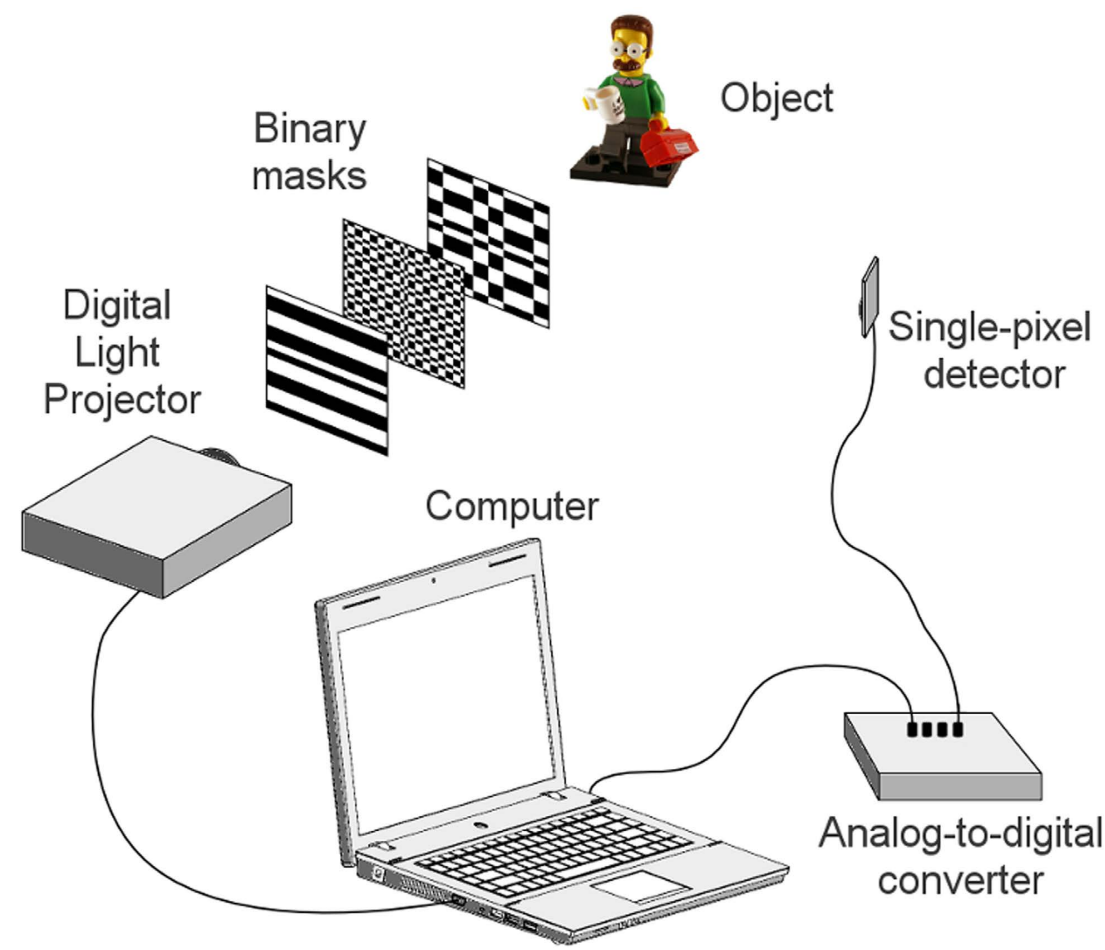

Figure 6. Experimental setup used for ACI reconstructions. The digital projector sends a predefined set of masks to different parts of the object. The light reflected from the object is measured with a bucket detector. The signal is digitalized and used to recover an image of the scene.

shows the average of the PSNR versus number of measurements for ACI and CS algorithms when the reconstructions are compared with the original images. In the second graph we show a time comparison between both methods. The time includes not only the CS and ACI algorithm computational time but also the masks projecting time. Even though the quality is similar, it is clear by watching at the lower graph, that the ACI technique has a great benefit in reconstruction times. As can be deduced from the results, high quality pictures can be achieved with sub-Nyquist measurement rates around $50 \%$. With those measuerement ratios and state-of-the-art DMD's, images of $128 \times 128$ pixels can be acquired at frame rates around $3 \mathrm{~Hz}(\sim 8000$ measurements at $22.7 \mathrm{kHz})$. Similar tests were made with higher resolutions with results even more favorable to the ACI technique. Images with a resolution of $256 \times 256$ pixels are reconstructed in less than a minute with the ACI algorithm in comparison with several days with the GPSR routine. Higher resolution images could not be compared as our equipment is not able to reconstruct images with resolutions above $256 \times 256$ pixels using CS.

Another huge benefit of the technique is that it recovers the regions of interest at high resolution using sub-Nyquist measurement rates. In Fig. 5 we show an example with three biological samples. For each sample, we chose a region of interest and we compare the PSNR of that region when using both techniques. As CS projects masks covering the entire scene, the quality of the whole image gradually improves with the number of projected masks, independently of the region of interest chosen. However, this does not happen with the ACI algorithm because masks are sent to different regions of the scene. In this case, the ACI curves have a steplike behaviour, where each step corresponds to a stage of the algorithm. If there are few regions of interest in the scene, steps are concentrated in the initial measurements (see green curve), while if the scene is plenty of sharp edges, the highest quality of the region is achieved later (see orange curve). In microscopy setups, where the samples usually lay onto specific regions of a slide, this characteristic can be used to recover specimens with very low number of measurements or to locate regions of interest in a fast way. Once those regions are located, the amplification of the system can be changed so the sample fills the full field of view of the system.

Experimental results. In order to test those ideas, we conducted a proof of concept experiment with a projector and a mid-range laptop. The experimental setup is shown in Fig. 6. It consists of a digital light projector, a photodiode, an analog-to-digital converter and a computer. The DLP sends the set of masks onto different regions of the object, resizing them when needed. Each set of resized masks is precomputed, and custom software written in Labview chooses the suitable one for each stage of the algorithm. As the number of pixels of each mask remains the same in all stages (the only change is the pixel size), the reconstruction algorithm computational charge is alleviated. By means of an optical collecting system, light reflected by the object is measured with the photodiode. Being the quantum efficiency of 

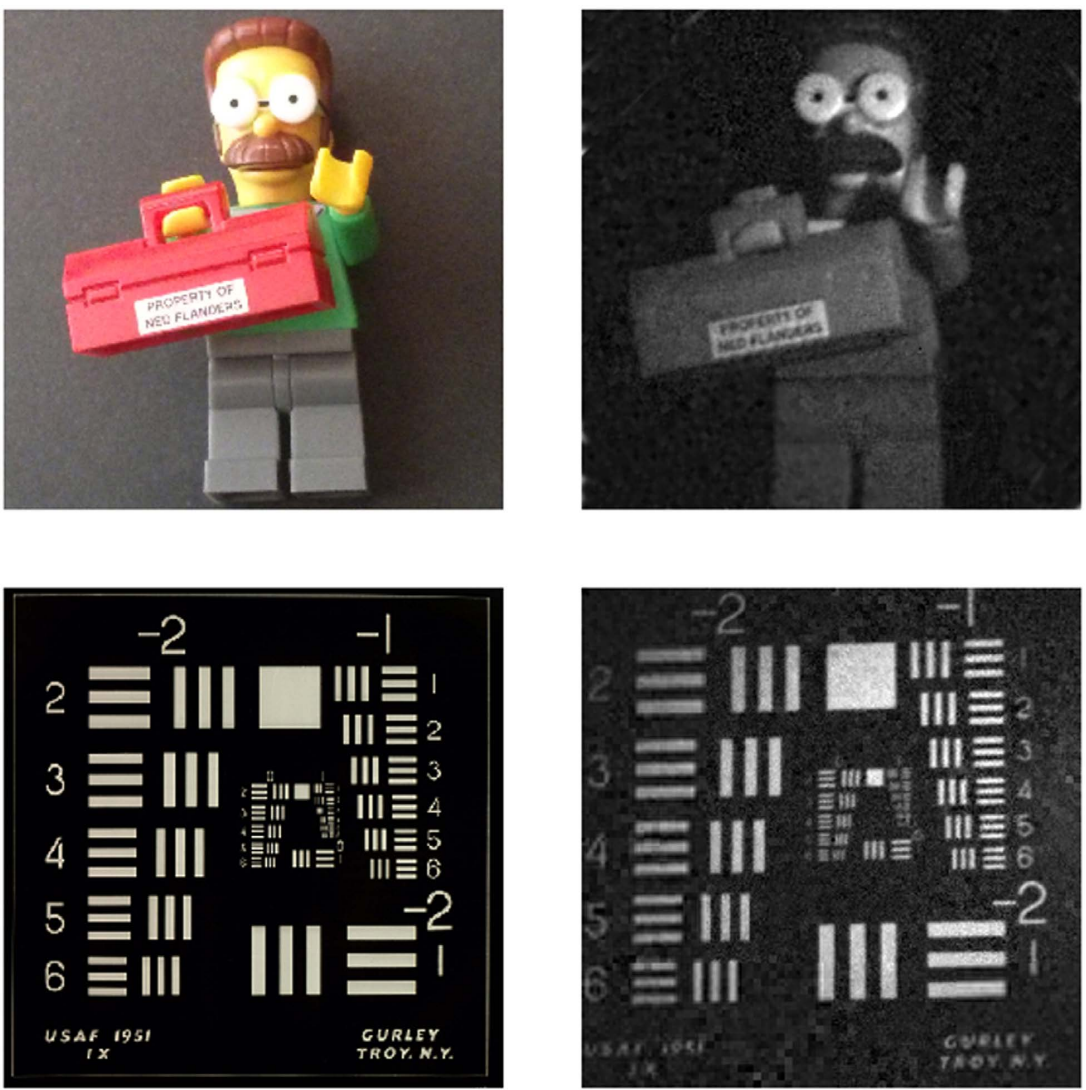

Figure 7. ACI experimental results. In the upper row, we show a $256 \times 256$ pixels LEGO ${ }^{\circledR}$ Ned Flanders picture (left) and its reconstruction via the ACI technique (right). The ACI reconstruction was acquired by using $88 \%$ of measurements of the total number of pixels. In the lower row, we show a $512 \times 512$ pixels USAF1951 test (left) and its ACI reconstruction (right). In this case, the reconstruction was acquired with a $55 \%$ of measurements of the total number of pixels. The only post-processing made to the ACI images was white balance correction.

photodetectors higher than CCD/CMOS sensors and given that more photons reach the detector at each measurement, signals acquired suffer less distortion from dark and read-out noise ${ }^{1}$. The analog-to-digital converter digitalizes the signal, and the computer reconstructs the images with custom code written in Matlab. The experimental process of projecting the patterns and measuring the electrical signal is controlled by custom software written in Labview.

In Fig. 7, two experimental reconstructions are shown. The first scene reconstructed is a small LEGO ${ }^{\circledR}$ object. We start the ACI algorithm with $64 \times 64$ Hadamard patterns and the number of stages is set to 3 . Then, the final resolution achieved is $256 \times 256$ pixels. Unlike standard CS techniques the time needed to reconstruct the scene only depends on the SLM refresh rate and not on the compressive strategy. For this particular reconstruction we have sent $88 \%$ of the total $256^{2}$ measurements established by the Nyquist criterion. In our experiments, we use a DLP LightCrafter 4500 from Texas Instruments. Even though the maximum refresh rate of this device is $4225 \mathrm{~Hz}$, when the number of patterns to be projected gets higher, memory limitations arise. Then, the patterns have to be sent using the video input of the device instead of being preloaded on the internal memory. The speed of this video input is limited to $120 \mathrm{~Hz}$. By encoding 24 different binary patterns in each video frame as a 24-bit image, the maximum speed acquired is $2880 \mathrm{~Hz}^{25}$. Bearing that in mind, the acquisition time with our equipment was 20.02 seconds. If state of the art SLM's are used, with refresh rates around $22.7 \mathrm{kHz}$ and high capacity internal memory, these limitations can be avoided, and reconstruction times of 2.54 seconds can be attained with this method.

As stated before, ACI stands out when capturing big resolution images. Due to the DLP specifications, the biggest square masks that can be projected have a size of $512 \times 512$ pixels. In the second row of Fig. 7 , we show a reconstruction of an USAF test with that resolution. In order to achieve this resolution, four stages of the ACI algorithm were used. As the picture gets bigger, the number of discarded regions tends to get higher, so greater compression ratios are achieved while maintaining good resemblance with the scene. In particular, for this second example we only used $55 \%$ of measurements of the $512^{2}$ stablished 
by the Nyquist criterion. With our setup, we acquired the image in 50.06 seconds. By using high-end DMD's, acquisition times of 6.35 seconds could be achieved.

\section{Discussion}

We have designed an ACI algorithm that allows recovering high resolution images at low time costs by using SPI. Compared to traditional CS approaches, we acquire images with equivalent quality in much lower times ${ }^{1,3}$. In fact, with the same number of measurements, CS needs post-processing to recover the image while ACI can do it live. Novel approaches like multi-diode design cameras or adaptive ghost imaging have also tackled the speed-resolution limitation with success ${ }^{20,26}$. However, our approach maintains the use of a single photodetector, which improves the SNR of the measurements when working on low-light level scenarios, such as biological environments. Furthermore, by using deterministic matrices as the basis of our masks, the method is better suited for fast mathematical operations or even using CS in each stage of the acquisition process ${ }^{22}$. We have also computationally demonstrated the effectiveness of the technique to perfectly recover the regions of interest of an image at sub-Nyquist measurement rates. For the scenes investigated here, containing relatively few regions of intereset, ACI has been shown to provide higher quality reconstructions in less time than the GPSR-Basic CS approach. Compared to other single-pixel techniques, we do not need a priory knowledge of the scene to achieve this speed ${ }^{18}$.

Huge technological efforts are focused on increasing resolution of optical devices. Up to now, SPI has failed to provide high resolution images due to time restrictions. The only limiting factor of ACI technique lies in the SLM refresh rate, enabling us to present high resolution experimental images with dimensions comparable to the SLM number of pixels, without needing stitching techniques and using a single photodiode as a detector.

It has to be also noted that ACI is a very flexible technique. For example, we can use traditional compressive techniques in each ACI stage to reduce even more the number of measurements needed. ACI can also be used to improve the performance of single-pixel cameras working in different regions of the visible, infrared and terahertz spectrum ${ }^{3,4,11}$. Future work in the ACI technique should be directed towards improving the adaptive scheme. This will involve searching edges in a more intelligent way. Instead of inspecting quadrants regularly placed in the scene, we could freely situate them on high density border zones to gather the information more efficiently. This will improve the quality of the recovered images at even lower measurement rates.

\section{Methods}

The DLP used in the experiments is a DLP LightCrafter 4500 from Texas Instruments. It contains a DMD and three coloured light sources (red, green and blue). A built-in optical system is used to project the patterns onto the scene. The photodetector used is PDA36A-EC from Thorlabs, and the electrical signal is digitalized with NI USB-6001 DAQ. All the experimental results were acquired with a Lenovo ThinkPad E531 laptop with $12 \mathrm{~GB}$ of RAM and an Intel Core i7 $2.20 \mathrm{GHz}$ processor. The biological images used in the simulations correspond to different samples from two slide sets from Carolina (\#292148A and \#293708).

$\mathrm{ACl}$ algorithm. Here we attach the pseudo-code of the ACI algorithm used in the experimental setup.

\begin{tabular}{|c|}
\hline Algorithm $\mathbf{1}$ ACI \\
\hline Input: $L \leftarrow$ number of stages \\
\hline$R \leftarrow$ final image resolution \\
\hline$Q \leftarrow$ Hadamard patterns of resolution: $\frac{R}{2^{L-1}}$ \\
\hline Output: $\quad$ finalImg $\leftarrow R \times R$ image of the scene \\
\hline for $\quad \mathrm{i}=\mathrm{L}$ to $1 \quad$ do \\
\hline Divide the scene into $4^{L-i}$ quadrants. \\
\hline for $\quad \mathrm{j}=1$ to $4^{L-i} \quad$ do \\
\hline if $\quad i \neq L$ and quadrantRelevance $(\mathrm{j})<$ threshold \\
\hline childrenQuadrantRelevance $(\mathrm{j}) \leftarrow$ Set to 0 the quadrantRelevance of all its children \\
\hline quadrantImg $(\mathrm{j}) \leftarrow$ Use the information of its father to recover the image of quadrant $\mathrm{j}$. \\
\hline else \\
\hline quadrantImg $(\mathrm{j}) \leftarrow$ Use patterns $\mathrm{Q}$ to sample the quadrant $\mathrm{j}$ of the scene and recover its image. \\
\hline quadrantWavelet $(\mathrm{j}) \leftarrow$ perform one-level wavelet transform of quadrantImg(j) \\
\hline Continued \\
\hline
\end{tabular}




\begin{tabular}{|l|}
\hline \multicolumn{1}{|c|}{ childrenQuadrantRelevance $(\mathrm{j}) \leftarrow$ borders information extracted from quadrantWavelet $(\mathrm{j})$. } \\
\hline end for \\
\hline stageWavelet $(\mathrm{i}) \leftarrow$ compose the wavelet transform of stage $\mathrm{i}$. \\
\hline end for \\
\hline finalWavelet $\leftarrow$ use the information of all stageWavelet to recover the L-wavelet transform information of the scene. \\
\hline finalImg $\leftarrow$ Perform a L-level inverse wavelet transform to recover the $R \times R$ image of the scene. \\
\hline
\end{tabular}

\section{References}

1. Duarte, M. F. et al. Single-Pixel Imaging via Compressive Sampling. IEEE Signal Process. Mag. 25, 83-91 (2008).

2. Howland, G.A., Lum, D.J., Ware, M. R. \& Howell, J. C. Photon counting compressive depth mapping. Opt. Express 21, 23822-23837 (2013)

3. Tajahuerce, E. et al. Image transmission through dynamic scattering media by single-pixel photodetection. Opt. Express 22,16945 (2014).

4. Durán, V. et al. Compressive imaging in scattering media. Opt. Express 23, 14424-14433 (2015).

5. Ntziachristos, V. Going deeper than microscopy: the optical imaging frontier in biology. Nat. Methods 7, 603-614 (2010).

6. Sun, B. et al. 3D computational imaging with single-pixel detectors. Science 340, 844-847 (2013).

7. Durán, V., Clemente, P., Fernández-Alonso, M., Tajahuerce, E. \& Lancis, J. Single-pixel polarimetric imaging. Opt. Lett. 37, 824-826 (2012).

8. Soldevila, F. et al. Single-pixel polarimetric imaging spectrometer by compressive sensing. Appl. Phys. B 113, 551-558 (2013).

9. Welsh, S. S., Edgar, M. P., Bowman, R., Sun, B. \& Padgett, M. J. Near video-rate linear Stokes imaging with single-pixel detectors. J. Opt. 17, 025705 (2015).

10. Edgar, M. P. et al. Simultaneous real-time visible and infrared video with single-pixel detectors. Sci. Rep. 5, 10669 (2015).

11. Watts, C. M. et al. Terahertz compressive imaging with metamaterial spatial light modulators. Nat. Photonics 8, 605-609 (2014).

12. Chen, H., Xi, N., Song, B. \& Lai, K. Single pixel infrared camera using a carbon nanotube photodetector. Sensors, 2011 IEEE (2011).

13. Shrekenhamer, D., Watts, C. M. \& Padilla, W. J. Terahertz single pixel imaging with an optically controlled dynamic spatial light modulator. Opt. Express 21, 12507 (2013).

14. Chan, W. L. et al. A single-pixel terahertz imaging system based on compressed sensing. Appl. Phys. Lett. 93, 121105 (2008).

15. Romberg, J. Imaging via Compressive Sampling. IEEE Signal Process. Mag. 25, 14-20 (2008).

16. Noor, I. \& Jacobs, E. L. Adaptive compressive sensing algorithm for video acquisition using a single-pixel camera. J. Electron. Imaging 22, 021013 (2013).

17. Sankaranarayanan, A. C., Studer, C. \& Baraniuk, R. G. CS-MUVI: Video compressive sensing for spatial-multiplexing cameras. in 2012 IEEE International Conference on Computational Photography (ICCP) 1-10 (IEEE, 2012).

18. Radwell, N. et al. Single-pixel infrared and visible microscope. Optica 1, 285-289 (2014).

19. Aßmann, M. \& Bayer, M. Compressive adaptive computational ghost imaging. Sci. Rep. 3, 1545 (2013).

20. Yu, W. K. et al. Adaptive compressive ghost imaging based on wavelet trees and sparse representation. Opt. Express 22, $7133-7144$ (2014).

21. Sen, P. et al. Dual photography. ACM Trans. Graph. 24, 745 (2005).

22. Blanchard, J. D. Toward deterministic compressed sensing. Proc. Natl. Acad. Sci. USA 110, 1146-1147 (2013).

23. Monajemi, H., Jafarpour, S., Gavish, M. \& Donoho, D. L. Deterministic matrices matching the compressed sensing phase transitions of Gaussian random matrices. Proc. Natl. Acad. Sci. USA 110, 1181-1186 (2013).

24. Figueiredo, M. A. T., Nowak, R. D. \& Wright, S. J. Gradient Projection for Sparse Reconstruction: Application to Compressed Sensing and Other Inverse Problems. IEEE J. Sel. Top. Signal Process 1, 586-597 (2007).

25. Thorlabs, Inc. DLPÂ ${ }^{\circledR}$ LightCrafter 4500TM Evaluation Module User's Guide. at http://www.ti.com/lit/ug/dlpu011d/dlpu011d. pdf (2014) Date of access: 03/08/2015.

26. Herman, M. A., Tidman, J., Hewitt, D., Weston, T. \& McMackin, L. A higher-speed compressive sensing camera through multidiode design. in Proceedings of the SPIE (ed. Ahmad, F.) 8717, 871706 (2013).

\section{Acknowledgements}

This work was supported in part from MINECO (grant FIS2013-40666-P), Generalitat Valenciana (grants PROMETEO2012-021 and ISIC 2012/013), and Universitat Jaume I (P1-1B2012-55).

\section{Author Contributions}

F.S. and E.S. conceived, conducted the experiments and wrote the manuscript; F.S., E.S., P.C., E.T. and J.L. discussed the results and revised the manuscript.

\section{Additional Information}

Competing financial interests: The authors declare no competing financial interests.

How to cite this article: Soldevila, F. et al. High-resolution adaptive imaging with a single photodiode. Sci. Rep. 5, 14300; doi: 10.1038/srep14300 (2015).

(c) (1) This work is licensed under a Creative Commons Attribution 4.0 International License. The images or other third party material in this article are included in the article's Creative Commons license, unless indicated otherwise in the credit line; if the material is not included under the Creative Commons license, users will need to obtain permission from the license holder to reproduce the material. To view a copy of this license, visit http://creativecommons.org/licenses/by/4.0/ 



\title{
Full-color stereoscopic imaging with a single-pixel photodetector
}

\author{
Eva Salvador-Balaguer, Pere Clemente, Enrique Tajahuerce, Filiberto Pla and Jesús Lancis
}

\begin{abstract}
We present an optical system for stereoscopic color imaging by using a single-pixel detector. The system works by illuminating the input scene with a sequence of microstructured light patterns generated by a color digital light projector (DLP). A single monochromatic photodiode, synchronized with the DLP, measures the light scattered by the object for each pattern. The image is recovered computationally by applying compressive sensing techniques. The RGB chromatic components of the image are discriminated by exploiting the time-multiplexed color codification of the DLP. The stereoscopic pair is obtained by splitting the light field generated by the DLP and projecting microstructured light patterns onto the sample from two different directions. The experimental setup is configured by simple optical components, a commercial photodiode and an offthe-shelf DLP projector. Color stereoscopic images of a 3D scene obtained with this system are shown.
\end{abstract}

Index Terms-Optical imaging, color imaging, digital micromirror device (DMD), stereo image processing.

\section{INTRODUCTION}

$\mathrm{C}_{\mathrm{r}}$ omputational imaging with single-pixel detectors is a remarkable alternative to conventional imaging techniques. It enables to obtain spatial information of an object, such as the reflectance distribution or other optical properties, by sampling the scene with a set of microstructured light patterns [1]. A simple bucked detector, for instance a photodiode, records the signal associated to each pattern and the image is reconstructed by mathematical algorithms. In this way, by avoiding sensor arrays, it is possible to add new degrees of freedom to the sensing process, allowing one to use very sensitive light sensors, to explore unusual spectral bands for imaging, or to use exotic photodetectors such as spectropolarimeters.

The technique is closely related to ghost imaging [2-4] and dual photography methods [5], which also use single-pixel detectors to reconstruct images. In the first case, imaging is based on the correlation between two signals. One signal is the

This work was supported in part from MINECO (grant FIS2013-40666-P), Generalitat Valenciana (grants PROMETEO2012-021 and ISIC 2012/013), and Universitat Jaume I (P1-1B2012-55).

Eva Salvador-Balaguer, Enrique Tajahuerce and Jesús Lancis, are with GROC UJI, Institute of New Imaging Technologies (INIT), Castelló, Spain (e-mail: salvadoe@uji.es)

Filiberto Pla is with Institute of New Imaging Technologies (INIT), Universitat Jaume I, Castelló, Spain.

Pere Clemente is with Servei Central d'Instrumentació Científica (SCIC), Universitat Jaume I, Castelló, Spain. intensity distribution of the light illuminating the object, as measured by using a detector array or evaluated by numerical simulation, while the second signal collects the total amount of light actually interacting with the object. In the second case the image is obtained by exploiting the Helmholtz reciprocity principle. This is mainly used in computer graphics research, and it is based on the idea that the flow of light can be reversed without altering the radiance transfer. Besides, some high resolution imaging techniques, such as fluorescence microscopy, also benefit from single-pixel detectors by using point scanning illumination. In fact, the introduction of microstructured light patterns for excitation in these techniques has shown improved performance [6].

The detection scheme based on single-pixel sensors has several advantages compared to conventional imaging techniques using sensor arrays. The simplicity of the sensing device allows them to work efficiently in conditions where light is scarce [7]. It also allows measuring the spatial distribution of multiple physical dimensions of the scene in a simple way. In this direction, single-pixel detection arquitectures have been designed for polarimetric imaging [8], color or multispectral imaging [9,10], time-of-flight imaging [11,12] or holography [13]. Moreover, single-pixel detectors provide a broader spectral range compared to conventional cameras, permitting to extend imaging techniques to different spectral regions $[14,15]$. Furthermore, it has been proved the ability of single-pixel cameras to perform non-invasive imaging through scattering media in biological tissues [16,17]. All these advantages could make single-pixel imaging a relevant technique in biomedical imaging, where fast, highresolution, multispectral, and tolerant to scattering imaging is required.

One of the main characteristics of imaging techniques using single-pixel detectors is that they are very well adapted to apply the theory of compressive sampling (CS) $[1,6,7,18,19]$. This theory exploits the fact that natural images tend to be sparse, i.e. only a small set of the expansion coefficients is nonzero when a suitable basis of function to express the image is chosen. In this way, images can be retrieved with a number of measurements lower than that established by the ShannonNyquist limit.

Several approaches have been proposed for applying these techniques to three-dimensional (3D) scenes. In principle, one may think that by simply displacing the light detector in any 2D single-pixel camera configuration it would be possible to obtain different $2 \mathrm{D}$ perspectives of a $3 \mathrm{D}$ scene. However, it 
has been shown that this displacement only changes the apparent illumination direction of the scene [5]. Using shape from shading approaches, this effect has been used to get $3 \mathrm{D}$ spatial information of an object [20, 21]. To this end, several photodetectors located at different positions record signals associated to the collection of illumination patterns simultaneously. The 3D shape is then reconstructed from the surface gradients obtained by comparing the illumination information of different images.

Nowadays, for many imaging applications it is even more important to efficiently display $3 \mathrm{D}$ information than to reconstruct the $3 \mathrm{D}$ shape of objects in the scene. The principle of stereoscopic vision can then be applied for 3D information recording and visualization, as it is done in commercial 3D movies by using switching or polarized glasses. The 3D perception is created by the human brain through the fusion of the pair of different images acquired by the eyes. In this work we present an optical system for stereoscopic color imaging based on computational imaging with a single-pixel detector together with a CS strategy. Our system is able to produce full-color stereoscopic images of a scene by using a low number of optoelectronic components, just a simple monochrome photodetector and a digital light projector.

\section{Single-PIXEL IMAGING AND COMPRESSIVE SENSING}

The operation of a single-pixel camera is shown schematically in Fig. 1. A sequence of $M$ microstructured light patterns with irradiance distribution $\Psi_{i}(m, n)$, being $m$, and $n$ discrete spatial coordinates and $i=1, \ldots, M$, is projected onto the input object. Light back scattered by the object is collected by the photodiode. If we denote with $T(m, n)$ the reflectance distribution of the object at the points sampled by the light patterns, then the photodiode measures sequentially the $M$ inner products

$$
I_{i}=\sum_{n=1}^{\sqrt{N}} \sum_{m=1}^{\sqrt{N}} \Psi_{i}(m, n) \cdot T(m, n) .
$$

In Eq. (1), $N$ is the number of pixels of the microstructured light patterns. The sampling operation in Eq. (1) implies that the spatial resolution of this imaging technique is determined by that of the projected light patterns.

Different approaches for single-pixel imaging use different

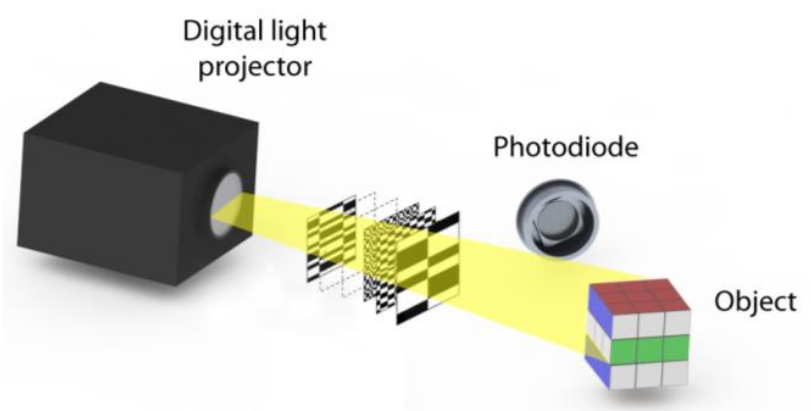

Fig. 1. Single-pixel scheme. A sequence of binary masks are projected onto an object and the light is collected by a photodiode. sampling functions $\Psi_{i}(m, n)$, being random patterns, for example, very common for the subsequent application of CS algorithms. In our work the sampling patterns are 2D functions $H_{i}(m, n)$ pertaining to the Walsh-Hadamard basis [22]. The 2D patterns represented in Fig. 1 are examples of these functions. This choice provides several advantages. Firstly, these patterns are members of an orthonormal basis. In this way, the intensity measurements, $I_{\mathrm{i}}$, directly provide the representation of the object in the basis. This also means that, in principle, by using all the functions of the basis the object could be exactly recovered for a given sampling frequency. Secondly, natural images tend to be sparse in the Hadamard basis, making these functions very useful also for compressive sensing purposes. And third, these patterns are binary function with values +1 and -1 . Therefore it is very easy to codify them with fast binary amplitude modulators.

Taking into account the definition of the Hadamard matrices, it is straightforward to show that, for any two patterns with index $i$ and $j$,

$$
\sum_{n=1}^{\sqrt{N}} \sum_{m=1}^{\sqrt{N}} H_{i}(m, n) \cdot H_{j}(m, n)=N \cdot \delta_{i j},
$$

where $\delta_{i j}$ is the Kronecker delta. Therefore, by using a sequence of $M$ Hadamard patterns, the irradiance distribution of the object in Eq. (1) can be estimated by applying a simple superposition principle in the following way:

$$
T^{\prime}(m, n)=\frac{1}{N} \sum_{i=1}^{M} I_{i} \cdot H_{i}(m, n) .
$$

It is important to note that in the absence of noise, by using a sequence of $N$ different Hadamard patterns Eq. (3) provides an exact replica of the object with a sampling resolution of $\mathrm{N}$ pixels. Note also that this approach looks similar to ghost imaging techniques if we realize that the operation in Eq. (3) can be understood as a parallel correlation between the sequence of measured irradiances $I_{\mathrm{i}}$ and the sequence of light irradiance illuminating each pixel $H_{i}(m, n)$.

The main limitation in imaging by single-pixel techniques is that they may require long acquisition times. This time depends on the number $M$ of projected masks, the projection rate $R_{\text {SLM }}$ and the integration time $t_{\text {int }}$ of the light detector through the equation

$$
t_{a}=M\left(\frac{1}{R_{S L M}}+t_{\mathrm{int}}\right) .
$$

Ideally the integration time should be as short as possible and the frequency rate as high as allowed by the digital light projector. A way to further decrease the acquisition time is by reducing the number of measurements. This can be done very efficiently by using CS algorithms because natural images tend to be sparse in the frequency space. The CS theory establishes that by using a number $M<N$ of randomly chosen patterns, it is possible to reconstruct the original image 


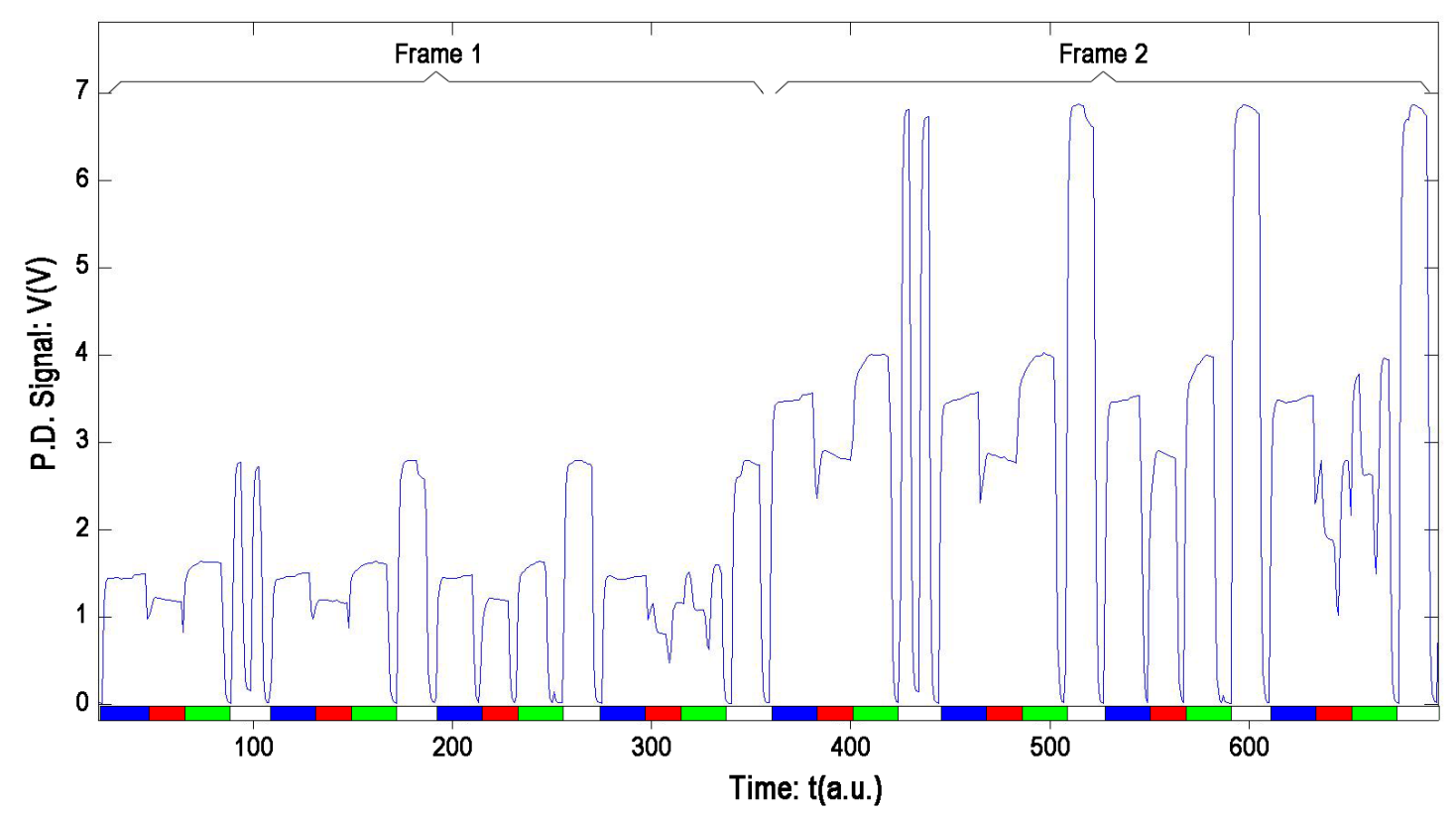

Fig. 2. Signal captured by the photodiode for two consecutive frames in which an arbitrary pair of Hadamard patterns have been sent. In the horizontal axis of this graph, arbitrary units are used to express time. In the vertical axis the signal voltage is given by Volts.

with high quality. The idea is better stated by rewriting the measurement process in Eq. (1) in matrix form as

$$
\vec{I}=\Phi \cdot \vec{t}=\Phi(\Gamma \cdot \vec{s})=\Theta \cdot \vec{s},
$$

where $\vec{I}$ is a $M \times 1$ vector containing the measured coefficients, and $\vec{t}$ and $\vec{s}$ are $N \times 1$ vectors representing the input object in the sampling space and in the Hadamard frequency space, respectively. Matrix $\Phi$ is an $M \times N$ matrix containing a random subset of $M$ Hadamard patters codified in the different rows, and matrix $\Gamma$ is the transformation matrix between the sampling space and the Hadamard space. The product of matrix $\Phi$ and $\Gamma$ gives the matrix $\Theta$ acting directly on $\vec{s}$. In CS, the undetermined matrix relation in Eq. (5) is solved by off-line reconstruction algorithms such as those based on convex optimization or greedy algorithms. In our approach we use a convex optimization algorithm based on the minimization of the $\ell_{1}$ norm of $\vec{s}$ subjected to the restriction given by Eq. (5). In particular, the object estimation, $\vec{t}^{\prime}$, is obtained by solving

$$
\min _{t^{\prime}}\left\|\Gamma^{-1} \vec{t}^{\prime}\right\|_{l_{1}} \text { subject to } \Phi \overrightarrow{t^{\prime}}=\vec{I}
$$

Note that by using CS algorithms, acquisition time in Eq. (4) is reduced but certain amount of post-processing time is added to reconstruct the final image. Furthermore, CS algorithms are known to be time consuming. For that reason some recent approaches aiming to get high resolution imaging at high frame rates focus on reducing this post-processing time by using different alternatives to CS based on adaptive sensing $[23,24]$.

\section{SINGLE-PIXEL COLOR IMAGING}

The key elements to implement a single-pixel camera, according to the approach shown in Fig. 1, are a spatial light modulator, to sample the input object with microstructured light patterns, and a light detector. In our setup we use an offthe-shelf digital light projector (DLP) based on a digital micromirror device (DMD) to generate the light patterns. This is a low-cost alternative to scientific-grade DMD devices that, additionally, incorporates the light source, allows color codification of the output light patterns, and is controlled by very simple standard video signals. In particular, the DLP used in our experiments is a Dell M110 Ultra-Mobile Projector with a 0.45 " WXGA S450 DMD. The light detector, measuring the light scattered by the object for each projected pattern, is a photodiode Thorlabs DET36A EC. The photodiode output signal is digitized by a DAQ card, NI USB-6003 connected to a computer.

To get color information from the scene, we take advantage of the codification procedure used by the DLP for color video projection. In the standard video projection mode, white light from the projector lamp passes through a spinning color wheel. The color wheel filters the light so that it changes sequentially to red, green, blue and white colors. In particular, for the video projector used in our experiment, each RGB chromatic component, and the white component, are encoded onto 4 time slots within a frame. This sequence is represented by color horizontal bars in the lower part of Fig. 2. Depending on how much color is required, mirrors of the DMD are tilted on or off a shorter or a longer time within the corresponding time slot. The white slot is used to control the brightness of the 
image. Therefore, the DLP technology relies on the viewer's eyes to fusion the light into the final color by time multiplexing.

In this way, we can obtain color information with a single monochromatic photodiode by projecting black and white Hadamard patterns with the video projector and measuring the photodiode signal at the proper time. In particular, we send a single Hadamard pattern per frame and measure the amount of light scattered by the object for each RGB chromatic channel, $\mathrm{I}_{\mathrm{iR}}, \mathrm{I}_{\mathrm{iG}}$ and $\mathrm{I}_{\mathrm{iB}}$, integrating the photodiode signal during the time slot associated to each channel. The color irradiance distribution of the input object is estimated by using the superposition approach in Eq. (3), or the CS approach in Eqs. (5) and (6) for each chromatic component. Fig. 2 shows the experimental signal provided by the monochromatic photodiode when two consecutive arbitrary Hadamard patterns are projected onto a scene following the setup in Fig. 1. It can be seen that four different colors are detected for each frame, the three chromatic components R, G, and B, plus a white component. And four different time slots are used to codify each color, thus providing 16 different time slots. The total amount of light scattered by the object for each chromatic component is measured by integrating the signal along the corresponding RGB time slots. The white slot is used in our

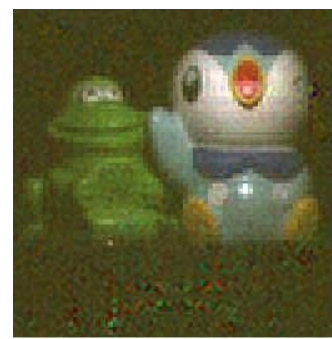

Fig. 3. Color image, with $256 \times 256$ pixels, of an object obtained by using the single-pixel scheme shown in Fig. 1 and CS algorithms.

application for synchronization purposes. In Fig. 3 we show the color image of an object reconstructed with our experimental setup. For this particular example we used Hadamard patterns of 256x256 pixels. Moreover using CS the total number of measurements to recover the scene was $10 \%$ of the $256^{2}$ measurements established by the Nyquist criterion.

\section{STEREOSCOPIC COLOR IMAGING}

When the goal of an imaging technique is not to reconstruct a complete 3D model but to visualize a realistic 3D scene, the best option consists in imitating the stereoscopic process followed by humans to get depth perception. Actually, our intention is to adapt the setup in Fig. 1 to be able to obtain stereoscopic information with single-pixel detection. In principle, one may think that by displacing the photodetector in the setup in Fig. 1 it would be possible to obtain different $2 \mathrm{D}$ perspectives of the $3 \mathrm{D}$ scene. However in single-pixel imaging is not the position of the photodiode but the orientation of the light projector what provides the different $2 \mathrm{D}$ perspectives.

In order to clarify the difference between capturing the

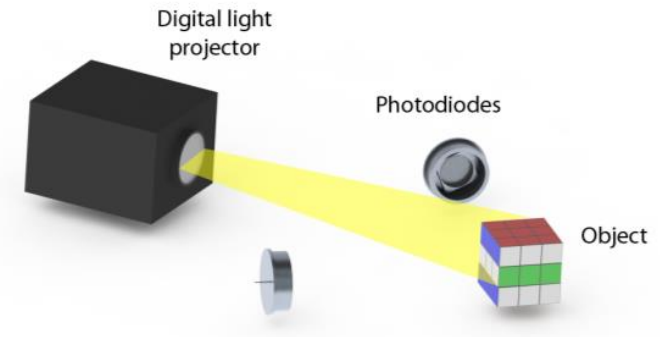

Fig. 4. Experimental setup for single-pixel imaging with two photodetectors. The signal provided by each photodiode is used to generate a different image of the scene.

scene with several photodiodes and our final approach we perform first the experiment depicted in Fig. 4. The input scene is sampled with a sequence of micro structured light patterns while two photodiodes located at different positions record light intensity signals. In our approach the $3 \mathrm{D}$ object is placed at $32 \mathrm{~cm}$ from the DLP. The pattern size and the pixel pitch at that distance are $3.2 \times 3.2 \mathrm{~cm}$ and $250 \mu \mathrm{m}$ respectively. A different $2 \mathrm{D}$ color image is obtained from each signal by using the approach described in Section III. The results are shown in Fig. 5. Fig. 5(a) is an image of the scene captured by a CCD camera, Fig. 5(b) is the image reconstructed with the signal provided by the left photodiode, and Fig.5(c) is the one

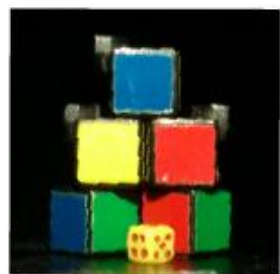

(a)

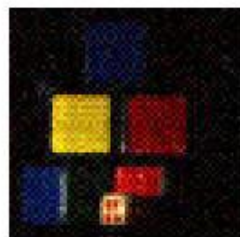

(b)

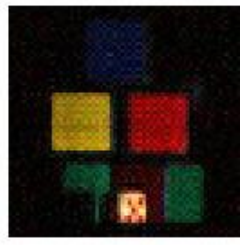

(c)
Fig. 5. (a) Image of the input scene captured by a CCD camera, (b) $128 \times 128$ image obtained by the left photodiode in Fig. 4 and (c) $128 \times 128$ image obtained by the right photodiode in Fig. 4 . Images in (b) and (c) provide the same perspective of the scene but with different illumination.

obtained by using the right photodiode. It can be seen, comparing Figs 5(b) and (c), that they correspond to the same perspective of the input scene and thus they do not provide disparity to be applied in stereoscopy. However, the images appear to be illuminated from different directions. This fact can be checked by comparing the images of the dice in the foreground of both figures. Note that number 4 of the dice is only seen by using information from the left photodiode while number 5 is only shown from that of the right one. Each image is the same as that obtained by substituting the DLP with a conventional camera and the photodiode by a white-light point source located at the same position, as can be shown by the Helmholtz reciprocity principle.

For obtaining two different 2D perspectives of a scene to be represented on a 3D display, or to be used for analyzing disparity, we developed the experimental setup shown in Fig. 6 . In this configuration each pattern is projected towards the 3D scene from two different directions by displaying the same pattern in two different positions of the DLP. A $90^{\circ}$ beam 
splitter and two mirrors, separated a distance equal to the interocular distance, are configured in such a way that both patterns overlap at the same plane in the 3D scene. In this second setup the $3 \mathrm{D}$ object is placed at $30 \mathrm{~cm}$ from the DLP. The pattern size and the pixel pitch at that distance are $6 \times 6 \mathrm{~cm}$ and $234 \mu \mathrm{m}$ respectively. The photodiode is placed at $6 \mathrm{~cm}$ from the $3 \mathrm{D}$ object. The light scattered by the object for each pattern is captured by a single monochromatic photodiode placed in front of the object. Again the photodetector signal is synchronized with the sequence of patterns, following the method in Section III. In this way, each set of patterns provides each one of the images of the stereoscopic pair.

In principle, each element of the pair of black and white patterns used to generate the two different perspectives should be projected independently onto the object in order to measure the photodiode signal associated to that perspective. However a faster alternative is to send a pair of patterns with chromatically opposite colors (red and cyan), as is shown in Fig. 6. This will provide us directly with an anaglyph, that is, a picture consisting of the overlapping of two stereoscopic images of the object, in two complementary colors. The method is similar to that described in Section III to reconstruct a color image. It is based in the time multiplexing nature of the light projected by the DLP, which codifies color information sequentially, as is shown in Fig. 2. This fact allows us to discriminate each RGB chromatic component from the signal captured by a single monochromatic photodiode. Therefore, after codifying each perspective with different colors, as is proposed in Fig. 6, we are able to discriminate not only the color but also the stereo pair. Despite anaglyph is not the best method to display stereoscopic images, it will allow us to analyze the results obtained in preliminary experiments so that they can be viewed with the appropriate color glasses.

Experimental results showing different 2D color perspectives of an input object are shown in Fig. 7. Fig. 7(a) shows a color image obtained by using the signal provided by the photodiode in Fig. 6 when the set of binary masks is projected from the left mirror and is the same as Fig. 3. Fig. 7(b) is the equivalent one obtained by using the light patterns coming from the right mirror. Finally, Fig. 7(c) is the anaglyph obtained from the previous images, similar to the one that it is obtained by sending red and cyan patterns simultaneously as described above. To get Fig. 7(c), only the red channel in Fig. 7(a) is used for the left image, while the green and blue channels in Fig. 7(b) are used for the right image. In this experiment we use Hadamard patterns of $256 \times 256$ pixels. The

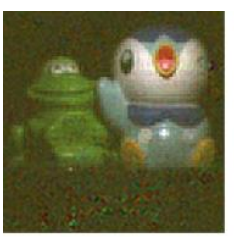

(a)

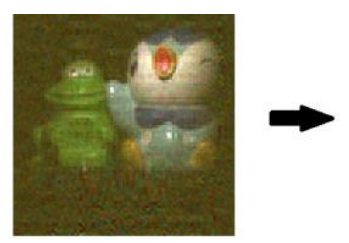

(b)

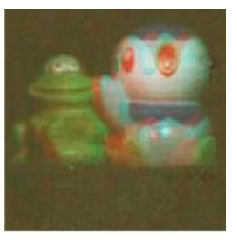

(c)
Fig. 7. Pair of $256 \times 256$ stereoscopic images, in (a) and (b), and the resulting anaglyph (c) is the anaglyph obtained from the previous images (a) and (b). For a better visualization of image (c), we have enhanced its brightness and reduced the noise.

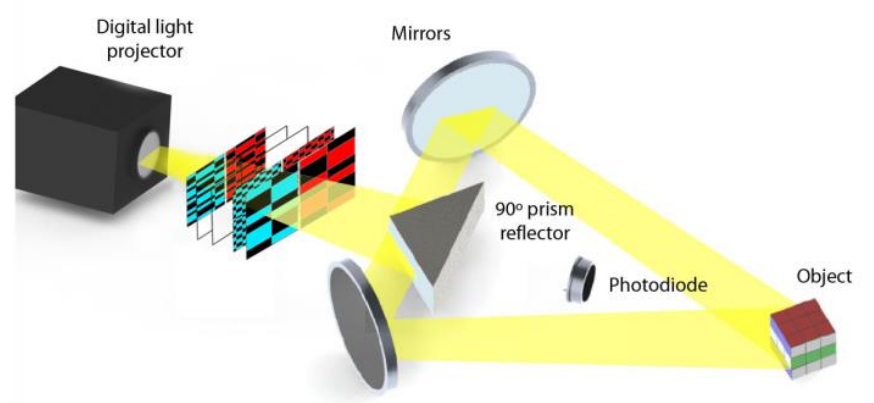

Fig. 6. Experimental setup to record stereoscopic images with a single photodetector. Pairs of Hadamard patterns with chromatically opposite colors overlap at a plane in the $3 \mathrm{D}$ scene. The signal from a single monochromatic photodiode allows us to obtain an anaglyph image of the object.

maximum frequency of our light projector is $60 \mathrm{~Hz}$, and this is the maximum rate to project the patterns. Nevertheless, as explained above in Fig. 3, we only used $10 \%$ of the $256^{2}$ needed patterns, allowing us to obtain the anaglyph image in 109 seconds.

In contrast to imaging systems based on multiple cameras we do not need any calibration or rectification algorithm to get the stereoscopic pair. The calibration is accomplished by the preliminary overlapping of two patterns in a plane of the $3 \mathrm{D}$ scene. Then, once the prism and mirrors are properly placed the experimental setup can be used for several scenes.

\section{CONCLUSION}

In this paper we have shown that it is possible to produce full-color stereoscopic images with a single photodiode and an off-the-shelf projector. In this way, we have proposed a lowcost setup to produce a pair of images that can be used as an input in a 3D display. We have also clarified the difference between using several photodiodes and several projection viewpoints. In the proposed approach, the $3 \mathrm{D}$ information of the scene is provided by the disparity and not by light shading.

In principle, time required to project light patterns implies a low frame rate. However, to partially solve this problem we have used a CS algorithm and we plan to use more efficient adaptive compressive strategies in the near future. We expect that these methods will allow us to capture and visualize 3D scenes at practicable frame rates.

Single-pixel cameras are a promising alternative to conventional imaging techniques in applications such as polarimetric and multispectral imaging, or to deal with exotic spectral bands. Additionally, they have been applied with success in imaging through scattering media. This new approach can be the first step to extend all these applications to stereoscopic imaging.

\section{REFERENCES}

[1] M. F. Duarte, M. A. Davenport, D. Takhar, J. N. Laska, T. Sun, K. F. Kelly and R. G. Baraniuk, "Single-pixel imaging via compressive sampling," IEEE Signal Proc. Mag., Vol. 25, pp. 83-91 (2008).

[2] A. Gatti, E. Brambilla, and L. A. Lugiato, "Quantum Imaging," Progress in Opt., Vol. 51, pp. 251 (2008).

[3] J. H. Shapiro, "Computational ghost imaging," Phys. Rev. A, Vol. 78, pp. 061802 (2008).

[4] Y. Bromberg, O. Katz, Y. Silberberg, "Ghost imaging with a single detector,” Phys. Rev. A, Vol. 79, pp. 053840 (2009). 
[5] P. Sen, B. Chen, G. Garg, S. R. Marschner, M. Horowitz, M. Levoy, and H. P. A. Lensch, "Dual photography," ACM Trans. Graph., Vol. 24, pp. 745-755 (2005).

[6] V. Studer, J. Bobin, M. Chahid, H. Mousavi, E. Candes, and M. Dahan, "Compressive fluorescence microscopy for biological and hyperspectral imaging," Proc. Nat. Acad. Sci., Vol. 109, pp. E1679-E1687 (2012).

[7] G. A. Howland, D. J. Lum, M. R. Ware, and J. C. Howell, "Photon counting compressive depth mapping," Opt. Express, Vol. 21, pp. 23822- 23837 (2013).

[8] V. Durán, P. Clemente, M. Fernández-Alonso, E. Tajahuerce, J. Lancis, "Single-pixel polarimetric imaging," Opt. Lett., Vol. 37, pp. 824-826 (2012).

[9] F. Soldevila, E. Irles, V. Durán, P. Clemente, M. Fernández-Alonso, E. Tajahuerce, J. Lancis, "Single-pixel polarimetric imaging spectrometer by compressive sensing," Appl. Phys. B, Vol. 113, pp. 551-559 (2013).

[10] S. S. Welsh, M. P. Edgar, R. Bowman, P. Jonathan, B. Sun and M. J. Padgett, "Fast full-color computational imaging with single-pixel detectors," Opt. Express, Vol. 21, pp. 23068-23074 (2013).

[11] A. Kirmani, D. Venkatraman, D. Shin, A. Colaço, F. N. C. Wong, J. H. Shapiro, V. K. Goyal, "First-Photon Imaging," Science, Vol. 343, pp 58-61 (2013)

[12] A. Kirmani, A. Colaço, F. N. C. Wong, and V. K. Goyal, "Exploiting sparsity in time-of-flight range acquisition using a single time-resolved sensor," Opt. Express, Vol. 22, pp. 21485-21507 (2011).

[13] P. Clemente, V. Durán, E. Tajahuerce, P. Andrés, V. Climent, and J. Lancis, "Compresssive holography with a single pixel detector," Opt. Lett, Vol. 38, pp. 2524-2527 (2013).

[14] W. L. Chan, K. Charan, D. Takhar, K. F. Kelly, R. G. Baraniuk, D. M. Mittleman, "A single-pixel terahertz imaging system based on compressed sensing," Appl. Phys. Lett. Vol. 93, pp. 121105 (2008).

[15] C. M. Watts, D. Shrekenhamer, J. Montoya, G. Lipworth, J. Hunt, T. Sleasman, S. Krishna, D.R. Smith and W.J. Padilla, "Terahertz compressive imaging with metamaterial spatial light modulators," Nat. Photonics, Vol. 8, pp. 605-609 (2014)

[16] V. Durán, F. Soldevila, E. Irles, P. Clemente, E. Tajahuerce, P. Andrés, and J. Lancis, "Compressive imaging in scattering media," Opt. Express, Vol. 23, pp. 14424-14433 (2015).

[17] E. Tajahuerce, V. Durán, P. Clemente, E. Irles, F. Soldevila, P. Andrés, and J. Lancis, "Image transmission through dynamic scattering media by single-pixel photodetection,” Opt. Express, Vol. 22, pp. 16945-16955 (2014).

[18] E. J. Candès and M. B. Walkin, “An introduction to compressive sampling," IEEE Signal Proc. Mag. Vol 25, pp. 21-30 (2008).

[19] D. Donoho, "Compressed sensing," IEEE Trans. Inf. Theory, Vol. 52, pp. 1289-1306 (2006)

[20] B. Sun, M. P. Edgar, R. Bowman, L. E. Vittert, S. Welsh, A. Bowman and M. J. Padgett, "3D computational imaging with single-pixel detectors," Science, Vol. 340, pp. 844-847 (2013).

[21] Y. Zhang, G. M. Gibson, R. Hay, R. W. Bowman, M. J. Padgett and M. P. Edgar, "A fast 3D reconstruction system with a low-cost camera accessory," Sci. Rep., Vol. 5, pp. 10909 (2015).

[22] W. Pratt, J. Kane and H. Andrews, "Hadamard transform image coding," Proc. IEEE, Vol. 57, pp. 58-68 (1969).

[23] M. P. Edgar, G. M. Gibson, R. W. Bowman, B. Sun, N. Radwell, K. J. Mitchell, S. S. Welsh, and M. J. Padgett, "Simultaneous real-time visible and infrared video with single-pixel detectors," Sci. Rep., Vol. 5, pp. 10669 (2015)

[24] F. Soldevila, E. Salvador-Balaguer, P. Clemente, E. Tajahuerce and J. Lancis, "High-resolution adaptive imaging with a single photodiode," Sci. Rep., Vol. 5, pp. 14300 (2015).

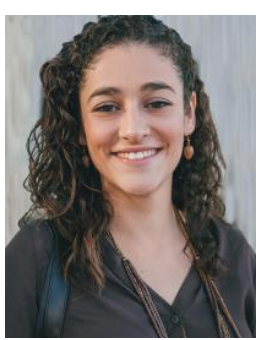

Eva Salvador (Castellón, 1987) received the B.S in Computer Engineering and the M.S. in Artificial Intelligence from the Universitat Jaume I, Castellón, Spain in 2010 and 2012 respectively. She received the Bachelor of Engineering in Computer Engineering from Athlone Institute of Technology, Ireland in 2009. Since 2012 she is a PhD student in advanced computer systems at Universitat Jaume I. Her current research interest includes image processing, 3-D image visualization and single-pixel imaging.

Ms. Salvador is a member of the Optical Society of America (OSA), the international society for optics and photonics (SPIE) and the European Physical Society (EPS). She is a board member in the action committee of the EPS Young Minds and she is the president of Group of Optics Castellón Young Minds Section.

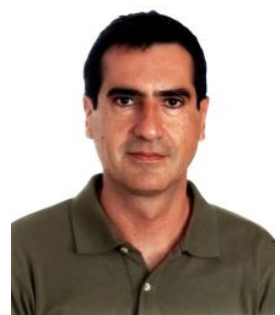

Enrique Tajahuerce is associate professor in optics at the Department of Physics in Universitat Jaume I, Castellón, Spain. He develops its research at the Institute of New Imaging Technologies (INIT) in the same university, where he is the deputy director since 2010. He received the $\mathrm{PhD}$ in physics from Universidad de Valencia, Spain, in 1998. He has developed research at the Technological Institute of Optics (AIDO) in Valencia, Spain, from 1989 to 1992 and at the Electrical and Computer Engineering Department in the University of Connecticut, Storrs, USA, from 1999 to 2000.

Dr. Tajahuerce research interests lie in the areas of diffractive optics, adaptive optics, optical security and encryption, digital holography, and computational imaging. $\mathrm{He}$ is co-author of 6 patents, 14 book chapters, more than 100 research papers (cited more than 1800 times, h-index=18) and over 120 communications in international conference meetings (36 of them by invitation). He is Senior Member of SPIE, and member of OSA, EOS, and Sociedad Española de Óptica (SEDO). In 2008, Dr. Tajahuerce received the IEEE Donald G. Fink Prize Paper Award.

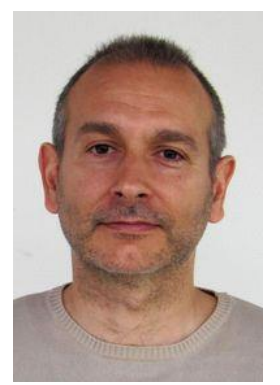

Filiberto Pla is a Full Professor at the Departament de Llenguatges i Sistemes Informàtics, University Jaume I, Castellón de la Plana, Spain. He received the BSc and PhD degrees in Physics from the University of Valencia in 1989 and 1993, respectively. He has been a Visiting Scientist at Silsoe Research Institute, the University of Surrey, and the University of Bristol in the United Kingdom; CEMAGREF in France; the University of Genoa in Italy; Instituto Superior Técnico of Lisbon in Portugal; and the Swiss Federal Institute of Technology ETH-Zurich and the idiap Research Institute in Switzerland.

At present, Prof. F. Pla is the Director of the Institute of New Imaging Technologies at the University Jaume I. His current research interests are colour and spectral image analysis, visual motion analysis, 3-D image visualization, and pattern recognition techniques applied to image processing.

Prof. F. Pla is a member of the Spanish Association for Pattern Recognition and Image Analysis (AERFAI), which is a part of the International Association for Pattern Recognition (IAPR). 


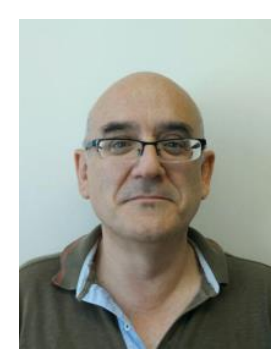

Dr. Jesús Lancis (Alicante, 1965) is a full professor in Optics at Universitat Jaume I in Castellón, where he currently leads the photonics research group "Grupo de Investigación de Óptica de Castellón, GROC·UJI" (https://sites.google.com/a/uji.es/photonic $\mathrm{s}-u j \mathrm{j} /$ ). The group is engaged in basic research to deliver on the promise of photonics breakthroughs. Dr. Lancis' laboratory is focused on digital control of light beams with microstructured masks codified onto megapixel spatial light modulators. This work is aimed to overcome the limitations of current photonics technologies for healthcare and laser manufacturing processes. Dr. Lancis has been the key researcher in more than 10 research programmes at the local, regional, national and international level. He has contributed more than 160 research papers (cited 1153 times, h-index=18) in major photonics journals located in the first positions of the ISI Journal Citation Reports. He has presented more than 40 invited or keynote talks on photonics in different meetings organized by well-established scientific societies (OSA, IEEE, EOS, EPS, SPIE) and supervised 4 early stage researchers that obtained the PhD degree in Physics.

Dr. Lancis is a Senior Member of the Optical Society OSA and a regular member of the European and the Spanish Optical Societies. Dr. Lancis leads the Doctoral Training Center of Universitat Jaume I, where he is strongly committed to promote excellence and good practice in training of early stage researchers. 



\author{
Stereoscopic color imaging by compressive sensing \\ with a single-pixel photodetector \\ Eva Salvador-Balaguer ${ }^{1}$, Pere Clemente $^{2}$, Mercedes Fernández-Alonso ${ }^{1}$, \\ Enrique Tajahuerce ${ }^{1}$ and Jesús Lancis ${ }^{1}$ \\ ${ }^{I}$ GROC·UJI, Institute of New Imaging Technologies (INIT), Universitat Jaume I, 12071-Castelló (Spain) \\ ${ }^{2}$ Servei Central d'Instrumentació Científica (SCIC), Universitat Jaume I, 12071-Castelló (Spain) \\ *E-mail: salvadoe@uji.es
}

\title{
1. Introduction
}

Computational imaging with single-pixel detectors is an emerging technique that enables to obtain spatial information of an object, such as the reflectance distribution, by sampling the scene with a set of microstructured light patterns [1]. The technique is closely related to ghost imaging [2,3] and dual photography methods [4], which use also single-pixel detectors to reconstruct images by correlation or by exploiting the principle of reciprocity.

This detection scheme has several advantages compared to conventional imaging techniques using photodetectors with spatial structure. For example, it allows measuring the spatial distribution of multiple optical properties of the scene in a simple way. In this direction, single-pixel detection arquitectures have been designed for polarimetric imaging [5], color or multispectral imaging [6,7] or holography [8]. Besides, single-pixel detectors provide a broader spectral range compared to conventional cameras, permitting to extend imaging techniques to different spectral regions [9]. Moreover, imaging techniques using single-pixel detectors are well adapted to apply the theory of compressive sampling (CS) $[10,11]$. This theory exploits the fact that natural images tend to be sparse, i.e. only a small set of the expansion coefficients is nonzero when the suitable basis is chosen. In this way, images can be retrieved with a number of measurements lower than that established by the Shannon-Nyquist limit.

Several approaches have been proposed for applying these techniques to three-dimensional (3D) scenes. Some of them provide 2D color or spectral information with single-pixel detectors such as color photodiodes or fiber spectrometers [6,7]. In principle, one may think that by displacing the single-pixel detector in these systems it would be possible to obtain different $2 \mathrm{D}$ perspectives of the $3 \mathrm{D}$ scene. However, it has been shown that this displacement changes only the apparent illumination direction of the scene [4]. Nevertheless, this effect has been used to get 3D spatial information of an object [12]. To this end, several photodetectors located at different positions record signals simultaneously. The 3D shape is then reconstructed from the surface gradients obtained by comparing the illumination of different images.

Nowadays, for many applications it is even more important to display 3D information than to reconstruct the 3D shape of objects in the scene. The principle of stereoscopic vision can then be applied for 3D information recording and visualization, as is done in commercial 3D movies by using switching or polarized glasses. The 3D perception is created by the human brain by fusing the pair of different images acquired by the eyes.

In this work we present an optical system for stereoscopic color imaging based on computational imaging with a single-pixel detector together with compressive sensing strategies. Our system is able to produce full-color stereoscopic images of a scene by using a low number of optoelectronic components, just a simple monochrome photodetector and a digital light projector. Color stereoscopic images of a 3D scene obtained experimentally are shown.

\section{System overview and results}

The experimental setup is shown in Fig. 1. The key element of the system is a conventional digital light projector (DLP) that uses a digital micromirror device (DMD) to modulate the light provided by three color light emitting diodes (LEDs). An optical system, consisting of a beam splitter based on $90^{\circ}$ prisms and two mirrors, splits and redirects the light emitted by the DLP towards the 3D scene from two different directions. The light reflected by the object is then recorded by an amplified photodiode.

The DLP projects sequentially a set of microstructured patterns onto the scene. For this application we choose a family of binary intensity patterns derived from the Walsh-Hadamard basis. By synchronizing the projection of each pattern with the lecture of the photodiode, we are able to measure the coefficients that, by CS techniques, allow us to reconstruct a $2 \mathrm{D}$ image of the scene. 


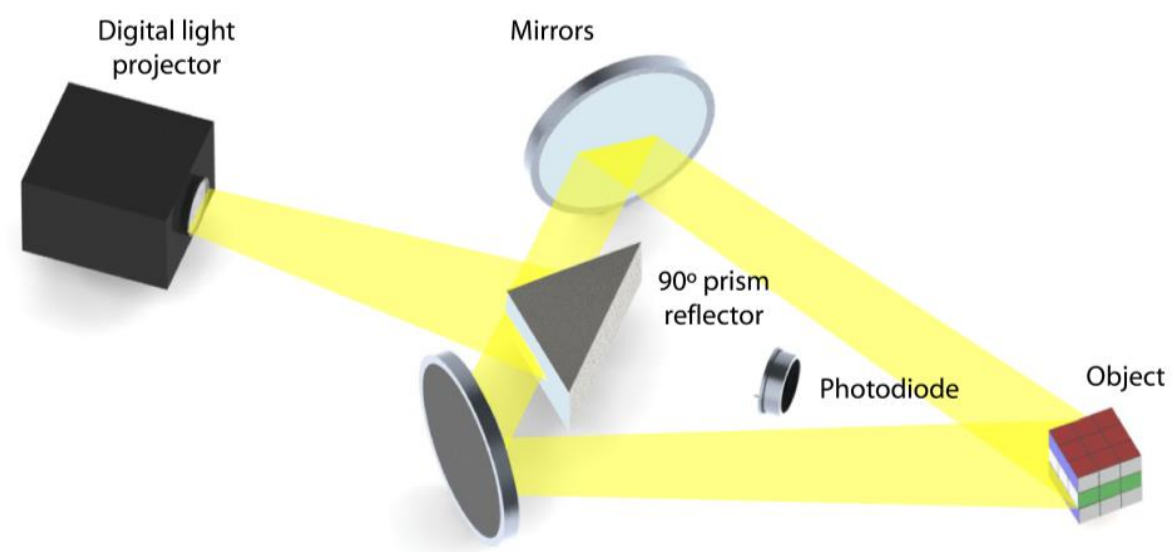

Figure 1 Experimental setup to capture full-color stereoscopic images with a single-pixel detector.

Color information is obtained decoding the photodiode signal, by taking advantages of the way the DLP codifies the projected light. In the standard video projection mode, the DLP sends streams of binary patterns with alternating RGB colors. Therefore, by projecting binary patterns, but acquiring signals synchronized with each color, we are able to measure the color content of the light reflected by the object. A preliminary analysis of the projector signal needs to be performed to synchronize the signals.

To get two different perspectives, each pattern is projected into the $3 \mathrm{D}$ scene from two different directions by displaying the pattern in two different positions of the DLP. The beam splitter and the mirrors are configured in such a way that both patterns overlap in the same plane of the 3D scene, as is shown in Fig. 1. Again the photodetector signal is synchronized with each collection of patterns providing different 2D color perspectives of the object. The final stereoscopic image is built from these two perspectives.

In our experiment we use binary patterns with $128 \times 128$ pixels. Therefore the final stereoscopic images are also limited to this resolution. We reduce the number of measurements by using CS with a sampling ratio of 5:1. The maximum rate for each perspective is $60 \mathrm{~Hz}$ because we use a standard video projector with this maximum frequency and we send a white binary pattern per frame.

The results are shown in Fig. 2. Fig. 2(a) shows the color image obtained when projecting the set of binary patterns from the left mirror, Fig. 2(b) is obtained by using the right mirror and Fig. 2(c) is the anaglyph obtained from the previous images. To obtain the anaglyph in Fig. 2(c), only the red channel of Fig. 2(a) is used for the left image, while the green and blue channels of Fig. 2(b) are used for the right image. Despite anaglyph is not the best method to display stereoscopic images, it allows us to present the result obtained with the system in Fig. 1 in a way that can be seen with the appropriate anaglyph glasses.

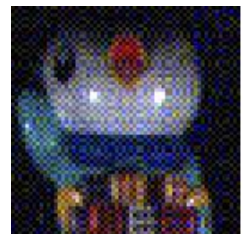

(a)

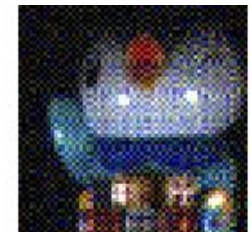

(b)

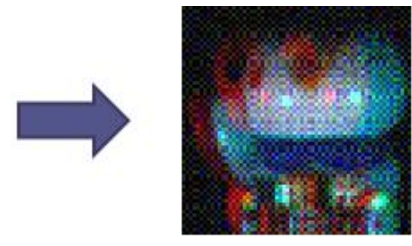

(c)

Figure 2 Pair of stereoscopic images, in (a) and (b), and the resulting anaglyph (c) obtained with the single-pixel color stereoscopic camera in Fig. 1.

Results in Fig. 2 prove the feasibility of our approach to record color stereoscopic images of 3D scenes with a single-pixel detector. One important advantage of single pixel stereoscopy is that, in contrast to imaging systems based on multiple cameras, we do not need any calibration or rectification process. Our calibration is accomplished by the initial overlapping of the two patterns in a plane of the 3D scene. Therefore, once the prism and the mirrors are properly placed the experimental setup can be used for several scenes. 


\section{Acknowledgments}

This work has been partly funded by Universitat Jaume I through project P1-1B2012-55 and by Generalitat Valenciana through Prometeo Excellence Program (project PROMETEO/2012/021).

\section{References}

[1] M. F. Duarte, M. A. Davenport, D. Takhar, J. N. Laska, T. Sun, K. F. Kelly and R. G. Baraniuk, "Single-pixel imaging via compressive sampling," IEEE Signal Proc. Mag. Vol. 25, pp. 83-91 (2008).

[2] J. H. Shapiro, “Computational ghost imaging," Phys. Rev. A, Vol. 78, pp. 061802 (2008).

[3] Y. Bromberg, O. Katz, Y. Silberberg, "Ghost imaging with a single detector," Phys. Rev. A, Vol. 79, pp. 053840 (2009).

[4] P. Sen, B. Chen, G. Garg, S. R. Marschner, M. Horowitz, M. Levoy, and H. P. A. Lensch, "Dual photography," ACM Trans. Graph. Vol. 24, pp. 745-755 (2005).

[5] V. Durán, P. Clemente, M. Fernández-Alonso, E. Tajahuerce, J. Lancis, "Single-pixel polarimetric imaging," Opt. Lett. Vol. 37, pp. 824-826 (2012).

[6] F. Soldevila, E. Irles, V. Durán, P. Clemente, M. Fernández-Alonso, E. Tajahuerce, J. Lancis, "Single-pixel polarimetric imaging spectrometer by compressive sensing," Appl. Phys. B, Vol. 113, pp. 551-559 (2013).

[7] S. S. Welsh, M. P. Edgar, R. Bowman, P. Jonathan, B. Sun and M. J. Padgett, "Fast full-color computational imaging with single-pixel detectors," Opt. Express, Vol. 21, pp. 23068-23074 (2013).

[8] P. Clemente, V. Durán, E. Tajahuerce, P. Andrés, V. Climent, and J. Lancis, "Compresssive holography with a single pixel detector," Opt. Lett, Vol. 38, pp. 2524-2527 (2013).

[9] W.L. Chan, K. Charan, D. Takhar, K.F. Kelly, R.G. Baraniuk, D.M. Mittleman, "A single-pixel terahertz imaging system based on compressed sensing," Appl. Phys. Lett. Vol. 93, pp. 121105 (2008).

[10] E. J. Candès and M. B. Walkin, "An introduction to compressive sampling," IEEE Signal Proc. Mag. Vol. 25, pp. 21-30 (2008).

[11] M. F. Duarte, M. A. Davenport, D. Takhar, J. N. Laska, T. Sun, K. F. Kelly, and R. G. Baraniuk, "Single-Pixel Imaging via Compressive Sampling," IEEE Signal Process. Mag. Vol. 25, pp. 83-91 (2008).

[12] B. Sun, M. P. Edgar, R. Bowman, L. E. Vittert, S. Welsh, A. Bowman and M. J. Padgett, "3D computational imaging with single-pixel detectors," Science, Vol. 340, pp. $844-847$ (2013). 



\title{
Full-color stereoscopic single-pixel camera based on DMD technology
}

\author{
Eva Salvador-Balaguer*a,c ${ }^{*}$ Pere Clemente ${ }^{\mathrm{b}}$, Enrique Tajahuerce ${ }^{\mathrm{a}, \mathrm{c}}$, Filiberto Pla $^{\mathrm{c}}$ and Jesús Lancis ${ }^{\mathrm{a}, \mathrm{c}}$ \\ ${ }^{a}$ Grup de Recerca d'Òptica de Castelló (GROC), Universitat Jaume I, Castelló, Spain;

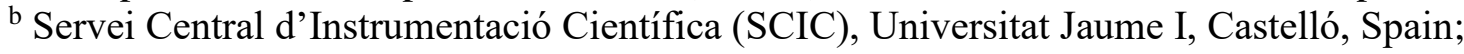 \\ ${ }^{\mathrm{c}}$ Institute of New Imaging Technologies (INIT), Universitat Jaume I, Castelló, Spain;
}

\begin{abstract}
Imaging systems based on microstructured illumination and single-pixel detection offer several advantages over conventional imaging techniques. They are an effective method for imaging through scattering media even in the dynamic case. They work efficiently under low light levels, and the simplicity of the detector makes it easy to design imaging systems working out of the visible spectrum and to acquire multidimensional information. In particular, several approaches have been proposed to record 3D information. The technique is based on sampling the object with a sequence of microstructured light patterns codified onto a programmable spatial light modulator while light intensity is measured with a single-pixel detector. The image is retrieved computationally from the photocurrent fluctuations provided by the detector.

In this contribution we describe an optical system able to produce full-color stereoscopic images by using few and simple optoelectronic components. In our setup we use an off-the-shelf Digital Light Projector (DLP ${ }^{\circledR}$ ) based on a digital micromirror device (DMD) to generate the light patterns. To capture the color of the scene we take advantage of the codification procedure used by the DLP projector for color video projection. To record stereoscopic views we use a $90^{\circ}$ beam splitter and two mirrors, allowing us two project the patterns form two different viewpoints. By using a single monochromatic photodiode we obtain a pair of color images that can be used as input in a 3-D display. To reduce the time we need to project the patterns we use a compressive sampling algorithm. Experimental results are shown.
\end{abstract}

Keywords: Optical Imaging, color imaging, digital micromirror device (DMD)

\section{INTRODUCTION}

The use of single-pixel detectors for computational imaging has become an alternative to conventional imaging techniques. By sampling the scene with a set of microstructured light patterns [1] it is possible to obtain spatial information of an object, such as the reflectance distribution or other optical properties. A simple bucked detector, for instance a photodiode, records the information derived from the overlapping of an object and a light pattern. With the information of the signal associated to all patterns, mathematical algorithms are used to reconstruct the image. In this way, using sensors without spatial resolution, it is possible to use very sensitive light sensors to explore unusual spectral bands for imaging, or to use exotic photodetectors such as spectropolarimeters.

This technique is closely related to ghost imaging [2-4] and dual photography methods [5], which also use single-pixel detectors to reconstruct images. In the first case, imaging is based on the correlation between two signals. One signal is the intensity distribution of the light illuminating the object, while the second signal collects the total amount of light actually interacting with the object. In the second case the image is obtained by exploiting the Helmholtz reciprocity principle. This is mainly used in computer graphics research, and it is based on the idea that the flow of light can be reversed without altering the radiance transfer. Besides, some high-resolution imaging techniques, such as fluorescence microscopy, also benefit from single-pixel detectors by using point scanning illumination. In fact, the introduction of microstructured light patterns for excitation in these techniques has shown improved performance [6].

Single-pixel imaging has several advantages compared to conventional imaging techniques using sensor arrays. For example, the simplicity of the sensing device allows working efficiently in conditions where light is scarce [7]. It also allows measuring the spatial distribution of multiple optical properties of the scene in a simple way. In this direction, single-pixel detection arquitectures have been designed for polarimetric imaging [8], color or multispectral imaging [9,10], time-of-flight imaging [11,12] or holography [13]. Moreover, single-pixel detectors provide a broader spectral range compared to conventional cameras, allowing to extend imaging techniques to different spectral regions [14,15].

Emerging Digital Micromirror Device Based Systems and Applications IX, edited by Michael R. Douglass, Benjamin L. Lee, Proc. of SPIE Vol. 10117, 101170M · C 2017 SPIE CCC code: $0277-786 \mathrm{X} / 17 / \$ 18 \cdot$ doi: $10.1117 / 12.2250230$ 
Furthermore, single pixel cameras have proved the ability to perform non-invasive imaging through scattering media in biological tissues [16,17]. All these advantages could make single-pixel imaging a relevant technique in biomedical imaging, where fast, high-resolution, multispectral, and tolerant to scattering imaging is required.

On the other hand, the proliferation of 3D imaging technology has been evident over the last decades. Since its beginnings in the film industry now 3D technology has become fundamental in many different disciplines. For that reason, several approaches have been proposed for applying single-pixel techniques to three-dimensional (3D) scenes. In principle, one may think that by simply displacing the light detector in any $2 \mathrm{D}$ single-pixel camera configuration it would be possible to obtain different perspectives of a 3D scene. However, it has been shown that displacement on bucket detectors only changes the apparent illumination direction of the scene [5]. Using shape from shading approaches, this effect has been used to get 3D spatial information of an object $[18,19]$. To this end, several photodetectors located at different positions record for the same illumination pattern, different reflection signals depending on the position of the detector. Then, the 3D shape is reconstructed from the surface gradients obtained by comparing the illumination information of the images obtained by the different detectors.

Instead of reconstructing the 3D shape of objects in the scene, nowadays, for many imaging applications it is even more important to efficiently display the 3D information. To this end, the principle of stereoscopic vision can be applied to record and later visualize $3 \mathrm{D}$ information, as it is done in the film industry by the use of switching or polarized glasses. For a human to create the 3D perception each eye has to acquire slightly different images from a scene. Then, the brain fuse the pair of images received creating the $3 \mathrm{D}$ perception. In this work we describe an optical system for stereoscopic color imaging based on computational imaging with a single-pixel detector [20]. Our system is able to produce full-color stereoscopic images of a scene by using a low number of optoelectronic components, just a simple monochrome photodetector and a digital light projector. Besides, we show that it is possible to obtain depth information from our single-pixel stereoscopic measurements, building in this way a simple device for depth-map imaging with single-pixel detectors. Experimental results are shown.

\section{METHODOLOGY}

\subsection{Single-pixel imaging definition}

The operation mode of a single-pixel camera is shown in Fig. 1. A sequence of $\mathrm{M}$ microstructured light patterns is projected onto the input object. The irradiance distribution of all patterns $(i=1, \ldots, M)$ is defined by $\Psi_{i}(m, n)$, being $\mathrm{m}$, and $\mathrm{n}$ discrete spatial coordinates. Light back scattered by the object is collected with a photodiode. If we denote with $T(m, n)$ the reflectance distribution of the object, then the photodiode sequentially measures the M inner products

$$
I_{i}=\sum_{n=1}^{\sqrt{N}} \sum_{m=1}^{\sqrt{N}} \Psi_{i}(m, n) \cdot T(m, n) .
$$

In Eq. (1), $\mathrm{N}$ is the number of pixels of the microstructured light patterns. The sampling operation in Eq. (1) implies that the spatial resolution of this imaging technique is determined by the patterns resolution.

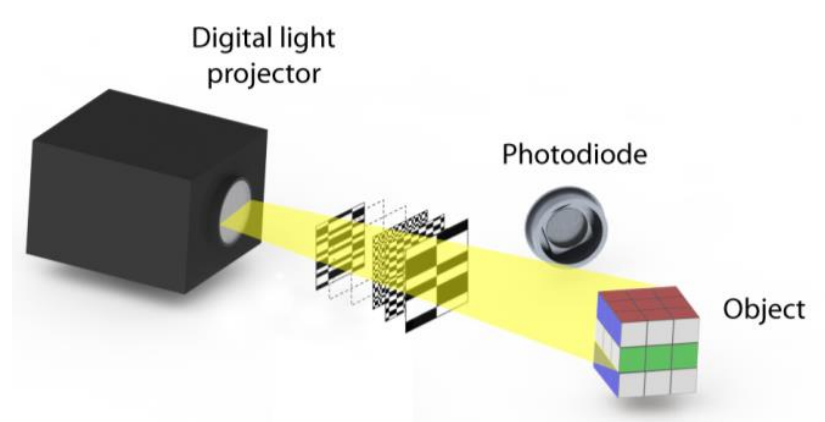

Fig. 1. Single-pixel scheme. A sequence of binary masks is projected onto an object and the light is collected by a photodiode. 
Different approaches for single-pixel imaging use different sampling functions $\Psi_{i}(m, n)$. In our work the sampling patterns are 2D functions $H_{i}(m, n)$ pertaining to the Walsh-Hadamard basis [20]. This choice provides several advantages. Firstly, these patterns are members of an orthonormal basis. In this way, the intensity measurements, Ii, directly provide the representation of the object in the basis. This also means that using all the functions of the basis the object could be exactly recovered for a given sampling frequency. Moreover, these patterns are binary, therefore it is very easy to codify them with fast binary amplitude modulators.

Taking into account the definition of the Hadamard matrices, it is straightforward to show that, for any two patterns with index $\mathrm{i}$ and $\mathrm{j}$,

$$
\sum_{n=1}^{\sqrt{N}} \sum_{m=1}^{\sqrt{N}} H_{i}(m, n) \cdot H_{j}(m, n)=N \cdot \delta_{i j},
$$

where $\delta_{i j}$ is the Kronecker delta. Therefore, by using a sequence of $M$ Hadamard patterns, the irradiance distribution of the object in Eq. (1) can be estimated by applying a simple superposition principle in the following way:

$$
T^{\prime}(m, n)=\frac{1}{N} \sum_{i=1}^{M} I_{i} \cdot H_{i}(m, n) .
$$

It is important to note that in the absence of noise, by using a sequence of $N$ different Hadamard patterns Eq. (3) provides an exact replica of the object with a sampling resolution of $N$ pixels. Note also that this approach looks similar to ghost imaging techniques if we realize that the operation in Eq. (3) can be understood as a parallel correlation between the sequence of measured irradiances $I i$ and the sequence of light irradiance illuminating each pixel $\mathrm{Hi}(m, n)$.

\subsection{Single-pixel color imaging}

The key elements of a single-pixel camera, according to the approach shown in Fig. 1, are a spatial light modulator and a light detector. In our setup we use an off-the-shelf digital light projector based on a digital micromirror device (DMD) to generate the light patterns. This is a low-cost alternative to scientific-grade DMD devices that, additionally, incorporates the light source, allows color codification of the output light patterns, and is controlled by very simple standard video signals. In particular, the DLP projector used in our experiments is a Dell M110 Ultra-Mobile Projector with a 0.45 ", WXGA S450 DMD. The light detector, measuring the light scattered by the object for each projected pattern, is a photodiode Thorlabs DET36A EC. The photodiode output signal is digitized with the DAQ card NI USB-6003.

To get the color information from the scene, we take advantage of the codification procedure used by the DLP projector. In the standard video projection mode, white light from the projector lamp passes through a spinning color wheel. The color wheel filters the light so that it changes sequentially to red, green, blue and white. In particular, for the video projector used, colors are encoded onto 4 time slots within a frame. Color horizontal bars in the lower part of Fig. 2 represent this sequence. Depending on how much color is required, mirrors of the DMD are tilted on or off a shorter or a longer time within the corresponding time slot. Therefore, the DLP projector technology relies on the viewer's eyes to fuse the light into the final color by time multiplexing.

We can obtain color information with a single monochromatic photodiode by projecting black and white Hadamard patterns with the video projector and measuring the photodiode signal at the proper time. In particular, we send a single Hadamard pattern per frame and measure the amount of light scattered by the object for each RGB chromatic channel, $\mathrm{I}_{\mathrm{iR}}, \mathrm{I}_{\mathrm{iG}}$ and $\mathrm{I}_{\mathrm{iB}}$, integrating the photodiode signal during the time slot associated to each channel. The color irradiance distribution of the input object is estimated by using the superposition approach in Eq. (3) for each chromatic component. Fig. 2 shows the experimental signal provided by the monochromatic photodiode when two consecutive arbitrary Hadamard patterns are projected onto a scene following the setup in Fig. 1. It can be seen that four different colors are detected for each frame, the three chromatic components R, G, and B, plus a white component. And four different time slots are used to codify each color, thus providing 16 different time slots. The total amount of light scattered by the object for each chromatic component is measured by integrating the signal along the corresponding RGB time slots. The white slot is used in our application for synchronization purposes. 


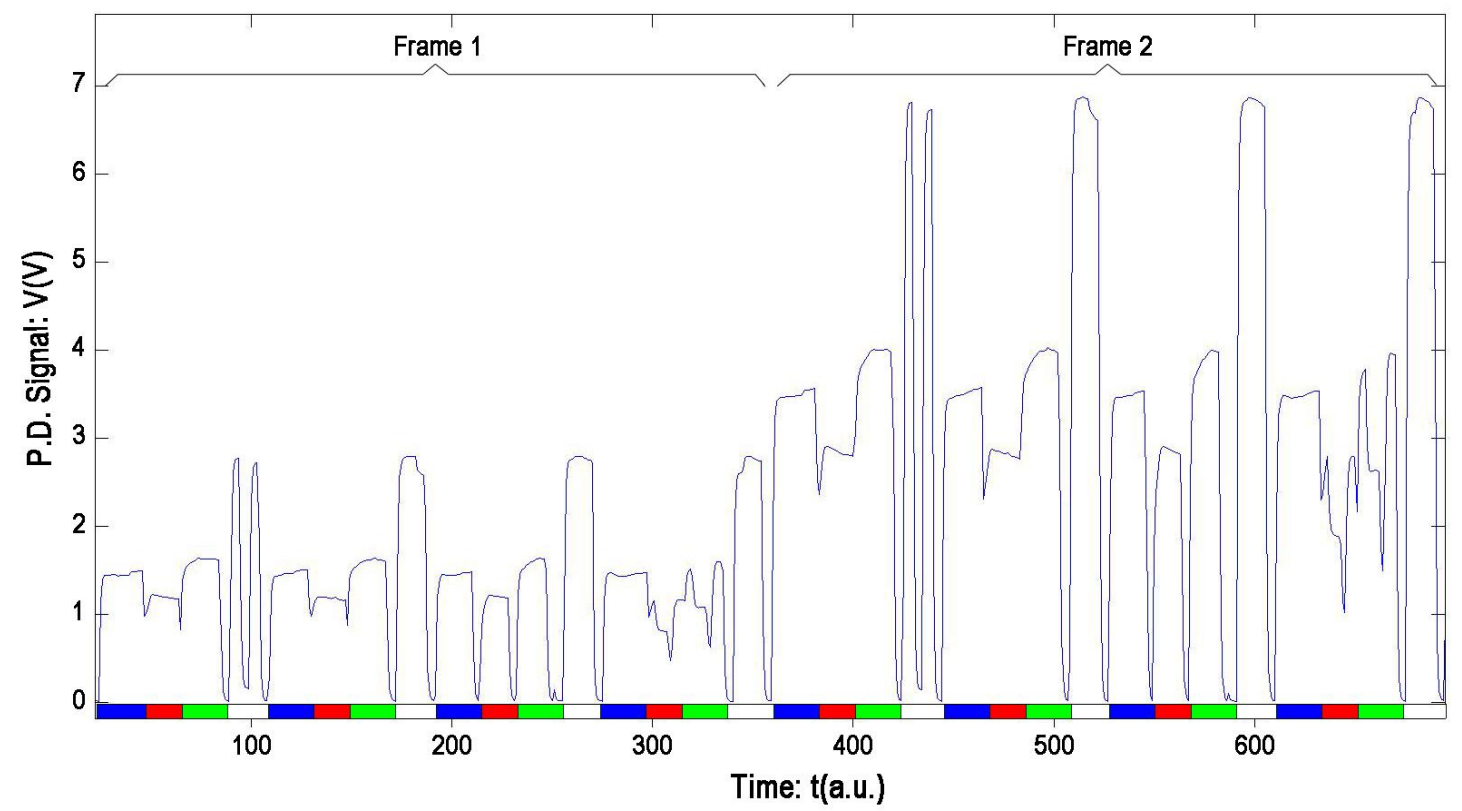

Fig. 2. Signal captured by the photodiode for two consecutive frames in which an arbitrary pair of Hadamard patterns have been sent. In the horizontal axis of this graph, arbitrary units are used to express time. In the vertical axis the signal voltage is given by Volts.

\section{RESULTS}

\subsection{Stereoscopic color imaging}

When the goal of an imaging technique is not to reconstruct a complete 3D model but to visualize a realistic 3D scene, the best option consists in imitating the stereoscopic process followed by humans to get depth perception. Actually, our intention is to adapt the setup in Fig. 1 to be able to obtain stereoscopic information with single-pixel detection. In principle, one may think that by displacing the photodetector in the setup in Fig. 1 it would be possible to obtain different $2 \mathrm{D}$ perspectives of the $3 \mathrm{D}$ scene. However in single-pixel imaging is not the position of the photodiode but the orientation of the light projector what provides the different $2 \mathrm{D}$ perspectives.

To obtain two different 2D perspectives of a scene we developed the experimental setup shown in Fig. 6. In this configuration each pattern is projected towards the 3D scene from two different directions by displaying the same pattern in two different positions of the DLP projector. A $90^{\circ}$ beam splitter and two mirrors, separated a distance equal to the interocular distance, are configured in such a way that both patterns overlap at the same plane in the $3 \mathrm{D}$ scene. In this setup the $3 \mathrm{D}$ object is placed at $30 \mathrm{~cm}$ from the DLP projector. The pattern size and the pixel pitch at that distance are $6 \times 6 \mathrm{~cm}$ and $234 \mu \mathrm{m}$ respectively. The photodiode is placed at $6 \mathrm{~cm}$ from the 3D object. The light scattered by the object for each pattern is captured by a single monochromatic photodiode placed in front of the object. The photodetector signal is synchronized with the sequence of patterns, following the method in Section 2.2. In this way, each set of patterns provides each one of the images of the stereoscopic pair.

In principle, each element of the pair of black and white patterns used to generate the two different perspectives should be projected independently onto the object in order to measure the photodiode signal associated to that perspective. However a faster alternative is to send a pair of patterns with chromatically opposite colors (red and cyan), as is shown in Fig. 3. This will provide us directly with an anaglyph, that is, a picture consisting of the overlapping of two stereoscopic images of the object, in two complementary colors. The method is similar to that described in Section 2.2 to reconstruct a color image. It is based in the time multiplexing nature of the light projected by the DLP projector, which codifies color information sequentially, as is shown in Fig. 2. This fact allows us to discriminate each RGB chromatic component from 
the signal captured by a single monochromatic photodiode. Therefore, after codifying each perspective with different colors, as is proposed in Fig. 3, we are able to discriminate not only the color but also the stereo pair. Despite anaglyph is not the best method to display stereoscopic images, it will allow us to analyze the results obtained in preliminary experiments so that they can be viewed with the appropriate color glasses.

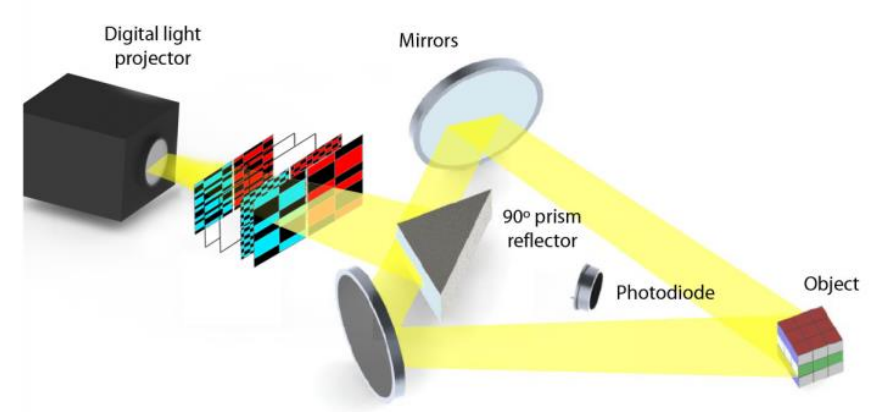

Fig. 3. Experimental setup to record stereoscopic images with a single photodetector. Pairs of Hadamard patterns with chromatically opposite colors overlap at a plane in the 3D scene. The signal from a single monochromatic photodiode allows us to obtain an anaglyph image of the object.

Experimental results showing different 2D color perspectives of an input object are shown in Fig. 4. Fig. 4(a) shows a color image obtained by using the signal provided by the photodiode in Fig. 3 when a set of black and white binary masks is projected from the left mirror. Fig. 4(b) is the equivalent one obtained by using the light patterns coming from the right mirror. Finally, Fig. 4(c) is the anaglyph obtained from the previous images, similar to the one that it is obtained by sending red and cyan patterns simultaneously as described above. To get Fig. 4(c), only the red channel in Fig. 4(a) is used for the left image, while the green and blue channels in Fig. 4(b) are used for the right image. In this experiment we use Hadamard patterns of $256 \times 256$ pixels. The maximum frequency of our light projector is $60 \mathrm{~Hz}$, and this is the maximum rate to project the patterns.

In contrast to imaging systems based on multiple cameras we do not need any calibration or rectification algorithm to get the stereoscopic pair. The calibration is accomplished by the preliminary overlapping of two patterns in a plane of the $3 \mathrm{D}$ scene. Then, once the prism and mirrors are properly placed the experimental setup can be used for several scenes.

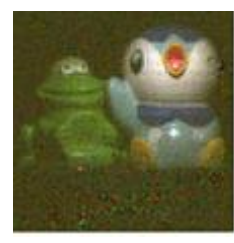

(a)

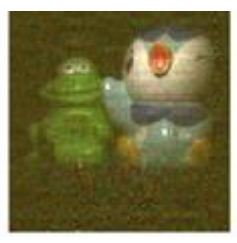

(b)

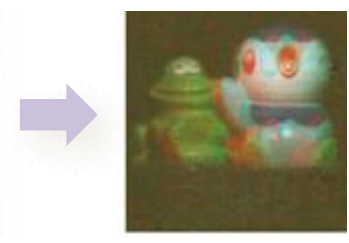

(c)

Fig. 4. Pair of 256x256 stereoscopic images, in (a) and (b), and the resulting anaglyph (c) is the anaglyph obtained from the previous images (a) and (b). For a better visualization of image (c), we have enhanced its brightness and reduced the noise.

Finally, there are several algorithms that allow building disparity maps using a pair of stereoscopic images. The algorithm used in this work is based on the proposal of Klaus et al. [22] that produces a disparity map where farther objects are represented brighter than closer objects. Then, it is possible not only to get 3D perception but to obtain depth information of the scene. As the algorithm used is sensible to noise we have designed a simpler scenario to test the idea. It consist of two simple geometrical figures (a square and a pentagon) with a depth separation of $2 \mathrm{~cm}$ (Fig.5). The objects are placed at a distance of $30 \mathrm{~cm}$ from the DLP pojector. The resulting disparity map is shown in Fig. 5 (c). 


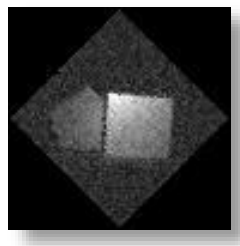

(a)

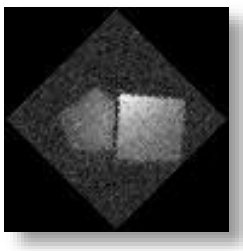

(b)

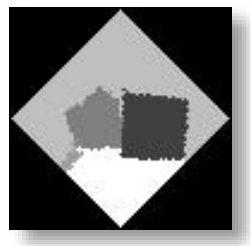

(c)

Fig. 5. Pair of 256x256 stereoscopic images, in (a) and (b), and the resulting disparity map (c)

\section{CONCLUSION}

In this paper we have shown that it is possible to produce full-color stereoscopic images with a single photodiode and an off-the-shelf projector. In this way, we have proposed a low-cost setup to produce a pair of images that can be used as an input in a 3D display. In the proposed approach, the 3D information of the scene is provided by the disparity and not by light shading.

It has also being shown that using the pair of stereoscopic images obtained with the single pixel approach, it is possible to get depth information of the scene.

Single-pixel cameras are a promising alternative to conventional imaging techniques in applications such as polarimetric and multispectral imaging, or to deal with exotic spectral bands. Additionally, they have been applied with success in imaging through scattering media. This new approach can be the first step to extend all these applications to stereoscopic imaging.

\section{REFERENCES}

[1] Duarte M. F., Davenport M. A., Takhar D., Laska J. N., Sun T., Kelly K. F. and Baraniuk R. G., "Single-pixel imaging via compressive sampling," IEEE Signal Proc. Mag., Vol. 25, pp. 83-91 (2008).

[2] Gatti A., Brambilla E., and Lugiato L. A., "Quantum Imaging," Progress in Opt., Vol. 51, pp. 251 (2008).

[3] Shapiro J. H., “Computational ghost imaging," Phys. Rev. A, Vol. 78, pp. 061802 (2008).

[4] Bromberg Y., Katz O., Silberberg Y., "Ghost imaging with a single detector," Phys. Rev. A, Vol. 79, pp. 053840 (2009).

[5] Sen P., Chen B., Garg G., Marschner S. R., Horowitz M., Levoy M., and Lensch H. P. A., "Dual photography," ACM Trans. Graph., Vol. 24, pp. 745-755 (2005).

[6] Studer V., Bobin J., Chahid M., Mousavi H., Candes E., and Dahan M., "Compressive fluorescence microscopy for biological and hyperspectral imaging,” Proc. Nat. Acad. Sci., Vol. 109, pp. E1679-E1687 (2012).

[7] Howland G. A., Lum D. J., Ware M. R., and Howell J. C., "Photon counting compressive depth mapping," Opt. Express, Vol. 21, pp. 23822- 23837 (2013).

[8] Durán V., Clemente P., Fernández-Alonso M., Tajahuerce E., Lancis J., "Single-pixel polarimetric imaging," Opt. Lett., Vol. 37, pp. 824-826 (2012).

[9] Soldevila F., Irles E., Durán V., Clemente P., Fernández-Alonso M., Tajahuerce E., Lancis J., "Single-pixel polarimetric imaging spectrometer by compressive sensing," Appl. Phys. B, Vol. 113, pp. 551-559 (2013).

[10] Welsh S. S., Edgar M. P., Bowman R., Jonathan P., Sun B. and Padgett M. J., "Fast full-color computational imaging with single-pixel detectors," Opt. Express, Vol. 21, pp. 23068-23074 (2013).

[11] Kirmani A., Venkatraman D., Shin D., Colaço A., Wong F. N. C., Shapiro J. H., Goyal V. K., "First-Photon Imaging," Science, Vol. 343, pp. 58-61 (2013).

[12] Kirmani A., Colaço A., Wong F. N. C., and Goyal V. K., "Exploiting sparsity in time-of-flight range acquisition using a single time-resolved sensor," Opt. Express, Vol. 22, pp. 21485-21507 (2011).

[13] Clemente P., Durán V., Tajahuerce E., Andrés P., Climent V., and Lancis J., "Compresssive holography with a single pixel detector," Opt. Lett, Vol. 38, pp. 2524-2527 (2013).

[14] Chan W. L., Charan K., Takhar D., Kelly K. F., Baraniuk R. G., Mittleman D. M., "A single-pixel terahertz imaging system based on compressed sensing," Appl. Phys. Lett. Vol. 93, pp. 121105 (2008). 
[15] Watts C. M., Shrekenhamer D., Montoya J., Lipworth G., Hunt J., Sleasman T., Krishna S., Smith D.R. and Padilla W.J., "Terahertz compressive imaging with metamaterial spatial light modulators," Nat. Photonics, Vol. 8, pp. 605-609 (2014).

[16] Durán V., Soldevila F., Irles E., Clemente P., Tajahuerce E., Andrés P., and Lancis J., "Compressive imaging in scattering media," Opt. Express, Vol. 23, pp. 14424-14433 (2015).

[17] Tajahuerce E., Durán V., Clemente P., Irles E., Soldevila F., Andrés P., and Lancis J., "Image transmission through dynamic scattering media by single-pixel photodetection," Opt. Express, Vol. 22, pp. 16945-16955 (2014).

[18] Sun B., Edgar M. P., Bowman R., Vittert L. E., Welsh S., Bowman A. and Padgett M. J., "3D computational imaging with single-pixel detectors," Science, Vol. 340, pp. 844-847 (2013).

[19]Zhang Y., Gibson G. M., Hay R., Bowman R. W., Padgett M. J. and Edgar M. P., "A fast 3D reconstruction system with a low-cost camera accessory," Sci. Rep., Vol. 5, pp. 10909 (2015).

[20] Salvador-Balaguer E., Clemente P., Tajahuerce E., Pla F., and Lancis J., "Full-Color Stereoscopic Imaging With a Single-Pixel Photodetector," J. Display Technol. Vol. 12, pp. 417-422 (2016).

[21] W. Pratt, J. Kane and H. Andrews, "Hadamard transform image coding," Proc. IEEE, Vol. 57, pp. 58-68 (1969).

[22] Klaus, A., Sormann, M., \& Karner, K. "Segment-based stereo matching using belief propagation and a selfadapting dissimilarity measure”. In 18th International Conference on Pattern Recognition (ICPR'06) Vol. 3, pp. 15-18 (2006). 